\title{
SETOR AUTOMOTIVO BRASILEIRO: EVOLUÇÃO DA ESTRUTURA PRODUTIVA E SUA IMPORTÂNCIA \\ REGIONAL NOS ANOS 90
}

\section{KeRLYNG CECChINI}

Bacharel em Ciências Econômicas

Orientador: Prof. Dr. JOAQUIM JOSÉ MARTINS GUILHOTO

\begin{abstract}
Dissertação apresentada à Escola Superior de Agricultura "Luiz de Queiroz", Universidade de São Paulo, para obtenção do título de Mestre em Ciências, Área de Concentração: Economia Aplicada.
\end{abstract}

P IR A C I C A B A

Estado de São Paulo - Brasil

Dezembro - 2004 
Dados Internacionais de Catalogação na Publicação (CIP) DIVISĀO DE BIBLIOTECA E DOCUMENTAÇĀO - ESALQ/USP

\section{Cecchini, Kerlyng}

Setor automotivo brasileiro: evolução da estrutura produtiva e sua importância regional nos anos $90 /$ Kerlyng Cecchini.-- Piracicaba, 2004. 190 p. : il.

Dissertação (mestrado) - - Escola Superior de Agricultura Luiz de Queiroz, 2005. Bibliografia.

1. Brasil 2. Desenvolvimento econômico 3. Economia regional 4. Indústria automobilística 4. Relações econômicas I. Título

CDD 338.476292 
Dedico esse trabalho aos meus pais, Waldir e Olinda Cecchini e aos meus irmãos Wilker, Ketlyng e Keron Cecchini. 


\section{AGRADECIMENTOS}

Algumas pessoas foram muito importantes para que eu chegasse até aqui. A todas elas, agradeço de coração.

Agradeço especialmente aos meus pais, Waldir e Olinda Cecchini, que me ensinaram a dar valor ao conhecimento e à sua busca permanente. Expresso aqui minha profunda admiração pelo quanto deixam a vida lhes ensinar. Agradeço pela bela família que constituíram, e por acreditarem, absurdamente, em cada um dos meus passos. Aos meus queridos irmãos: o Wilker, a Ketlyng e a Keron, agradeço pela amizade e pelos momentos de alegria e incentivo, em especial, aqueles que recarregavam minhas energias nos finais de semana que passei em casa no primeiro ano do mestrado.

Ao Prof Dr. Mariano de Matos Macedo, que, enquanto meu chefe no IBQP, muito me ensinou como economista e que, definitivamente plantou a idéia do mestrado na minha cabeça, expresso os mais sinceros agradecimentos, além de profundo respeito e admiração pelo profissional incansável que é.

Ao meu orientador, Prof. Dr. Joaquim José Martins Guilhoto, agradeço por acreditar em meu potencial e nortear com muita competência meu trabalho. Agradeço não só pelo aprendizado proporcionado durante o mestrado e pela sua imensa paciência mas também pela sua amizade. Sou muito grata também pela oportunidade em participar do grupo de Projeções Econômicas do CEPEA e do Hewllet Project.

Agradeço ainda a Hewllet Foundation, por financiar minha visita à Universidade de Illinois, em Urbana-Champaign, em especial ao Prof. Werner Baer e ao Prof. Joseph Love, coordenadores do Hewllet Project. Ao Prof Geoffrey Hewings, agradeço pelo incentivo constante e pela hospitalidade no Regional Economics 
Application Laboratorie (REAL) em Mlinois. Certamente não poderia deixar de registrar meu agradecimento ao Chokri Dridi, pelos fundamentais esclarecimentos sobre o método de fuzzy clusters e suas recomendações bibliográficas.

Aos Profs. Joaquim Bento de Souza Ferreira Filho, Eduardo Simões de Almeida e a Prof. ${ }^{\text {a }}$ Márcia Azanha Ferraz Dias de Moraes agradeço a leitura cuidadosa e as relevantes contribuições apresentadas no seminário e na fase de qualificação deste trabalho. Ao Prof. Alexandre Lahóz Mendonça de Barros, expresso minha admiração pelo seu talento como mestre e como pessoa, e agradeço o aprendizado no decorrer do curso de mestrado, sua amizade e as ricas contribuições ao longo desse trabalho.

Tenho muito a agradecer às instituições nas quais tive o privilégio de trabalhar em Curitiba ao longo do mestrado. Todas contribuíram de alguma forma, direta ou indiretamente, para a realização deste trabalho. Em primeiro lugar, agradeço ao Instituto Brasileiro de Qualidade e Produtividade no Paraná (IBQP), em especial ao Dr. Mariano de Matos Macedo e ao Fulgencio Torres, por permitirem que eu realizasse minhas atividades profissionais à distância no primeiro ano do mestrado.

Também teria sido impossível finalizar essa dissertação sem realizar as viagens a São Paulo e a Piracicaba, as quais só foram possíveis graças a compreensão dos meus atuais coordenadores. Assim, agradeço ao meu coordenador no Instituto de Tecnologia do Paraná (TECPAR), Augusto Cesar Fayet e à sua equipe, e à minha coordenadora nas Faculdades Integradas Curitiba (FIC), Prof. a Mônica de Farias Mascarenhas e Lemos.

Agradeço ainda às grandes amizades conquistadas neste período, em especial ao carinho das amigas da Genética, Patrícia Felippe Cardoso, Luciana Cursino e Adalgisa Torres, que me ensinaram um pouquinho sobre bactérias, cheiro da chuva e genética do arroz, e com as quais compartilhei momentos de muita alegria. Lembrarei sempre com carinho dos amigos conquistados em Piracicaba: Margarida, Andréa Dorr, Rosangela e dos demais colegas da pós-graduação.

À Lana Mirian Santos da Silva, minha amiga guerreira, irmãzinha de coração, minha admiração e agradecimento pela amizade eterna. Talvez por ser tão elétrica 
quanto eu, compartilhamos horas de estudo e trabalho tão enriquecedoras, sonhos e expectativas nesta jornada. Agradeço ainda aos amigos de Curitiba que sempre estiveram presentes, torcendo por mim, em especial ao Francisco Teixeira Neto, a Andrea Ferreira Dias e a Cristiane Almeida. Ao Flávio, que foi muito mais que um amigo, agradeço o apoio, o companheirismo e o carinho no início do curso.

Agradeço também a atitude sempre prestativa, encontrada nos momentos em que precisei da ajuda da Maielli, da Ligiana, do Álvaro, dos demais funcionários do departamento e dos professores do curso de pós-graduação.

Finalmente agradeço a Deus, por ter colocado todas essas pessoas especiais no meu caminho. E por me mostrar outros caminhos, tão desafiadores quanto este, para que eu possa seguir em frente. 


\section{SUMÁRIO}

Página

LISTA DE FIGURAS.........................................................................

LISTA DE QUADROS............................................................................ xii

LISTA DE TABELAS................................................................................ xiii

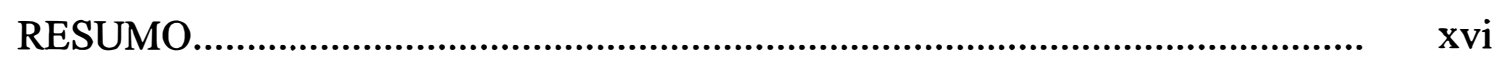

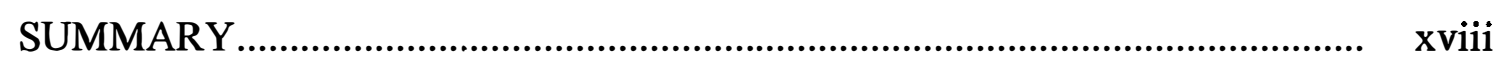

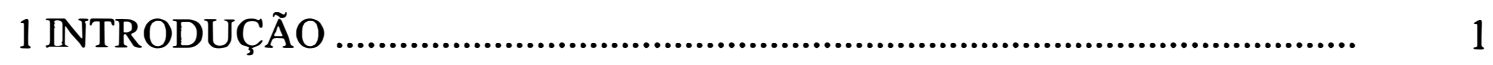

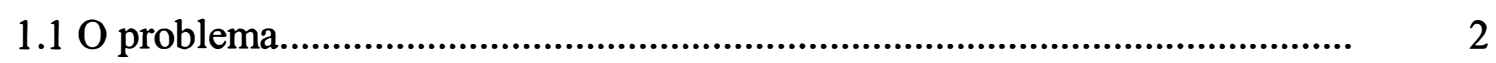

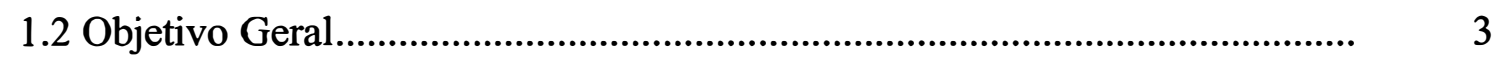

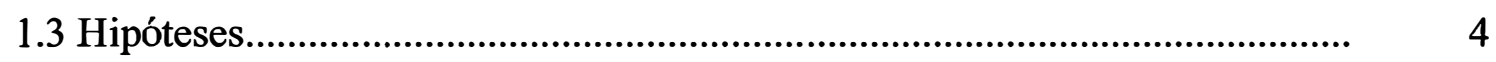

1.4 Organização do trabalho........................................................................ 5

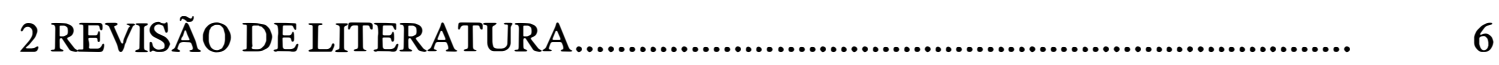

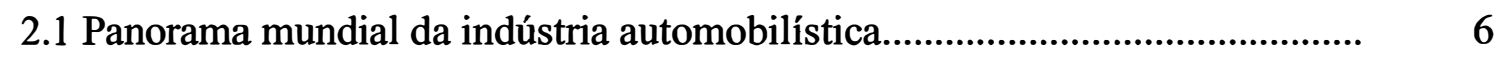

2.1.1 Dinâmica do modo de produção.................................................................... 6

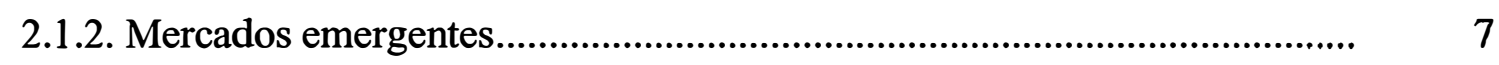

2.1.3 O setor automotivo no Brasil.............................................................. 10

2.1.4 O papel do Estado: da implantação às fases recentes de consolidação e modernização............................................................................................ 10

2.1.5 Panorama nos anos 90 no setor automotivo brasileiro............................. 18

2.1.6 Investimentos e configuração regional recente........................................ 23

3 MATERIAL E MÉTODOS......................................................................... 29

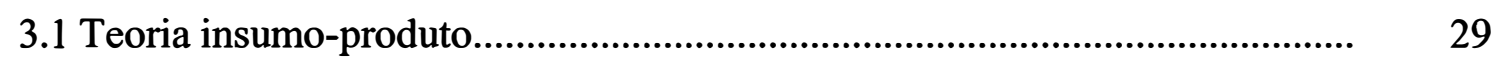

3.2 Modelo básico de insumo produto....................................................... 30 
3.3.Modelos de insumo-produto regionais e inter-regionais.................................. 35

3.4 Métodos de análise da estrutura produtiva................................................... 42

3.4.1 Índices de ligação Hirschman-Rasmussen................................................... 42

3.4.2 Índices puros de ligação.............................................................................. 44

3.4.3 Multiplicadores de impacto...................................................................... 47

3.5 Identificação e análise de clusters com base na teoria insumo-produto.......... 51

3.6 Fuzzy clusters.......................................................................................... 58

3.6.1 Teoria dos conjuntos nebulosos............................................................. 59

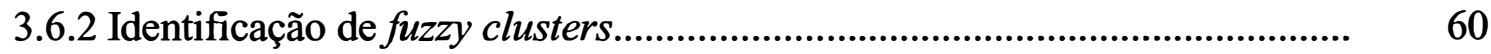

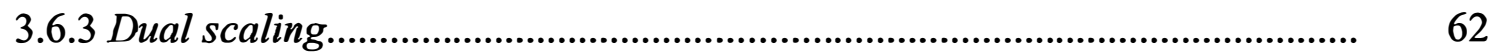

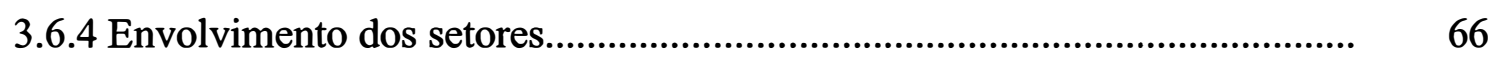

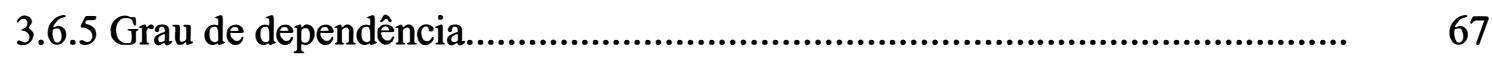

3.7 Método de cálculo do valor adicionado, pessoal ocupado e produtividade

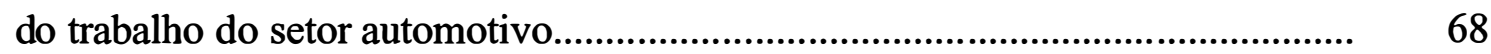

3.7.1 Valor adicionado.......................................................................................... 69

3.7.2 Pessoal ocupado.................................................................................... 71

3.7.3 Produtividade do trabalho..............................................................................

3.7.4 As matrizes de insumo-produto....................................................................

4 RESULTADOS E DISCUSSÃO.................................................................

4.1 Evolução do valor adicionado, pessoal ocupado e produtividade no setor

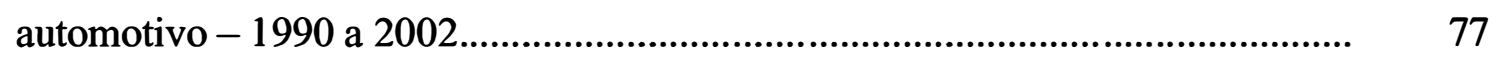

4.2 Fuzzy clusters.............................................................................................

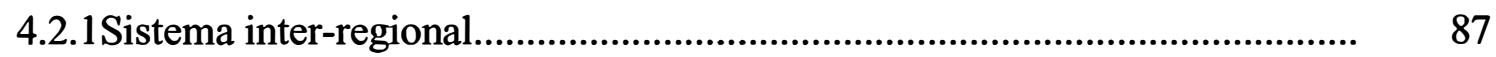

4.2.2 Clusters nas regiões isoladas.................................................................... 98

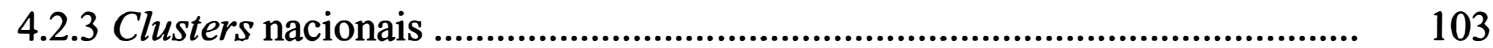

4.3.Índices de ligações intersetoriais................................................................. 105

4.3.1 Hirschman -Rasmussem.................................................................... 106

4.3.2 Índice puro de ligação................................................................................ 116

4.4 Multiplicadores................................................................................... 127

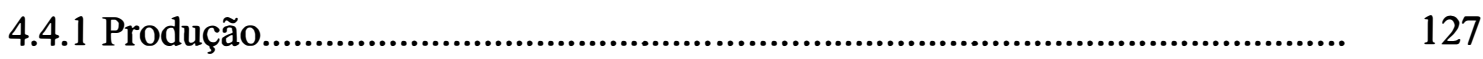


4.4.2 Emprego

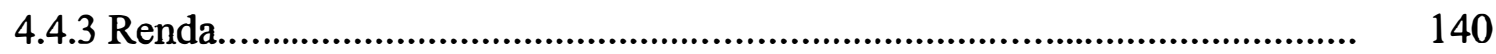

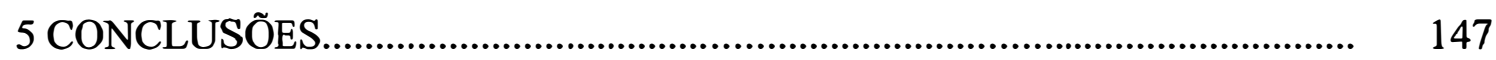

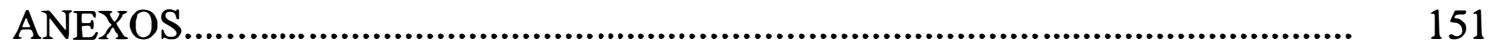

REFERÊNCIAS BIBLIOGRÁFICAS............................................................... 182 
chaves do sistema inter-regional (índices dependentes) segundo o critério McGilvray - 1999...

15 Índices de ligações intersetoriais Rasmussen-Hirschman para trás (15.1) e para frente (15.2) dos setores chaves do sistema inter-regional (índices

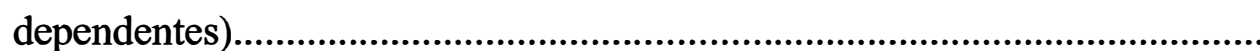

16 Índices de ligação totais mais elevados do sistema inter-

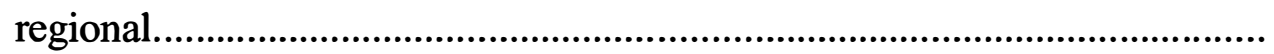

17 Índices puros de ligação pra trás (17.1) e para frente (17.2) mais elevados do sistema inter-regional. 


\section{LISTA DE QUADROS}

Página

1 Projetos aprovados pelo Geia. Brasil, 1956-1957 .............................................. 13

2 Políticas para a indústria automobilística no período 1990 a 1995................... 14

3 Fluxos para uma economia de 2 setores.............................................................. 31

4 Fluxos inter-regionais no modelo insumo-produto................................................ 39

5 Produtos contemplados nas atividades de Automóveis, caminhões e

ônibus e Fabricação de outros veículos, peças e acessórios..................................... 78 


\section{LISTA DE TABELAS}

Página

1 Frota de autoveículos em países selecionados nos anos de 1991, 1995 e 2000 e taxa de crescimento médio anual no período 1991 a 2000 (em mil unidades)

2 Brasil - Proteção tarifária incidente sobre automóveis e veículos comerciais leves no período de janeiro de 1990 a maio de 2000.

3 Produção de automóveis, comerciais leves, caminhões e ônibus. Brasil 1990-2001

4 Desempenho da indústria brasileira de autopeças - 1990 a 2002 ................... 22

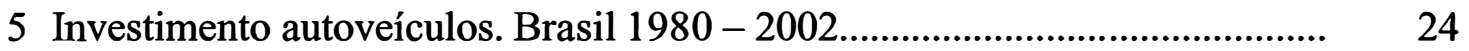

6 Distribuição regional do investimento direto estrangeiro (IED) das montadoras de autoveículos. Brasil. 1996-2001............................................ 25

7 Distribuição regional da indústria automobilística brasileira.

8 Evolução do valor adicionado no setor automotivo - 1990 a 2002 (em bilhões de R\$).

9 Evolução do pessoal ocupado no setor automotivo $\quad$ - 1990 a 80 2002.

10 Evolução da produtividade do trabalho no setor automotivo - 1990 a 2002 (em R\$ mil)

11 Clusters segundo perfis de compra no sistema inter-regional 1999.

12 Clusters segundo perfis de venda no sistema inter-regional 1999.

13 Grau de envolvimento das principais atividades dos clusters segundo perfis 
de compra relacionados ao setor automotivo (\%)........................................... 92

14 Grau de envolvimento das principais atividades dos clusters segundo perfis de compra relacionados ao setor automotivo (\%)......................................... 93

15 Clusters identificados segundo perfis de compras nas regiões isoladas.......... 99

16 Clusters identificados segundo perfis de vendas nas regiões isoladas.............. 99

17 Clusters identificados na economia 1990 e 2002 ......................................... 103

18 Índice de ligação intersetoriais (independentes) de Hirschman-Rasmussen para trás para as regiões Norte $(\mathrm{N})$, Nordeste $(\mathrm{NE})$, Centro Oeste $(\mathrm{CO})$, São Paulo (SP), resto do Sudeste (RSE) e Sul (S) - 1999.......................................

19 Índice de ligação intersetoriais (independentes) de Hirschman-Rasmussen para trás para as regiões Norte $(\mathrm{N})$, Nordeste $(\mathrm{NE})$, Centro Oeste (CO), São Paulo (SP), resto do Sudeste (RSE) e Sul (S) - 1999.....................................

20 Índices de ligação HR dependentes, para frente e para trás -Regiões Norte,

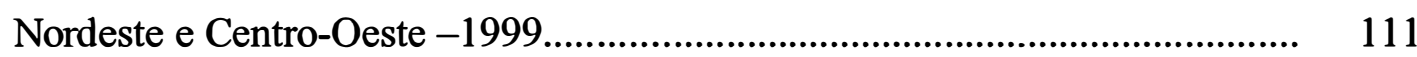

21 Índices de ligação HR dependentes, para frente e para trás - São Paulo, Resto do Sudeste e Região Sul -1999.

22 Índice puros de ligação para trás (independentes) para as regiões Norte $(\mathrm{N})$, Nordeste (NE), Centro Oeste (CO), São Paulo (SP), resto do Sudeste (RSE) e Sul (S) - 1999).

23 Índice puros de ligação para frente (independentes) para as regiões Norte $(\mathrm{N})$, Nordeste (NE), Centro Oeste (CO), São Paulo (SP), resto do Sudeste (RSE) e Sul (S) - 1999 .

24 Índice puros de ligação totais (independentes) para as regiões Norte $(\mathrm{N})$, Nordeste (NE), Centro Oeste (CO), São Paulo (SP), resto do Sudeste (RSE) e Sul (S) - 1999...

25 Índice puros de ligação para trás, para frente e totais (dependentes) para as regiões Norte $(\mathrm{N})$ e Nordeste $(\mathrm{NE})-1999$.

26 Índice puros de ligação para trás, para frente e totais (independentes) para as regiões Centro-Oeste (CO) e São Paulo (SP) - 1999.

27 Índice puros de ligação para trás, para frente e totais (independentes) para as 
regiões resto do Sudeste (RSE) e Sul (S) - 1999...................................... 124

28 Multiplicadores de Produção do tipo I para atividades selecionadas - 1999... 128

29 Multiplicadores de Produção do tipo I em percentual para atividades selecionadas - 1999 .

30 Multiplicadores de Produção do tipo II para atividades selecionadas 1999.

31 Multiplicadores de Produção do tipo II em percentual para atividades selecionadas - 1999 .

32 Multiplicador de Emprego do tipo I e do tipo II segundo as regiões Norte, Nordeste e Centro-Oeste.

33 Multiplicador de Emprego do tipo I e do tipo II segundo as regiões São Paulo, resto do Sudeste e Sul.

34 Número total de empregados gerados na economia, pela variação de um milhão de reais na demanda final

35 Número total de empregos gerados pela variação da demanda final de um milhão de reais, considerando o consumo das famílias endógeno, segundo regiões -1999 .

36 Percentual de empregos gerados pela variação da demanda final de um milhão de reais, considerando o consumo das famílias endógeno, segundo regiões - 1999 .

37 Multiplicador de Emprego do tipo I e do tipo II segundo as regiões Norte, Nordeste e Centro -Oeste.

38 Multiplicador de Emprego do tipo I e do tipo II segundo as regiões São Paulo, resto do Sudeste e Sul.

39 Geração de renda direta, indireta e induzido na economia, considerando o consumo das famílias endógeno - 1999.

40 Geração de renda direta e indireta considerando o consumo das famílias endógeno, segundo regiões - 1999.

41 Percentual de geração de renda direta e indireta considerando o consumo das famílias endógeno, segundo regiões - 1999 


\title{
SETOR AUTOMOTIVO BRASILEIRO: EVOLUÇÃO DA ESTRUTURA PRODUTIVA E SUA IMPORTÂNCIA REGIONAL NOS ANOS 90
}

\author{
Autora: KERLYNG CECCHINI \\ Orientador: Prof. Dr. JOAQUIM JOSÉ MARTINS GUILHOTO
}

\section{RESUMO}

O principal objetivo deste trabalho foi analisar a evolução da estrutura produtiva do setor automotivo brasileiro e sua importância nas regiões brasileiras nos anos 90 . O estudo se justifica haja vista a intensa utilização, pelos governos federal e estaduais, de instrumentos de política visando atrair investimentos para este setor nesse período. As análises foram realizadas com base nos fundamentos da teoria insumo-produto. Foram utilizadas as matrizes de insumo-produto nacionais para estimação do valor adicionado, pessoal ocupado e produtividade do trabalho do setor automotivo para o período de 1990 a 2002. Recorreu-se ainda a um modelo insumo-produto inter-regional construído para 6 regiões da economia brasileira: Norte, Nordeste, Centro-Oeste, São Paulo, resto do Sudeste e Sul, referente ao ano de 1999. Dessa forma, foi possível avaliar o poder de encadeamento setorial, bem como os efeitos de transbordamento em termos de produção, emprego e renda entre as regiões brasileiras. Adicionalmente, utilizou-se o método de identificação e análise de fuzzy clusters proposto por Dridi e Hewings (2002a) na análise da estrutura produtiva nacional e regional. Dentre os principais 
resultados obtidos na análise de clusters destacam-se a importância das atividades do setor automotivo localizadas em São Paulo e no Sul no relacionamento com os demais clusters regionais do sistema. Além disso, observou-se que os clusters nacionais apresentam menor dependência entre si em 2002, relativamente a 1990. Isso sugere que com a abertura comercial e a conseqüente entrada de produtos importados na década de 90, as relações produtivas domésticas tornaram-se menos densas na economia brasileira. As análises da estrutura produtiva, por sua vez, indicam que as atividades do setor automotivo, em geral apresentam elevado poder de interligação para trás, exercendo papel relevante como setores demandantes de insumos da economia. Os resultados também revelam a importância na dinâmica produtiva nacional da atividade de Peças e outros veículos de São Paulo, classificada como um setor chave na economia. Concluise que além dos encadeamentos para trás, a importância do setor pode ser explicada em virtude da oferta de peças de reposição para manutenção da frota de veículos da economia. Essa atividade, portanto, ao mesmo tempo em que apresenta potencial de geração de emprego, intensifica as relações produtivas econômicas, sendo interessante sua utilização como foco de uma política de desenvolvimento setorial regional. A análise também aponta para a importância do setor de Comércio de veículos e peças em termos de geração de emprego e em termos de poder de encadeamento na estrutura produtiva. Além do setor de autopeças, conclui-se também a importância de se enfatizar as atividades econômicas fornecedoras de insumos a esse setor como a metalurgia, siderurgia, indústria de plásticos, componentes eletrônicos, nos objetivos de políticas de desenvolvimento setorial. Como esperado, São Paulo, resto do Sudeste e Sul são as regiões mais favorecidas no que se refere aos transbordamentos de renda, produção e emprego, visto que apresentam maior complexidade produtiva. 


\section{BRAZILIAN AUTOMOTIVE INDUSTRY: PERFORMANCE OF THE PRODUCTIVE STRUCTURE AND ITS REGIONAL IMPORTANCE IN THE 90s}

Author: KERLYNG CECCHINI

Adviser: Prof. Dr. JOAQUIM JOSÉ MARTINS GUILHOTO

\section{SUMMARY}

The main objective of this study was to analyze the productive structure of the Brazilian automotive industry and its importance towards the Brazilian regions in the 90s. This study is justified due to the many political instruments applied by federal and states govemments in order to attract investments for the sector in this period of time. The analysis was based on input-output principles. National input-output matrix has been used to estimate the value added, employment, and labor productivity of automotive industry for the period 1990 to 2002. It has been adopted a inter-regional input-output model built up to six regions of the Brazilian economy: North, Northeast, Center West, Sao Paulo state, rest of Southeast and South, conceming 1999. In this sense, it was possible to evaluate the interindustrial linkages, as well as the overflows concerning production, employment, and income in Brazilian regions. In addition, in national and regional productive structure it was applied the method of identification and analysis of fuzzy clusters, suggested by Dridi and Hewings (2002a). The main results of the clusters analysis stressed the importance of automotive economic activities located in 
Sao Paulo and in the South. Besides, it was noted that national clusters present less dependence on each other in 2002, when compared to 1990 . This information allowed to realize that, as a result of commercial liberalization and the entrance of imported products, the domestic productive relationship became less dynamic. In turn, the productive structure analysis, shows that, in general, the automotive industry presents high backward linkages, being relevant as a demanding industry of inputs from others sectors of the economy. The results also revealed the relative importance of components and other vehicles industries in Sao Paulo, classified as a key-sector in the Brazilian economy. Besides the backward linkages, the importance of these industries can be explained by the supply of components for the maintenance of the fleet. This economic activity has a huge potential in terms of employment and also can intensify the interindustrial relationships. It is interesting to use it as a focus for development of regional policies. The analysis also revealed the importance of the vehicles and components commerce industries in terms of employment, as well as concerning linkages empowerment of the productive structure. Moreover, besides the importance of automotive parts industry, it is possible to conclude the importance to emphasize its suppliers such as metallurgy, steel industry, plastics and electronic components industries, as a goal for industrial development policies. As expected, Sao Paulo, the rest of Southeast and South are the regions who benefited from overflows conceming income, production and employment, as well these regions present a productive structure more complex. 


\section{INTRODUÇÃO}

O cenário mundial da indústria automobilística nos anos 90 é marcado pela adoção do modo de produção flexível, conhecido como produção enxuta, e pelas novas estratégias de mercado, decorrentes da estagnação dos mercados maduros. Esse cenário favorece a reorientação dos investimentos no setor automobilístico de países cujos mercados são considerados emergentes, como a Índia, China e o Brasil.

No caso do Brasil, em particular, o ambiente macroeconômico e a política explícita, visando tanto à modernização e ao aumento da capacidade produtiva, quanto a uma maior integração econômica do setor ao Mercosul, tornam-se estímulos adicionais aos novos investimentos no setor.

Com a instituição do Regime Automotivo em 1995, empresas industriais fabricantes de automóveis se beneficiaram das tarifas especiais de importação de produtos provenientes de países pertencentes ao Mercosul. A partir desse período, governos estaduais, em face da expectativa dos futuros investimentos no setor ampliaram a concessão de incentivos, instaurando uma verdadeira guerra fiscal na economia brasileira na segunda metade da década de 90 .

Todavia, o impacto esperado dessa indústria, em termos de geração de emprego, produção e renda, nem sempre recai sobre a região que efetivamente recebeu o investimento. Em parte, porque nem todos os estados contam com uma estrutura produtiva sofisticada, dependendo, em geral, de segmentos produtivos complementares a produção de automóveis, localizados especialmente na Região Sudeste. Já no que se refere à dinâmica de produção, as estratégias atuais estão baseadas no fornecimento de módulos ou sistemas, prevalecendo um pequeno número de fornecedores mundiais no relacionamento direto com as montadoras. Estes, ao gerenciar seus próprios 
fornecedores, empresas do segmento metal-mecânico (segunda e terceira camada), privilegiam critérios de eficiência, escala, custo, e qualidade. Visando atender a esses critérios, nem sempre optam por fornecedores de peças e componentes da região onde se instalam.

A adoção de medidas de incentivo pelo governo brasileiro visando proporcionar o desenvolvimento da indústria automobilística e de autopeças, além de estimular um necessário debate sobre a eficiência das políticas públicas recentes, levanta pertinentes questionamentos a respeito da importância relativa desse setor no desenvolvimento de economias regionais, bem como sobre seu papel na estrutura produtiva nacional.

Na teoria econômica, a análise insumo-produto tem sido amplamente explorada em estudos que pretendem identificar e analisar o perfil produtivo de economias diversas. Sua importância tem sido especialmente reconhecida na literatura como valioso instrumento de suporte à elaboração de políticas públicas.

Dentre as análises derivadas da aplicação deste modelo, cabe destacar neste estudo dois gnupos. Um deles reúne aquelas que permitem avaliar o impacto sobre a economia de variações da demanda final, bem como as análises derivadas da mensuração de índices de ligação setorial. O segundo engloba as análises que têm por objeto o comportamento dos setores em bloco, fazendo uso tanto da identificação de clusters ou agrupamentos de setores segundo a semelhança dos seus fluxos de bens e serviços, quanto da mensuração da importância econômica destes blocos, mediante o cálculo do seu Produto Interno Bruto (PIB).

Posto isso, justifica-se a aplicação destes métodos visando identificar e quantificar as relações que o setor automotivo estabelece na economia brasileira, contribuindo para um melhor entendimento do seu papel na estrutura produtiva nacional.

\subsection{0 problema}

O esforço recente realizado pelo estado no fortalecimento da indústria automobilística e de autopeças, justifica uma ampla discussão acerca da importância 
relativa dessas atividades econômicas na estrutura produtiva nacional e no contexto de suas regiões, a qual tem sido pouco explorada na literatura. Questiona-se sobretudo, se essas atividades econômicas geram efeitos sobre as regiões que pertencem, ou predominam efeitos de transbordamento em termos de produção, emprego e renda para as demais regiões brasileiras? Uma vez estabelecida na estrutura de uma determinada região, as atividades econômicas pertencentes a esse setor estabelecem relações produtivas similares a outros setores a ponto de liderar um agrupamento setorial importante para a região? Como vem evoluindo a trajetória do setor automotivo nos anos $90 ?$

\subsection{Objetivo geral}

Este estudo tem por objetivo realizar uma avaliação da importância do setor automotivo, constituído no presente trabalho pelas atividades econômicas de Automóveis, caminhões e ônibus, e Peças e outros veículos, na estrutura produtiva brasileira à luz da teoria insumo-produto. Consistem em perguntas centrais deste trabalho:

(i) O setor automotivo pode ser caracterizado como um setor-chave na estrutura produtiva brasileira? Qual a importância relativa desse setor nas regiões brasileiras?

(ii) Qual a dimensão do impacto do setor automotivo de uma determinada região brasileira sobre as demais?

(iii) As atividades pertencentes a esses setores estabelecem relações produtivas similares a outros setores a ponto de liderar um agrupamento setorial nas regiões ou na economia nacional?

(iv) Como o setor automotivo tem evoluído nos anos 90 ? 
Tendo como base o sistema inter-regional (Guilhoto et al., 2004) composto por seis regiões, a saber Norte, Nordeste, Centro-Oeste, São Paulo, resto do Sudeste e Sul, apresentando um nível de desagregação correspondente a 31 setores em cada região, pretende-se, especificamente:

1) Mensurar os impactos sobre a produção, emprego e renda decorrentes das variações da demanda final do setor automotivo nas regiões supra citadas;

2) Quantificar os efeitos de transbordamento do setor automotivo de uma região para o restante da economia;

3) Avaliar se as atividades econômicas constituintes do setor automotivo podem ser caracterizadas como indústrias-líderes ou de suporte na economia, sob a ótica de agrupamentos produtivos do tipo fuzzy clusters nas regiões brasileiras, bem como na estrutura produtiva nacional.

4) Quantificar a evolução do valor adicionado, do pessoal ocupado e da produtividade do trabalho deste setor nos anos 90 .

Cabe acrescentar que o estudo concentra-se em parte dos aspectos pertinentes à elaboração de políticas setoriais. Outras questões relativas ao impacto do setor sobre as relações no mercado de trabalho e sobre o meio ambiente, assim como o seu papel no progresso tecnológico da economia, devem ser cuidadosamente observadas na elaboração de trabalhos complementares, uma vez que vão além dos objetivos propostos pelo método de análise escolhido neste trabalho.

\subsection{Hipóteses}

A hipótese a ser verificada neste trabalho é a de que o setor automotivo se caracteriza como um setor chave para a economia, no que se refere a importância dos seus encadeamentos setoriais. 
Espera-se também que este setor exerça maior importância para a economia nas regiões onde sua indústria tenha se consolidado há mais tempo, como em São Paulo, no resto do Sudeste e no Sul. Neste sentido, também espera-se que, nestas regiões, estas atividades liderem clusters produtivos. Além disso, supõe-se que as regiões de São Paulo e do resto do Sudeste sejam favorecidas em termos de transbordamento decorrentes dos impactos do setor automotivo localizado nas regiões Norte, Nordeste e Centro-Oeste e Sul.

\subsection{Organização do trabalho}

Além desse capítulo introdutório, o presente trabalho está estruturado em mais quatro capítulos. O segundo capítulo faz uma revisão acerca das principais transformações que ocorreram no setor automotivo no contexto mundial e tece considerações sobre a evolução recente do setor na economia brasileira. Também são tratadas nesse capítulo as políticas voltadas para o setor na fase de consolidação no Brasil e, em especial nos anos 90.

O terceiro capítulo apresenta o referencial teórico do modelo insumo-produto, contemplando além dos aspectos conceituais, o detalhamento dos métodos de análise estrutural e de identificação de clusters, assim como considerações sobre a base de dados utilizada. Os resultados obtidos na aplicação do modelo são apresentados e discutidos no quarto capítulo. O quinto e último capítulo cinco discorre sobre as conclusões e recomendações de políticas para o setor. 


\section{REVISÃO DE LITERATURA}

\subsection{Panorama mundial da indústria automobilística}

\subsubsection{Dinâmica do modo de produção}

De acordo com Womack et al. (1992), a indústria automobilística vem influenciando historicamente o modo de produção dos bens econômicos em geral. A primeira grande contribuição ocorreu após a Primeira Guerra Mundial, quando a produção em massa foi adotada inicialmente pelas empresas norte-americanas Ford e General Motors - GM, e mais tarde difundida na economia. Em meados dos anos 70, enquanto a crise do petróleo evidenciava a necessidade de um modo de produção mais flexível, consolidava-se no Japão a produção enxuta.

O autor ressalta que a idéia de flexibilizar a produção e as equipes de trabalho, associada à busca incessante pela qualidade e redução de custos, consistem nos princípios básicos da produção enxuta. Importantes transformações nas formas de relacionamento da montadora com seus fornecedores decorrem destes fundamentos. Enquanto na produção em massa a montadora gerenciava e estabelecia especificações técnicas para todos os fornecedores de peças e componentes do automóvel, na produção enxuta esse processo passa a ser cada vez mais simplificado.

A montadora automobilística japonesa passou a organizar seus fornecedores em camadas ou níveis funcionais, estabelecendo relações apenas com aqueles fornecedores de sistemas mais complexos ou módulos, como sistemas de interiores, sistemas de freio e tração, pertencentes à primeira camada. Este tipo de organização também é chamada de produção modular. Dessa forma, era possível gerenciar um menor número de empresas fornecedoras, as quais por sua vez, estavam vinculadas aos fornecedores de peças, de segunda e terceira camada. Segundo Baldwin e Clark (1997) e Humphrey et al. 
(2000), os fornecedores da primeira camada passavam a ser responsáveis pela escolha de seus próprios fornecedores, bem como pelo atendimento destes às exigências de qualidade da montadora.

Como observa Humphrey et al. (2000), além da escolha dos mesmos fornecedores de primeira camada em múltiplas localizações produtivas no mundo, a produção modular implica no compartilhamento de plataformas e na padronização de design em escala mundial. Essas estratégias são denominadas, respectivamente, de follow sourcing e follow design.

A difusão mundial da produção enxuta e de suas ferramentas ocorreu de forma gradativa, tornando-se mais intensa com as crises que atingiram os mercados europeu e norte americano, em meados dos anos 70 e início dos anos 80 .

No caso do Brasil, o processo de adoção deste modo de produção tem ocorrido de forma bem mais lenta. Atualmente, a despeito dos esforços realizados na implantação de alguns elementos desse modo de produção desde o início da década de 80 , ainda persistem unidades produtivas defasadas em relação ao padrão de produção vigente internacionalmente ${ }^{1}$.

\subsubsection{Mercados emergentes}

"Nos anos 90, o mercado mundial da indústria automobilística apresenta uma clara divisão entre os chamados mercados maduros e os mercados emergentes. Neste período, os mercados maduros, dotados de uma indústria automobilística mais desenvolvida, representados pela Tríade Estados Unidos, Japão e Europa, já mostram sinais de estagnação. Os mercados emergentes, por sua vez, apresentam elevado

\footnotetext{
${ }^{1}$ Como destaca Ferro (1992), é interessante observar a defasagem tecnológica da indústria brasileira desde seus primórdios. Enquanto no final dos anò 70, o Japão consolidava o novo modo de produção, o Brasil ainda adentrava, com 50 anos de atraso, na produção em massa, operando gigantescas linhas de montagem do Fusca e da Kombi, na Volkswagen.
} 
potencial de crescimento dessa indústria e reúnem países como o Brasil, China e Índia (Humphrey et al., 2000).

A evolução da frota de autoveículos consiste em um indicador relevante na análise do comportamento dos mercados. Como indica a Tabela 1 a seguir, nos Estados Unidos e no Japão o crescimento médio anual dessa variável, no período de 1991 a 2000, foi de $1,83 \%$ e 2,16\%, respectivamente. Mesmo em países europeus, como na Alemanha, Itália e França essa taxa atingiu, no máximo, 2,31\% (Alemanha).

Tabela 1. Frota de autoveículos em países selecionados nos anos de 1991, 1995 e 2000 e taxa de crescimento médio anual no período 1991 a 2000 (em mil unidades)

\begin{tabular}{lcccc}
\hline \multicolumn{1}{c}{ País } & 1991 & 1995 & 2000 & $\begin{array}{c}\text { Taxa de crescimento } \\
\text { médio anual } \\
(1991-2000)\end{array}$ \\
\hline Estados Unidos & 188.136 & 201.5 & 221.475 & 1,83 \\
Japão & 59.915 & 66.854 & 72.649 & 2,16 \\
Alemanha & 38.504 & 43.561 & 47.307 & 2,31 \\
Itália & 31.033 & 32.807 & 36.165 & 1,71 \\
França & 28.827 & 30.295 & 33.813 & 1,79 \\
Reino Unido & 26.429 & 27.942 & 31.423 & 1,94 \\
Federação Russa & 24.500 & 23.495 & 26.263 & 0,51 \\
Espanha & 15.152 & 17.284 & 21.427 & 3,93 \\
Brasil & 13.145 & 15.77 & 19.31 & 4,37 \\
Canadá & 15.98 & 16.668 & 17.571 & 1,06 \\
México & 10.399 & 12.523 & 15.487 & 4,52 \\
$\rightarrow$ China & 6.114 & 10.4 & $13.190 *$ & 8,92 \\
Austrália & 9.649 & 11.207 & 12.528 & 2,94 \\
Coréia do Sul & 4.248 & 8.469 & 12.06 & 12,29 \\
Holanda & 5.801 & 6.29 & 7.19 & 2,41 \\
Argentina & 5.959 & 5.903 & 6.645 & 1,22 \\
África do Sul & 5.221 & 5.99 & 6.046 & 1,64 \\
Bélgica & 4.391 & 4.755 & 5.222 & 1,94 \\
Áustria & 3.812 & 4.368 & 4.493 & 1,84 \\
Suécia & 3.943 & 3.953 & 4.387 & 1,19 \\
Outros & 94.149 & 96.725 & 134.679 & 4,06 \\
\hline
\end{tabular}

Fonte: Associação Nacional de Veículos Automotores (Anfavea) (2003)

(*) Dados referentes a 1998 
Em contraste, os mercados chinês e sul-coreano demonstram um crescimento acelerado no mesmo período, apresentando uma variação da frota na ordem de 8,92\% e 12,29\% , respectivamente. Destaque também pode ser atribuído ao Brasil e ao México, países onde a variação da frota além de expressiva, foi similar nos dois países, 4,37\% e $4,50 \%$, respectivamente.

Segundo alguns analistas, a relação entre a frota de veículos e o número de habitantes do país permite obter uma dimensão prévia acerca do potencial do mercado automobilístico. Segundo a Anfavea (2004), em 2001 o Brasil possuía cerca de 8,6 habitantes por autoveículo. Esta relação é similar ao México e à Argentina, que respectivamente apresentam 6,1 e 5,2 habitantes por autoveículos, e relativamente alta se comparada aos países mais desenvolvidos. Observando a Figura 1, verifica-se que em países mais desenvolvidos, como Estados Unidos, Japão e França, a relação não atinge 2 habitantes por veículo em 2001.

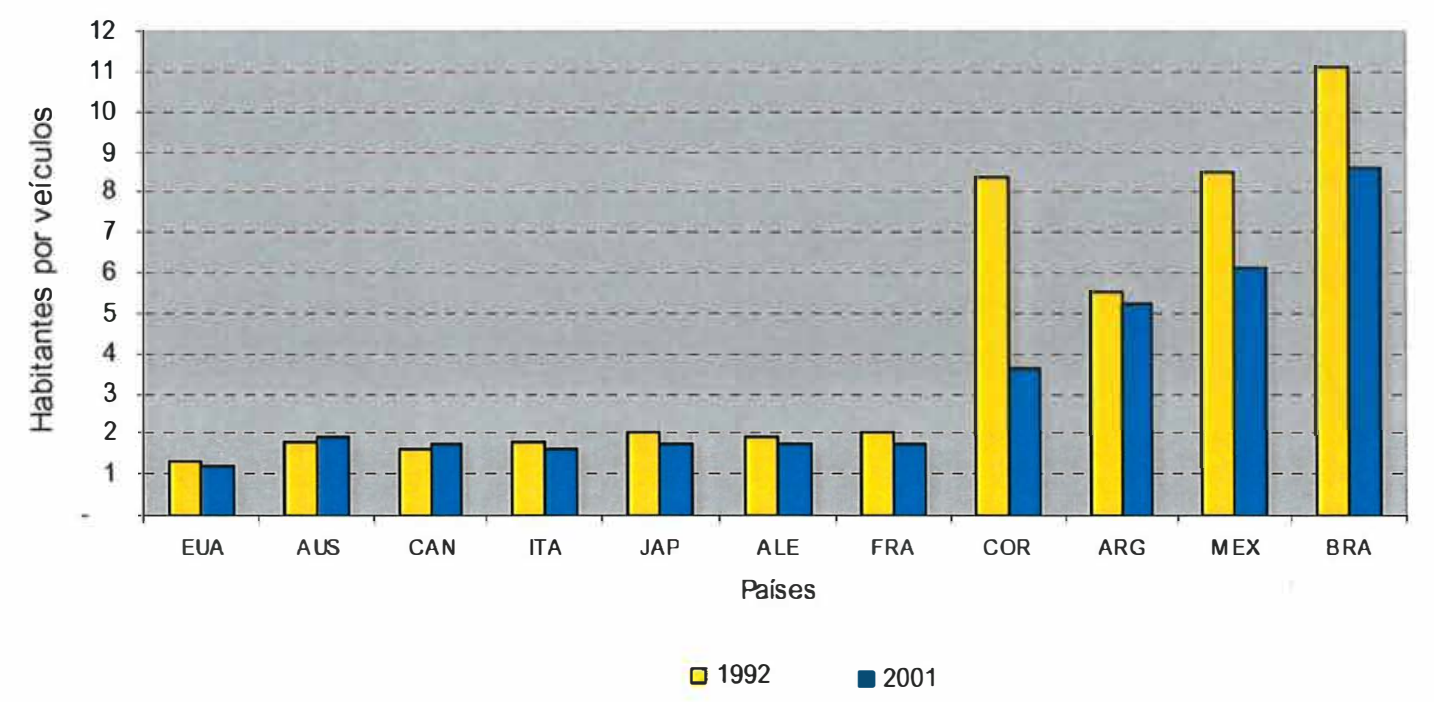

Figura 1 - Habitantes por autoveículo em países selecionados, 1992 e 2001 Fonte: Anfavea (2004)

Nota: países: Estados Unidos (EUA), Austrália (AUS) Canadá (CAN), Itália (ITA), Japão (JAP), Alemanha (ALE), França (FRA), Coréia do Sul (COR), Argentina (ARG), México (MEX), Brasil (BRA) 
"Conforme Humphrey et al. (2000), os mercados emergentes podem ser segmentados em três categorias:

1) Mercados autônomos com elevado grau de proteção da indústria doméstica, como a China e a Índia;

2) Mercados periféricos integrados, localizados próximos do Canadá, Estados Unidos e Leste Europeu, como o México e a Europa Central;

3) Mercados regionais emergentes, que integram países emergentes em uma única região, como o Brasil, pertencente ao Mercosul, bem como países pertencentes à Associação de Nações do Sudeste Asiático (ASEAN).

" Para Humphrey et al. (2000), a presença de um sistema regulatório mais flexível e de instituições sociais frágeis nestes países emergentes potencializaram as novas formas de relacionamento entre a montadora e a empresa fornecedora, com destaque para o fornecimento modular e a criação de condomínios industriais.

\subsection{O setor automotivo no Brasil}

\subsubsection{O papel do Estado: da implantação às fases recentes de consolidação e modernização}

A ativa atuação do estado foi decisiva para o desenvolvimento da indústria automobilística brasileira, contribuindo tanto nas suas fases iniciais de implantação e consolidação, que marcaram os anos 50 e 60, quanto nos recentes movimentos de modernização e desconcentração regional observados na década de 90.

Segundo Ferro (1992), o Brasil teve sua primeira unidade de montagem de veículos, a Ford, instalada no bairro Ipiranga em São Paulo no ano de 1919. Os veículos eram montados a partir de componentes enviados diretamente pela matriz, situada em Detroit, nos Estados Unidos. Logo em seguida, em 1923, a General Motors se instalou na mesma região paulista, buscando atender a demanda por veículos comerciais. 
Naquela época, as condições viárias nacionais eram bastante precárias. A primeira rodovia nacional, a Rio-São Paulo, foi inaugurada somente em 1928, e era constituída de terra batida. A despeito da precariedade do sistema viário do período, a frota de veículos registrava larga expansão no cenário urbano brasileiro, passando de 30 mil unidades no início dos anos 20, para 250 mil em 1930 (Ferro, 1992).

A produção nacional era limitada, de tal maneira que o mercado doméstico apresentava extrema dependência dos produtos importados. Baer (1995) salienta que, posteriormente, no período da Segunda Guerra Mundial, em virtude da impossibilidade de importar diversos componentes, o setor de equipamentos de transporte demonstra incapacidade de operar na sua plena capacidade. A estrutura produtiva brasileira da época ainda não permitia a produção local de automóveis. Além de apresentar uma indústria metalúrgica incipiente, voltada para a produção de bens de baixo grau de sofisticação produtiva (peças de reposição de máquinas têxteis e utensílios domésticos), o país ainda necessitava do desenvolvimento de uma indústria siderúrgica, que se consolidaria mais tarde (Ferro, 1992; Baer, 1995).

A falta de peças e componentes para reposição no mercado doméstico neste período estimulou o surgimento das primeiras oficinas artesanais no país, originando o segmento de autopeças no Brasil (Ferro, 1992; Shapiro, 1994)

Os esforços iniciais para a implantação da indústria automobilística no Brasil surgem somente no governo de Getúlio Vargas (1951-1954) que, ao visar à constituição de uma indústria de base, fortalece o segmento de siderurgia brasileiro, criando a Companhia Siderúrgica Nacional, entre outras empresas relevantes (Ferro, 1992).

Já na segunda metade da década de 50, observa-se um comprometimento efetivo do governo com o desenvolvimento do setor, decorrente da política de desenvolvimento adotada na administração do então presidente Juscelino Kubitschek. Seu programa de política, estruturado mediante o Plano de Metas, cobria cinco áreas: energia, transporte, fornecimento de alimentos, educação e indústria de base. Esta última, além da indústria automobilística, reunia a indústria do aço, alumínio, cimento, 
celulose, maquinaria pesada e produtos químicos (Baer, 1995; Orenstein e Sochaczewski, 1990).

"O Plano de Metas contemplava ainda um programa de desenvolvimento específico voltado para a indústria automobilística, organizado por intermédio do então Banco Nacional de Desenvolvimento Econômico (BNDE). O programa concedia um tratamento especial para importações de equipamentos, matérias primas e componentes por um determinado período de tempo (Baer, 1995).

"Este programa foi dirigido pelo Grupo Executivo da Indústria Automobilística (GEIA), e tinha como objetivo estabelecer a instalação dessa indústria no Brasil. Conforme Santos e Burity (2002), compreendiam responsabilidades do GEIA a definição de normas de instalação, metas de produção e planos de nacionalização do setor, tendo como prioridade produzir veículos de carga e atenuar a deterioração do balanço de pagamentos, decorrente das crescentes importações de automóveis e peças. "

" Santos e Burity (2002) afirmam que a concessão de cotas para importação de peças não produzidas no país, o câmbio favorecido para importação de equipamento e a isenção tarifária para importação de componentes destinados a automóveis, consistiram em alguns dos incentivos de natureza cambial e fiscal, adotados pelo governo federal neste período.

A Ford e a GM, já instaladas no país, juntamente com a Fábrica Nacional de Motores (FNM), a International Harvester, Scania e Mercedes, apresentaram projetos de produção de ônibus e caminhões ao GEIA, ao passo que as empresas européias Volkswagen, Vemag e Simca, e a nacional Willys direcionaram sua produção para o mercado de automóveis (Ferro, 1992). Ao todo, 11 projetos foram aprovados pelo GEIA, como mostra o Quadro 1 a seguir. 


\begin{tabular}{|lc|}
\hline \multicolumn{1}{|c|}{ Empresa } & Produto \\
\hline General Motors & Caminhão médio e leve \\
Ford Motor Co. Exports & Caminhão médio e leve \\
Mercedes-Benz do Brasil & Caminhão médio e pesado e ônibus \\
Toyota do Brasil & Jipe \\
Volkswagen do Brasil & Utilitário e carro de passeio \\
Vemag AS Veículos e Maquinas Agrícolas & Utilitário, jipe e carro de passeio \\
Scania - Vabis do Brasil & Caminhão pesado \\
Fábrica Nacional de Motores & Caminhão pesado e carro de passeio \\
International Harvester Máquinas & Caminhão pesado \\
Willys- Overland & Jipe, Utilitário, carro de passeio \\
S.A. Ind de Motores, Caminhões e Ônibus, Simca & Carro de passeio \\
do Brasil & \\
\hline
\end{tabular}

Quadro 1 - Projetos aprovados pelo GEIA. Brasil, 1956-1957

Fonte: Shapiro (1994)

"Como resultado, ao final do governo de Kubstischek, cerca de metade da produção da indústria automobilística consistia em automóveis de passageiros e o restante compunha-se de utilitários e caminhões (Baer, 1995).

Para Ferro (1992) a fragilidade do Estado e do capital nacional para o desenvolvimento dessa indústria fez com que se buscasse o capital estrangeiro para a produção em massa. Contudo, já se previa a necessidade de nacionalização da produção. Segundo Santos e Burity (2002), uma das metas previa que em 1960, caminhões e veículos utilitários deveriam atingir $90 \%$ de nacionalização, e jipes e carros de passeio, $95 \%$.

Nos anos 70, o BNDES foi responsável pelo apoio financeiro e inúmeros programas de reestruturação de setores sem canais de acesso a um crédito mais barato e de longo prazo, através de programas específicos, um deles para a indústria de autopeças. Destaque também para o II PND (Plano de Desenvolvimento Nacional). Entretanto, a partir dos choques do petróleo e do II PND surgem divergências entre o interesse público e privado (Bedê, 1997).

"No início dos anos 90, a presença do estado na elaboração de políticas para o setor ganha força novamente. Como destacam Bonelli e Veiga (2003), em nenhum outro "segmento industrial os incentivos foram tão extensos e a política setorial tão explícita" neste período. 
São adotadas políticas protecionistas desde o início da década, conforme mostra a Quadro 2 a seguir.

\begin{tabular}{|c|c|}
\hline Governo /Período & Políticas/Medidas \\
\hline Collor (1990-1992) & $\begin{array}{l}\text { 1990: Programa de redução tarifaria ( } 80 \% \text { a } 35 \%) \text { de } 1990 \text { a } 1994 \text {. Incentivos } \\
\text { financeiros suspensos, barreiras não tarifárias eliminadas. Incentivos fiscais (redução } \\
\text { IPI) para carros pequenos. Iniciativa do Mercosul com Argentina, Uruguai e Paraguai. } \\
\text { 1992: Processo de Arbitragem Setorial (Câmara Setorial). Metas para preços, produção, } \\
\text { exportação, emprego e salários são negociadas por montadoras, fornecedores, } \\
\text { sindicatos e governo. Redução de impostos (IPI e ICMS) são colocadas em vigor para } \\
\text { promover o crescimento da demanda. }\end{array}$ \\
\hline $\begin{array}{l}\text { Itamar Franco (1993- } \\
\text { 1994) }\end{array}$ & $\begin{array}{l}\text { Fevereiro de 1993: Processo de Arbitragem Setorial Renegociado. Novas metas são } \\
\text { estabelecidas. } \\
\text { Abril de 1993: Incentivos fiscais são concedidos a carros populares: IPI cai a } 0,1 \% \text {, } \\
\text { ICMS é reduzido e exceções para COFINS. } \\
\text { Outubro, 1994: Governo baixa as tarifas para } 20 \% \text { (que era meta somente para 2001) }\end{array}$ \\
\hline $\begin{array}{l}\text { Fernando } \quad \text { Henrique } \\
\text { Cardoso }(1994-2002)\end{array}$ & $\begin{array}{l}\text { Fevereiro de 1995: Nova reunião do processo de Arbitragem Setorial (tarifas são } \\
\text { elevadas novamente para } 32 \% \text {, IPI para carros populares se eleva para } 8 \% \text { ) } \\
\text { Março de 1995: aumento das tarifas para } 70 \% \\
\text { Junho de 1995: Nova política é estabelecida pelo governo (quotas de importação, } \\
\text { redução tarifaria para } 2 \% \text { para equipamentos e componentes associados a performance } \\
\text { exportadoras, incentivos de investimentos são concedidos - depreciação acelerada) } \\
\text { Importação de carros da Argentina são exceções para as novas medidas. }\end{array}$ \\
\hline
\end{tabular}

Quadro 2 - Políticas para a indústria automobilística no período 1990 a 1995

Fonte: Laplane e Sarti (1997)

Tendo em vista a retomada de investimentos e a promoção de exportações via aumento da competitividade, o governo brasileiro adotou o Regime Automotivo em 1995. O Programa estabelecia um regime de proteção elevado para o setor e foi reformulado em 1997 para contemplar os Estados menos desenvolvidos. Além de um pacote de incentivos fiscais para implantação das empresas, incluía incentivos diferenciados para as plantas instaladas nas regiões Norte, Nordeste e Centro-Oeste (Bonelli e Veiga, 2003; Laplane e Sarti, 1997; Santos e Burity, 2002);

"Segundo Santos e Burity (2002), o regime concedia redução de 50\% do imposto de importação de veículos para as montadoras que já produzissem ou estivessem em vias de produzir no país. Outrossim, as importações de bens de capital, ferramental e moldes para matérias-primas também sofreram reduções tarifárias drásticas. Os reflexos da redução do imposto de importação foram observados no setor de autopeças, 
pressionando seus preços. Além das tarifas de importação, reduziu-se o IPI para bens de capital, matéria-prima, autopeças, pneumáticos e material de embalagem."

No caso das empresas já instaladas eram exigidos índices médios de nacionalização de $60 \%$. Para as empresas novas, esse índice era de $50 \%$, além de um sistema de compensação de importações com exportações.

A Tabela 2 apresenta uma indicação do grau de proteção tarifária concedido ao setor automobilístico durante o Regime Automotivo.

Tabela 2. Brasil - Proteção tarifária incidente sobre automóveis e veículos comerciais leves no período de janeiro de 1990 a maio de 2000

\begin{tabular}{ccc}
\hline Períodos & $\begin{array}{c}\text { Alíquota do imposto de importação } \\
\text { (\%) }\end{array}$ & $\begin{array}{c}\text { Regime automotivo } \\
\text { (\%) }\end{array}$ \\
\hline jan./90 & 65 & - \\
mai./90 & 85 & - \\
fev./91 & 60 & - \\
fev./92 & 50 & - \\
out./92 & 40 & - \\
jun./93 & 35 & - \\
set./94 & 20 & - \\
fev./95 & 32 & - \\
mar./95 & 70 & 35,0 \\
jan.97 & 63 & 31,5 \\
jan./98 & 49 & 24,5 \\
jul./98 & 45 & 22,5 \\
jan./99 & 35 & 17,5 \\
mai./00 & 35 & 0 \\
\hline
\end{tabular}

Fonte: Bonelli (2001)

Um regime especial de comércio entre Argentina e Brasil a partir de 1995 estabelecia o Acordo Automotivo Argentina-Brasil. As dificuldades de relações comerciais entre os dois países, entretanto, tornaram-se evidentes com a desvalorização do real em relação ao peso, em janeiro de 1999. A adoção de regimes cambiais diferentes entre os dois países - fixo na Argentina e flutuante no Brasil - impedia o fortalecimento de relações comerciais neste setor, na medida que favorecia a indústria 
brasileira. As negociações em torno da extensão do regime se prolongaram e só foram restabelecidas em novembro de 2000, com um novo acordo. A partir de 2000, estabeleceu-se entre os dois países uma política comum para o setor, referente ao período de 2000 a 2005 (Bonelli e Veiga, 2003; Bonelli, 2001).

A concessão de incentivos, contudo, não ficou restrita ao âmbito federal. Dentre as políticas realizadas pelos estados com a finalidade de atrair investimentos, Santos e Burity (2002) e Bonelli (2001) verificam a utilização de medidas que variam desde a utilização de gastos diretos, como financiamentos e participação de capital, até o apoio no fornecimento de infra-estrutura e no processo de simplificação de registros. As medidas largamente criticadas, entretanto, se referem àquelas que comprometem a arrecadação do Imposto sobre Circulação de Mercadorias (ICMS), a principal fonte de recursos dos governos estaduais. São estas últimas medidas que justificam o termo guerra fiscal utilizado para caracterizar o comportamento dos governos estaduais neste período.

Os efeitos da guerra fiscal são tema de debate na literatura. Para Perobelli e Piancastelli (1996), a guerra fiscal acaba tratando-se de uma simples renúncia fiscal, tornando-se inócua. Os autores argumentam que a adoção pelos estados de um conjunto de instrumentos bastante similar, reforça a questão locacional como fator decisivo no fluxo de investimentos.

Bonelli (2001) complementa sugerindo que os reais beneficiários da redução do ICMS são as empresas multinacionais montadoras de automóveis. Segundo o autor, as empresas tiveram a oportunidade de instalar suas fábricas a um custo muito baixo, uma vez que certamente se instalariam no país na ausência dos incentivos.

$\mathrm{O}$ autor argumenta que os Estados podem ser os perdedores, já que, por ocasião de seu estudo, não se conheciam trabalhos que estimassem a relação custo-benefício das regiões onde houve renúncia fiscal avaliando, simultaneamente, o impacto na geração de emprego e renda; e o custo decorrente da perda de receita tributária e dos gastos com infra-estrutura, energia elétrica, água e saneamento básico, doação de terrenos etc. 
Arbix e Rodrigues-Pose (2001) convergem com a visão anterior ao defenderem que a competição territorial foi puramente um gasto. Na visão desses autores, o bemestar que a indústria gera é neutralizado pelos custos diretos e indiretos de atração dos investimentos. $\mathrm{Na}$ ótica global, essa competição territorial implica no fechamento de outras plantas, e, portanto, proporciona a diminuição da atividade econômica e o aumento do desemprego no país.

Segundo Bonelli (2001), o Governo Federal manifestou-se no sentido de tentar acabar com a guerra fiscal, atrelando a concessão de benefícios fiscais ao Conselho Nacional de Política Fazendária (Confaz). Entretanto, em virtude da pressão dos Estados menos desenvolvidos, apenas as isenções diretas de ICMS permaneceram requerendo a autorização unânime do Confaz. As demais formas indiretas de concessão de benefícios, como a concessão de créditos estaduais no valor do ICMS devido, a taxas de juros inferiores as de mercado, não necessitam de aprovação.

A larga utilização da redução de alíquotas e do diferimento ${ }^{2}$ do ICMS é acompanhada de outras medidas diversas. No caso fluminense, as novas unidades da Volkswagen tiveram a postergação por cinco anos do pagamento de $75 \%$ do ICMS, beneficios de infraestrutura, com a disponibilidade de gás natural, telefonia digital, água e energia elétrica. Praticamente, os mesmos benefícios oferecidos para a instalação da fábrica de ônibus e caminhões em Resende. A doação de áreas e lotes industriais foi adotada pelo governo paranaense visando atrair a instalação da fábrica da montadora Renault no Estado.

Conforme Santos e Burity (2002), dentre as medidas complementares utilizadas é possível destacar:

\footnotetext{
2 Diferimento do ICMS significa isentar o imposto para o primeiro agente da cadeia produtiva, possibilitando que este venda o produto mais barato. O próximo agente, mesmo tendo que pagá-lo integralmente, aufere um ganho financeiro, visto que o ICMS é um imposto sobre o valor adicionado ao produto (Bonelli, 2001).
} 
(i) Obras, serviços de infra-estrutura como a construção de subestações, terminais marítimos e unidades para tratar efluentes sanitários, bem como instalações produtivas e terrenos oferecidos pelo Estado;

(ii) participação acionária, mediante a utilização tanto de fundos estaduais de desenvolvimento a exemplo da Peugeot no Rio de Janeiro, quanto de fundos resultantes da privatização de empresas estaduais, como no caso da Renault, no Paraná;

(iii) concessão de créditos para capital de giro e capital fixo, providos, na maioria dos Estados, por fundos estaduais de desenvolvimento;

(iv) diferimento do ICMS para viabilizar operações de devolução total ou parcial desse imposto quando gerado pela empresa;

(v) isenção de impostos municipais, como ISS e IPTU; e

(vi) garantias, como cauções ou fianças bancárias, benefícios acordados perante o risco de mudanças na legislação, oferecidas pelo governo estadual.

"O conjunto de políticas voltado para o setor automobilístico nos anos 90 resultou na efetiva ampliação da capacidade de produção e na modernização do parque industrial. Os desdobramentos dessa reestruturação foram observados especialmente nos níveis de produção, emprego e comércio exterior, objeto da próxima seção."

\subsection{Panorama nos anos 90 no setor automotivo brasileiro}

No período de 1990 a 2003, a produção de autoveículos - automóveis, comerciais leves, caminhões e ônibus - duplicou na economia brasileira, passando de 914 mil para 1,8 milhões de unidades. Esse crescimento foi mais expressivo na produção de automóveis de passeio, cujo volume de 663 mil unidades observado em 1990 cresceu 2,3 vezes, atingindo em 2003, 1,5 milhões, como mostram a Figura 2 e a Tabela 5. 


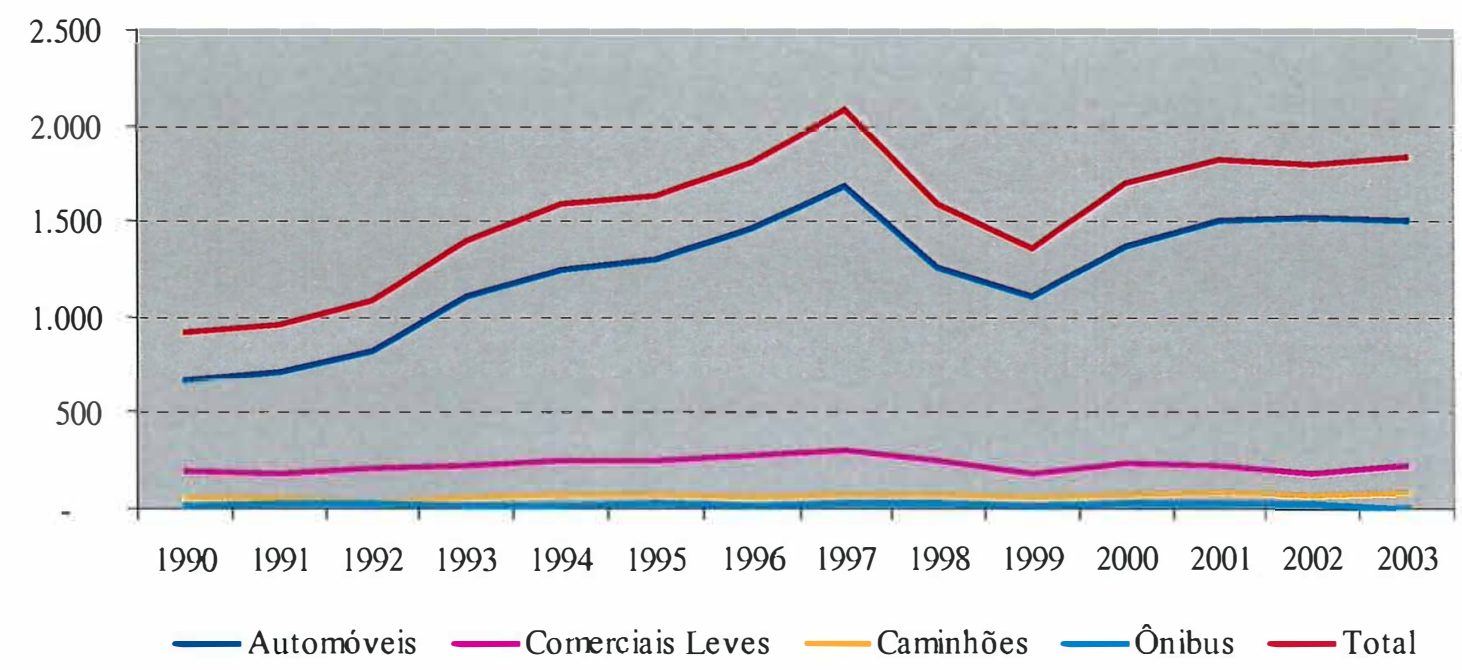

Figura 2 - Produção de autoveículos no Brasil - 1990 a 2003

Fonte: Anfavea (2004)

Tabela 3. Produção de automóveis, comerciais leves, caminhões e ônibus. Brasil 19902003

\begin{tabular}{cccccc}
\hline Ano & Automóveis & $\begin{array}{c}\text { Comerciais } \\
\text { Leves }\end{array}$ & Caminhões & Ônibus & Total \\
\hline 1990 & 663.084 & 184.754 & 51.597 & 15.031 & 914.466 \\
1991 & 705.303 & 182.609 & 49.295 & 23.012 & 960.219 \\
1992 & 815.959 & 201.591 & 32.025 & 24.286 & 1.073 .861 \\
1993 & 1.100 .278 & 224.387 & 47.876 & 18.894 & 1.391 .435 \\
1994 & 1.248 .773 & 251.044 & 64.137 & 17.435 & 1.581 .389 \\
1995 & 1.297 .467 & 239.399 & 70.495 & 21.647 & 1.629 .008 \\
1996 & 1.458 .576 & 279.697 & 48.712 & 17.343 & 1.804 .328 \\
1997 & 1.677 .858 & 306.545 & 63.744 & 21.556 & 2.069 .703 \\
1998 & 1.254 .016 & 247.044 & 63.773 & 21.458 & 1.586 .291 \\
1999 & 1.109 .509 & 176.994 & 55.277 & 14.934 & 1.356 .714 \\
2000 & 1.361 .721 & 235.161 & 71.686 & 22.672 & 1.691 .240 \\
2001 & 1.501 .586 & 214.936 & 77.431 & 23.163 & 1.817 .116 \\
2002 & 1.520 .285 & 179.861 & 68.558 & 22.826 & 1.791 .530 \\
2003 & 1.504 .998 & 216.112 & 78.938 & 26.990 & 1.827 .038 \\
\hline
\end{tabular}

Fonte: Anfavea (2004) 
Verifica-se que o crescimento do volume de produção de autoveículos se concentra no período de 1990 a 1997, sofrendo uma brusca retração em 1998/1999, tendo voltado a recuperar o crescimento a partir de 2000. Essa retração está associada ao desaquecimento do mercado interno, uma vez que a maior parte da produção é destinada ao consumo doméstico ${ }^{3}$.

O crescimento da produção reflete em parte a modernização e ampliação da capacidade produtiva dessa indústria no Brasil. Além dos reflexos na produção, a modernização observada na indústria implicou menor utilização de mão de obra no setor. Em 1990, a produção de autoveículos empregava no Brasil 117.396 pessoas. Em 2002, o volume de pessoas empregadas na produção destes veículos era 81.737 , ou seja, $70 \%$ do nível registrado no início da década, conforme dados apresentados na Figura 3.

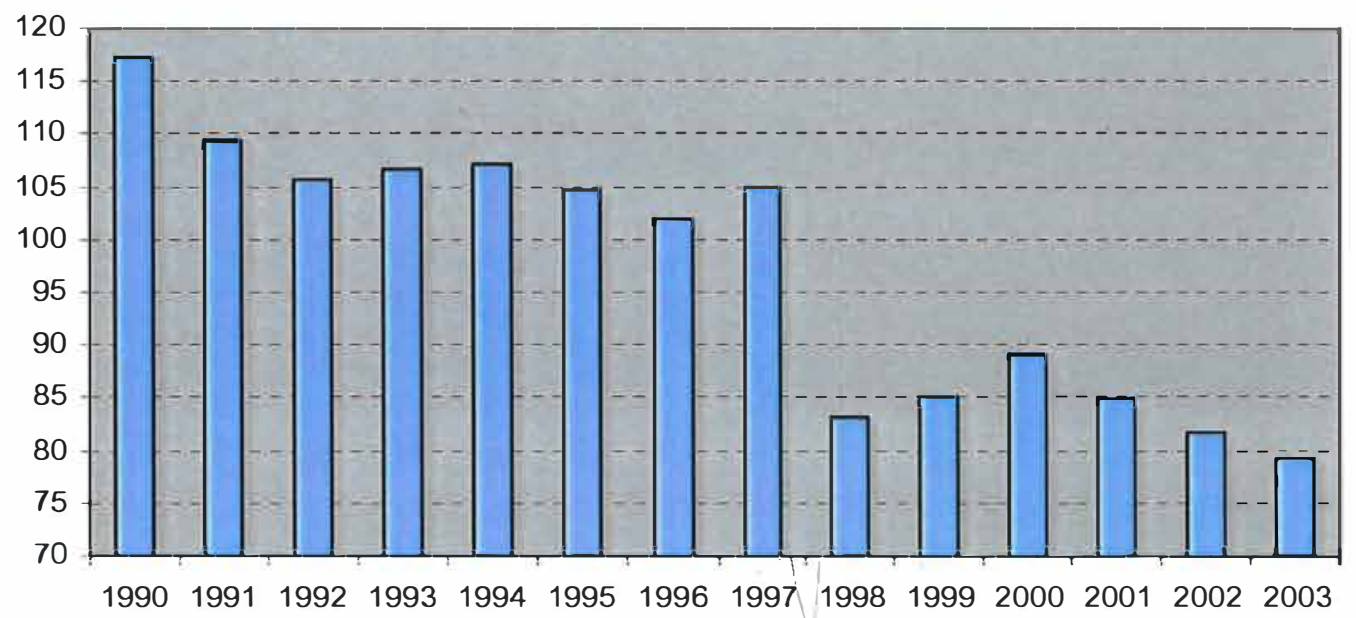

Figura 3 - Emprego na produção de autoveículos . Brasil 1990-2002 (em mil pessoas) Fonte: Anfavea (2004)

\footnotetext{
${ }^{3}$ Em 2003, cerca de $71 \%$ da produção de autoveículos destinou-se ao abastecimento do mercado interno (Anfavea, 2004)
} 
A redução do nível de pessoas ocupadas decorre em grande parte, da automação e robotização de algumas plantas nesse período. $O$ setor também sofreu uma intensa reestruturação interna da produção. Segundo Salerno (2002), na tentativa de adequar-se ao padrão de eficiência de operações estabelecido pelas empresas japonesas, observou-se a adoção de diversos instrumentos como just in time, trabalho em equipe, qualidade total (TQC/TQM), certificações segundo normas internacionais de qualidade.

De acordo com as estimativas apresentadas em Anfavea (2004), em 2003 a indústria automobilística brasileira contava com um total de 48 fábricas, distribuídas em 7 estados e 27 municípios. Dessas 48 fábricas, cerca de 22 foram inauguradas no período de 1996 a 2002. Com uma capacidade de produção de 3,2 milhões de veículos por ano, essa indústria gerou cerca de $\mathrm{R} \$ 10$ bilhões de tributos diretos e $\mathrm{R} \$ 1,5$ bilhões de indiretos. Segundo a entidade, a indústria automobilística, incluindo máquinas agrícolas e automotrizes, é responsável pela geração de 92 mil empregos diretos, e estabeleceu nesse ano relações inter-setoriais com mais de 200 mil empresas e 3,7 mil concessionárias. Seu PIB, incluindo a indústria de autopeças, representava cerca de 13, 5 \% do PIB industrial do Brasil e 4,5 \% do PIB nacional. 


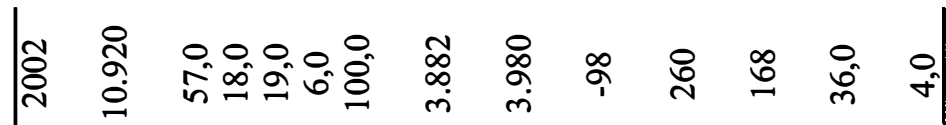

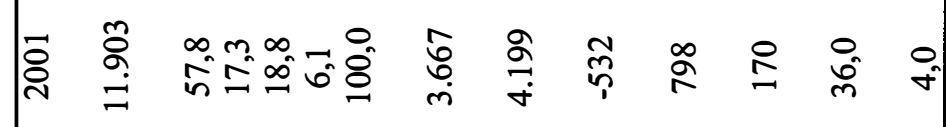

完

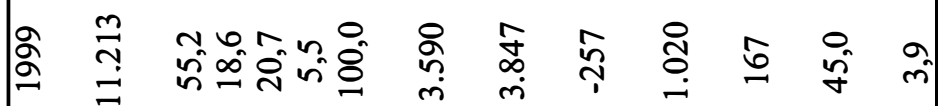

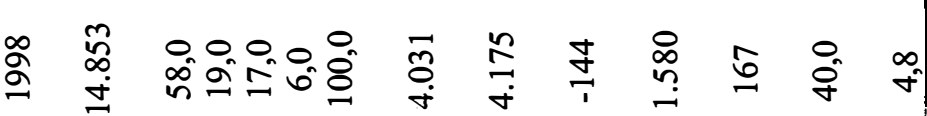

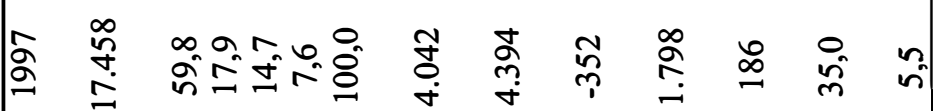

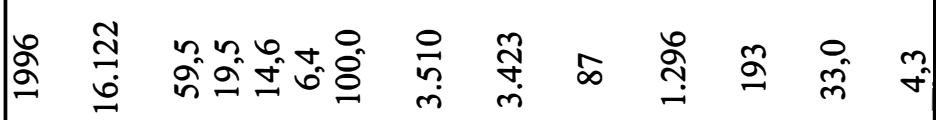

ঠ్రి

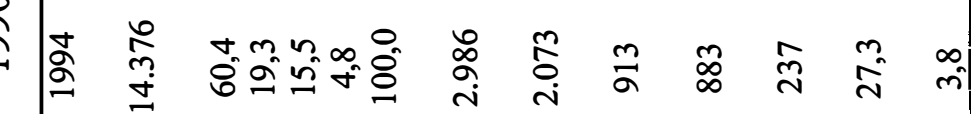

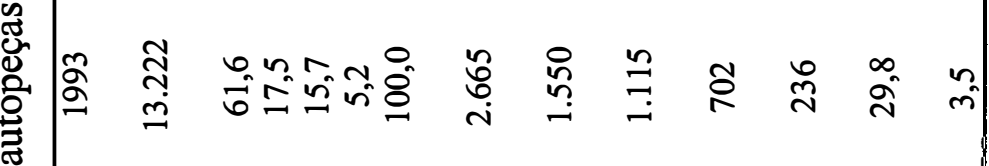

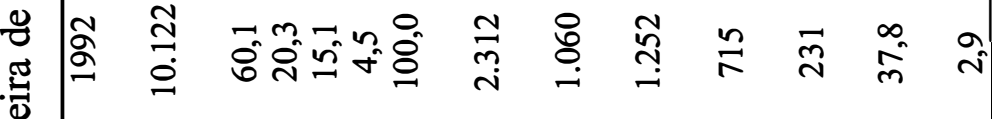

莺

营

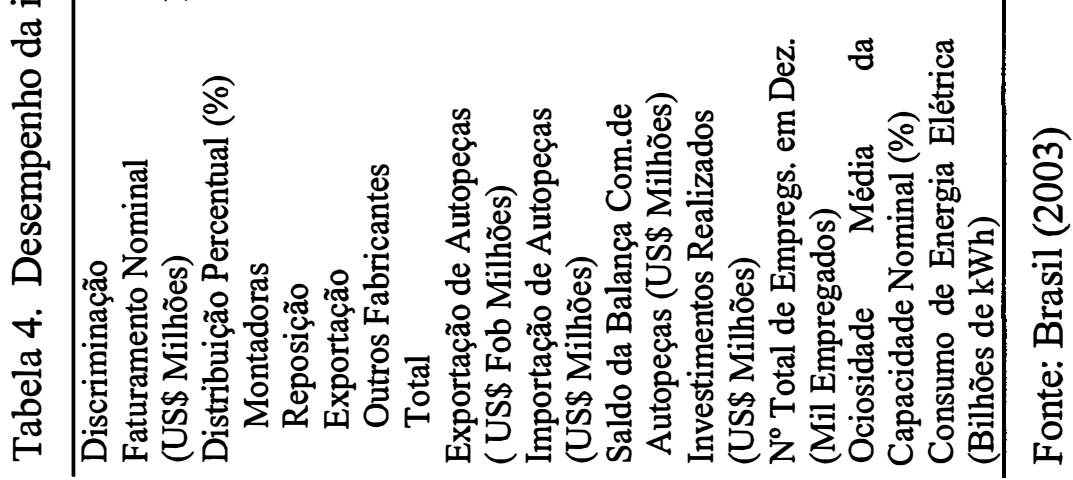


Seguindo a trajetória observada na produção de autoveículos, a indústria de autopeças é marcada pelo crescimento até 1997, como indicam os dados da Tabela 4. Os anos seguintes, por sua vez, verifica-se um desaquecimento do volume de faturamento do setor.

"As exportações do setor apresentaram um crescimento de $82 \%$ no período de 1990 a 2002. Por outro lado, a instalação de novas montadoras estrangeiras no Brasil, bem como as estratégias globais adotadas por estas empresas, implicaram a elevação significativa do volume importado do setor. O volume de importação que em 1990 era de US\$ 837 milhões, cresceu quase cinco vezes até 2002, atingindo US\$3,9 bilhões."

Constata-se também a tendência crescente de investimentos realizados no setor até o final dos anos 90, os quais se mostram mais expressivos no período de 1995 a 1998. Considerando o período de 1990 a 2002, esses investimentos totalizaram U\$ $\$ 13,2$ bilhões.

\subsection{Investimentos e configuração regional recente}

Nos anos 90, empresas mundiais anunciaram investimentos na economia brasileira visando estabelecer novas plantas ou reestruturar as antigas. Empresas como a Fiat, Ford, General Motors e Volkswagen ampliaram sua presença no mercado nacional, enquanto outras como a Mercedes e Renault se estabeleceram como novos entrantes. Os vultuosos investimentos nesta indústria nos anos 90 são semelhantes àqueles observados no período inicial de sua instalação (Arbix e Rodrigues-Pose, 2001).

De fato, os investimentos realizados na indústria automobilística foram expressivos. No que se refere exclusivamente à produção de autoveículos, no período de 1990 a 2002, os investimentos ultrapassam US\$ 18 bilhões, sendo que $80 \%$ deste total se concentram a partir de 1994, conforme os dados apresentados na Tabela 5 a seguir. 
Tabela 5. Investimento autoveículos. Brasil 1980 - 2002

\begin{tabular}{cccc}
\hline Ano & US\$ milhões & Ano & US\$ milhões \\
\hline 1980 & 489 & 1990 & 790 \\
1981 & 645 & 1991 & 880 \\
1982 & 530 & 1992 & 908 \\
1983 & 373 & 1993 & 886 \\
1984 & 293 & 1994 & 1.195 \\
1985 & 478 & 1995 & 1.694 \\
1986 & 526 & 1996 & 2.359 \\
1987 & 580 & 1997 & 2.092 \\
1988 & 572 & 1998 & 2.335 \\
1989 & 602 & 1999 & 1.791 \\
& & 2000 & 1.651 \\
& & 2001 & 1.750 \\
& & 2002 & 976 \\
\hline
\end{tabular}

Fonte: Anfavea (2004)

A orientação regional destes investimentos, entretanto, foi diversa. Segundo dados da Anfavea (2004) e de Santos e Pinhão (1999), é possível sistematizá-los segundo região de destino como apresenta a tabela a seguir (Tabela 6).

" O projeto da Ford, inicialmente em Guaíba, Rio Grande de Sul, previa investimentos de 500 milhões de dólares e uma capacidade instalada de $100 \mathrm{mil}$ unidades de veículos (Calvalcante e Uderman, 2003). Demais investimentos como os anunciados pela Mitsubish, Ásia e Hyundai não foram concretizados, em virtude da crise asiática. 
Tabela 6. Distribuição regional do investimento direto estrangeiro (IED) das montadoras de autoveículos. Brasil, 1996-2001

\begin{tabular}{|c|c|c|c|c|c|}
\hline Localização & Empresa & $\begin{array}{l}\text { País de } \\
\text { origem }\end{array}$ & $\begin{array}{c}\text { Data de } \\
\text { investimento }\end{array}$ & $\begin{array}{l}\text { Investimento } \\
\text { mínimo } \\
\text { planejado } \\
\text { (em milhões } \\
\text { de US\$) }\end{array}$ & $\begin{array}{c}\text { Capacidade } \\
\text { Anual } \\
\text { Planejada } \\
\text { (em mil) }\end{array}$ \\
\hline \multicolumn{6}{|l|}{ São Paulo } \\
\hline $\begin{array}{l}\text { São Bernardo do } \\
\text { Campo }\end{array}$ & BMW/ L.Rover & $\begin{array}{l}\text { Reino } \\
\text { Unido }\end{array}$ & 1998 & 150 & 150 \\
\hline São Carlos & Volkswagen & Alemanha & Em operação & 250 & $300 *$ \\
\hline Indaiatuba & Toyota & Japão & 1999 & 150 & 15 \\
\hline Sumaré & Honda & Japão & Em operação & 100 & 30 \\
\hline \multicolumn{6}{|l|}{ Paraná } \\
\hline $\begin{array}{l}\text { São José dos } \\
\text { Pinhais }\end{array}$ & Renault & França & 1999 & 750 & $100 / 110$ \\
\hline $\begin{array}{l}\text { São José dos } \\
\text { Pinhais }\end{array}$ & Audi & Alemanha & 1999 & 600 & 120 \\
\hline Campo Largo & $\begin{array}{l}\text { Chrysler/ } \\
\text { BMW }\end{array}$ & $\begin{array}{c}\text { EUA/ } \\
\text { Alemanha }\end{array}$ & 1999 & 600 & 120 \\
\hline \multicolumn{6}{|l|}{ Minas Gerais } \\
\hline Juiz de Fora & Mercedes & Alemanha & 1999 & 820 & 70 \\
\hline Betim & Fiat & Itália & 1998 & 500 & $5.000 *$ \\
\hline Sete Lagoas & Iveco & Itália & 1998 & 250 & 20 \\
\hline Belo Horizonte & Fiat & Itália & 1999 & 200 & 100 \\
\hline \multicolumn{6}{|l|}{ Rio Grande do Sul } \\
\hline Gravataí & GM & EUA & 1999 & 600 & 120 \\
\hline Caxias do Sul & Navistar & EUA & 1998 & 50 & 5 \\
\hline \multicolumn{6}{|l|}{ Rio de Janeiro } \\
\hline Porto Real & PSA-Peugeot & França & 2000 & 600 & 1.000 \\
\hline Resende & Volkswagen & Alemanha & Em operação & 250 & 50 \\
\hline \multicolumn{6}{|l|}{ Bahia } \\
\hline Camaçari & Ford & EUA & 2001 & 1300 & 250 \\
\hline
\end{tabular}

Fonte: Anfavea (2004), Santos e Pinhão (1999)

O projeto da Ford, inicialmente em Guaíba, Rio Grande de Sul, previa investimentos de 500 milhões de dólares e uma capacidade instalada de 100 mil unidades de veículos (Calvalcante e Uderman, 2003). Demais investimentos como os anunciados pela Mitsubish, Ásia e Hyundai não foram concretizados, em virtude da crise asiática. 
Várias razões são mencionadas para explicar a desconcentração regional desta indústria, e o grau de importância atribuído a cada uma delas é divergente na literatura. Arbix e Rodrigues-Pose (2001) ressaltam sobretudo, que, no passado a presença de mãode-obra qualificada e infra-estrutura superior no Sudeste contribuíram para o desenvolvimento do setor nesta região. Mais recentemente, o custo relativo da mão-deobra inferior nas demais regiões do país e a melhoria da qualificação da mão-de-obra contribuem para a desconcentração da produção. Com relação aos salários, certamente há que se levar em conta a melhor organização da mão-de-obra do Sudeste, revelada especialmente pelo poder de negociação dos sindicados do $\mathrm{ABC}$ paulista perante as montadoras de veículos e empresas do segmento de autopeças. Ainda recaem sobre a região metropolitana de São Paulo as externalidades associadas à poluição e ao congestionamento urbano.

Assim, a indústria automobilística brasileira, que se apresentava historicamente concentrada no Estado de São Paulo e na região Sudeste, recentemente tem mostrado desconcentração em favor das demais regiões brasileiras. A Tabela 7 a seguir mostra a configuração regional atual das principais empresas dessa indústria. 
Tabela 7. Distribuição regional da indústria automobilística brasileira

\begin{tabular}{|c|c|c|c|c|}
\hline Região & Estado & Cidade/Município & Principais Empresas & Produtos \\
\hline \multirow[t]{2}{*}{ Norte } & Amazonas & Manaus & $\begin{array}{l}\text { Cross Lander } \\
\text { Pólos de duas Rodas }\end{array}$ & Motociclos \\
\hline & & & Agrale & Montagem de motocicletas e scooters \\
\hline \multirow{2}{*}{$\begin{array}{l}\text { Nordest } \\
\text { e }\end{array}$} & Ceará & Catole Horizonte & Troller & \\
\hline & Bahia & Camaçari & Ford & Automóveis \\
\hline \multirow[t]{18}{*}{ Sudeste } & Minas Gerais & Betim & Fiat Automóveis & Automóveis, comerciais leves, motores \\
\hline & & Sete Lagoas & $\begin{array}{l}\text { Iveco } \\
\text { Iveco-Fiat }\end{array}$ & $\begin{array}{l}\text { Comerciais leves e caminhões e onibus } \\
\text { (Iveco) }\end{array}$ \\
\hline & & Juiz de Fora & DaimlerChrysler & Automóveis \\
\hline & Rio de Janeiro & Duque de Caxias & Óbvio & \\
\hline & & Porto Real & $\begin{array}{l}\text { Citroën } \\
\text { Peugeot }\end{array}$ & $\begin{array}{l}\text { Automóveis, comerciais leves } \\
\text { caminhões. Motores. }\end{array}$ \\
\hline & & Resende & VW Caminhões & Caminhões e chassis de ônibus. \\
\hline & São Paulo & Indaiatuba & Toytota & Automóveis \\
\hline & & $\begin{array}{l}\text { São Bernardo do } \\
\text { Campo }\end{array}$ & DaimlerChrysler & Caminhões, ônibus e agregados \\
\hline & & & Ford & $\begin{array}{l}\text { Automóveis, comerciais leves, } \\
\text { caminhões }\end{array}$ \\
\hline & & & Karmann-Ghia & $\begin{array}{l}\text { Ferramentaria, dispositivos, } \\
\text { estamparia, conjuntos e subconjuntos, } \\
\text { carrocerias, protótipos, montagem de } \\
\text { veículos }\end{array}$ \\
\hline & & & Land Rover & Comerciais leves \\
\hline & & & Scania & $\begin{array}{l}\text { Caminhões ônibus, motores industriais } \\
\text { e marítimos . }\end{array}$ \\
\hline & & & Toyota & Autopeças \\
\hline & & & Volkswagen & Automóveis, comerciais leves \\
\hline & & $\begin{array}{l}\text { São Jose dos } \\
\text { Campos }\end{array}$ & General Motors & $\begin{array}{l}\text { Automóveis, comerciais leves, } \\
\text { fundição, preparação de CKD para } \\
\text { exportação, motores e transmissões. }\end{array}$ \\
\hline & & São Caetano do Sul & General Motors & Automóveis \\
\hline & & Sumaré & Honda & Automóveis \\
\hline & & Taubaté & Volkwagen & Automóveis \\
\hline \multirow[t]{7}{*}{ Sul } & Paraná & São Jose dos Pinhais & Audi/Volkswagen & Automoveis, comerciais leves \\
\hline & & & Nissan & Comerciais leves \\
\hline & & & Renault & $\begin{array}{l}\text { Automóveis, motores e comerciais } \\
\text { leves }\end{array}$ \\
\hline & & Curitiba & Volvo & $\begin{array}{l}\text { Caminhões, cabines de caminhões, } \\
\text { ônibus e motores }\end{array}$ \\
\hline & & Caxias do Sul & Agrale & Caminhões, ônibus. \\
\hline & & & International & Montagem de caminhões \\
\hline & & Gravataí & General Motors & Automóveis \\
\hline $\begin{array}{l}\text { Centro } \\
\text { - Oeste }\end{array}$ & Goiás & Catalão & Mitsubishi & Comerciais leves \\
\hline
\end{tabular}

Fonte: Automotivebusiness (2004); Anfavea (2004) 
Mesmo com os movimentos recentes de desconcentração regional, o volume de produção do Estado de São Paulo ainda sobressai perante os demais Estados. Segundo a Anfavea (2004), cerca de 53,4\% da produção brasileira de autoveículos é produzida nesse Estado. Minas Gerais, Paraná e Bahia aparecem na seqüência com participações de $20,1 \%, 7,6 \%$ e $7,5 \%$ respectivamente, no volume de produção. 


\section{MATERIAL E MÉTODOS}

\subsection{Teoria insumo-produto}

Wassily Leontief desenvolveu a teoria insumo-produto a fim de obter um método capaz de descrever as informações dos fluxos de insumo e de produção referentes a cada um dos setores de uma região econômica, em um determinado período de tempo. Em 1936, Leontief, consolidou o ferramental analítico conhecido classicamente como análise insumo produto ao publicar os primeiros resultados sobre o funcionamento da economia americana no ano de 1919. Quase quatro décadas mais tarde, em 1973, teria seu trabalho reconhecido com um Prêmio Nobel (Feijó et al., 2001; Leontief, 1986).

A primeira tabela construída foi da economia soviética em 1925 (Richardson, 1972; Feijó et al., 2001; Miller e Blair, 1985).

Os elementos fundamentais para a elaboração desta estrutura teórica foram estabelecidos em estudos bem anteriores ao seu, realizados por Quesnay e Walras. Quesnay, em meados do séc. XVIII, ao publicar o Tableau Economique em 1758 demonstrou preocupação em estruturar a economia em classes e setores, ao mesmo tempo em que enfatizou as suas relações e estabeleceu os conceitos iniciais de fluxos circular e equilíbrio geral. Posteriormente, em 1874, Walras avançou ao construir um modelo de equilíbrio geral, cujos coeficientes relacionavam a quantidade de fatores requeridas à produção de uma unidade de um determinado bem à quantidade total do bem produzida (Miller e Blair, 1985, Dorfman, 1954, Richarson, 1972).

As matrizes insumo-produto construídas para economia norte-americana, foram em verdade, uma tentativa de se construir um Tableau Economique para os Estados Unidos (Miller e Blair, 1985). Dorfman (1954) observa que, ao conceber a teoria insumo-produto, Leontief adotou um modelo bastante similar ao de Walras, 
diferenciando-o por algumas simplificações, imprescindíveis para viabilizar a estimação das equações envolvidas no modelo. Essencialmente, as simplificações consistiram em: (i) agregar as incontáveis mercadorias tratadas por Walras em um menor número de produtos - um para cada setor da economia; (ii) diminuir o número de equações, tanto da oferta (referentes aos setores que não produzem matérias-primas, em especial, os vários tipos de trabalho), quanto da demanda, referente ao consumo final; e (iii) e adotar uma função de produção linear.

Ao propor a aplicação de seu modelo, constituindo a análise insumo-produto, Leontief proporciona um instrumental que vem adquirindo cada vez mais importância na formulação de diretrizes de políticas. Uma vez que, no curto prazo, a análise de insumoproduto é capaz de propiciar o entendimento da estrutura de funcionamento de uma economia, uma vasta literatura sobre o tratamento empírico das relações intersetoriais vêm se consolidando desde o estabelecimento inicial do modelo (Leontief, 1986; Dorfman, 1954).

\subsection{Modelo básico de insumo-produto}

Em termos matemáticos, o modelo pode ser representado por um sistema de equações lineares, na forma matricial, de maneira que cada uma das equações descreva na economia a distribuição de um produto referente a uma determinada indústria ou setor. As interpretações econômicas provenientes da utilização do modelo advêm da resolução deste sistema de equações, por intermédio de uma matriz inversa, bem como das demais derivações algébricas do modelo (Miller e Blair, 1985; Guilhoto, 2001).

De uma maneira simplificada, é possível representar os fluxos de uma economia com apenas 2 setores da seguinte forma: 


\begin{tabular}{|c|c|c|c|c|c|c|c|c|}
\hline & & etores & adores & & & & & \\
\hline & & & & & man & Final & & Producão $(X)$ \\
\hline Setores & 1 & $Z_{11}$ & $Z_{12}$ & $C_{I}$ & $I_{l}$ & $G_{1}$ & $E_{l}$ & $X_{I}$ \\
\hline Vendedores (i) & 2 & $Z_{21}$ & $Z_{22}$ & $C_{2}$ & $I_{2}$ & $G_{2}$ & $E_{2}$ & $X_{2}$ \\
\hline Setor de & $W$ & $L_{l}$ & $L_{2}$ & & & & & $L$ \\
\hline Pagamentos & & $N_{l}$ & $N_{2}$ & & & & & $N$ \\
\hline & & $M_{I}$ & $M_{2}$ & $M_{C}$ & $M_{I}$ & $M_{G}$ & $M_{E}$ & $M$ \\
\hline $\begin{array}{l}\text { Total da Produção } \\
(X)\end{array}$ & & $X_{I}$ & $X_{2}$ & $C$ & $I$ & $G$ & $E$ & $X$ \\
\hline
\end{tabular}

Quadro 3 - Fluxos para uma economia de 2 setores

Fonte: adaptado de Miller e Blair $\left(1985\right.$, p.9) ${ }^{4}$

Em que,

$z_{i j}$ : produção do setor utilizada como insumo intermediário pelo setor $j$;

$C_{i}$ : produção do setor $i$ que é destinada às famílias;

$G_{i}$ : produção do setor $i$ que é destinado ao governo (consumo + investimento do governo);

$I_{i}$ : produção do setor $i$ que é destinada ao investimento;

$E_{i}$ : produção do setor $i$ que é destinada às exportações;

$X_{i}$ : produção doméstica total do setor $i$ (demanda final e insumos intermediários);

$C_{i}+G_{i}+I_{i}$ : demanda final doméstica;

$Y_{i}$ : Total da demanda final atendida pelo setor $i\left(C_{i}+G_{i}+I_{i}+E_{i}\right)$

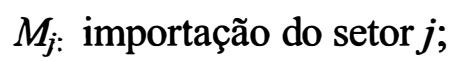

\footnotetext{
${ }^{4}$ Nas matrizes insumo-produto do Brasil, a demanda final não realiza pagamentos para salários, aluguéis e juros.
} 
$L_{j}$ : salários pagos pelo setor $j$;

$N_{j}$ : aluguéis, juros, lucros e tributos pagos pelo setor $j$;

$W_{i}$ : valor adicionado $\left(L_{i}+N_{i}\right)^{5}$.

Como demonstra a tabela é possível obter o valor bruto da produção através de duas formas de cálculo. Uma delas é obtida pelas informações da linha, como descreve a equação (3), a outra pela coluna, como se observa na equação (6), indicadas a seguir:

$$
\begin{aligned}
& \sum_{j=1}^{n} z_{i j}=z_{i 1}+z_{i 2} \\
& Y_{i}=C_{i}+I_{i}+G_{i}+E_{i} \\
& X_{i}=\sum_{j=1}^{n} z_{i j}+Y_{i} \\
& \sum_{i=1}^{n} z_{i j}=z_{1 i}+z_{2 i} \\
& V A_{i}=L_{i}+N_{i} \\
& X=\sum_{i=1}^{n} z_{i j}+V A_{i}+M_{I}
\end{aligned}
$$

${ }^{5}$ Vale mencionar que, diferente do modelo básico apresentado por Miller e Blair (1985), a Tabela de Transações das Matrizes Insumo-produto do Brasil, apresentam o valor adicionado detalhado nas seguintes categorias: salários, contribuições sociais, impostos sobre a produção e excedente operacional bruto (Feijó et al., 2001). 
O modelo possibilita obter uma matriz de coeficientes técnicos $\mathbf{A}$, formada pelos coeficientes técnicos diretos $a_{i j}$, na qual os seus elementos são definidos por:

$$
a_{i j}=\frac{z_{i j}}{X_{j}}
$$

Os coeficientes técnicos assim formulados, ao relacionarem o consumo intermediário de um dado setor $j$, e o valor de produção total desse setor $j$, pressupõem relações fixas entre os setores e os insumos da economia. Essas relações, portanto, são estabelecidas sob a hipótese de retornos constantes à escala no modelo.

A idéia implícita na função de produção adotada no modelo é de que a escassez de um dos fatores de produção utilizado na produção de um determinado bem define o máximo de produção deste bem na economia. Essa função de produção, pode ser representada pela expressão a seguir:

$$
X_{j}=\min \left(\frac{z_{i j}}{a_{i j}}, \cdots \frac{z_{n j}}{a_{n j}}\right)
$$

As equações de produção de cada setor, podem ser reescritas de forma a se obter um sistema de equações lineares (9), cujos parâmetros representam os coeficientes técnicos de produção, da seguinte forma:

$$
X_{i}=a_{i 1} X_{1}+a_{i 2} X_{2}+\cdots+a_{i 1} X_{i}+\cdots+a_{i n} X_{n}+Y_{i}
$$


Ao rearrajar os termos deste sistema, é possível estabelecer as seguintes matrizes genéricas:

$$
\begin{aligned}
\mathbf{A} & =\left[\begin{array}{cccc}
a_{11} & a_{12} & \cdots & a_{1 n} \\
a_{21} & a_{22} & \cdots & a_{2 n} \\
\vdots & \vdots & \cdots & \vdots \\
a_{n 1} & a_{n 2} & \cdots & a_{n n}
\end{array}\right] \\
\mathbf{X} & =\left[\begin{array}{c}
X_{1} \\
X_{2} \\
\vdots \\
X_{n}
\end{array}\right] \\
\mathbf{Y} & =\left[\begin{array}{c}
Y_{1} \\
Y_{2} \\
\vdots \\
Y_{n}
\end{array}\right]
\end{aligned}
$$

Em que,

$\mathbf{I}=$ matriz identidade;

$\mathbf{A}=$ matriz de coeficientes técnicos $(n \times n)$;

$\mathbf{X}=$ vetor do valor bruto de produção $(n \times 1)$;

$\mathbf{Y}=$ vetor da demanda final total $(n \times n)$.

Desde que a matriz resultante da expressão (I - A) seja uma matriz não-singular, ou seja, se sua matriz inversa existir, é possível escrever a expressão: 


$$
X=(I-A)^{-1} Y
$$

em que,

$(\mathrm{I}-\mathrm{A})^{-1}$ representa a matriz inversa de Leontief.

Os coeficientes da matriz inversa de Leontief expressam as quantidades de insumos, direta e indiretamente, necessários para a produção de uma unidade de demanda final do setor $j$.

A equação (13), ao multiplicar do vetor da demanda final $Y$ pela matriz inversa de Leontief, possibilita obter o nível total de produção por setor da economia. Possibilita mensurar os impactos totais causados por choques exógenos, provenientes de variações dos componentes da demanda final (consumo das famílias, exportações e investimento privado). Assim, essa equação traduz o aspecto fundamental do modelo insumo-produto. As análise derivadas desta equação serão exploradas mais adiante nas seções que tratam das análises de impacto setorial.

\subsection{Modelos de insumo-produto regionais e inter-regionais ${ }^{6}$}

A ênfase dada às pesquisas quantitativas com o objetivo de analisar a relevância econômica de determinadas regiões, estados ou áreas metropolitanas, desde o fím da II Guerra Mundial, favoreceu, em grande parte, o desenvolvimento dos modelos de insumo-produto regionais.

Os primeiros avanços na elaboração de modelos de análise regional foram obtidos com as iniciativas de Isard e Kuenner (1953) e Miller (1957). Na inexistência de uma matriz de coeficientes regionais, os autores utilizaram a matriz de coeficientes

\footnotetext{
${ }^{6}$ Esta seção foi descrita com base em Miller e Blair (1985).
} 
técnicos nacional associada a um procedimento de ajuste com base na participação da oferta regional da produção de cada um dos setores.

A participação da oferta para um setor $j$, pode ser descrita pela relação a seguir, cujo numerador representa a produção nacional disponível na região $R$, e o denominador, representava o total de produção do bem $j$ disponível na região $R$.

$$
p_{j}^{R}=\frac{\left(X_{j}^{R}-E_{j}^{R}\right)}{\left(X_{j}^{R}-E_{j}^{R}+M_{j}^{R}\right)}
$$

em que,

$X_{j}^{R}$ : produção regional total do setor $j$;

$E^{R}{ }_{j}$ : exportações do bem $j$ da região $R$;

$M^{R}$ : importações do bem $j$ pela região $R$.

Dessa forma, $\quad p_{j}^{R}$ representa o quanto a região $R$ pode atender da demanda de total do bem $j$.

As participações estimadas $p_{j}^{R}$, para todos os setores podem ser organizadas em um vetor $P$. Multiplicando a matriz A de coeficientes técnicos nacionais por $P$ diagonalizado, representado a seguir por $\hat{P}$ tem-se a matriz $\mathrm{A}^{\mathrm{R}}$ de coeficientes técnicos regionais. De forma análoga ao modelo de insumo produto original, uma vez tendo-se a demanda final regional, o uso da matriz definida anteriormente possibilita obter a produção total regional.

$$
X^{R}=(I-\hat{P} \cdot A)^{-1} Y^{R}
$$


Entretanto, as fortes hipóteses implícitas neste procedimento são apontadas por diversos autores na literatura. Essencialmente isso se deve ao fato de que a obtenção da matriz de coeficientes técnicos regionais requer a alteração de todos os elementos da linha da matriz nacional de maneira uniforme, já que a matriz deve ser pré-multiplicada pelo vetor $\hat{P}$. Isso significa que a elaboração da matriz regional assume, por exemplo, que um conjunto de setores consumidores de um determinado insumo realize suas compras nas empresas da região, segundo as mesmas proporções observadas na economia nacional. Logo que o elemento fundamental da análise - as particularidades técnicas regionais - não são passíveis de serem captadas, esse método não é recomendado pela literatura.

Tendo como base uma matriz de insumo-produto elaborada especificamente para uma determinada região $L$ que se relaciona com uma região $M$, por exemplo, é possível obter os coeficientes regionais da região $L$ e os coeficientes que se estabelecem com o comércio de ambas as regiões da seguinte forma:

$$
\begin{aligned}
& a_{i j}^{L L}=\frac{z_{i j}^{L L}}{X_{j}^{L}} \\
& a_{i j}^{M L}=\frac{z_{i j}^{M L}}{X_{j}^{L}}
\end{aligned}
$$

em que,

$z_{i j}^{L L}$ representa o fluxo monetário da venda do setor $i$ pertencente a região $L$ para o setor $j$, situado da mesma forma em $L$; 
$z_{i j}^{M L}$ representa o fluxo monetário da venda do setor $i$ pertencente a região $M$ para o setor $j$, pertencente a região $L$;

$X_{j}^{L}$ representa o total da produção de cada setor da região $L$.

Dessa forma, a matriz de fluxos regionais e a matriz de fluxos inter-regionais podem ser descritas, respectivamente, como:

$$
\begin{aligned}
& A^{L L}=Z^{L L}\left(\hat{X}^{L}\right)^{-1} \\
& A^{M L}=Z^{M L}\left(\hat{X}^{L}\right)^{-1}
\end{aligned}
$$

Somando os coeficientes das matrizes $A^{L L}$ e $A^{L M}$ é possível obter a matriz de coeficientes de $A^{L}$. O impacto na produção de todos os setores da economia nacional decorrente de uma mudança na demanda da região $L$ pode ser encontrado da seguinte forma:

$$
X=\left(I-A^{L}\right)^{-1} Y^{L}
$$

Os impactos somente sobre a região $L$, por sua vez, requerem maior detalhe de informações sobre os insumos, sendo necessário utilizar a matriz $P$ diagonalizada, como mostra a equação a seguir:

$$
X^{L}=\left(I-\hat{P} A^{L}\right)^{-1} Y^{L}
$$


Os modelos descritos anteriormente são denominados de insumo-produto regionais. No entanto, importantes efeitos produzidos pela interação entre as atividades econômicas de diferentes regiões não são contemplados nestes modelos. Assim, a demanda por produtos de uma determinada região pode encadear a produção de insumos provenientes da própria região, ou de outras regiões do sistema econômico observado. Da mesma forma, as demais regiões do sistema ao ativarem a produção de insumos para a região que originalmente gerou a demanda, podem requerer insumos produzidos nesta região.

Os modelos de insumo-produto inter-regionais são mais apropriados quando se pretende analisar as interações entre as regiões econômicas. Em linhas gerais, uma matriz de fluxos inter-regionais pode ser representada pelo Quadro 4, a seguir:

\begin{tabular}{|cc|cccccc|}
\hline & $\begin{array}{c}\text { Setores } \\
\text { Vendedores }\end{array}$ & $\begin{array}{c}\text { Setores } \\
\text { Compradores }\end{array}$ & 1 & 2 & 3 & 1 & 2 \\
\hline \multirow{2}{*}{ Região $L$} & 1 & 2 & $Z_{11}^{L L}$ & $Z_{12}^{L L}$ & $Z_{13}^{L L}$ & $Z_{11}^{L M}$ & $Z_{12}^{L M}$ \\
& 3 & & $Z_{21}^{L L}$ & $Z_{22}^{L L}$ & $Z_{23}^{L L}$ & $Z_{21}^{L M}$ & $Z_{22}^{L M}$ \\
& 1 & & $Z_{31}^{L L}$ & $Z_{32}^{L L}$ & $Z_{33}^{L L}$ & $Z_{31}^{L M}$ & $Z_{32}^{L M}$ \\
Região $M$ & & & $Z_{11}^{M L}$ & $Z_{12}^{M L}$ & $Z_{13}^{M L}$ & $Z_{11}^{M M}$ & $Z_{12}^{M M}$ \\
& 2 & & $Z_{21}^{M L}$ & $Z_{22}^{M L}$ & $Z_{23}^{M L}$ & $Z_{21}^{M M}$ & $Z_{22}^{M M}$ \\
\hline
\end{tabular}

Quadro 4 - Fluxos inter-regionais no modelo insumo-produto

Fonte: Miller e Blair (1985, p.9)

A tabela anterior representa um sistema com 2 regiões distintas $L$ e $M$. A estrutura produtiva da região $L$ é constituída por 3 setores, e a da região $M$ por apenas 2 setores. $O$ produto do setor na região $L$ será:

$$
X_{1}^{L}=z_{11}^{L L}+z_{12}^{L L}+z_{13}^{L L}+z_{11}^{L M}+z_{12}^{L M}+Y_{1}^{L}
$$


Utilizando as equações (16) e (17), a expressão anterior pode ser descrita como:

$$
X_{1}^{L}=a_{11}^{L L} X_{1}^{L}+a_{12}^{L L} X_{2}^{L}+a_{13}^{L L} X_{3}^{L}+a_{11}^{L M} X_{1}^{M}+a_{12}^{L M} X_{2}^{M}+Y_{1}^{L}
$$

Algebricamente, ao movermos todos os termos relativos a $X^{L}, X^{M}$ na equação, tem-se que:

$$
\left(1-a_{11}^{L L}\right) X_{1}^{L}-a_{12}^{L L} X_{2}^{L}-a_{13}^{L L} X_{3}^{L}-a_{11}^{L M} X_{1}^{M}-a_{12}^{L M} X_{1}^{M}=Y_{1}^{L}
$$

Utilizando o mesmo raciocínio descrito nas equações (22), (23) e (24) é possível obter expressões para se obter o valor de produção $\left(X_{2}{ }^{L}, X_{3}{ }^{L}, X_{1}{ }^{M} X_{2}{ }^{M}\right)$ e a demanda final $\left(Y_{2}{ }^{L}, Y_{3}{ }^{L}, Y_{1}{ }^{M} Y_{2}{ }^{M}\right)$ para os demais setores do sistema.

Em termos matriciais, a matriz de coeficientes para um modelo inter-regional para 2 regiões constitui-se de 4 submatrizes:

$$
A=\left[\begin{array}{ll}
A^{L L} & A^{L M} \\
A^{M L} & A^{M M}
\end{array}\right]
$$

Os vetores $X^{L}$ e $X^{M}$ constituirão o vetor de produção total, $\mathrm{X}$

$$
X=\left[\begin{array}{l}
X^{L} \\
X^{M}
\end{array}\right]
$$

$\mathrm{O}$ vetor da demanda final, Y será composto pelos vetores $Y^{L} \mathrm{e} Y^{M}$

$$
Y=\left[\begin{array}{l}
Y^{L} \\
Y^{M}
\end{array}\right]
$$

O modelo completo de insumo inter-regional pode ser representado por: 


$$
\begin{aligned}
& (I-A) X=Y \\
& \left(I-A^{L L}\right) X^{L L}-A^{L M} X^{M}=Y^{L} \\
& -A^{M L} X^{L}+\left(I-A^{M M}\right) X^{M}=Y^{M} \\
& \left\{\left[\begin{array}{ll}
I & 0 \\
0 & I
\end{array}\right]-\left[\begin{array}{ll}
A^{L L} & A^{L M} \\
A^{M L} & A^{M M}
\end{array}\right]\right\} \cdot\left[\begin{array}{l}
X^{L} \\
X^{M}
\end{array}\right]=\left[\begin{array}{l}
Y^{L} \\
Y^{M}
\end{array}\right]
\end{aligned}
$$

Considerando na equação (26), a variação da demanda final da região $M$ nula, ou seja $Y^{M}=0$, temos que:

$$
\begin{aligned}
& X^{M}=\left(I-A^{M M}\right)^{-1} A^{M L} X^{L} \\
& \left(I-A^{L L}\right) X^{L}-A^{L M}\left(I-A^{M M}\right)^{-1} A^{M L} X^{L}=Y^{L}
\end{aligned}
$$

Comparando com a expressão (28) com a expressão $\left(I-A^{L L}\right)^{-1} X^{L}=Y^{L}$, que seria equivalente para um modelo de uma única região, observa-se que na expressão (28) um termo adicional, destacađo a seguir:

$$
A^{L M}\left(I-A^{M M}\right)^{-1} A^{M L} X^{L}
$$

A expressão acima representa o efeito feedback regional. A interpretação pode ser realizada desmembrando a expressão da seguinte forma: 
$A^{M L} X^{L}$ : representa o aumento da produção de insumos produzidos em $M$ destinados a L, decorrentes do aumento de produção em $L$;

$\left(I-A^{M M}\right)^{-1}$ ao ser multiplicado pelo termo anterior capta os efeitos diretos e indiretos na região $M$ decorrentes do aumento da produção dessa região, necessário para a fornecimento de insumos para a produção em $L$;

$A^{L M}\left(I-A^{M M}\right)^{-1} A^{M L} X^{L}=Y$ : A variação da produção da região $M$, por sua vez, demanda insumos da região $L$, a qual originalmente teve sua produção acrescida em virtude da maior produção de $M$.

\subsection{Métodos de análise da estrutura produtiva}

Os setores-chave de uma economia podem ser identificados mediante o seu grau de encadeamento, ou de interligações, que são capazes de estabelecer com os demais setores da estrutura produtiva. Os métodos utilizados na identificação destes setores são objeto desta seção.

\subsection{1 Índices de ligação Hirschman-Rasmussen}

Os índices de Hirschman-Rasmussen estabelecem os setores com maior poder de encadeamento dentro da economia mediante índices de ligação para frente $\left(U_{i}\right)$ e para trás $\left(U_{j}\right)$. Esses índices, são calculados a partir de uma matriz $\mathbf{B}$, inversa de Leontief e podem ser definidos como nas equações a seguir.

Índice de ligações para frente:

$$
U_{i}=\frac{\left[B_{i^{*}} / n\right]}{B^{*}}
$$


Índice de ligações para trás:

$$
U_{j}=\frac{\left[\begin{array}{c}
B_{*_{j}} / n \\
n
\end{array}\right]}{B^{*}}
$$

em que,

$b_{i j}$ : elemento da matriz inversa de Leontief;

$B^{*}:$ média de todos os elementos de $\mathrm{B}$;

$B_{i} *$ soma de todos os elementos de uma linha de B;

$B_{j}$ : soma da coluna de B.

Segundo Guilhoto et al. (1994), os índices de ligação para frente refletem o quanto um setor é demandado pelos demais setores da estrutura produtiva de uma economia. Em outras palavras, significa que esses índices mensuram a importância da utilização dos bens produzidos por esse setor na forma de insumos na produção dos demais setores da economia. Os índices de ligação para trás, ao contrário, representam o quanto um setor consome ou demanda dos outros setores da economia, ou seja, quanto suas compras são capazes de dinamizar as atividades econômicas que antecedem a produção de seus bens.

As séries desses índices relativos apresentam o valor um como média. Dessa forma, os setores classificados como chave devem se posicionar acima da média da economia em termos de poder de encadeamento setorial para frente, ou para trás. McGilvray (1977) estabelece um critério mais restrito, atribuindo a classificação de setores-chave àqueles que apresentam, simultaneamente, índices de ligação para frente $\mathrm{e}$ para trás maiores que um. 


\subsection{2 Índices puros de ligação}

Uma vez que os índices de ligação Hirschman-Rasmussen não consideram a importância dos níveis de produção de cada setor analisado, encontram-se na literatura avanços metodológicos a fim de sofisticar esse método de identificação e análise dos setores-chave, realizados por Cella (1984), Clements (1990). No mesmo sentido, Guilhoto et al. (1996) estabelecem uma abordagem alternativa, denominada GHS (Guilhoto, Hewings, Sonis). Segundo esta abordagem, a importância é avaliada tendo por base os encadeamentos produtivos e a geração de produção de cada setor. O método permite comparar uma situação inicial, onde os fluxos produtivos se estabelecem na economia considerando a presença de um setor específico, a uma segunda situação, na qual é simulado o funcionamento da economia excluindo esse setor da estrutura produtiva.

Os índices, tal como definidos por Guilhoto et al. (1996) podem ser derivados partindo da matriz $\mathbf{A}$, definida anteriormente como a matriz de coeficientes técnicos ou de insumos diretos de um setor $j$ e dos demais setores:

$$
\mathbf{A}=\left[\begin{array}{ll}
A_{j j} & A_{j r} \\
A_{r j} & A_{r r}
\end{array}\right]
$$

Em que,

$A_{j j}:$ representa a matriz dos insumos diretos do setor $j$;

$A_{r r}:$ representa a matriz do resto da economia;

$A_{i j}$ : representa a matriz dos insumos comprados pelo setor $j$ do resto da economia;

$A_{j r}$ : matriz dos insumos diretos comprados pelo resto da economia do setor $j$.

A obtenção da matriz inversa de Leontief, representada anteriormente por B é realizada utilizando a matriz A proveniente da equação (32):: 


$$
B=(I-A)^{-1}=\left[\begin{array}{ll}
B_{j j} & B_{j r} \\
B_{r j} & B_{r r}
\end{array}\right]=\left[\begin{array}{cc}
\Delta_{i j} & 0 \\
0 & \Delta_{r r}
\end{array}\right]\left[\begin{array}{cc}
\Delta_{j} & 0 \\
0 & \Delta_{r}
\end{array}\right]\left[\begin{array}{cc}
I & \mathrm{~A}_{j r} \Delta_{r} \\
\mathrm{~A}_{r j} \Delta_{j} & I
\end{array}\right]
$$

Em que,

$$
\begin{aligned}
& \Delta_{j}=\left(I-A_{j j}\right)^{-1} \\
& \Delta_{r}=\left(I-A_{r r}\right)^{-1} \\
& \Delta_{j j}=\left(I-\Delta_{j} \mathrm{~A}_{j r} \Delta_{r} \mathrm{~A}_{r j}\right)^{-1} \\
& \Delta_{r r}=\left(I-\Delta_{r} \mathrm{~A}_{r j} \Delta_{j} \mathrm{~A}_{j r}\right)^{-1}
\end{aligned}
$$

Onde, a equação (34) mensura a interação do setor $j$ com ele mesmo e a equação (35) representa a interação do restante da economia com ele mesmo. A equação (36), por sua vez, representa o quanto o setor $j$ tem que produzir para o restante da economia para que esta atenda às suas necessidades de consumo. A equação (37) capta o quanto o restante da economia necessita produzir para o setor $j$ para que este atenda às suas necessidades.

Da formulação do modelo de Leontief, conforme equação (13), tem-se que:

$$
\left[\begin{array}{l}
X_{j} \\
X_{r}
\end{array}\right]=\left[\begin{array}{cc}
\Delta_{j j} & 0 \\
0 & \Delta_{r r}
\end{array}\right]\left[\begin{array}{cc}
\Delta_{j} & 0 \\
0 & \Delta_{r}
\end{array}\right]\left[\begin{array}{cc}
I & \mathrm{~A}_{j r} \Delta_{r} \\
\mathrm{~A}_{r j} \Delta_{j} & I
\end{array}\right]\left[\begin{array}{l}
Y_{j} \\
Y_{r}
\end{array}\right]
$$

Desenvolvendo a expressão acima, obtém-se: 


$$
\left[\begin{array}{c}
X_{j} \\
X_{r}
\end{array}\right]=\left[\begin{array}{cc}
\Delta_{j j} & 0 \\
0 & \Delta_{r r}
\end{array}\right]\left[\begin{array}{l}
\Delta_{j} Y_{j}+\Delta_{j} \mathrm{~A}_{j r} \Delta_{r} Y_{r} \\
\Delta_{r} \mathrm{~A}_{r j} \Delta_{j} Y_{j}+\Delta_{r} Y_{r}
\end{array}\right]
$$

De onde é possível extrair os índices puros de ligação para trás $(P B L)$ e para frente $(P F L)$, conforme as seguintes equações:

$$
\begin{aligned}
& P B L=\Delta_{r} \mathrm{~A}_{r j} \Delta_{j} Y_{j} \\
& P F L=\Delta_{j} \mathrm{~A}_{j r} \Delta_{r} Y_{r} \\
& P T L=P B L+P F L
\end{aligned}
$$

Dessa forma, o índice puro de ligação para trás representado por $P B L$ na equação (40) indica o impacto da produção do setor $j$ sobre o restante da economia. $O$ índice puro de ligação para frente, $P F L$ na equação (41) indica o impacto da produção do resto da economia sobre o setor $j$. O índice puro total de ligações, $P T L$, indica a soma dos dois impactos, equação (42).

Uma forma alternativa consiste em recorrer aos índices normalizados. Esses índices são obtidos por intermédio da divisão do índice puro de ligação calculado do setor, pelo valor médio do índice encontrado para o total da economia. 


\subsubsection{Multiplicadores de impacto}

Os multiplicadores derivados do modelo insumo-produto, por considerarem a interdependência setorial possibilitam avaliar os impactos sobre a economia com maior grau de detalhes (Miernyck, 1975).

Calculados a partir da matriz inversa de Leontief, os multiplicadores mensuram os impactos, diretos e indiretos, da variação dos componentes da demanda final (consumo, gastos do governo, formação bruta de capital fixo e exportações) de um setor em particular, sobre a uma determinada variável de análise. No presente trabalho, como será descrito adiante, pretende-se avaliar o aumento no valor de produção, do emprego, da renda e geradas, em virtude do aumento de cada unidade monetária da demanda final.

A análise, entretanto, não de restringe aos impactos puramente decorrentes das relações intersetoriais. É possível considerar os efeitos induzidos pelo fluxo de consumo e de renda das famílias na atividade econômica, distinguindo dois tipos de multiplicadores: do tipo I e do tipo II. No primeiro caso, o consumo das famílias é exógeno ao sistema. Fazem parte da sua análise os impactos sobre o setor que sofreu o choque da demanda final, denominados efeitos diretos, e os impactos sobre os demais setores da economia, denominados indiretos.

Os multiplicadores do tipo II, por sua vez, além de contemplarem os efeitos diretos e indiretos, consideram os efeitos induzidos pelo consumo das famílias. Como mencionado, seu cômputo requer a endogeneização do consumo das famílias ao sistema. Neste caso, a matriz inversa de Leontief, é obtida a partir da matriz de uso convencional, acrescida de um setor representando o consumo das famílias. As relações de insumo deste setor adicional (na linha) representam as relações dos diversos setores consumindo o insumo trabalho. As relações de compra desse setor, expressam o consumo dos diversos produtos produzidos pelos setores da economia pelas famílias. Como descrito por Mienyck, os multiplicadores do tipo II indicam os impactos em cadeia provenientes das reações interindustriais (Miernyck, 1975; Miller e Blair, 1985). 
Quanto maior o grau de independência, ou quanto menor dependência das exportações, maiores serão as variações sobre a renda. Assim, multiplicadores de renda para o país, serão maiores do que os encontrados ao se analisar uma região ou estado em particular. Além disso, no tocante aos efeitos diretos, um setor intensivo em mão de obra, produzirá uma variação sobre a renda superior às variações produzidas por setores intensivos em capital. Entretanto, ao incluir na análise os impactos indiretos, verifica-se que esta situação se inverte. Isso decorre do fato que os setores que privilegiam o emprego de mão-de-obra, em detrimento dos demais insumos, apresentam menores interações com os demais setores da economia. As reações em cadeia na economia tendem a ser maiores nos setores intensivos em capital (Miernyck, 1975).

\section{a) Multiplicador de produção}

Define-se como multiplicador de produção de setor $j$, o total de produção de todos os setores da economia necessários para satisfazer uma unidade monetária da demanda final desse setor. O multiplicador de produção do tipo I pode ser expresso por:

$$
M P_{j}=\sum_{i=1}^{n} b_{i j}, \quad j=1, \ldots n
$$

sendo que,

$j$ representa um determinado setor da economia,

$b_{i j}$ um elemento da matriz $\mathrm{B}=(\mathrm{I}-\mathrm{A})^{-1}$.

Como detalhado anteriormente, o multiplicador de produção do tipo II requer uma matriz de relações intersetoriais endogeneizando o consumo das famílias, representada a 
seguir por $\bar{A}$. Sendo uma matriz B, sua inversa de Leontief, tal que $\bar{B}=(I-\bar{A})^{-1}$, em que $\bar{b}_{i j}$ representam seus coeficientes.

Posto isso, o multiplicador de produção do tipo II pode ser representado por:

$$
M \overline{P_{j}}=\sum_{i=1}^{n} \bar{b}_{i j}, \quad j=1, \ldots . . n
$$

sendo que,

$j$ representa um determinado setor da economia, e

$\bar{b}_{i j}$ um elemento da matriz $\bar{B}=(I-\bar{A})^{-1}$

\section{b) Multiplicador do emprego}

O multiplicador de emprego para um determinado setor expressa o número de empregos gerados no total da economia, para cada pessoa adicional empregada no setor j. O multiplicador do tipo I, pode ser representado por:

$$
M E_{j}=\sum_{i=1}\left(w_{n+1, i} \cdot b_{i j}\right) w_{n+1, i}
$$

em que,

$w_{n+1, i}$ é o coeficiente de emprego por unidade monetária de produção;

$b_{i j}$ um elemento da matriz $\mathrm{B}=(\mathrm{I}-\mathrm{A})^{-1}$.

O multiplicador de produção do tipo II, pode ser obtido por:

$$
M \bar{E}_{j}=\sum_{i=1}\left(w_{n+1, i} \cdot \bar{b}_{i j}\right) w_{n+1, i} \quad j=1, \ldots, n
$$

em que, 
$w_{n+1}$, representa o número de empregados gerados por unidade monetária $\mathrm{e}$

$\bar{b}_{i j}$ um elemento da matriz $\bar{B}=(I-\bar{A})^{-1}$

\section{c) Multiplicador de renda}

Consiste no efeito sobre a renda no total da economia, decorrente do aumento de uma unidade da renda de um setor em particular proveniente do aumento da produção necessário para atender à variação da demanda final do setor $j$ em uma unidade. Pode ser expresso como:

$$
M R_{j}=\sum_{i=1}^{n}\left(r_{n+1, i} \cdot b_{i j}\right) / r_{n+1, j}
$$

em que,

$r_{n+l}$ representa um elemento da linha do coeficiente de remuneração das famílias;

$b_{i j}$ um elemento da matriz $\mathrm{B}=(\mathrm{I}-\mathrm{A})^{-1}$.

O multiplicador do tipo II pode ser calculado da seguinte forma:

$$
M \bar{R}_{j}=\sum_{i=1}^{n}\left(r_{n+1, i} \cdot \bar{b}_{i j}\right) / r_{n+1, j}
$$

em que,

$r_{n+1}$ representa um elemento da linha do coeficiente de remuneração das famílias;

$\mathrm{e}^{\bar{b}_{i j}}$ um elemento da matriz $\bar{B}=(I-\bar{A})^{-1}$ 


\subsection{Identificação e análise de clusters com base no insumo-produto}

Grande parte das análises econômicas setoriais, ao utilizarem as fontes de dados oficiais nacionais e internacionais, adotam os sistemas de classificação que segmentam a economia segundo atividades econômicas, setores e/ou segmentos industriais.

A análise das informações dessa forma, no entanto, nem sempre permite compreender a complexidade do comportamento produtivo. Neste sentido, diversos estudos recorrem a enfoques alternativos, como agnupamentos setoriais ou clusters nas análises de fluxos de bens serviços provenientes da matrizes insumo-produto (Roelandt e Hertog, 1999).

Segundo Czamanski e Ablas (1979), um cluster compreende um "conjunto de setores cujos fluxos de bens e serviços apresentam maior grau de interligação entre si relativamente aos demais setores da economia". Dessa forma, o conceito de cluster não apresenta, necessariamente, uma conotação geográfica ou espacial.

Uma das mais relevantes contribuições na identificação de clusters com base na teoria insumo-produto é atribuída ao estudo de Czamanski \& Ablas (1979). Os autores discutem e analisam 14 estudos que buscam identificar clusters e complexos industriais ${ }^{7}$.

Segundo Czamanski e Ablas (1979), os métodos de identificação podem ser baseados em dois critérios: matemático e espacial. No primeiro caso aparecem em destaque a utilização de análise multivariada e da teoria gráfica. No que se refere ao critério espacial, os estudos recorrem ao grau de interligação (com base nos fluxos interindustriais) e ao grau de aglomeração espacial, com ênfase nos fluxos interindustriais, partindo da análise da economia nacional, fazendo uso em grande parte da matriz de insumo-produto nacional.

${ }^{7}$ Os complexos industriais além de serem caracterizados por um grupo de indústrias interligadas por intensos fluxos de bens e serviços, apresentam expressiva similaridade em seus padrões de localização. Observa-se, no entanto, uma certa confusão no emprego destes termos na literatura. Não obstante, em Streit (1969) e Bergsman $(1972,1975)$, o termo complexo foi utilizado com um sentido bem mais restrito, se referindo apenas a uma aglomeração em particular em uma localização especifica. 
Embora muitos autores assumam a hipótese de que a existência de clusters nacionais possa induzir a formação de complexos industriais regionais, ou ainda que, de certa forma, tais clusters possam fundamentar a base para a construção de políticas visando à formação de grupos industriais regionais, certamente, apenas um estudo rigoroso poderia examinar o grau de contribuição dos clusters nacionais na formação de complexos industriais regionais.

Streit (1969) define os complexos industriais utilizando e analisando dois tipos de coeficiente, um referente a uma medida de associação geográfica entre pares de setores; e outro medindo a intensidade dos fluxos interindustriais. Segundo Czamanski (1974) o trabalho de Streit (1969) é um dos melhores dessa categoria.

Bergsman et al. $(1972$, 1975) por sua vez, utilizam dados de distribuição espacial de setores industriais norte-americanos. Bergsman et al. (1972), tendo como base coeficientes de correlação lineares de ordem zero, mensuraram a extensão da associação espacial em termos de emprego, e em seguida, foram derivados todos os pares possíveis de indústrias, arranjando-os em forma de uma matriz simétrica. A seguir, utilizando-se de uma análise fatorial, e de acordo com o principal produto, foram identificados os complexos industriais. No segundo estudo, Bergsman (1975), tendo como base informações de uma área metropolitana maior, foram calculados os coeficientes de correlação (do tipo rank) com base nos dados de emprego. Os clusters são calculados recorrendo-se a uma análise hierárquica de clusters, que estabelece conjuntos mutuamente exclusivos e agregações exaustivas. $\mathrm{O}$ algoritmo inicia juntando os dois setores mais correlacionados em um grupo, o qual passa a ser tratado como uma indústria. $\mathrm{O}$ processo, então, se repete até que todos os setores tenham sido rearranjados. A definição dos níveis de agrupamento, entretanto, é arbitrária ${ }^{8}$.

\footnotetext{
${ }^{8}$ Embora os grupos sejam tratados como clusters no trabalho de Bergsman et al. (1975), segundo a visão de Czamanski e Ablas (1979), tratam-se, de complexos industriais.
} 
Como ressaltam Czamanski \& Ablas (1979) estes estudos ao tratarem do problema de agregação espacial de setores industriais, apresentam alguns problemas. $\mathrm{O}$ primeiro deles se refere ao fato de que o emprego, assim como os demais fenômenos urbanos, resultam em coeficientes de correlação elevados, porém sem significado. Além disso, todas as indústrias, de certa forma, são atraídas para os centros urbanos, haja vista a existência de fatores de produção e mercados. Neste sentido, a existência de uma correlação espacial entre duas indústrias não demonstra apenas a atração mútua entre elas, mas também a orientação de ambas a um determinado centro urbano.

Outros exemplos de trabalhos que procuram identificar agrupamentos produtivos incluem Roepke et al. (1974), Bergman (1997) e Hewings et al.(1998).

Hoen (2002) compara os resultados de doze diferentes métodos de identificação de clusters e avalia qual desses métodos oferece o melhor resultado. Segundo o autor, o método mais comum na identificação de clusters é o método filiére. Este método aponta um ou dois setores com elementos pertencentes a um cluster se os encadeamentos entre os setores for relativamente expressivo. As variáveis utilizadas para identificação dos clusters são os coeficientes dos insumos, os coeficientes de produção ou a matriz inversa de Leontief.

A semelhança tecnológica também é a preocupação de Blin e Cohen (1977). Os autores agrupam os setores da matriz insumo-produto de 1967 dos Estados Unidos visando obter o menor viés de agregação revelando os setores que responderiam de forma semelhante em respostas às variações da demanda final. Como mencionam os autores, os métodos consistem basicamente na associação de quatro elementos: a escolha de um critério de otimização, uma medida de semelhança entre os setores, um algoritmo para encontrar a divisão ótima e finalmente, a análise dos clusters.

Oosterhaven et al. (1999) utilizam matrizes inter-regionais para detectar agrupamentos, ou clusters de atividade econômica em regiões da Holanda. Os autores argumentam que os métodos padrões de delimitação de clusters (elementar e 
hierárquico $)^{9}$ não podem ser diretamente aplicados em análises inter-regionais, pelo fato de tais métodos não realizarem uma distinção entre a importância relativa e absoluta dos fluxos intermediários, fator de relevância na análise em um contexto de duas regiões. Assim, os autores definem os clusters com base nos fluxos inter-regionais, porém informações de exportações e importações inter-regionais são consideradas. $\mathrm{O}$ método utiliza três critérios para delimitar os clusters: os fluxos intermediários, o coeficiente de produção e o coeficiente de insumos, onde para cada um são estabelecidas restrições com base em valores pré-definidos.

A seguir, segundo Hoen (2002), são apresentados alguns dos métodos mais utilizados.

\section{a) Método de maximização}

O método mais usualmente utilizado na identificação de clusters é o método de maximização. Este método consiste, basicamente, na adoção dos seguintes passos: (i) escolha uma das seguintes matrizes: matriz de insumo-produto; matriz de coeficientes de insumo; matriz dos coeficientes de produção ou matriz inversa de Leontief; (ii) atribuição do valor zero para todos os elementos da diagonal da matriz; (iii) identificação do elemento (setor) de maior valor; (iv) agrupamento dos dois setores onde o elemento de maior valor seja coincidente; (v) estabelecer uma nova matriz de insumoproduto, com um setor a menos; (vi) repetir os passos (ii) a (v) até que um certo número de clusters, definido exogenamente, seja identificado.

b) Método de maximização restrita

Este método consiste em uma sofisticação do método anterior, e basicamente se diferencia daquele nos passos (i) e (iii). Pode ser sistematizado da seguinte forma: (i) escolha das restrições do tipo $z_{i j}>\alpha_{l}, a_{i j}>\alpha_{2}, e b_{i j}>\alpha_{l}$, onde tipo $z_{i j}$, se referem aos insumos fornecidos do setor $i$ para o setor $j$, $a_{i j}$ é o coeficiente de insumos do consumo intermediário, $b_{i j}$ é o coeficiente de produção do consumo intermediário e os valores de

\footnotetext{
${ }^{9}$ Conforme a descrição do autor, o método elementar corresponde ao método de maximização e o método hierárquico ao método de maximização restrita, ambos detalhados anteriormente.
} 
$\alpha_{1}$ e $\alpha_{2}$ são especificados exogenamente; (ii) escolha de uma das seguintes matrizes: matriz de insumo-produto; matriz de coeficientes de insumo; matriz dos coeficientes de produção ou matriz inversa de Leontief; (iii) atribuição do valor zero para todos os elementos que não satisfazem as restrições; (iv) atribuição do valor zero para todos os elementos da diagonal da matriz; (v) identificação do elemento (setor) de maior valor; (vi) agrupar os dois setores onde o elemento de maior valor seja coincidente; (vii) estabelecer uma nova matriz de insumo-produto, com um setor a menos; (viii) repetir os passos (iv) a (vii) até que um certo número de clusters, especificado exogenamente, seja identificado.

c) Método de diagonalização

O método de diagonalização também é conhecido como matriz bloco-diagonal. Essa matriz consiste em um caso especial da matriz de triangularização (Dietzenbacher,1996), a qual permite separar as partes de uma matriz que não apresentam conexões com as demais. Aplicado de forma apropriada este método identifica blocos de matrizes ao longo da diagonal principal. Os elementos fora dos blocos de matrizes da diagonal consistem em blocos de zeros.

Estabelecidos os elementos que devem ser zerados, os remanescentes devem formar uma estrutura de diagonal em blocos, os quais são em verdade, as sub-matrizes que dividirão a economia em clusters. Este método segue os passos: (i) escolha de um nível de significância $\alpha$; (ii) seleção de todos os elementos que pertençam aos $\alpha$ maiores elementos e para os quais os coeficientes de insumo e de produção também pertençam aos $\alpha$. maiores coeficientes; (ii) atribuição do valor zero para todos os elementos que não tiverem sido selecionados no passo; (iii) seleção de uma matriz (matriz de insumoproduto; matriz de coeficientes de insumo; matriz dos coeficientes de produção ou matriz inversa de Leontief), checar a possibilidade de decomposição e rearranjo dos setores de forma que seus elementos da matriz estejam em blocos; (iv) formação dos clusters conforme os setores que pertencerem a um mesmo bloco. 
Uma desvantagem deste método é que os clusters não são baseados em nenhuma restrição de ligações, ou seja, não estão definidos conforme os links mais relevantes, como nos métodos anteriores.

d) Fusão hierárquica

Consiste em utilizar-se uma matriz $\mathbf{A}$, de coeficientes técnicos e considerar cada uma das colunas dessa matriz que, na verdade, expressam a função de produção do jésimo setor em um espaço de $\boldsymbol{n}$ dimensões. Toma-se, então, a distância Euclidiana entre os vetores como medida da heterogeneidade dos insumos entre dois setores iniciais. Quanto maior for a distância entre os vetores, então a fusão destes dois setores será adiada até que se encontre um outro setor, menos distante, que possa agregar o cluster.

Hoen (2002) aplica cada um dos métodos a cada um dos tipos de matrizes de dados: matriz de insumo-produto; matriz de coeficientes de insumo; matriz dos coeficientes de produção ou matriz inversa de Leontief; e compara os resultados, concluindo que a aplicação destes métodos apresentam basicamente os seguintes problemas:

- Escolha dos dados. O autor ressalta que teoricamente, nenhuma matriz é preferivel a outra. No entanto, na medida em que cada uma delas apresenta informações diferentes, os clusters identificados têm significados diferentes. Em outras palavras, cada uma das matrizes identifica clusters sob óticas diferentes. Isso porque enquanto a matriz de coeficientes dos insumos expressa a importância dos fornecedores, a matriz de coeficientes de produção enfatiza as relações de compradores, a matriz de consumo intermediário expressa a importância das transações na economia, ao mesmo tempo em que a matriz inversa de Leontief leva em consideração os efeitos diretos e indiretos da economia. $\mathrm{O}$ autor considera que o método mais elegante deveriam ser aquele que apresentasse os mesmos resultados para todas as tabelas utilizadas.

- Resultados inconsistentes. Segundo Hoen (2002), como não há uma posição clara acerca de qual tabela deve ser utilizada, da mesmo forma, não é possível afirmar qual das óticas de cluster é a mais correta. 
- Mega clusters. Geralmente estes clusters, identificados por um conjunto de setores, são tidos como resíduos. Quando se utilizam as matrizes de insumo intermediário no método de maximização o aparecimento destes clusters parece plausível pois à medida em que se agrupam setores os valores mais elevados de insumo intermediário apresentam maior probabilidade de se juntarem a outros setores. No entanto, o aparecimento destes clusters no método da matriz bloco diagonal não parece plausível, sendo, portanto, difícil de explicar economicamente. Cabe ressaltar, no entanto, que o aparecimento de mega clusters só ocorre quando são definidos, a priori, um certo número de clusters. Caso contrário, os setores se agnupam em um maior número de clusters.

- Mini clusters. Os resultados obtidos mostraram clusters que compreendiam apenas dois setores. Teoricamente, espera-se que os clusters contenham mais do que somente dois setores fortemente interconectados. Geralmente mini-clusters não aparecem quando se utiliza o método baseado em matrizes bloco diagonal.

De acordo com Hoen (2002), o método da matriz bloco diagonal parece ser o mais apropriado por apresentar os melhores resultados. Entretanto, este método requer algumas restrições para selecionar os mais importantes elementos em uma matriz. Sugere-se a utiližação do vałor de restrições. Definida uma restrição, por exemplo, de $5 \%$, arribui-se o valor zero para aqueles elementos da matriz utilizada que satisfizerem a restrição, de forma que a matriz bloco derivada do método pode indicar os setores que pertencem a um mesmo cluster.

Em suma, vários métodos são utilizados na literatura na identificação e análise de clusters. Alguns métodos apresentam como vantagens a utilização direta da matriz de uso ou de coeficientes técnicos, não requerendo nenhum tratamento prévio dos dados. Cabe observar, entretanto que um dos problemas dos métodos apresentados por Hoen (2002) consiste no grau de arbitrariedade do pesquisador. Os métodos de maximização restrita e da matriz bloco diagonal requerem a escolha de valores de restrição para a análise. Tais decisões arbitrárias, implicam conhecimento mais profundo da estrutura produtiva por parte do pesquisador. 
Outro aspecto que diferencia os métodos aqui apresentados do método escolhido para realização deste trabalho refere-se ao tipo de cluster identificado. Os métodos anteriores permitem identificar clusters formados por um número restrito de setores, denominados crisp clusters. Nessas análises, os setores pertencem a apenas um cluster, não sendo possível sua participação em mais de um cluster simultaneamente. proporcionando análises distantes da realidade econômica.

Neste sentido, Czamanski (1974) utilizando quatro coeficientes diferentes demonstra uma das primeiras tentativas de avaliar clusters segundo os setores mais importantes. Mais recentemente, Dridi e Hewings (2002) utilizam a análise de clusters do tipo fuzzy, que busca levar em conta a complexidade das relações produtivas no estabelecimento dos agnupamentos setoriais. $\mathrm{O}$ método não requer que o pesquisador escolha de forma arbitrária os valores de restrições, exigido pelos demais métodos. É fundamental acrescentar que os agrupamentos são identificados de tal forma que todos os setores da economia pertençam a um determinado cluster, em diferentes graus. Essas características foram preponderantes na escolha do método, que será tratado com mais detalhes a seguir.

\subsection{Fuzzy clusters}

Os agrupamentos setoriais, ou como estão sendo denominados neste trabalho, clusters, mesmo apresentando maior similaridade entre si, não restringem suas relações de compra e venda de insumos a um pequeno número de atividades da estrutura produtiva. Ao contrário, os setores estabelecem relações de compra e venda de insumos com um grande número de setores.

Em outras palavras, é possível que algumas atividades, ao serem agrupadas segundo as relações de compra e venda de insumos, pertençam a mais de um cluster ao mesmo tempo.

Utilizando a teoria dos conjuntos nebulosos, fuzzy set theory, é possível realizar uma análise levando em consideração essa fluidez da estrutura produtiva. Dridi e 
Hewings (2002a), apresentam a utilização da análise de fuzzy clusters decorrente desta teoria como uma proposta metodológica de avaliação de clusters setoriais e fazem um exercício com a matriz da economia americana. Ao reconhecer as limitações da abordagem crisp tradicional, a abordagem do tipo fuzzy pretende realizar uma análise mais coerente com a complexidade da estrutura produtiva.

Uma aplicação deste método em estudo sobre a economia brasileira pode ser encontrada em Simões (2003). O autor utiliza a abordagem de fuzzy clusters com o objetivo de identificar complexos industriais espaciais no Estado de Minas Gerais, aplicando o método semelhante ao utilizado neste estudo, utilizando uma matriz de acessibilidade espacial multi-setorial, derivada da matriz insumo-produto. A diferença básica consiste nos dados utilizados. A matriz utilizada por Simões (2003), por se tratar de uma matriz espacial, já contempla medidas de distância entre seus setores. Por outro lado, o presente trabalho, ao utilizar os dados matriz de uso, requer uma decomposição dessa matriz, a fim de se obter distâncias entre os setores. Esse método, denominado

dual scaling será detalhado no item 3.6.3 da próxima seção, que visa detalhar a metodologia utilizada.

\subsubsection{Teoria dos conjuntos nebulosos}

A teoria dos conjuntos nebulosos consiste em um dos principais elementos da lógica fuzzy. Os conjuntos convencionais do tipo crisp apresentam limites bem definidos, e podem ser representados por uma lista de elementos que pertencem ou não pertencem ao conjunto. Nos conjuntos do tipo fuzzy, ao contrário, cada elemento pode pertencer a mais de um conjunto, em diferentes graus como mostra a Figura 4, a seguir (Cox, 1995). 


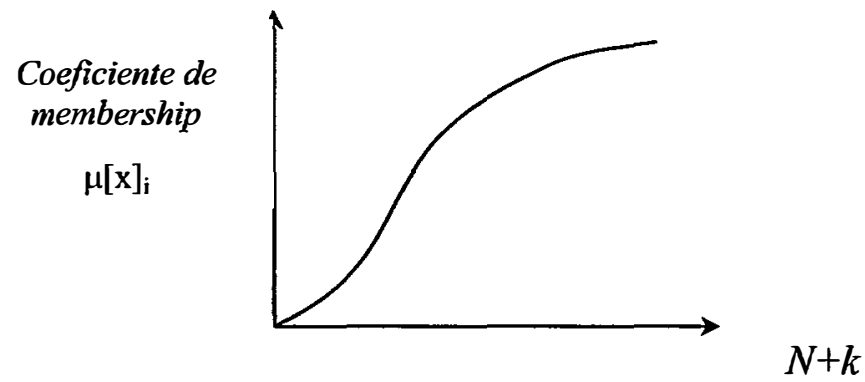

Elementos (Domínio do conjunto fuzzy)

Figura 4 - Estrutura dos conjuntos do tipo fuzzy

Na Figura 4, o eixo horizontal representa todos os elementos do conjunto, enquanto o eixo vertical quantifica a participação de cada um desses elementos no conjunto fuzzy. Trata-se de uma representação genérica da função de membership, $\mu[\mathrm{x}]_{\mathrm{i}}$ que associa cada elemento do domínio ao conjunto do tipo fuzzy. A função de membership será detalhada adiante.

\subsubsection{Identificacao de fuzzy clusters}

A seguir, o método de identificação de fuzzy cluster é descrito, conforme demonstrado por Dridi e Hewings (2002a).

Considerando $X$ um conjunto finito de pontos, onde um ponto genérico e denominado por $x$, um subconjunto fuzzy de $X$, denominado $A$, será caracterizado por uma função de membership $\mu_{A}(x)$, que associará, a cada ponto $x$, um coeficiente dentro de um intervalo real de $[0,1]$.

Assim, o subconjunto fuzzy $A$ é conjunto de pares ordenados $\left\{\left(\left(x \mid \mu_{A}(x)\right) ; \forall x \in X\right\}\right.$, onde $\mu_{A}(x)$ é o coeficiente de membership do elemento $x$ em $A$. 
Se denominarmos $A_{k,}, \forall k=1, \ldots K$, todos os subconjuntos de um conjunto universo $X$, têm-se as seguintes propriedades:

$$
\begin{aligned}
& \mu_{A_{k}}(x) \in[0,1] ; \forall x \in X, \forall k=1, . . K \\
& \sum_{k=1}^{K} \mu_{A_{k}}(x)=1
\end{aligned}
$$

Os autores mencionam controvérsias quanto ao formato da função de membership, especialmente porque este tipo de função é determinada $a d-h o c$, e adotam a proposta de Kaufman e Rosseeuw (1990). Segundo essa alternativa, os clusters são obtidos minimizando a seguinte função objetivo:

$$
\min _{\mu_{i k}} \sum_{v=1}^{K} \frac{\sum_{i, i^{\prime}}^{r} \mu^{2}{ }^{2} \mu^{2}{ }^{2}{ }^{\prime \prime} d_{i, i^{\prime}}}{2 \sum \mu^{2}{ }_{i^{\prime} v}}
$$

restrito a:

$$
\begin{aligned}
& \mu_{i v} \geq 0 ; \forall i=1, \ldots, r ; \forall v=1, \ldots, k \\
& \sum_{v=1}^{k} \mu_{i v}=1 ; \forall i=1, \ldots, r
\end{aligned}
$$

Em que:

$\mu_{i v}$ representa valores dos coeficientes de membership de cada um dos $i$ setores em relação aos $v$ clusters, que minimizarão a função; 
$d_{i, i^{\prime}}$ representa a distância Euclidiana calculada entre os setores da matriz submetida à análise de cluster, definida na seção a seguir.

Para os autores, este método apresenta vantagens em relação aos outros métodos de análise de fuzzy cluster. Isso porque este método minimiza os erros, ao utilizar um expoente unitário da distância, ao passo que nos demais métodos a distancia é utilizada ao quadrado.

O algoritmo fanny classifica $r$ objetos (no caso, setores) em $k$ clusters com base na observação de $s$ características, ou observações de uma variável. A obtenção das $s$ características requer uma decomposição da matriz de uso, mediante a técnica dual scaling, demonstrada a seguir.

\subsubsection{Dual scaling}

O método denominado dual scaling é uma técnica de análise descritiva multivariada apresentada por Nishisato (1994). Sua aplicação na matriz insumo-produto permite decompor a complexidade das associações que se estabelecem entre os setores da estrutura produtiva.

Segundo Dridi e Hewings (2002a) ${ }^{10}$, a técnica aplicada a uma tabela de contingência, no caso, uma tabela de fluxos intersetoriais, permite determinar um vetor de linhas e um vetor de colunas ponderadas (ou com pesos) que maximizam a relação:

$$
\eta^{2}=\frac{S S_{b}}{S S_{i}}
$$

Sendo:

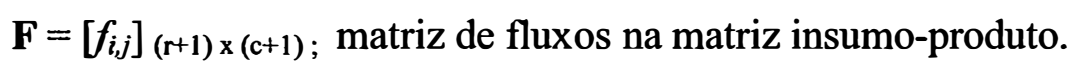

\footnotetext{
${ }^{10}$ A descrição da técnica está baseada em Dridi e Hewings (2002a)
} 
$\mathbf{f}_{r}$ : vetor do total de produção da matriz de insumo-produto.

$\mathbf{f}_{c}$ : vetor do total de insumos da matriz insumo-produto.

$\mathbf{D}_{r}$ : matriz diagonal com o total das linhas na diagonal principal;

$\mathbf{D}_{c}$ : matriz diagonal com o total das colunas na diagonal principal;

y: vetor de pesos resultante para os setores fornecedores;

$\mathbf{x}$ : vetor de pesos resultante para os setores demandantes;

$f_{t}$ : valor total ou intensidade da matriz insumo-produto.

Onde,

$S S_{b}$ expressa a variação entre as linhas de $\mathbf{F}$ e $S S_{t}$ expressa a variação total em toda a matriz insumo-produto.

Assim,

$$
\begin{aligned}
& S S_{b}=\mathbf{x}^{\prime} \mathbf{F}^{\prime} \mathbf{D}_{\mathbf{r}}^{-1} \mathbf{F} \mathbf{x}, \\
& S S_{t}=\mathbf{x}^{\prime} \mathbf{D}_{c} \mathbf{x}
\end{aligned}
$$

O problema de maximização pode ser resolvido fixando $S S_{t}$ e maximizando $S S_{b}$, em que o Lagrangeano será resolvido por:

$$
L(\mathbf{x}, \lambda)=\mathbf{x}^{\prime} \mathbf{F}^{\prime} \mathbf{D}_{\mathbf{r}}^{-1} \mathbf{F x}-\lambda\left(\mathbf{x}^{\prime} \mathbf{D}_{\mathbf{c}} \mathbf{x}-f_{t}\right)
$$

Com as condições de primeira ordem:

$$
\begin{aligned}
& \frac{\partial L}{\partial \mathbf{x}}=\mathbf{F}^{\prime} \mathbf{D}_{\mathbf{r}}^{-1} \mathbf{F x}-\lambda \mathbf{D}_{\mathbf{c}} \mathbf{x}=0 \\
& \frac{\partial L}{\partial \lambda}=\mathbf{x}^{\prime} \mathbf{D}_{\mathbf{c}} \mathbf{x}-f_{t}=0
\end{aligned}
$$


Pré-multiplicando por x' e organizando os termos, tem-se que a equação (52) pode ser reescrita por:

$$
\left(\mathbf{F}^{\prime} \mathbf{D}_{\mathbf{r}}^{-1} \mathbf{F}-\eta^{2} \mathbf{D}_{\mathbf{c}}\right) \mathbf{x}=\mathbf{0}
$$

A qual pré-multiplicada por $\mathbf{D}_{\mathbf{c}}^{-1}$, chega-se à seguinte equação característica ${ }^{11}$ :

$$
\left(\mathbf{D}_{\mathbf{c}} \mathbf{F}^{\prime} \mathbf{D}_{\mathbf{r}}^{-1} \mathbf{F}-\eta^{2} \mathbf{I}\right) \mathbf{x}=0
$$

Uma vez estabelecida uma solução de $\eta^{2}$; um vetor característico $\mathrm{x}$, associado ao mais alto valor de $\eta^{2}$ é encontrado na equação (54). O vetor característico y é encontrado utilizando a relação dual:

$$
y=\left(\frac{1}{\eta}\right) \mathbf{D}_{\mathbf{r}}^{-1} \mathbf{F x}
$$

Assim, pode se obter a primeira solução, ou seja, os primeiros vetores de peso $x$ e $y$ da nova matriz decomposta. Se a primeira solução for insuficiente para explicar a correlação entre linhas e colunas, novas soluções são encontradas, gerando outros vetores de peso $x$ e $y$. Neste caso, todas as $s$ possíveis soluções são encontradas

A aplicação desta técnica na matriz insumo-produto possibilita a obtenção de duas matrizes. Uma que estabelece $s$ pesos para as colunas e sua dimensões será $c \times s$,

\footnotetext{
${ }^{11}$ Segundo Chiang (1982), dada uma matriz $D, n \times n$, se encontrarmos um escalar $r$ e um vetor $x$, diferente de zero, tal que, a equação matricial $D x=r x$ seja satisfeita, $x$ é denominado vetor característico dessa matriz $D$. A equação $D x=r x$ pode ser reescrita como $D x-r I x=0$, ou $(D-r I) x=1$, onde $(D-r I)$ denominase equação característica de $D$.
} 
onde $c$ é numero de colunas da matriz original. A segunda matriz estabelece $s$ pesos para as linhas e sua dimensão será $r \mathrm{x} s$, onde $r$ é o numero de linhas da matriz original.

Assim, as matrizes resultantes terão a seguinte configuração:

$$
\begin{aligned}
\mathbf{X} & =\left(\begin{array}{ccccc}
x_{1,1} & \cdots & x_{1, k} & \cdots & x_{1, s} \\
\vdots & & \vdots & & \vdots \\
x_{j, 1} & \cdots & x_{j, k} & \cdots & x_{j, s} \\
\vdots & & \vdots & & \vdots \\
x_{c, 1} & \cdots & x_{c, k} & \cdots & x_{c, s}
\end{array}\right) \\
\mathbf{Y} & =\left(\begin{array}{ccccc}
y_{11,} & \cdots & y_{1, k} & \cdots & y_{1, s} \\
\vdots & & \vdots & & \vdots \\
y_{j, 1} & \cdots & y_{j, k} & \cdots & y_{j, s} \\
\vdots & & \vdots & & \vdots \\
y_{c, 1} & \cdots & y_{c, k} & \cdots & y_{c, s}
\end{array}\right)
\end{aligned}
$$

As matrizes $\mathrm{X}$ e Y são utilizadas para calcular a distância Euclidiana entre as linhas e colunas da seguinte forma:

$$
\begin{aligned}
& d_{i, i^{\prime}}=\sqrt{\sum_{k=1}^{s}\left(y_{i, k}-y_{i^{\prime}, k}\right)^{2}} ; \forall i=, \ldots r ; \forall i^{\prime}=1, \ldots, r \\
& d_{j, j^{\prime}}=\sqrt{\sum_{k=1}^{s}\left(x_{j, k}-x_{j^{\prime}, k}\right)^{2}} ; \forall j=, \ldots r ; \forall j^{\prime}=1, \ldots, r
\end{aligned}
$$


O passo seguinte consiste na realização da análise de cluster com base nas distancias calculadas a partir das matrizes ponderadas. O número de clusters analisados deve ser o maior possível (Simões, 2003). Na realização deste trabalho, utilizou-se o software S-PLUS, cuja análise de cluster do tipo fuzzy é obtida pelo algoritmo fanny e permite um número máximo de clusters tal que $k=\frac{s}{2}-1$, onde $s$ é o número de soluções encontradas como descrito no procedimento dual scaling.

Dessa forma, o resultado da análise de cluster consiste em uma matriz formada por vetores expressando os coeficientes de membership de cada um dos setores que formam os clusters identificados na economia. Essas matrizes são denominadas matrizes de membership.

As informações de membership subsidiam uma análise preliminar dos clusters produtivos. Outras medidas, como as detalhadas a seguir podem ser empregadas para melhor caracterizar a importância dos setores em cada clusters identificados.

\subsubsection{Envolvimento dos setores}

Segundo Dridi e Hewings (2002b), a importância relativa de um cluster pode ser obtida mediante o coeficiente denominado envolvimento, definido como:

$$
\operatorname{Env}_{A}\left(x_{i}\right)=\frac{\mu_{A}\left(x_{i}\right)}{\operatorname{card}(A)} ; \forall i=1, \ldots, n
$$

Em que,

$\mu_{A_{A}}\left(x_{i}\right)$ representa o grau de membership do setor ao cluster

$\operatorname{card}\left(A_{k}\right)=\sum \mu_{A_{A}}\left(x_{i}\right) ; \forall k \in C$, representa a cardinalidade dos setores, 
$X$ é um conjunto de pontos, neste caso, setores, $x_{i}$ finitos e contáveis,

$\forall i \in I=\{1, \ldots, N\}$

$A_{k}$ são os conjuntos tipo fuzzy de $X$.

$\forall k \in C=\{1, \ldots, K\}$

Assim, os valores mais elevados deste coeficiente de envolvimento indicam setores mais importantes no cluster, exercendo liderança no cluster em questão. Por sua vez, os valores baixos indicam os setores com importância secundária no cluster, ou seja, os setores que fornecem suporte a atividade principal do cluster.

\subsubsection{Grau de dependência ${ }^{12}$}

Consiste em um indicador de avaliação do quanto um conjunto fuzzy está contido em um outro conjunto fuzzy. Define-se por:

$$
D(B, A)=\frac{\operatorname{card}(B \cap A)}{\operatorname{card}(B)}=\frac{\sum_{i} \min \left(\mu_{A}\left(x_{i}\right), \mu_{B}\left(x_{i}\right)\right)}{\sum_{i}\left(\mu_{B}\left(x_{i}\right)\right)}
$$

12 Dridi e Hewings (2002b) se referem a esse indicador como subsethood. 
Assim, $D(B, A)$ expressa grau de dependência do cluster $\mathrm{A}$ em relação ao cluster B. A matriz de grau de dependência expressa a dependência mútua entre os clusters da estrutura produtiva.

\subsection{Método de cálculo do valor adicionado, pessoal ocupado e produtividade do trabalho do setor automotivo}

Pretende-se avaliar a evolução do setor automotivo nos anos 90 em termos do valor adicionado do setor, pessoal ocupado e produtividade do trabalho. Tendo por base o trabalho de Guilhoto et al. (2000), é possível mensurar a dimensão e evolução deste setor mediante a análise dos seguintes agregados:

a. Agregado da produção (P): compreende as atividades responsáveis pela produção dos bens finais do setor.

b. Agregado dos insumos (I): compreende as atividades que fornecem insumos e serviços ao agregado da produção;

c. Agregado da distribuição (D): compreende a comercialização e a distribuição dos produtos finais, realizados pelas atividades de comércio, transporte e as demais atividades dos serviços.

Foi considerado no agregado da produção (P) a atividade Automóveis, caminhões e ônibus. Neste caso, são considerados o valor adicionado e o pessoal ocupado destas atividades em sua totalidade.

No caso do agregado dos insumos, devem ser considerados apenas o valor adicionado gerado e o pessoal ocupado utilizado nas atividades que contribuem com insumos para a produção dos bens finais do setor. Estas parcelas podem ser estimadas com base nos coeficientes de valor adicionado e pessoal ocupado de cada atividade, os quais serão detalhados na seqüência. 
O agregado da distribuição leva em conta o valor adicionado e pessoal ocupado utilizados na distribuição e comercialização dos produtos finais. As atividades que melhor representam estes serviços são as margens de comércio e transportes, cujas parcelas são passíveis de estimação com base no coeficiente de participação da atividade na demanda final da economia.

A seguir, descreve-se o método de mensuração de cada uma das variáveis analisadas para os três agregados.

\subsubsection{Valor adicionado}

Para o cálculo do valor adicionado do setor são considerados o valor adicionado dos agregados da produção, dos insumos e do distribuição, conforme a expressão:

$$
V A_{s}=V A_{I}+V A_{P}+V A_{D}
$$

em que,

$V A_{s}=$ Valor adicionado do setor;

$V A_{I}=$ Valor adicionado do agregado dos insumos;

$V A_{P}=$ Valor adicionado do agregado da produção;

$V A_{D}=$ Valor adicionado do agregado da distribuição.

\section{Valor adicionado dos insumos $\left(V A_{I}\right)$}

O total dos insumos do setor consiste no vetor da atividade Automóveis, Caminhões e Ônibus da matriz de consumo intermediário. Cada uma das $\boldsymbol{n}$ linhas da coluna representa a parcela de consumo fornecido pelas atividades para a produção do bem final e deve ser multiplicada pelo seu coeficiente do valor adicionado $\left(\mathrm{CVA}_{\mathrm{i}}\right)$ específico. Este coeficiente expressa a relação entre os valores adicionado e produzido da atividade que fornece $o$ insumo e pode ser representado por: 


$$
C V A_{i}=V A_{p b} / X_{i}
$$

em que,

$C V A_{i}=$ Coeficiente do valor adicionado da atividade $i$

$V A_{p b}=$ Valor adicionado a preços básicos da atividade $i$;

$X_{i}=$ Valor da produção da atividade $i$;

Entretanto, para evitar a dupla contagem do valor adicionado, os insumos provenientes $\mathrm{da}(\mathrm{s})$ atividade(s) que compõe o agregado da produção não são considerados. Assim, o valor adicionado incorporado ao consumo intermediário é definido como:

$$
V A_{I}=\sum_{i=1}^{n} I_{i k} * C V A_{i}
$$

sendo que,

$k=$ atividades que constituem o agregado da produção;

$i=1,2 \ldots n$ atividades (exceto aquelas que constituem o agregado da produção);

em que,

$I_{i k}=$ valor total do insumo que a atividade $i$ fornece para as atividades que constituem $\mathrm{o}$ agregado da produção;

$C V_{i}=$ Coeficiente do valor adicionado da atividade $i$; 


\section{Valor adicionado da produção $\left(V A_{P}\right)$}

O valor adicionado da produção consiste no valor adicionado a preço básico das atividades consideradas no agregado da produção. Como mencionado, esta atividade se refere à fabricação de Automóveis, caminhões e ônibus.

\section{Valor adicionado da distribuição $\left(V A_{D}\right)$}

Na distribuição e comercialização de produtos são levados em consideração os valores adicionados das atividades relativas às Margens de Comércio e Transporte multiplicadas pela participação da demanda final das atividades que constituem o agregado da produção na demanda final doméstica ${ }^{13}$.

Tem-se que o valor adicionado da distribuição pode ser calculado por:

$$
V A_{D}=V A_{M} * \frac{D F_{k}}{D F D}
$$

em que,

$V A_{M}=$ Valor adicionado das Margens de Comércio e Transporte;

$D F_{k}=$ Demanda final das atividades que compõe o agregado da produção;

$D F D=$ Demanda final doméstica.

\subsubsection{Pessoal ocupado}

Seguindo a mesma lógica do cálculo do valor adicionado, o pessoal ocupado total do setor foi definido por:

\footnotetext{
${ }^{13} \mathrm{~A}$ margem de comércio do agronegócio foi calculada como a participação da demanda final dos produtos agropecuários e agroindustriais na demanda final doméstica em Guilhoto et al. (2000)
} 


$$
P O_{s}=P O_{I}+P O_{P}+P O_{D}
$$

em que,

$P O_{s}=$ Pessoal ocupado no setor;

$P O_{P}=$ Pessoal ocupado no agregado da produção;

$P O_{I}=$ Pessoal ocupado no agregado dos insumos;

$P O_{D}=$ Pessoal ocupado no agregado da distribuição.

\section{Pessoal ocupado na produção $\left(P O_{P}\right)$}

O pessoal ocupado na produção constitui-se do pessoal ocupado da atividade do agregado da produção.

\section{Pessoal ocupado nos insumos $\left(P O_{I}\right)$}

Para estimar o pessoal ocupado utilizado na produção é necessário ponderar os valores do consumo intermediário pelos coeficientes de pessoal ocupado específicos de cada atividade fornecedora de insumos. Para evitar a dupla contagem são excluídos também neste caso, os insumos provenientes da atividade que constitui o agregado da produção.

O coeficiente do pessoal ocupado expressa a relação entre o pessoal ocupado e o valor produzido de cada atividade, e pode ser representado por:

$$
C P O_{i}=P O_{i} / X_{i}
$$

em que,

$C P O_{i}=$ Coeficiente do pessoal ocupado da atividade $i$; 
$P O_{i}=$ Pessoal ocupado da atividade $i$

$X_{i}=$ Valor da produção da atividade $i$

O pessoal ocupado na geração dos insumos pode ser calculado por intermédio da expressão:

$$
P O_{C I}=\sum_{i=1}^{n} I_{i k} * C P O_{i}
$$

sendo que,

$k=$ atividades que constituem a cadeia produtiva

$i=1,2 \ldots n$ atividades (exceto aquelas que constituem a cadeia)

em que,

$I_{i k}=$ valor total do insumo que a atividade $i$ fornece para as atividades que constituem o agregado da produção.

\section{Pessoal ocupado na distribuição $\left(P O_{D}\right)$}

Como no cálculo do valor adicionado, o pessoal ocupado da distribuição leva em consideração o pessoal ocupado das atividades relativas a Margens de Comércio e Transportes multiplicadas pela participação da demanda final das atividades que constituem o agregado da produção na demanda final doméstica. Obtém-se da seguinte forma:

$$
P O_{D F}=P O_{M} * \frac{D F_{K}}{D F D}
$$

em que, 
$P O_{D}=$ Pessoal ocupado do agregado da distribuição;

$P O_{M}=$ Pessoal ocupado nas Margens de Comércio e Transportes;

e as outras variáveis são como definidas anteriormente.

\subsubsection{Produtividade do trabalho}

Finalmente, a relação entre o valor adicionado e o pessoal ocupado total nos permite obter a produtividade do trabalho do setor, e pode ser expressa por:

$$
P T_{s}=\frac{V A_{s}}{P O_{s}}
$$

em que, como visto anteriormente em (58) e (62),

$V A_{S}=V A_{I}+V A_{P}+V A_{D}$

$P O_{S}=P O_{I}+P O_{P}+P O_{D}$

\subsection{As matrizes de insumo-produto}

Conforme recomendação das Nações Unidas, as Matrizes Insumo-Produto devem fazer parte do Sistema de Contas Nacionais (SCN) do país. O Instituto Brasileiro de Geografia e Estatística (IBGE), agência oficial de estatísticas do Brasil, divulga o SCN anualmente, porém com uma defasagem de dois anos. A última informação disponível se refere ao ano de 2002. No primeiro ano são divulgados os dados preliminares, no segundo, os semidefinitivos e no terceiro, têm-se os dados definitivos. Só então, com base nos dados definitivos do SCN é que são elaboradas as matrizes insumo-produto. No entanto, isso não vem ocorrendo desde a divulgação da matriz de 1996, sendo necessário a estimação dessas matrizes para os anos subseqüentes.

Em Guilhoto et al. (2002) é proposta uma forma de estimação dessas matrizes com base no SCN. Em essência, o SCN apresenta a oferta global a preços do 
consumidor, ao passo que as matrizes insumo-produto devem contemplar a oferta nacional e preços básicos. Por conseguinte, torna-se necessário estimar a parcela dos impostos indiretos líquidos e da importação para se obter os dados coerentes com o modelo insumo-produto. Os autores sugerem que as colunas de impostos indiretos líquidos e de produtos importados sejam distribuídas ao longo das linhas com base na distribuição do valor da produção. $\mathrm{O}$ estudo mostra que, para os anos em que as matrizes já foram divulgadas, os dados estimados apresentam robustez.

Dessa forma, no processo de identificação de clusters nacionais e na mensuração do valor adicionado, pessoal ocupado e produtividade do setor automotivo, foram utilizadas: (i) matrizes de uso originalmente calculadas pelo IBGE para o período de 1990 a 1996, e (ii) matrizes estimadas para o período de 1997 a 2002 com base em Guilhoto et al. (2002).

Nas análises de impacto regional e na identificação de clusters regionais, os dados utilizados são oriundos do modelo inter-regional elaborado para a economia brasileira do ano de 1999 realizado por Guilhoto et al. (2004). ${ }^{14} \mathrm{O}$ modelo compreendendo 31 setores e 6 regiões: Norte, Nordeste, Centro-Oeste, São Paulo, Resto do Sudeste e Sul.

A construção deste modelo teve por base a utilização da matriz estimada para a economia brasileira para o ano de 1999, como mencionado anteriormente. As informações que permitiram construir as matrizes regionais, referentes aos valores de produção regional e desagregação setorial nacional, foram obtidas em diversas fontes de dados. Destacam-se sobretudo as informações provenientes da Pesquisa Industrial Anual, Pesquisa Industrial dos Serviços, Pesquisa da Construção Civil, Censo Agropecuário do IBGE, Balanço Anual da Gazeta Mercantil, Ministério das Minas e Energia.

${ }^{14}$ GUILHOTO, J.J.M. (USP. Faculdade de Economia, Administração e Contabilidade, São Paulo). Comunicação pessoal, 2004. 


\section{RESULTADOS E DISCUSSÃO}

As informações apresentadas nesta seção permitem caracterizar a evolução do setor automotivo brasileiro no período de 1990 a 2002 e avaliar sua importância na estrutura produtiva nacional e regional em termos geração de produção, emprego e renda.

Inicialmente pretendeu-se mensurar e avaliar a evolução do valor adicionado, do pessoal ocupado e da produtividade do trabalho nos agregados que compõem o setor automotivo, considerando neste cômputo tanto a contribuição das atividades fornecedoras de insumos à sua produção, quanto daquelas que contribuem para a distribuição e comercialização destes bens finais.

A seguir buscou-se avaliar se as atividades pertencentes a esse setor estabelecem um perfil de relações de compra e de venda semelhantes às outras atividades na estrutura produtiva, de tal maneira que sejam capazes de liderar um cluster produtivo. Esta análise foi realizada considerando a dimensão convencional das matrizes insumo-produto da economia brasileira, divulgadas pelo IBGE $(42 \times 42)$, visando identificar a existência ou não da alteração do padrão destas relações de similaridade como os demais setores da economia ao longo dos anos 90 . O mesmo método foi aplicado no sistema inter-regional, constituído de seis regiões, cada uma dessas desagregada em 31 setores, na pretensão de comparar a similaridade das relações de compra e venda com os demais setores da economia regional.

Finalmente, um último conjunto de informações se refere às analises setoriais clássicas, constituídas pelo cálculo dos índices de ligação intersetoriais e das análises de impacto, concentradas nas variáveis produção, emprego e renda, tendo como base os sistema inter-regional mencionado anteriormente. 


\subsection{Evolução do valor adicionado, pessoal ocupado e produtividade no setor automotivo - 1990 a 2002}

A estimação do valor adicionado, do pessoal ocupado e da produtividade do trabalho no setor automotivo brasileiro visando avaliar sua evolução ao longo do período 1990 a 2002 é tratada neste sub-item.

Para o período em questão, as matrizes insumo-produto da economia brasileira estão disponíveis no mesmo nível de desagregação setorial do Sistema de Contas Nacionais, detalhado segundo 42 setores. Neste nível de agregação, identificam-se como atividades econômicas associadas à indústria automobilística (automóveis, caminhões e ônibus) e de autopeças as seguintes atividades: (i) Automóveis, caminhões e ônibus; e (ii) Fabricação de outros veículos, peças e acessórios. O Quadro 5 apresenta com maior detalhe essa classificação. $\mathrm{Na}$ primeira coluna desta tabela podemos observar as atividades contempladas na fabricação de Automóveis, caminhões e ônibus, enquanto a segunda coluna apresenta as atividades econômicas contempladas na Fabricação de outros veículo, peças e acessórios.

Um dos objetivos deste trabalho é avaliar de que forma as transformações que ocorreram na produção de automóveis e de autopeças na economia brasileira nos anos 90 repercutiram na geração de valor adicionado e de emprego neste setor. Por essa razão, ao mensuração do valor adicionado, pessoal ocupado e da produtividade do trabalho do setor automotivo foi realizada considerando os produtos finais contemplados somente na atividade econômica de Automóveis, caminhões e ônibus, conforme detalhado na primeira coluna do Quadro 5. 


\begin{tabular}{|c|c|}
\hline Fabricação de automóveis, caminhões e ônibus & Fabricação de outros veículos, peças e acessórios \\
\hline Fabricação de automóveis e utilitários & Fabricação de material elétrico para veículos \\
\hline Fabricação de caminhões e ônibus, inclusive chassis & Fabricação de motores para veículos \\
\hline Fabricação de carrocerias para caminhões & Fabricação de autopeças mecânicas para veículos \\
\hline Fabricação de carrocerias para ônibus & Produção de serviços de recondicionamento de motor \\
\hline \multirow[t]{8}{*}{ Fabricação de carrocerias para automóveis e utilitários } & Fabricação de bancos e estofados para veículos \\
\hline & $\begin{array}{l}\text { Fabricação de embarcações e de serviços de reparação } \\
\text { naval }\end{array}$ \\
\hline & Fabricação de estruturas flutuantes \\
\hline & $\begin{array}{l}\text { Fabricação de turbinas,motores e peças para } \\
\text { embarcações } \\
\text { Fabricação de veículos ferroviários e serviços de } \\
\text { reparação }\end{array}$ \\
\hline & Fabricação de peças para veículos ferroviários \\
\hline & $\begin{array}{l}\text { Fabricação de aeronaves,peças para aeronaves e serviços } \\
\text { de reparação }\end{array}$ \\
\hline & Fabricação de bicicletas e motocicletas,inclusive peças \\
\hline & Fabricação de outros veículos \\
\hline
\end{tabular}

Quadro 5 - Produtos contemplados nas atividades de Automóveis, caminhões e ônibus e

Fabricação de outros veículos, peças e acessórios

Fonte: IBGE (1999)

Como descrito anteriormente na metodologia, o setor foi mensurado segundo três agregados: produção, insumos e distribuição. O agregado da produção consiste no valor adicionado da atividade principal, Fabricação de automóveis, caminhões e ônibus. No agregado dos insumos são estimados os valores adicionados de todos os componentes utilizados como insumos na atividade econômica principal. Estima-se, portanto, o valor adicionado para o conjunto de insumos utilizados na fabricação de automóveis (têxteis, borracha, materiais plásticos, peças e componentes, tintas, eletrônicos etc). Da mesma forma, estima-se o total do valor adicionado que é gerado pela distribuição dos produtos finais automóveis, caminhões e ônibus, mediante a contribuição das atividades de Margens de comércio e Margens de transporte. A mesma lógica é utilizada para estimação do pessoal ocupado nos três agregados, sendo possível obter a produtividade (parcial) do fator trabalho no setor e nos agregados.

Assim, estão contemplados no cômputo do valor adicionado do setor automotivo os insumos utilizados na produção de automóveis, caminhões e ônibus, como as peças, 
componentes e acessórios como motores, estofados, e acessórios. Ficam excluídos do cálculo a produção e a distribuição de embarcações, veículos ferroviários e aeronaves, assim como as peças e serviços destinadas a produção desses respectivos bens.

Os dados relativos à evolução do valor adicionado, pessoal ocupado e produtividade do trabalho no período de 1990 a 2002 para os três agregados são apresentados nas Tabelas 8, 9 e 10 a seguir. Do ponto de vista do valor adicionado na economia, o setor automotivo, representava $1,42 \%$ do PIB brasileiro em 2002. Em termos de emprego, essa representatividade é menos expressiva, de forma que o setor responde por $0,9 \%$ do emprego total da economia.

Tabela 8. Evolução do valor adicionado no setor automotivo - 1990 a 2002 (em R\$ mil)

\begin{tabular}{lcccc}
\hline Ano & Insumos & Produção & Distribuição & Total \\
\hline 1990 & 4.909 .056 & 4.247 .696 & 3.969 .048 & 13.125 .800 \\
1991 & 4.781 .690 & 4.867 .234 & 4.355 .244 & 14.004 .168 \\
1992 & 4.525 .859 & 4.665 .702 & 4.348 .307 & 13.539 .868 \\
1993 & 5.293 .226 & 5.763 .555 & 5.036 .093 & 16.092 .873 \\
1994 & 6.086 .071 & 6.524 .147 & 4.873 .614 & 17.483 .832 \\
1995 & 7.121 .341 & 6.776 .144 & 5.510 .484 & 19.407 .969 \\
1996 & 7.888 .174 & 6.822 .641 & 5.287 .987 & 19.998 .802 \\
1997 & 8.691 .168 & 7.859 .768 & 6.529 .567 & 23.080 .503 \\
1998 & 6.781 .811 & 6.284 .532 & 5.754 .822 & 18.821 .166 \\
1999 & 5.618 .553 & 5.382 .528 & 4.408 .905 & 15.409 .986 \\
2000 & 7.059 .987 & 6.719 .832 & 5.380 .947 & 19.160 .767 \\
2001 & 6.733 .685 & 6.841 .018 & 5.280 .832 & 18.855 .535 \\
2002 & 6.443 .494 & 6.323 .053 & 4.314 .214 & 17.080 .761 \\
$\begin{array}{l}\text { Taxa de } \\
\text { crescimento }\end{array}$ & & & & \\
médio anual & 2,29 & 3,37 & & \\
(\%) & & & & \\
\hline
\end{tabular}


Tabela 9. Evolução do pessoal ocupado no setor automotivo - 1990 a 2002

\begin{tabular}{lrrrr}
\hline Ano & \multicolumn{1}{c}{ Insumos } & \multicolumn{1}{c}{ Produção } & \multicolumn{1}{c}{ Distribuição } & \multicolumn{1}{c}{ Total } \\
\hline 1990 & 223.128 & 108.400 & 259.151 & 590.679 \\
1991 & 210.120 & 96.500 & 291.436 & 598.056 \\
1992 & 193.738 & 85.900 & 284.597 & 564.235 \\
1993 & 205.310 & 87.700 & 307.444 & 600.455 \\
1994 & 220.711 & 90.200 & 309.372 & 620.282 \\
1995 & 249.824 & 87.900 & 339.120 & 676.844 \\
1996 & 328.558 & 79.200 & 290.941 & 698.699 \\
1997 & 352.872 & 81.800 & 342.737 & 777.409 \\
1998 & 283.098 & 67.500 & 304.804 & 655.402 \\
1999 & 237.446 & 72.500 & 228.039 & 537.986 \\
2000 & 300.949 & 80.000 & 282.883 & 663.832 \\
2001 & 291.281 & 78.300 & 269.828 & 639.409 \\
2002 & 282.162 & 75.200 & 246.880 & 604.241 \\
Taxa de crescimento & 1,98 & $(3,00)$ & $(0,40)$ & 0,19 \\
médio anual (\%) & & & & \\
\hline
\end{tabular}

Interessante observar que os agregados da produção e dos insumos se assemelham em termos de participação na geração total do valor adicionado do setor, como indica a Tabela 8. Deve-se atentar para o fato de que os valores apresentados se referem a valores em reais a preços de 2002. Avaliando o deflator implícito do valor adicionado para a atividade Automóveis, caminhões e ônibus, observa-se uma variação negativa de $11,4 \%$ em 2002, muito superior a variação dos preços nas atividades que compõem o agregados dos insumos, como por exemplo a Fabricação de outros veículos, peças e acessórios, que registrou uma variação de $-6,4 \%$.

O agregado dos insumos, além da importância relativa perante os outros dois agregados em termos de geração de valor adicionado, contribui para a parcela mais significativa de pessoal ocupado do setor (Figura 5). Em 2002, essa parcela era de 37,72 \%. No período de 1990 a 2002, este foi o único agregado que apresentou uma taxa média de crescimento anual do pessoal ocupado positiva, de 1,98\%. Para o mesmo período, verificam-se, respectivamente, taxas médias anuais de crescimento negativas de $3,00 \%$ e $0,40 \%$ nos agregados da produção e dos serviços. 


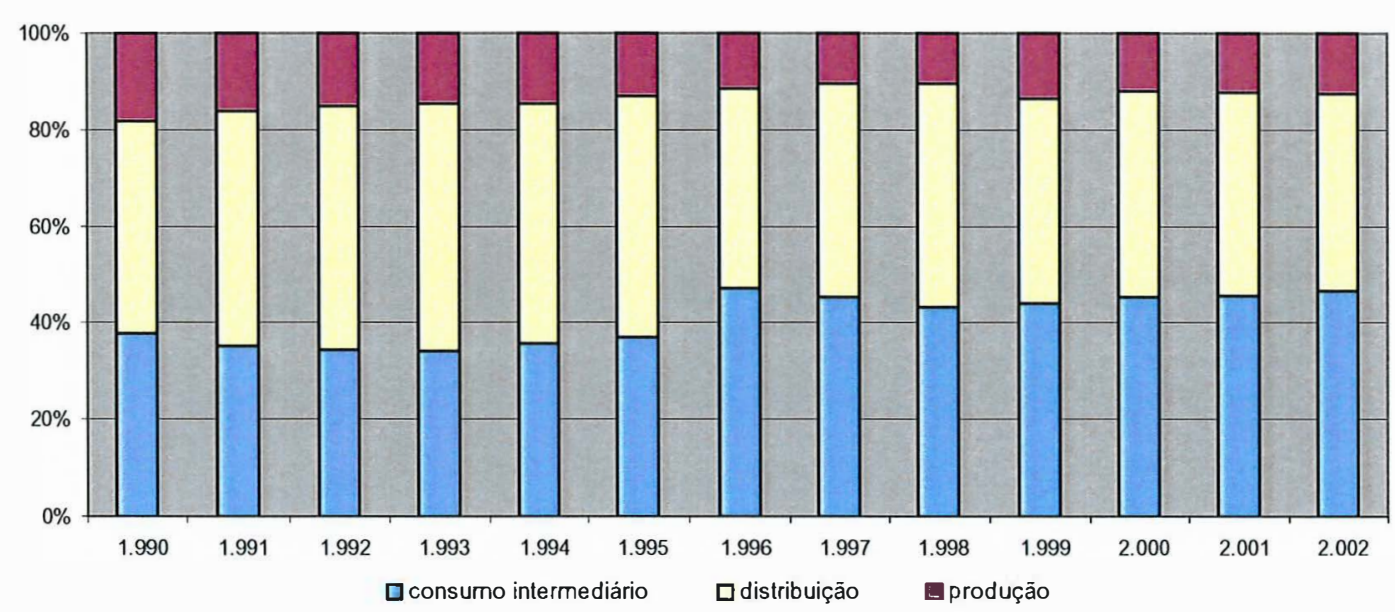

Figura 5 - Participação no pessoal ocupado total do setor automotivo segundo agregados (consumo intermediário, produção, distribuição) - 1990 a 2002

Como observado na revisão de literatura, nos anos de 1996 e 1997, impulsionada pelo desempenho da indústria automobilística, a indústria de autopeças registrou crescimento. O reflexo do crescimento no setor automotivo pode ser observado na Figura 6. 


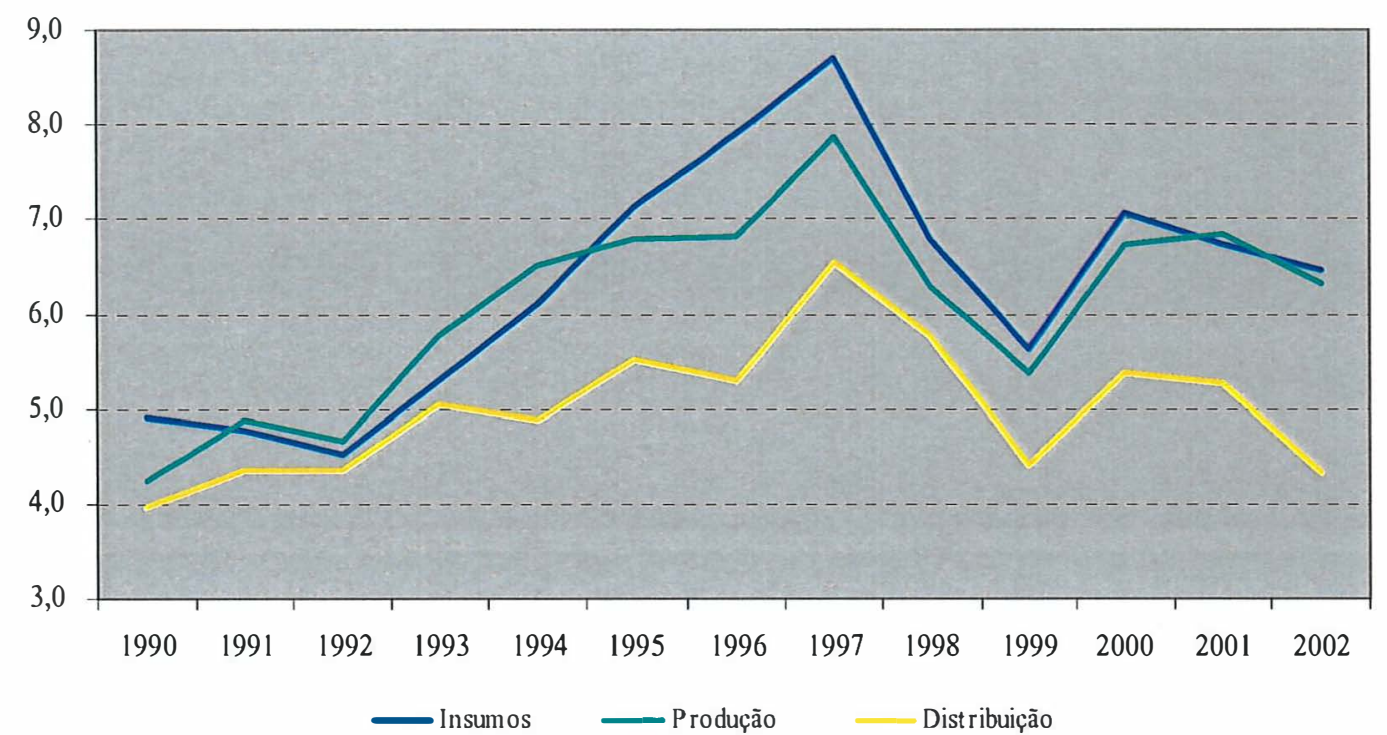

Figura 6 - Evolução do valor adicionado no setor automotivo segundo agregados - 1990 a 2002 (em bilhões de R\$)

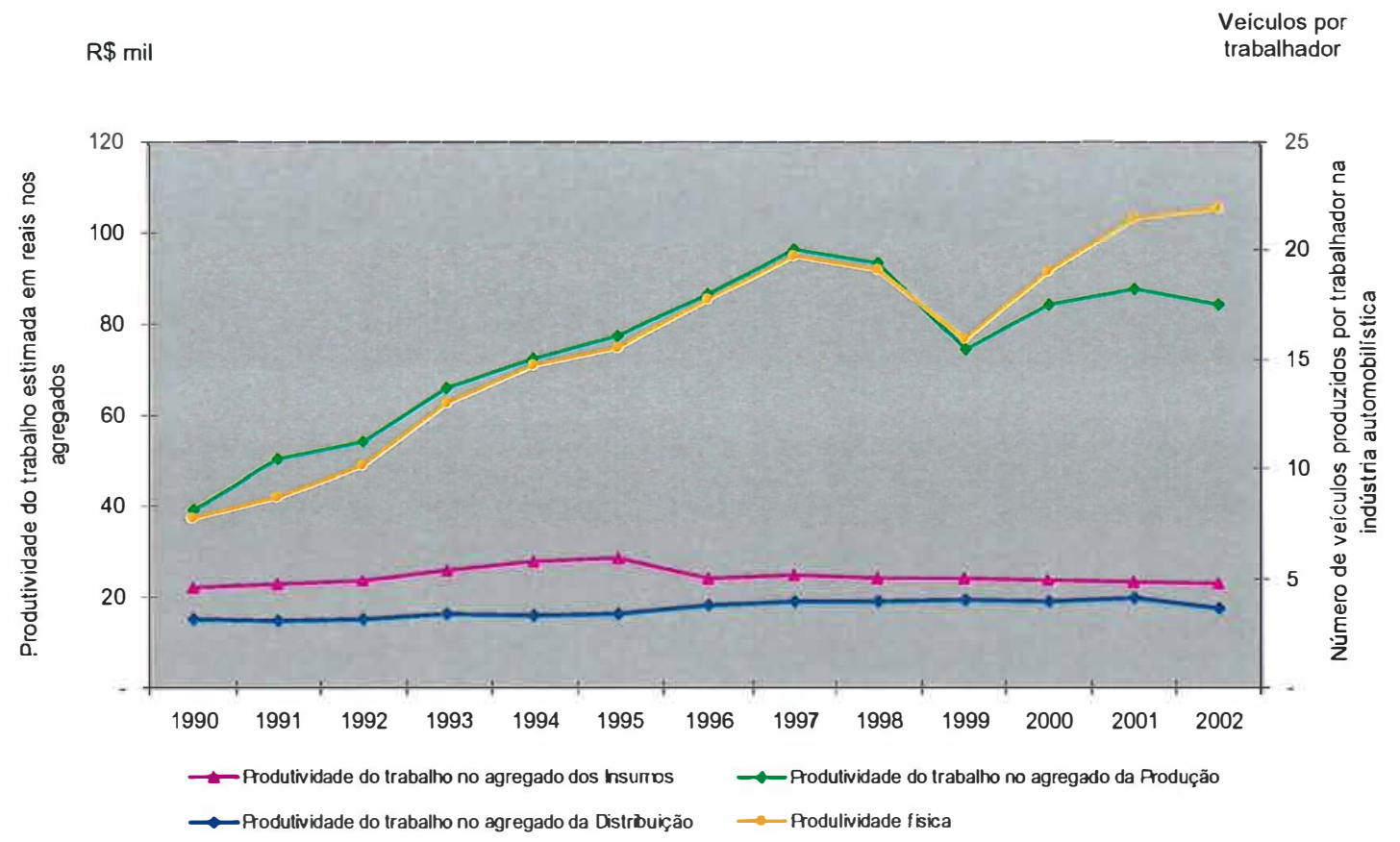

Figura 7 - Evolução da produtividade do trabalho no setor automotivo segundo agregados - 1990 a 2002 
No que se refere a evolução da produtividade do fator trabalho ${ }^{15}$, é esperado que seus níveis sejam mais elevados no agregado da produção, como mostra Figura 7. Considerando o período como um todo, verifica-se o crescimento da produtividade do trabalho no setor em todos os agregados, mas especialmente observado no agregado da produção, da ordem de 6,57\% ao ano, em média (Tabela 10). É interessante observar no entanto, que neste mesmo agregado, nos anos de 1998, 1999 e 2002, observa-se o declínio da produtividade do trabalho. De maneira menos acentuada, esse declínio também é registrado no agregado dos insumos a partir de 1997 e no agregado da distribuição em 1998 e 2002.

Cabe ressaltar que, segundo a teoria econômica, com os investimentos de capital observados no setor seria esperado uma elevação da produtividade do trabalho e não declínio neste período. Sobre essa discussão, alguns pontos merecem ser mencionados. Em primeiro lugar, as matrizes estimadas para os anos a partir de 1997 são matrizes estimadas a partir do SCN. Portanto, os valores estimados a preços básicos, tem como base de cálculo os valores a preços do consumidor divulgados pelo SCN.

Em segundo lugar, os dados de produtividade do trabalho, mensurados em Reais $^{16}$, não expressam a relação entre quantidades desejável para um indicador de produtividade. Mesmo que os dados reflitam as alterações dos preços dos bens finais de cada atividade econômica, o crescimento observado na produção de automóveis por trabalhador na indústria automobilística confirma o aumento de produtividade expressivo deste fator de produção. Segundo os dados da Anfavea (2004), em 1990 eram produzidos 7,79 autoveículos por trabalhador na indústria automobilística brasileira. Em 2002, cada trabalhador produziu o equivalente a 21,92 autoveículos. Isso significa um crescimento médio de $9,0 \%$ ao ano. A mesma queda da produtividade estimada para o agregado da produção é observada na evolução da produtividade fisica do fator trabalho.

\footnotetext{
${ }^{15} \mathrm{~A}$ forma mais adequada de captar as variações de produtividade é mediante o cálculo da produtividade total dos fatores. Seu cômputo, entretanto, requer uma série do estoque de capital, indisponível em nível setorial nas estatísticas sistemáticas e oficiais do Sistema de Contas Nacionais do Brasil.

${ }^{16}$ Os dados das matrizes insumo-produto são divulgados somente em valores monetários para que os fluxos entre os setores sejam comparáveis entre si.
} 
É pertinente também observar os elevados níveis de capacidade ociosa com que o setor vem operando na economia brasileira.

Tabela 10. Evolução da produtividade do trabalho no setor automotivo - 1990 a 2002 (em R \$ mil)

\begin{tabular}{lrrrr}
\hline Ano & Insumos & Produção & Distribuição & \multicolumn{1}{c}{ Total } \\
\hline 1990 & 22,00 & 39,19 & 15,32 & 22,22 \\
1991 & 22,76 & 50,44 & 14,94 & 23,42 \\
1992 & 23,36 & 54,32 & 15,28 & 24,00 \\
1993 & 25,78 & 65,72 & 16,38 & 26,80 \\
1994 & 27,57 & 72,33 & 15,75 & 28,19 \\
1995 & 28,51 & 77,09 & 16,25 & 28,67 \\
1996 & 24,01 & 86,14 & 18,18 & 28,62 \\
1997 & 24,63 & 96,09 & 19,05 & 29,69 \\
1998 & 23,96 & 93,10 & 18,88 & 28,72 \\
1999 & 23,66 & 74,24 & 19,33 & 28,64 \\
2000 & 23,46 & 84,00 & 19,02 & 28,86 \\
2001 & 23,12 & 87,37 & 19,57 & 29,49 \\
2002 & 22,84 & 84,08 & 17,47 & 28,27 \\
Taxa de crescimento & 0,31 & 6,57 & 1,11 & 2,03 \\
médio anual (\%) & & & & \\
\hline
\end{tabular}

Um terceiro aspecto refere-se a evolução dos preços dos automóveis e a rentabilidade das montadoras de veículos. Com a maior participação dos carros populares nas vendas domésticas, que eram de 11,3\% em 1991 e em 2002 representam cerca de $66,7 \%$, a rentabilidade das empresas no Brasil tende a cair. Além destes veículos, que possuem preços inferiores aos modelos mais luxuosos e mais potentes responderem pela maior parcela das vendas domésticas, os tributos sobre os automóveis no Brasil são muito elevados. Segundo a Anfavea (2004) os tributos sobre automóveis representam, em média, cerca de $29,0 \%$ do preço ao consumidor. No caso de automóveis de 1000 cilindradas este percentual foi de 25,75 para o triênio 2002/2004. Para efeito de comparação, em países como a Itália, França e Reino Unido, essa participação é de $16,7 \%, 16,4$ e 14,9 \% respectivamente. Este cenário ajuda a contextualizar a evolução declinante do faturamento da indústria automobilística a partir de 1997, que se apresentou mais crítica em 1999, como mostra a Figura 8 a seguir. 


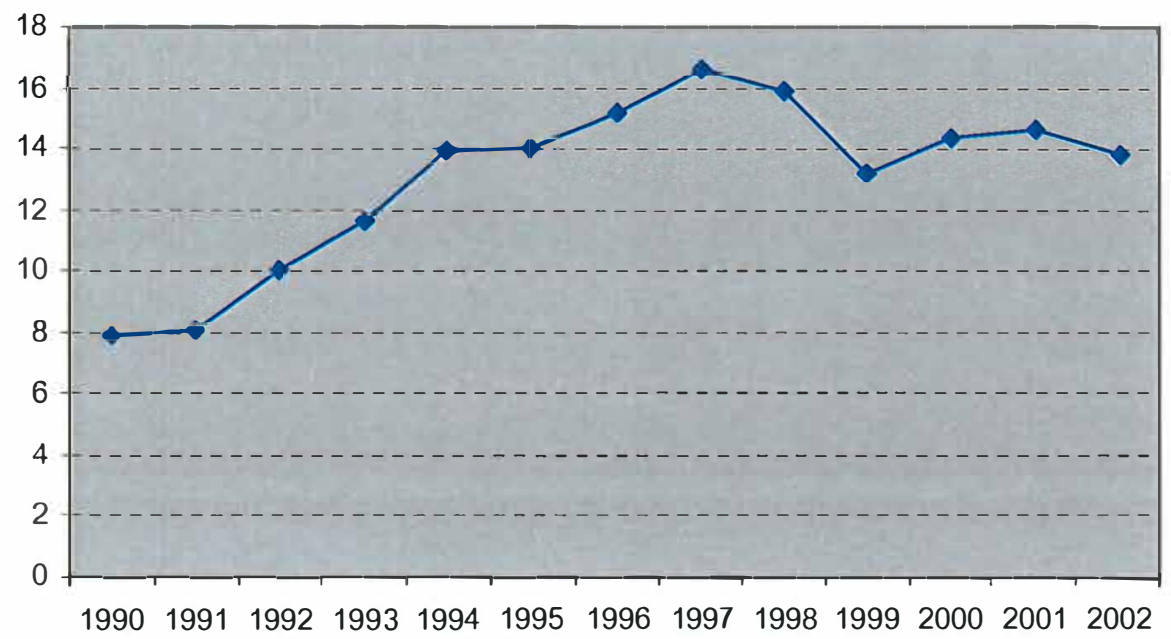

Figura 8 - Faturamento líquido da indústria de autoveículos brasileira - 1990 a 2002 (em bilhões de dólares)

Fonte: Anfavea (2004)

\subsection{Fuzzy clusters}

Os clusters identificados no presente trabalho se referem a agrupamentos de atividades econômicas identificados segundo as similaridades ou semelhança nos perfis das relações de compra e de venda dos setores na estrutura produtiva da economia. Esses clusters são denominados do tipo fuzzy, ou nebulosos, em virtude de considerarem a participação de todas as atividades econômicas em um agrupamento produtivo. As atividades mais importantes em um cluster, são denominadas atividades-líderes, e às demais atribui-se a denominação de atividades-suporte à produção dos bens finnais do cluster.

O primeiro passo no processo de identificação dos clusters consiste em decompor a matriz de uso em uma matriz de similaridade através do método dual scaling. Este procedimento resulta em duas matrizes de similaridade, uma referente às relações de compra e outra referente às relações de venda da economia. As duas matrizes 
resultantes apresentam dimensões $m \times n$, em que $m$ é o número de setores da economia e $n$ o número de variáveis de soluções encontradas na decomposição da matriz de uso original. Os vetores que constituem essas matrizes associam, portanto, cada uma das $n$ variáveis de similaridade encontradas na decomposição da matriz às diferentes atividades econômicas. O número de variáveis encontradas é utilizado para definir o número máximo de clusters da economia. ${ }^{17}$

As matrizes resultantes são submetidas a uma análise de clusters do tipo fuzzy, e geram como resultado matrizes denominadas matrizes de membership, apresentam dimensões $m \times c$, em que $m$ representa o número de setores da economia e $c$ o número de clusters identificados. Essas matrizes representam o grau de relacionamento de cada um dos setores da economia aos clusters. A soma ao longo da linha que representa cada setor nesta matriz é um.

Tendo por base as informações da matriz de membership, obtém-se a matriz de envolvimento. Essa matriz possui dimensões $m \times c$, em que $m$ representa o número de setores da economia e $c$ o número de clusters, como a sua matriz originária. Ao contrário da matriz anterior, os valores ao longo de cada coluna somam um, a fim de que seja captado o quanto uma atividade econômica pertence, ou está envolvida em um cluster, relativamente às demais atividades pertencentes ao mesmo cluster. Segundo Dridi e Hewings (2002a), esta informação consiste em uma medida mais precisa para avaliar o relacionamento das atividades econômicas nos clusters estabelecidos. Uma vez identificados os clusters, são mensurados os graus de dependência entre os clusters.

Neste trabalho, recorreu-se tanto à identificação dos clusters do ponto de vista do sistema inter-regional e das regiões isoladas para o ano de 1999, quanto do ponto de vista nacional, tendo por base as matrizes insumo-produto nacionais dos anos de $1990 \mathrm{e}$ 2002. Os resultados são discutidos com maior detalhe a seguir.

\footnotetext{
${ }^{17} \mathrm{O}$ procedimento é realizado no software SPLUS.
} 


\subsubsection{Sistema inter-regional}

A decomposição do sistema inter-regional utilizado, composto por 186 atividades econômicas, permite identificar um número máximo de 91 clusters. A Tabela 11 mostra cada um dos clusters identificados de acordo com os perfis de compra, segundo as atividades que apresentam o maior coeficiente de membership. Essas atividades são denominadas atividades-líderes do cluster. Na tabela os clusters são apresentados na ordem em que são identificados pelo método. Assim, o primeiro cluster apontado é liderado pela atividade Produtos alimentares no Norte.

$\mathrm{Na}$ Tabela 12, por sua vez, são apresentadas as atividades econômicas que lideram os clusters considerando os perfis de venda do sistema inter-regional. A leitura desta tabela pode ser feita de maneira similar à Tabela 11. Dessa forma, o primeiro cluster identificado segundo perfis de compra do sistema inter-regional é o cluster liderado pela atividade Agropecuária de São Paulo.

Considerando apenas as atividades relacionadas ao setor automotivo, dez clusters identificados por intermédio das relações de compra apresentam atividades relacionadas ao setor automotivo na liderança. No tocante às relações de venda, esse número corresponde a nove clusters. 
Tabela 11. Clusters segundo perfis de compra no sistema inter-regional 1999

\begin{tabular}{|c|c|c|}
\hline Atividades Lideres & Atividades Lideres & Atividades Lideres \\
\hline $1 \mathrm{~N}$ - Produtos alimentares & $31 \mathrm{NE}$ - Artigos de plásticos & 61 SP - Administração pública \\
\hline $2 \mathrm{~N}$ - Ext. mineral & $32 \mathrm{NE}$ - Vestuário e calçados & 62 SP - Vestuário e calçados \\
\hline $3 \mathrm{~N}$ - Comércio & $33 \mathrm{NE}$ - Ind. diversas & 63 S - Agropecuária \\
\hline $4 \mathrm{~N}$ - Min. não metálicos & 34 NE - Com. Veículos e peças & 64 SP - Ind. diversas \\
\hline 5 SP - Fab. máq. e tratores & $35 \mathrm{NE}$ - Comunicações & $65 \mathrm{SP}$ - Com. Veículos e peças \\
\hline $6 \mathrm{~N}-$ Metalurgia & 36 SP - Agropecuária & 66 SP - Comunicações \\
\hline $7 \mathrm{~N}$ - Mat.elétr. e equip. eletron. & $38 \mathrm{CO}$ - Ext. mineral & 67 RSE - Produtos alimentares \\
\hline $8 \mathrm{~N}$ - Caminhões e ônibus & $38 \mathrm{CO}$ - Serv. privados & 68 RSE - Serv. privados \\
\hline $9 \mathrm{~N}$ - Madeira e mobiliário & 39 CO - Min. não metálicos & 69 RSE - Min. não metálicos \\
\hline $10 \mathrm{~N}$ - Serv privados & $40 \mathrm{CO}$ - Metalurgia & 70 RSE - Metalurgia \\
\hline $11 \mathrm{~N}$ - Ind borracha & $41 \mathrm{CO}$ - Mat.elétr. e equip. eletron. & 71 RSE - Mat.elétr. e equip. eletron. \\
\hline $12 \mathrm{~N}$ - Refino de petróleo & 42 CO - Caminhões e ônibus & 72 RSE - Caminhões e ônibus \\
\hline $13 \mathrm{SP}$ - Químicos diversos & $43 \mathrm{CO}$ - Madeira e mobiliário & 73 RSE - Madeira e mobiliário \\
\hline $14 \mathrm{~N}$ - Farmácia e veterinária & $44 \mathrm{CO}$ - Ind borracha & 74 RSE - Ind borracha \\
\hline 15 SP - Artigos de plásticos & $45 \mathrm{CO}$ - Produtos alimentares & 75 RSE - Refino de petróleo \\
\hline $16 \mathrm{~N}$ - Ind têxtil & 46 CO - Refino de petróleo & 76 RSE - Farmácia e veterinária \\
\hline $17 \mathrm{~N}-$ SIUP & 47 CO - Farmácia e veterinária & 77 RSE - Ind têxtil \\
\hline $18 \mathrm{~N}$ - Transporte & $48 \mathrm{CO}$ - Ind têxtil & 78 RSE - SIUP \\
\hline 19 NE - Agropecuária & 49 S - Vestuário e calçados & 79 RSE - Transporte \\
\hline 20 NE - Administração pública & 50 CO - SIUP & $80 \mathrm{~S}$ - Administração pública \\
\hline 21 NE - Ext. petr., gás, carvão & 51 CO - Comércio & 81 S - Ext. petr., gás, carvão \\
\hline 22 NE - Construção civil & $52 \mathrm{CO}$ - Transporte & 82 S - Construção civil \\
\hline $23 \mathrm{NE}$ - Siderurgia & 53 RSE - Ext. mineral & $83 \mathrm{~S}$ - Siderurgia \\
\hline $24 \mathrm{NE}$ - Fab. máq. e tratores & 54 SP - Ext. petr., gás, carvão & $84 \mathrm{~S}$ - Fab. máq. e tratores \\
\hline $25 \mathrm{NE}$ - Automóveis & 55 SP - Construção civil & 85 S - Automóveis \\
\hline $26 \mathrm{NE}$ - Peças e outros veículos & 56 SP - Siderurgia & $86 \mathrm{~S}$ - Peças e outros veículos \\
\hline 27 NE - Celulose papel e gráfica & 57 SP - Automóveis & 87 S - Celulose papel e gráfica \\
\hline $28 \mathrm{NE}$ - Elem. químicos & $58 \mathrm{SP}$ - Peças e outros veículos & $88 \mathrm{~S}-$ Elem. químicos \\
\hline 29 RSE - Comércio & 59 SP - Celulose papel e gráfica & 89 S - Artigos de plásticos \\
\hline $30 \mathrm{NE}$ - Químicos diversos & $60 \mathrm{SP}$ - Elem. químicos & $\begin{array}{l}90 \mathrm{~S} \text { - Químicos diversos } \\
91 \mathrm{~S} \text { - Ind. diversas }\end{array}$ \\
\hline
\end{tabular}


Tabela 12. Clusters segundo perfis de venda no sistema inter-regional 1999

\begin{tabular}{|c|c|c|c|c|}
\hline atividades líderes & & atividades líderes & & atividades líderes \\
\hline 1 SP - Agropecuária & 31 & NE - Artigos de Plásticos & 61 & SP - Com. Veículos e peças \\
\hline $2 \mathrm{~N}-$ Ext. mineral & 32 & NE - Vestuário e calçados & 62 & SP - Administração Pública \\
\hline 3 NE - Extr.petr.gás, carvão & 33 & $\mathrm{NE}$ - Indústrias diversas & 63 & Nenhuma atividade \\
\hline $4 \mathrm{~N}$ - Min. não metálicos & 34 & NE - Administração Pública & 64 & RSE - Extrativa mineral \\
\hline $6 \mathrm{SP}$ - Máquinas e tratores & 35 & $\mathrm{NE}$ - Com. Veículos e peças & 65 & RSE - Minerais não metálicos \\
\hline $5 \mathrm{~N}$ - Metalurgia & 36 & Nenhuma atividade & 66 & RSE - Metalurgia \\
\hline $7 \mathrm{~N}$ - Comércio & 37 & CO - Extrativa mineral & 67 & RSE - Comércio \\
\hline $8 \mathrm{~N}$ - Mat.elétr. e equip. eletron. & 38 & CO - Minerais não metálicos & 68 & RSE - Mat.elétr. e equip. eletron. \\
\hline $9 \mathrm{~N}$ - Caminhões e ônibus & 39 & $\mathrm{CO}$ - Metalurgia & 69 & RSE - Caminhões e Ônibus \\
\hline $10 \mathrm{~N}$ - Madeira e mobiliário & 40 & CO - Serviços Privados & 70 & RSE - Madeira e Mobiliário \\
\hline $11 \mathrm{~N}$ - Ind borracha & 41 & CO - Mat.elétr. e equip. eletron. & 71 & RSE - Ind Borracha \\
\hline 12 SP - Químicos Diversos & 42 & CO - Caminhões e Ônibus & 72 & RSE - Refino de petróleo \\
\hline $13 \mathrm{~N}$ - Refino de petróleo & 43 & CO - Madeira e Mobiliário & 73 & RSE - Farmácia e Veterinária \\
\hline $14 \mathrm{~N}$ - Farmácia e veterinária & 44 & CO - Ind Borracha & 74 & RSE - Industria Têxtil \\
\hline $15 \mathrm{~N}$ - Ind têxtil & 45 & CO - Refino de petróleo & 75 & RSE - SIUP \\
\hline $16 \mathrm{~N}$ - Produtos alimentares & 46 & CO - Farmácia e Veterinária & 76 & RSE - Transporte \\
\hline $17 \mathrm{~N}-$ SIUP & 47 & CO - Industria Têxtil & 77 & RSE - Serviços Privados \\
\hline $18 \mathrm{~N}$ - Serv. privados & 48 & CO - SIUP & 78 & S - Agropecuária \\
\hline $19 \mathrm{~N}$ - Transporte & 49 & CO - Comércio & 79 & S - Máquinas e tratores \\
\hline $20 \mathrm{NE}$ - Agropecuária & 50 & CO - Transporte & 80 & S - Extr.petr.gás, carvão \\
\hline 21 SP - Artigos de Plásticos & 51 & SP - Extr.petr.gás, carvão & 81 & S - Construção civil \\
\hline $22 \mathrm{NE}$ - Siderurgia & 52 & SP - Construção civil & 82 & S - Siderurgia \\
\hline $23 \mathrm{NE}$ - Máquinas e tratores & 53 & SP - Siderurgia & 83 & S - Artigos de Plásticos \\
\hline 24 NE - Automóveis & 54 & SP - Automóveis & 84 & S - Automóveis \\
\hline $25 \mathrm{NE}$ - Pecas e Outros veículos & 55 & SP - Pecas e Outros veículos & 85 & S - Pecas e Outros veículos \\
\hline $26 \mathrm{NE}$ - Comunicações & 56 & SP - Celulose Papel e Gráfica & 86 & S - Celulose Papel e Gráfica \\
\hline 27 NE - Celulose Papel e Gráfica & 57 & SP - Elementos Químicos & 87 & S - Elementos Químicos \\
\hline $28 \mathrm{NE}$ - Elementos Químicos & 58 & SP - Comunicações & 88 & S - Químicos Diversos \\
\hline $29 \mathrm{NE}$ - Químicos Diversos & 59 & SP - Vestuário e calçados & 89 & S - Vestuário e calçados \\
\hline \multirow[t]{2}{*}{$30 \mathrm{NE}$ - Construção civil } & 60 & SP - Indústrias diversas & 90 & S - Indústrias diversas \\
\hline & & & 91 & S - Administração Pública \\
\hline
\end{tabular}


A Tabela 13 apresenta para todos os clusters identificados relacionados ao setor automotivo, as atividades econômicas com os maiores graus de envolvimento. Foram selecionadas 20 atividades econômicas, além da atividade-líder, que é utilizada como denominação do cluster. As demais atividades pertencentes ao cluster são denominadas atividades-suporte. Dessa forma, a atividade Caminhões e ônibus do Norte, que lidera o oitavo cluster identificado, apresenta um envolvimento de 61,29\% no cluster. Em seguida, aparecem segundo a importância do setor no cluster, as atividades de Automóveis do Norte e Extração de petróleo e gás no Centro-Oeste, com 0,96\% e $0,58 \%$ respectivamente.

Da mesma forma, a Tabela 14 apresenta o grau de envolvimento dos principais setores dos clusters segundo perfis de venda liderados por atividades do setor automotivo.

As mesmas atividades-líderes são observadas segundo os perfis de venda e segundo os perfis de compra considerando os clusters do setor automotivo. Destaca-se sobretudo a região de São Paulo, onde as atividades Automóveis, peças e outros veículos lideram clusters distintos. Cabe observar também que a atividade de Comércio de peças e veículos de São Paulo, relacionada ao setor automotivo também lidera um cluster no sistema. Aparecem como atividades-líderes de clusters ainda: Caminhões e Ônibus no resto do Sudeste, Automóveis e peças e outros veículos nos Sul, Caminhões e Ônibus no Centro-Oeste, Automóveis e peças e outros veículos no Nordeste e Caminhões no Norte.

Observa-se que os clusters identificados segundo perfis de compra nas regiões Norte e Centro-oeste e Nordeste (N - Caminhões e ônibus, NE - Automóveis e NE peças e outros veículos) se caracterizam por apresentarem em grande parte atividades de suporte dessas próprias regiões. Em geral, os clusters de São Paulo (SP - Automóveis , SP -Peças e outros veículos e SP-Comércio de veículos e peças), por sua vez, apontam como atividades suporte principais aquelas pertencentes a própria região de São Paulo, à região Sul e ao Resto do Sudeste. O cluster de Automóveis no Sul demonstra a importância das atividades da própria região e do Resto do Sudeste. Os clusters com maior grau de diversidade regional em atividades suporte são Peças no Sul e Caminhões 
e Ônibus no resto do Sudeste. No que se refere às relações de venda, a presença de atividades suporte da região Norte, Nordeste e Centro-Oeste nos clusters do setor automotivo é bem mais expressiva, especialmente no cluster liderado pela atividade de Comércio de veículos e peças.

Vale ressaltar que a identificação de cluster nas regiões Norte, Nordeste e Centro-Oeste deve ser avaliada com cautela, uma vez que o método identifica os clusters segundo a semelhança nos relacionamentos intersetoriais, não levando em conta o valor da produção total do setor. Nestas regiões, os resultados podem indicar o potencial de desenvolvimento de um cluster.

Um aspecto fundamental é que a relevância produtiva do setor automotivo do resto do Sudeste e de São Paulo não é captada pelo método ao utilizar o sistema interregional. Em outras palavras, o setor automotivo do resto do Sudeste e de São Paulo não está entre as atividades que apresentam os maiores valores de envolvimento setoriais dos clusters automotivos das regiões Norte, Nordeste e Centro-Oeste. Em parte, isso pode ser explicado pelo fato de que o método não considera o valor de produção total do setor, e sim os valores de insumo. 


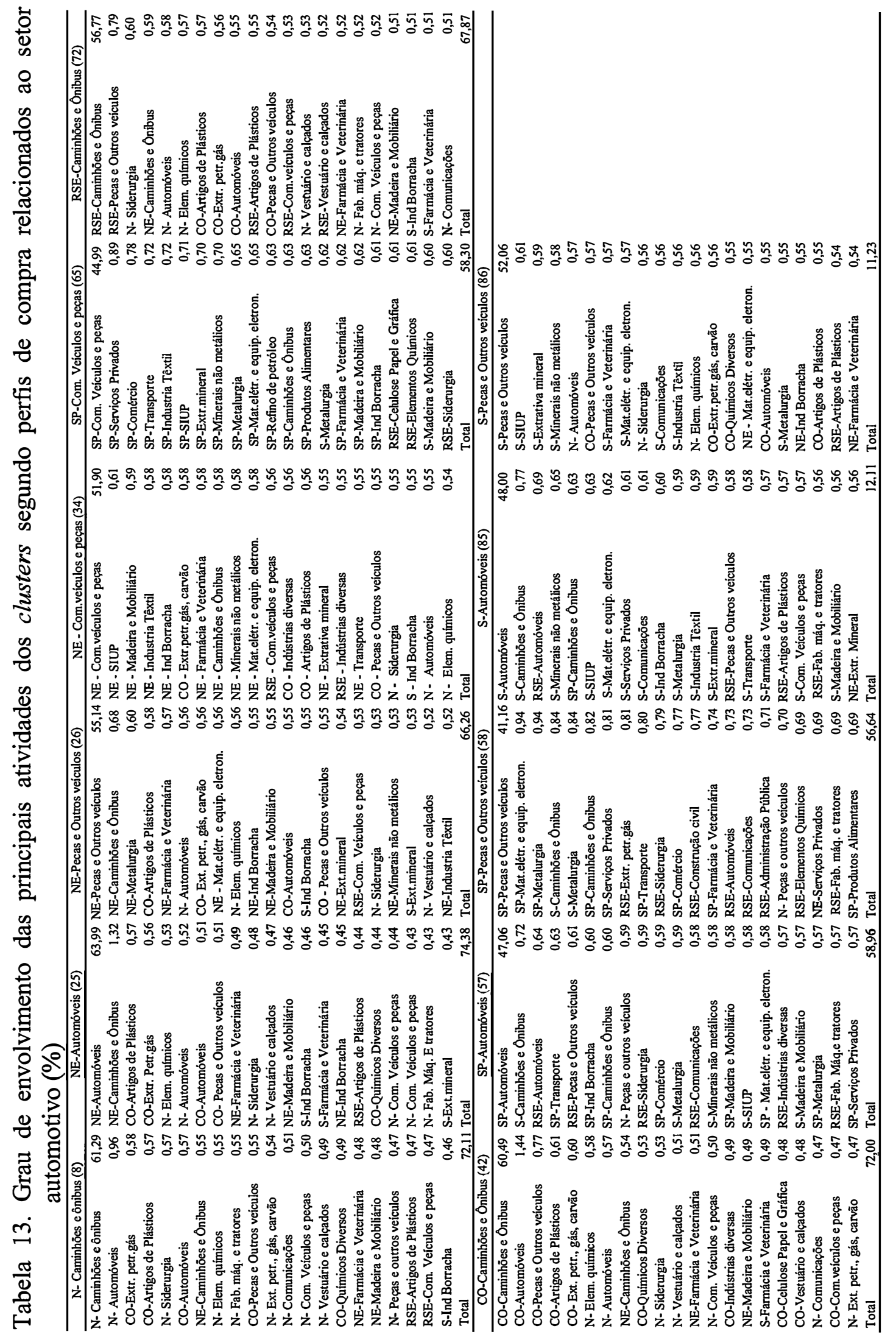




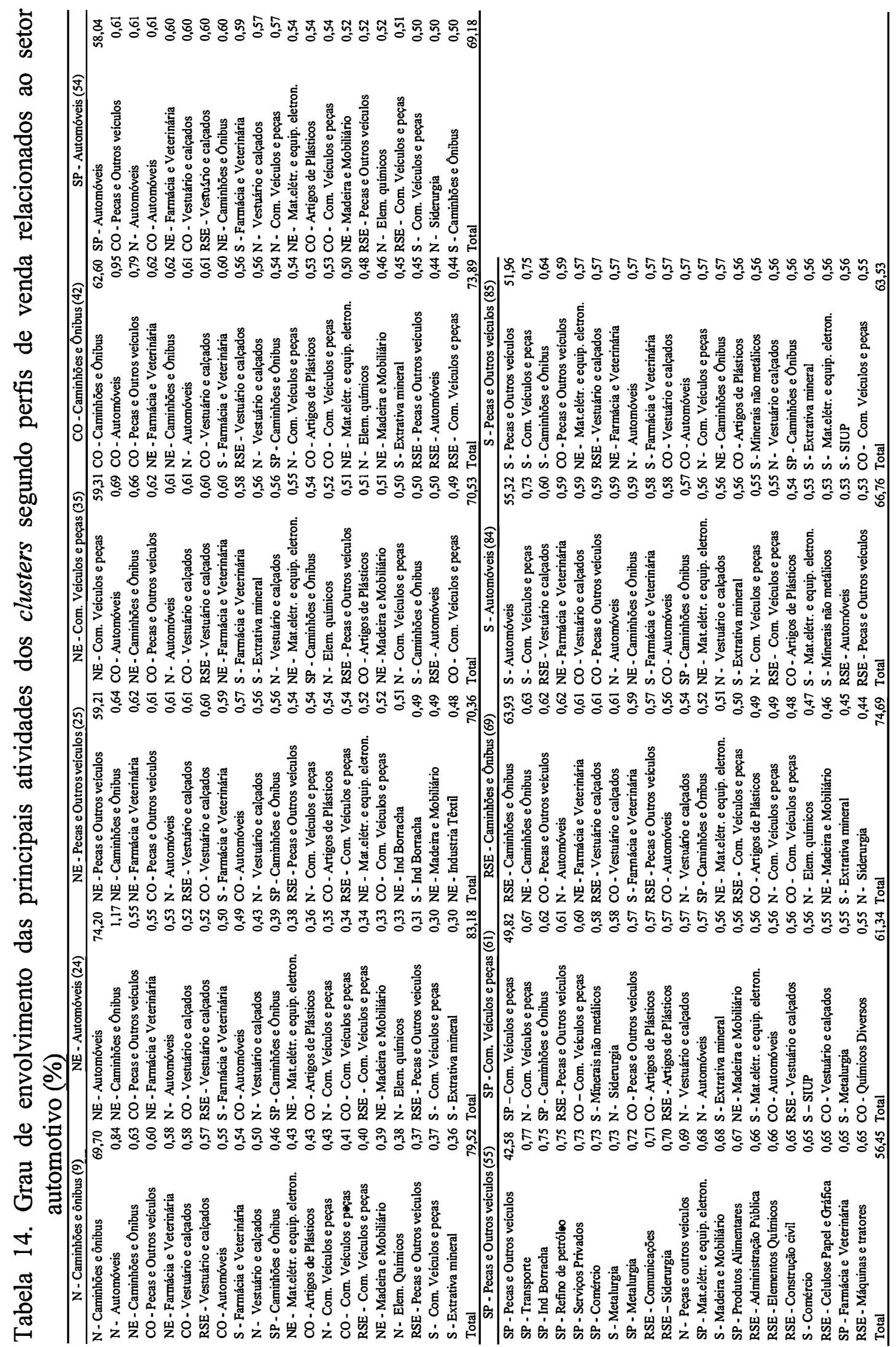


A fim de observar como os clusters se relacionam entre si, avalia-se o seu grau de dependência. $\mathrm{O}$ grau de dependência resulta em uma matriz de dimensões $c \times c$, em que $c$ representa o número de clusters da economia. A diagonal principal apresenta valores iguais a 1, expressando o grau de dependência máximo do setor em relação a si mesmo. As demais células da matriz apresentam valores que variam de zero a um, representando o grau de dependência mútua dos clusters.

Como sugerido por Dridi e Hewings (2002b), optou-se por considerar como grau de dependência relevante aqueles valores superiores a média, ou seja, superiores a 0,5 . Assim, visando observar a dependência entre os clusters do sistema inter-regional completo, a Figura 9 apresenta uma matriz com esses valores estimados para os clusters segundo perfis de compra. Nessa matriz gráfica, os valores superiores a 0,5 aparecem destacados com a cor vermelha, enquanto os valores inferiores a média, são representados pela cor azul.

Note que, na diagonal principal desta matriz, todos os valores estão acima da média. Na verdade, a diagonal expressa a dependência de um determinado cluster com ele mesmo. Dessa forma, os valores encontrados na diagonal principal serão sempre máximos, portanto iguais a um. Os clusters aparecem segundo a ordem em que foram encontrados na análise de cluster, como já indicado na Tabela 11. Segundo a figura, por exemplo, é possível dizer que o cluster de número 88 (liderado pela atividade SElementos químicos), apresenta dependência dos clusters de número 63 (S Agropecuária), 64 (SP - Ind. Diversas), 65 (SP - Com. Veículos e peças), 66 (SP Comunicações) , 67 (RSE - Produtos alimentares), 68 (RSE - Serv. privados ), 69 (RSE - Min. não metálicos), 70 (RSE - Metalurgia), e assim por diante.

No que tange ao setor automotivo, salientam-se os clusters liderados pelas respectivas atividades econômicas: Automóveis (57), Peças e outros veículos (58) e Comércio veículos e peças (65) de São Paulo; e Automóveis (85) na região Sul, sugerindo a maior importância destas atividades no funcionamento do sistema econômico do que aquelas que não apresentam grau de dependência relevante. 
Destacam-se ainda na economia os clusters liderados pelas atividades Transporte no Norte (18); Agropecuária (19), Administração pública (20), Extração de petróleo (21), Elementos químicos (28), Químicos diversos (30) e Comunicações (35) no Nordeste (37), Metalurgia (40), Comércio (51), Transporte (52) no Centro-Oeste, Extrativa Mineral no Resto do Sudeste (53); Celulose e papel (59), Elementos químicos (60), Administração pública (61), Indústrias diversas (64), Comunicações (66) em São Paulo; Produtos alimentares (67) Serviços privados (68), Minerais não metálicos (69), Metalurgia (70) e Transporte (79) no resto do Sudeste; Agropecuária (63), Administração pública (80), Celulose e papel (87), Artigos de plástico (89) e Indústrias diversas (91) no Sul. 


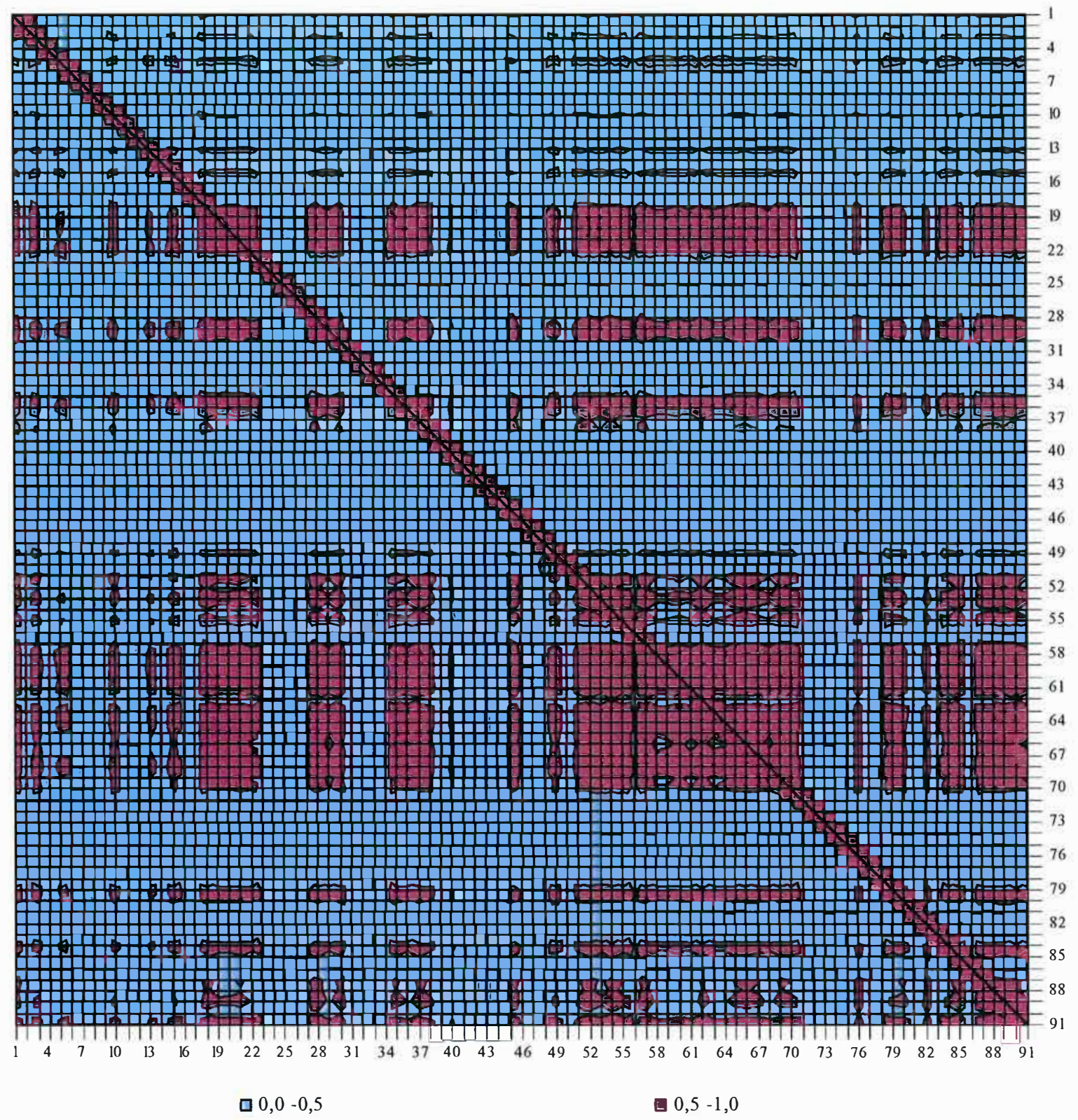

Figura 9 - Grau de dependência entre os clusters segundo perfis de compra no sistema inter-regional - 1999 


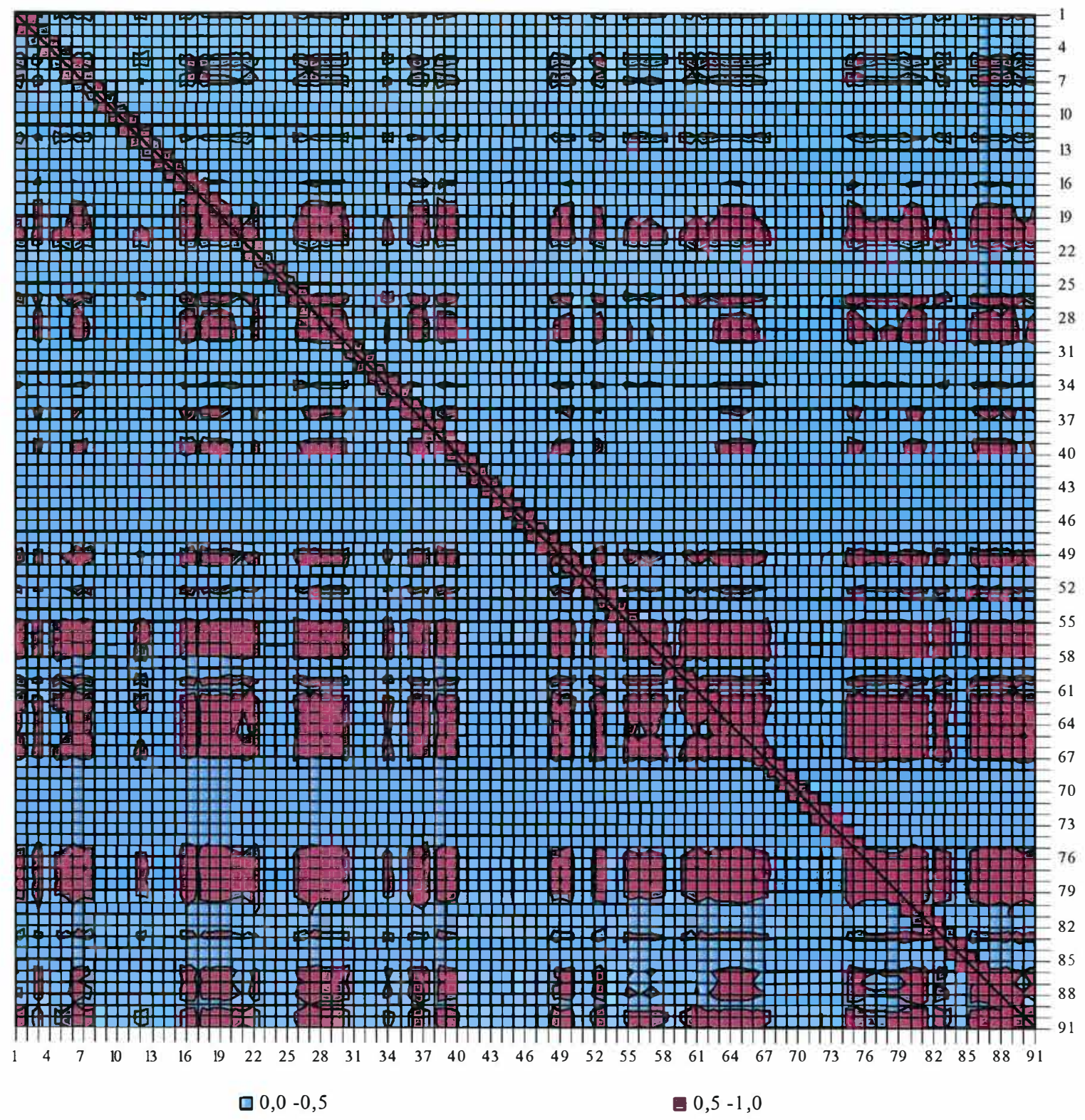

Figura 10 - Grau de dependência entre os clusters segundo perfis de venda no sistema inter-regional -1999 
$\mathrm{Na}$ Figura 10, observa-se a dependência entre os clusters segundo perfis de venda. A interpretação dessa figura é semelhante à Figura 9. Em geral, essa dependência é bem menor do que dos clusters segundo perfis de compra. Este comportamento pode ser explicado pelo fato de que muitos setores, produtores de bens finais, fornecem seus produtos diretamente para demanda final.

No caso do setor automotivo, merecem destaque apenas os clusters liderados pelas atividades Peças e outros veículos de São Paulo (55) e Comércio de veículos e peças (61) de São Paulo.

Outros clusters também se sobressaem em termos de uma dependência ou relacionamento com os demais clusters produtivos acima da média. Merecem destaque Administração pública (34) no Nordeste, Metalurgia (39), Serviços privados (40), Comércio (49), Transporte (50) no Centro- Oeste, Construção civil (52), Peças e Outros veículos (55), Celulose Papel e Gráfica (56), Indústrias diversas (60), Administração Pública (62) em São Paulo, Extrativa mineral (64), Metalurgia (66), Comércio (67), Transporte (76), Serviços privados (77) no Resto do Sudeste, Agropecuária (78), Máquinas e tratores (79), Artigos de Plásticos (83), Celulose Papel e Gráfica (86), Elementos químicos (87), Químicos diversos (88), Indústrias diversas (90), Administração pública (91) no Sul.

\subsubsection{Clusters nas regiões isoladas}

Avaliando isoladamente as regiões do sistema, não considerando, portanto, os fluxos inter-regionais, os resultados observados são muito semelhantes entre as regiões. Os clusters identificados com relação aos perfis de venda e de compra foram, em sua maioria, os mesmos para as regiões analisadas, como pode ser verificado, respectivamente, nas Tabelas 15 e 16. Essas tabelas indicam as atividades econômicas que lideram clusters nas seis regiões. Assim, verifica-se que, por exemplo a atividade Extrativa mineral lidera um cluster em todas as regiões analisadas. 
Tabela 15. Clusters identificados segundo perfis de compras nas regiões isoladas

\begin{tabular}{lcccccc}
\hline \multicolumn{1}{c}{ Atividades econômicas } & Norte & Nordeste & $\begin{array}{c}\text { Centro- } \\
\text { Oeste }\end{array}$ & $\begin{array}{c}\text { São } \\
\text { Paulo }\end{array}$ & $\begin{array}{c}\text { Resto do } \\
\text { Sudeste }\end{array}$ & Sul \\
\hline Ext. mineral & $\mathrm{x}$ & $\mathrm{x}$ & $\mathrm{x}$ & $\mathrm{x}$ & $\mathrm{x}$ & $\mathrm{x}$ \\
Min. não metálicos & $\mathrm{x}$ & $\mathrm{x}$ & $\mathrm{x}$ & $\mathrm{x}$ & $\mathrm{x}$ & $\mathrm{x}$ \\
Metalurgia & $\mathrm{x}$ & $\mathrm{x}$ & $\mathrm{x}$ & $\mathrm{x}$ & $\mathrm{x}$ & $\mathrm{x}$ \\
Mat.elétr. e equip. eletron. & $\mathrm{x}$ & $\mathrm{x}$ & $\mathrm{x}$ & $\mathrm{x}$ & $\mathrm{x}$ & $\mathrm{x}$ \\
Caminhões e ônibus & $\mathrm{x}$ & $\mathrm{x}$ & $\mathrm{x}$ & $\mathrm{x}$ & $\mathrm{x}$ & $\mathrm{x}$ \\
Madeira e mobiliário & $\mathrm{x}$ & $\mathrm{x}$ & $\mathrm{x}$ & $\mathrm{x}$ & $\mathrm{x}$ & $\mathrm{x}$ \\
Ind borracha & $\mathrm{x}$ & $\mathrm{x}$ & $\mathrm{x}$ & $\mathrm{x}$ & $\mathrm{x}$ & $\mathrm{x}$ \\
Refino de petróleo & $\mathrm{x}$ & $\mathrm{x}$ & $\mathrm{x}$ & $\mathrm{x}$ & $\mathrm{x}$ & $\mathrm{x}$ \\
Farmácia e veterinária & $\mathrm{x}$ & $\mathrm{x}$ & $\mathrm{x}$ & $\mathrm{x}$ & $\mathrm{x}$ & $\mathrm{x}$ \\
Ind têxtil & $\mathrm{x}$ & $\mathrm{x}$ & $\mathrm{x}$ & $\mathrm{x}$ & $\mathrm{x}$ & $\mathrm{x}$ \\
Produtos alimentares & $\mathrm{x}$ & $\mathrm{x}$ & $\mathrm{x}$ & $\mathrm{x}$ & $\mathrm{x}$ & $\mathrm{x}$ \\
S.I.U.P. & $\mathrm{x}$ & $\mathrm{x}$ & & $\mathrm{x}$ & $\mathrm{x}$ & $\mathrm{x}$ \\
Comércio & $\mathrm{x}$ & & $\mathrm{x}$ & $\mathrm{x}$ & $\mathrm{x}$ & \\
Administração pública & $\mathrm{x}$ & & $\mathrm{x}$ & $\mathrm{x}$ & $\mathrm{x}$ & \\
\hline
\end{tabular}

Tabela 16. Clusters identificados segundo perfis de vendas nas regiões isoladas

\begin{tabular}{lcccccc}
\hline \multicolumn{1}{c}{ Atividades econômicas } & Norte & Nordeste & $\begin{array}{c}\text { Centro- } \\
\text { Oeste }\end{array}$ & $\begin{array}{c}\text { São } \\
\text { Paulo }\end{array}$ & $\begin{array}{c}\text { Resto do } \\
\text { Sudeste }\end{array}$ & Sul \\
\hline Ext. mineral & $\mathrm{x}$ & $\mathrm{x}$ & $\mathrm{x}$ & $\mathrm{x}$ & $\mathrm{x}$ & \\
Min. não metálicos & $\mathrm{x}$ & $\mathrm{x}$ & $\mathrm{x}$ & $\mathrm{x}$ & $\mathrm{x}$ & $\mathrm{x}$ \\
Metalurgia & $\mathrm{x}$ & $\mathrm{x}$ & $\mathrm{x}$ & $\mathrm{x}$ & $\mathrm{x}$ & $\mathrm{x}$ \\
Mat.elétr. e equip. eletron. & $\mathrm{x}$ & $\mathrm{x}$ & $\mathrm{x}$ & $\mathrm{x}$ & $\mathrm{x}$ & $\mathrm{x}$ \\
Caminhões e ônibus & $\mathrm{x}$ & $\mathrm{x}$ & $\mathrm{x}$ & $\mathrm{x}$ & $\mathrm{x}$ & $\mathrm{x}$ \\
Madeira e mobiliário & $\mathrm{x}$ & $\mathrm{x}$ & $\mathrm{x}$ & $\mathrm{x}$ & $\mathrm{x}$ & $\mathrm{x}$ \\
Ind borracha & $\mathrm{x}$ & $\mathrm{x}$ & $\mathrm{x}$ & $\mathrm{x}$ & $\mathrm{x}$ & $\mathrm{x}$ \\
Refino de petróleo & $\mathrm{x}$ & & $\mathrm{x}$ & $\mathrm{x}$ & $\mathrm{x}$ & $\mathrm{x}$ \\
Farmácia e veterinária & $\mathrm{x}$ & $\mathrm{x}$ & $\mathrm{x}$ & $\mathrm{x}$ & $\mathrm{x}$ & $\mathrm{x}$ \\
Ind têxtil & $\mathrm{x}$ & $\mathrm{x}$ & $\mathrm{x}$ & $\mathrm{x}$ & $\mathrm{x}$ & $\mathrm{x}$ \\
Produtos alimentares & $\mathrm{x}$ & $\mathrm{x}$ & $\mathrm{x}$ & $\mathrm{x}$ & $\mathrm{x}$ & $\mathrm{x}$ \\
S.I.U.P. & $\mathrm{x}$ & $\mathrm{x}$ & & $\mathrm{x}$ & & $\mathrm{x}$ \\
Comércio & & & & & & $\mathrm{x}$ \\
Administração pública & & & & & $\mathrm{x}$ & \\
\hline
\end{tabular}


O grau de envolvimento das atividades econômicas em cada um dos clusters regionais é apresentado no Anexo (Tabelas 42 a 53). Nessas tabelas é possível observar o grau de envolvimento de cada atividade econômica da estrutura produtiva, em relação aos 14 clusters identificados. Cabe mencionar que o método prevê a identificação do número máximo de clusters na região analisada. Assim, considerando os 31 setores, foram identificados 14 clusters em cada região; entretanto, em algumas regiões observam-se clusters mal definidos. Esses clusters não apresentam nenhuma atividade econômica na liderança, verificando-se, ao contrário, a presença de diversas atividades econômicas com coeficientes de membership muito baixos.

Mesmo que, em geral, as mesmas atividades econômicas liderem a maioria dos clusters entre as regiões, a dependência entre os clusters, não considerando os fluxos entre regiões, é bastante distinta. Seguindo a mesma lógica da análise dos clusters do sistema inter-regional, as Figuras 11 e 12 mostram em vermelho, graus de dependência entre os clusters superiores à média da região.

Em linhas gerais, observa-se um maior relacionamento entre os clusters no que se refere aos perfis de compra. Como mencionado, no caso do sistema inter-regional, isso se explica por que os setores produtores de bens finais fornecem seus produtos diretamente para demanda final. Observa-se também que os clusters das regiões Nordeste, Norte e Centro-Oeste são menos dependentes entre si, se comparados às demais regiões analisadas.

No que tange ao setor automotivo, a única atividade econômica apontada como líder em um cluster é atividade Caminhões e Ônibus, em todas as regiões. Essa atividade está representada nas figuras a seguir pelos clusters de número (7) nas regiões Norte, Nordeste, Centro - Oeste, São Paulo, (8) no Resto do Sudeste e (6) no Sul, segundo perfis de compra. Com relação aos perfis de venda, a atividade lidera os clusters de número (7) no Norte, (9) no Nordeste, (8) no Centro-Oeste e Resto do Sudeste e (6) em São Paulo e na região Sul. Em geral, essa atividade apresenta um grau de dependência em relação aos demais clusters superior à média. 

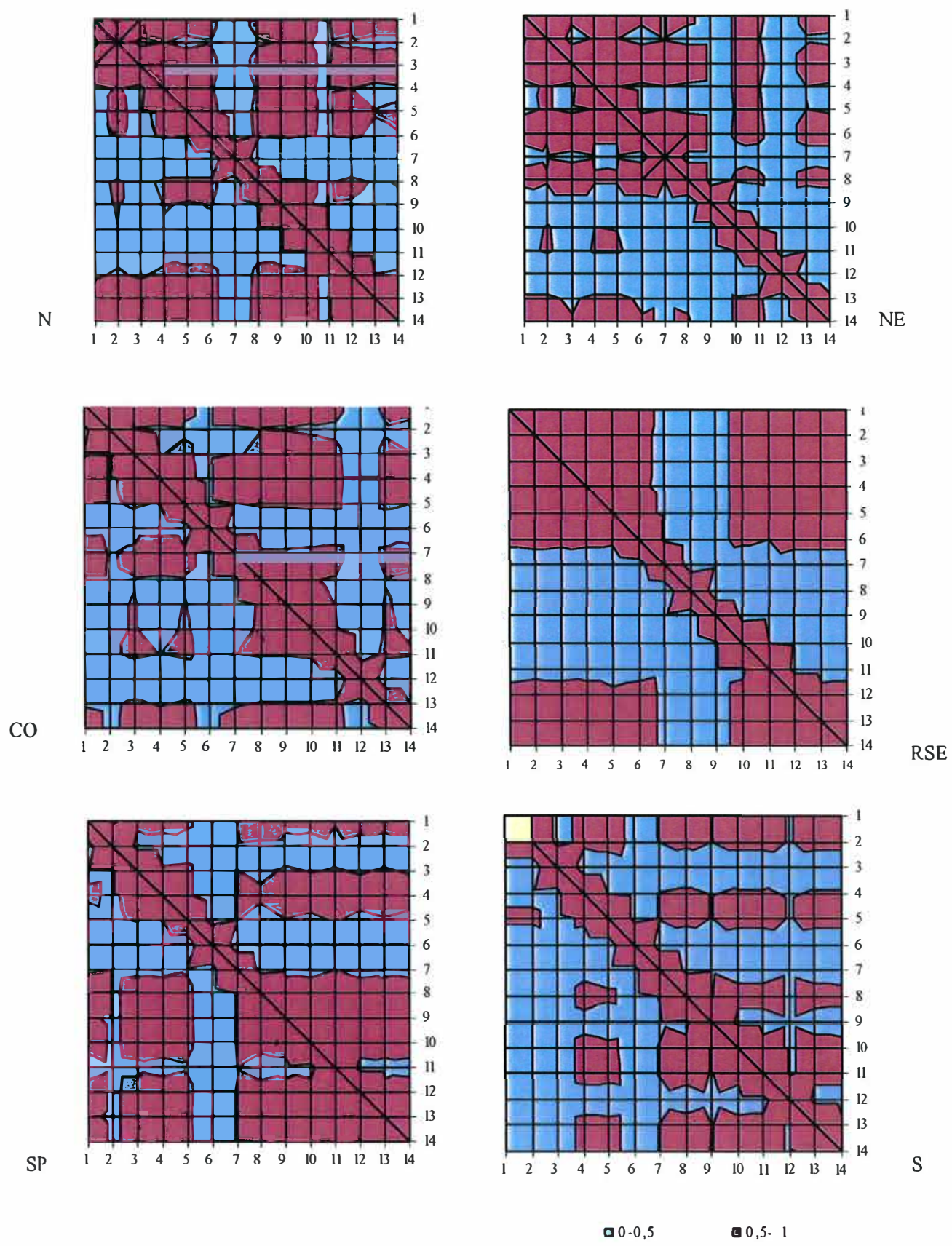

Figura 11 - Grau de dependência dos clusters segundo perfis de venda das regiões 
N
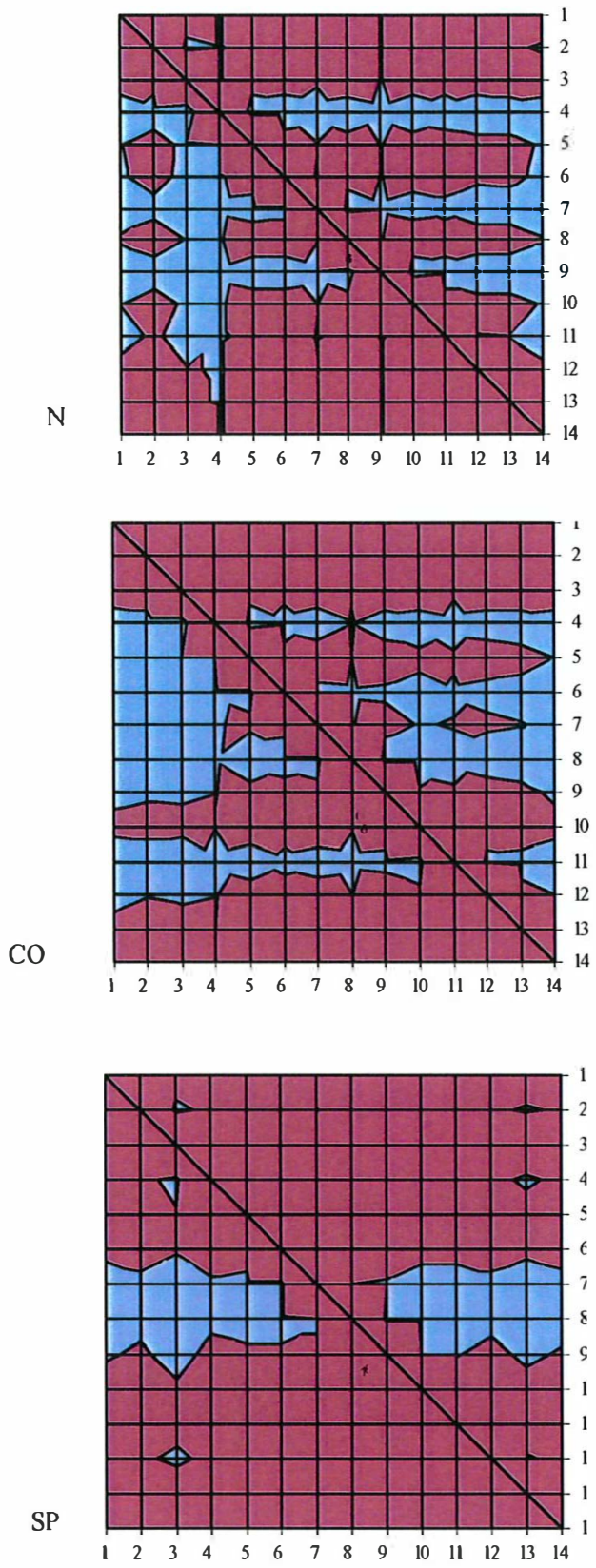
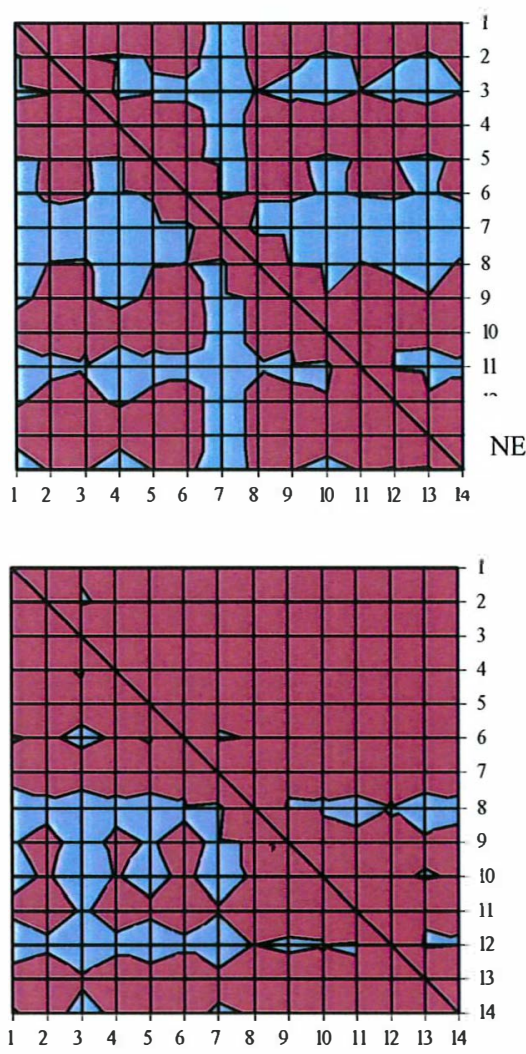

RSE

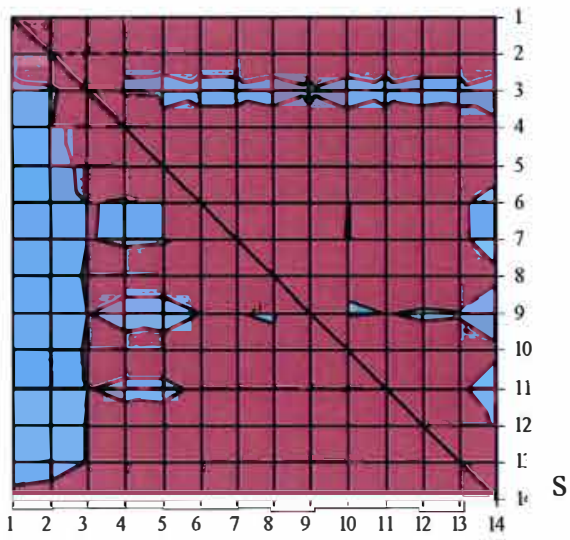

ㅁ0.0, 0 घ0, 5-1

Figura 12 - Grau de dependência dos clusters segundo perfis de compra das regiões 


\subsubsection{Clusters nacionais}

O método de identificação foi aplicado às matrizes da economia brasileira para os anos de 1990 e 2002. Na Tabela 17, é possível observar os clusters identificados segundo os perfis de compra e segundo os perfis de venda para os dois anos. No que se refere ao setor automotivo, destaque pode-se atribuir à atividade de Outros veículos e peças, que lidera um cluster nos dois períodos avaliados.

Tabela 17. Clusters identificados na economia brasileira em 1990 e 2002

\begin{tabular}{|c|c|c|c|c|c|c|}
\hline \multirow[b]{3}{*}{1} & \multicolumn{4}{|c|}{1990} & \multicolumn{2}{|c|}{2002} \\
\hline & Compras & & Vendas & & Compras & Vendas \\
\hline & Administração pública & 1 & Comércio & 1 & Comércio & 1 Comércio \\
\hline 2 & Extrativa mineral & 2 & Extrativa mineral & 2 & Extrativa mineral & 2 Extrativa mineral \\
\hline 3 & Minerais não-metálicos & 3 & Administração pública & 3 & Papel e gráfica & 3 Minerais não-metálicos \\
\hline 4 & Metalúrgia não-ferrosos & 4 & Minerais não-metálicos & 4 & Minerais não-metálicos & 4 Metalúrgia não-ferrosos \\
\hline 5 & Máquinas e tratores & 5 & Metalúrgia não-ferrosos & 5 & Metalúrgia não-ferrosos & 5 Máquinas e tratores \\
\hline 6 & Equipamentos eletrônicos & 6 & Máquinas e tratores & 6 & Máquinas e tratores & 6 Equipamentos eletrônicos \\
\hline 7 & Outros veículos e peças & 7 & Equipamentos eletrônicos & 7 & Administração pública & 7 Outros veículos e peças \\
\hline 8 & Comércio & 8 & Outros veículos e peças & 8 & Equipamentos eletrônicos & 8 Papel e gráfica \\
\hline 9 & Papel e gráfica & 9 & Papel e gráfica & 9 & Outros veículos e peças & 9 Elementos químicos \\
\hline 10 & Elementos químicos & 10 & Químicos diversos & 10 & Elementos químicos & 10 Químicos diversos \\
\hline 11 & Químicos diversos & 11 & Elementos químicos & 11 & Químicos diversos & 11 Artigos de plástico \\
\hline 12 & Artigos de plástico & 12 & Artigos de plástico & 12 & Artigos de plástico & 12 Artigos do vestuário \\
\hline 13 & Artigos do vestuário & 13 & Artigos do vestuário & 13 & Artigos do vestuário & 13 Indústria do café \\
\hline 14 & Indústria do café & 14 & Indústria do café & 14 & Indústria do café & 14 Abate de animais \\
\hline 15 & Abate de animais & 15 & Abate de animais & 15 & Abate de animais & 15 Indústria de açúcar \\
\hline 16 & Indústria de açúcar & 16 & Indústria de açúcar & 16 & Indústria de açúcar & 16 Out. Produtos alimentares \\
\hline 17 & Out. produtos alímentares & 17 & Out. produtos alimentares & 17 & Out. Produtos alimentares & 17 S.I.U.P \\
\hline 18 & S.I.U.P & 18 & S.I.U.P & 18 & S.I.U.P & 18 Comunicações \\
\hline 19 & Comunicações & 19 & Comunicações & 19 & Comunicações & 19 Administração pública \\
\hline
\end{tabular}

A dependência entre os clusters identificados nos dois anos avaliados pode ser observada na Figura 13. Comparando os dois períodos, verifica-se que a estrutura produtiva de 2002 apresenta clusters com menor dependência entre si. Esse padrão se observa tanto nos perfis de compra, como nos perfis de venda da economia. Uma possível explicação para esse comportamento pode ser atribuída à abertura da economia nos anos 90. Com o aumento das importações, as relações econômicas domésticas 
tornaram-se menos densas, uma vez que os insumos importados utilizados em alguns setores possuíam preços e/ou qualidade superiores aos similares nacionais.
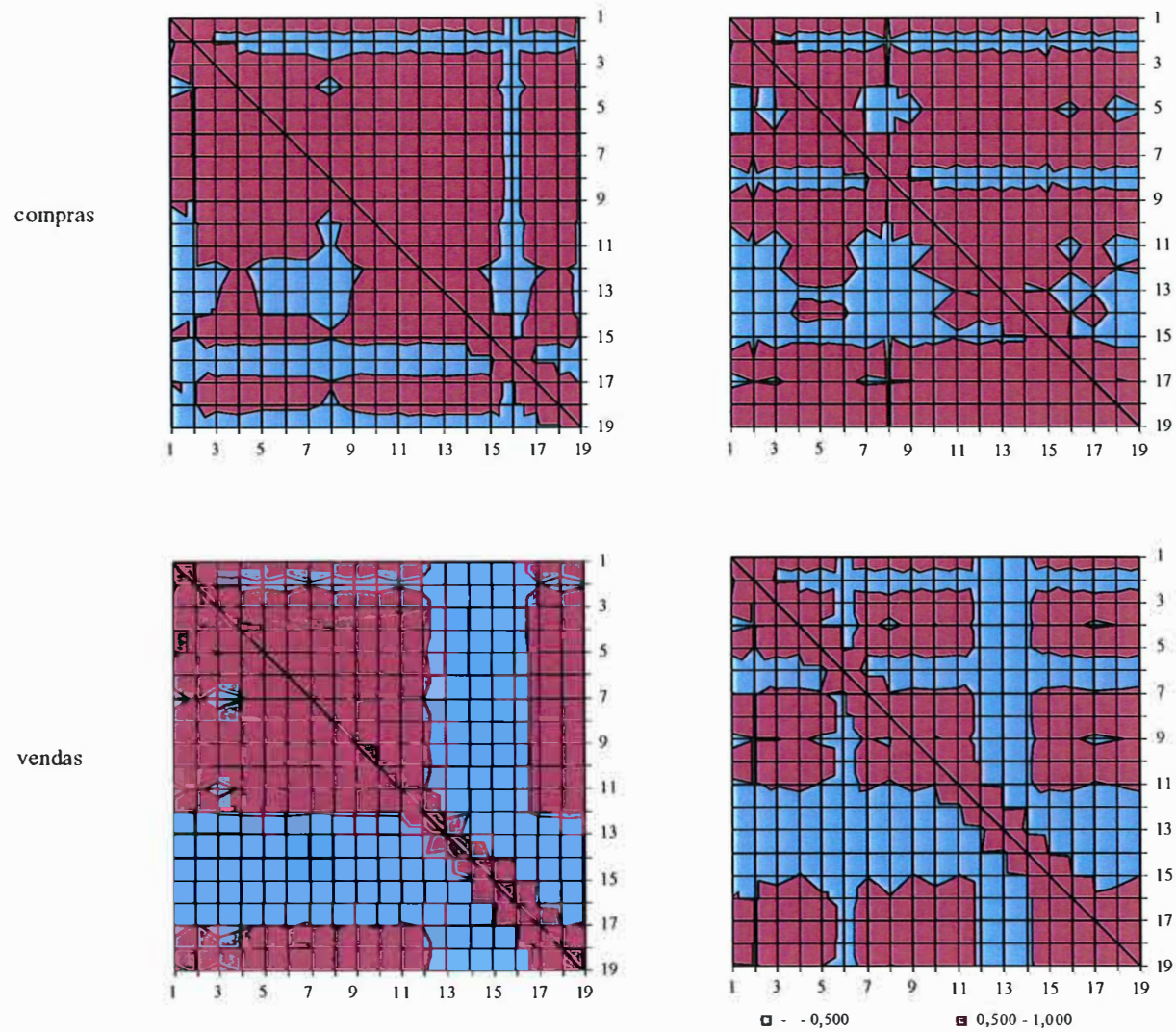

Figura 13 - Grau de dependência dos clusters em 1990 e 2002 
Vale lembrar que a metodologia aplicada trata-se de uma metodologia ainda preliminar, proposta por Dridi e Hewings (2002a e 2000b) e aplicada pelos autores na análise das matrizes de uso da economia dos Estados Unidos. Não se constatou aplicações de outros autores visando analisar os fluxos de insumos da economia brasileira. Simões (2003) aplicou o método obtendo resultados interessantes. O autor se baseou em informações de um matriz de acessibilidade espacial para identificar os fuzzy clusters, não recorrendo, portanto, a decomposição dos fluxos, como sugerem Dridi e Hewings (2002a). Neste caso Simões (2003), identifica clusters com um caráter espacial, diferente do que se propõe nesta análise.

\section{3 Índices de ligações intersetoriais}

A fim de avaliar se os setores pertencentes ao setor automotivo, considerando sua diversidade regional, foram calculados os índices de ligações intersetoriais Rasmussen-Hirschman e os índices puros de ligação para o ano de 1999.

A adoção de um sistema inter-regional permite realizar o cômputo dos índices de ligação de forma isolada para cada uma das regiões constituintes do sistema, obtendo índices independentes, ou ainda, considerando os efeitos de interação que possam ocorrer entre as regiões, obtendo os índices dependentes. Dada a diversidade regional da análise, optou-se por explorar ambos os índices.

Como descrito anteriormente na seção referente à metodologia de cálculo dos índices, as médias relativas a cada série de índices são iguais a um. Por esta razão, os resultados apresentados a seguir se referem a valores relativos à média da economia (região ou sistema inter-regional) analisada.

\subsubsection{Hirschman -Rasmussem}

A definição de setores-chaves por intermédio da análise dos índices de ligação Hirschman-Rasmussem pode ser realizada segundo dois critérios. O primeiro definido por Hirschman-Rasmussem considera como setores-chaves em uma determinada região, 
aqueles que apresentam ao menos um dos seus índices de ligação (para frente ou para trás) superior a um. McGilvray (1977), por sua vez, sugere um critério mais restrito, apontando como setores-chave da economia aqueles que apresentam índices superiores a média da economia tanto nas ligações para frente, quanto para trás, simultaneamente.

a) Índices independentes

A Tabela 18 e a Tabela 19 apresentam os índices de ligação independentes, para frente e para trás, relativos às seis regiões analisadas. No que se refere especificamente aos setores contemplados na definição de setor automotivo adotada no presente trabalho, os setores com índices de ligação para trás superiores à média da economia são a fabricação de Automóveis nas regiões Norte, Nordeste, Centro-Oeste e São Paulo; a fabricação de Caminhões e ônibus em todas as regiões, com exceção da região Sul; e a atividade de Peças e outros veículos no Nordeste, Centro-Oeste, Resto do Sudeste e Sul. Esses setores apresentam, portanto, elevado poder de encadeamento para trás, ou seja, exercem relevante papel na dinâmica da estrutura produtiva de suas regiões como demandantes de bens e serviços na economia.

Já a análise dos índices de ligação para frente do setor automotivo aponta como setores-chaves apenas as atividades de Peças e outros veículos na região Norte e São Paulo. Esse resultado se justifica especialmente pelo fato de que a maior parte do consumo dos produtos provenientes do setor automotivo destina-se diretamente a demanda final, como consumo das famílias e investimentos. A importância relativa desta atividade na região Norte deve-se à presença de empresas fornecedoras de peças e material elétrico para veículos instaladas na Zona Franca de Manaus.

Como as atividades econômicas Peças e outros veículos na região Norte e São Paulo apresentam, simultaneamente, índices de ligação para trás superiores à média da economia, são classificadas como setores-chaves na economia, segundo a abordagem de McGilvray (1977).

Segundo este critério mais restrito, pode-se destacar os seguintes setores-chave nas regiões analisadas: Siderurgia e Indústria têxtil em todas as regiões; Metalurgia em 
todas as regiões com exceção de São Paulo; S.I.U.P. na região Norte; Químicos Diversos, na região Nordeste; Celulose, papel e gráfica; Químicos diversos, Comércio Transporte, em São Paulo; Refino de petróleo, Químicos diversos no resto do Sudeste; Celulose papel e gráfica, Químicos diversos, S.I.U.P. e Comércio na região Sul. 
Tabela 18. Índice de ligação intersetoriais (independentes) de Hirschman-Rasmussen para trás para as regiões Norte $(\mathrm{N})$, Nordeste $(\mathrm{NE})$, Centro Oeste (CO), São Paulo (SP); resto do Sudeste (RSE) e Sul (S) - 1999

\begin{tabular}{|c|c|c|c|c|c|c|c|c|c|c|c|c|c|}
\hline & Atividades econômicas & $\mathrm{N}$ & ord & NE & Ord & $\mathrm{CO}$ & ord & SP & ord & RSE & ord & $\mathbf{S}$ & Ord \\
\hline 1 & Agropecuária & 0,908 & 26 & 0,854 & 25 & 0,783 & 27 & 0,822 & 29 & 0,993 & 14 & 0,815 & 28 \\
\hline 2 & Ext. mineral & 1,002 & 14 & 0,951 & 22 & 0,768 & 29 & 1,006 & 15 & 0,887 & 21 & 1,109 & 9 \\
\hline 3 & Ext. petr., gás, carvão & 0,928 & 23 & 0,799 & 26 & 0,668 & 31 & 0,864 & 25 & 0,788 & 30 & 0,853 & 25 \\
\hline 4 & Min. não metálicos & 1,014 & 11 & 1,041 & 16 & 0,972 & 15 & 1,102 & 5 & 0,975 & 15 & 1,081 & 10 \\
\hline 5 & Siderurgia & 1,378 & 1 & 1,283 & 1 & 1,422 & 1 & 1,458 & 1 & 1,290 & 1 & 1,503 & 1 \\
\hline 6 & Metalurgia & 1,095 & 6 & 1,074 & 13 & 1,298 & 3 & 0,988 & 17 & 1,239 & 2 & 0,865 & 22 \\
\hline 7 & Fab. máq. e tratores & 0,955 & 18 & 0,886 & 24 & 0,885 & 22 & 0,862 & 26 & 0,931 & 19 & 0,787 & 31 \\
\hline 8 & Mat.elétr. e equip. eletron. & 0,850 & 31 & 1,144 & 6 & 1,227 & 5 & 0,965 & 20 & 1,183 & 5 & 1,050 & 12 \\
\hline 9 & Automóveis & 1,003 & 13 & 1,146 & 5 & 1,198 & 6 & 1,061 & 9 & 0,851 & 25 & 0,973 & 17 \\
\hline 10 & Caminhões e ônibus & 1,005 & 12 & 1,134 & 8 & 1,181 & 7 & 1,045 & 10 & 1,163 & 7 & 0,792 & 30 \\
\hline 11 & Peças e outros veículos & 0,877 & 29 & 1,164 & 3 & 1,254 & 4 & 0,993 & 16 & 1,187 & 3 & 1,132 & 7 \\
\hline 12 & Madeira e mobiliário & 1,042 & 9 & 1,044 & 15 & 0,957 & 18 & 1,009 & 14 & 0,937 & 18 & 0,895 & 21 \\
\hline 13 & Celulose papel e gráfica & 1,078 & 7 & 1,135 & 7 & 1,090 & 11 & 1,076 & 7 & 0,972 & 16 & 1,158 & 5 \\
\hline 14 & Ind borracha & 1,043 & 8 & 1,148 & 4 & 1,131 & 10 & 1,043 & 11 & 1,153 & 8 & 1,174 & 4 \\
\hline 15 & Elem. químicos & 0,960 & 17 & 0,971 & 18 & 0,903 & 21 & 0,965 & 19 & 0,872 & 23 & 1,078 & 11 \\
\hline 16 & Refino de petróleo & 1,032 & 10 & 0,959 & 19 & 0,972 & 14 & 0,949 & 21 & 1,126 & 10 & 0,957 & 19 \\
\hline 17 & Químicos diversos & 0,886 & 28 & 1,109 & 9 & 0,997 & 13 & 1,065 & 8 & 1,113 & 12 & 1,179 & 3 \\
\hline 18 & Farmácia e veterinária & 0,949 & 19 & 1,008 & 17 & 1,052 & 12 & 0,878 & 24 & 0,891 & 20 & 1,120 & 8 \\
\hline 19 & Artigos de plásticos & 0,861 & 30 & 1,102 & 11 & 1,179 & 8 & 1,022 & 13 & 1,082 & 13 & 1,000 & 15 \\
\hline 20 & Ind têxtil & 1,163 & 3 & 1,245 & 2 & 1,307 & 2 & 1,293 & 2 & 1,185 & 4 & 1,301 & 2 \\
\hline 21 & Vestuário e calçados & 1,139 & 4 & 1,065 & 14 & 0,905 & 20 & 1,225 & 3 & 1,115 & 11 & 0,906 & 20 \\
\hline 22 & Produtos alimentares & 1,120 & 5 & 1,106 & 10 & 1,162 & 9 & 0,970 & 18 & 1,182 & 6 & 1,142 & 6 \\
\hline 23 & Ind. diversas & 0,978 & 15 & 1,079 & 12 & 0,967 & 17 & 1,037 & 12 & 1,130 & 9 & 0,826 & 26 \\
\hline 24 & SIUP & 1,218 & 2 & 0,956 & 20 & 0,968 & 16 & 0,948 & 22 & 0,962 & 17 & 1,004 & 14 \\
\hline 25 & Construção civil & 0,946 & 20 & 0,755 & 29 & 0,836 & 24 & 0,922 & 23 & 0,885 & 22 & 0,960 & 18 \\
\hline 26 & Comércio & 0,938 & 22 & 0,952 & 21 & 0,876 & 23 & 1,086 & 6 & 0,814 & 27 & 1,007 & 13 \\
\hline 27 & Com. veículos e peças & 0,913 & 24 & 0,711 & 30 & 0,911 & 19 & 0,832 & 28 & 0,799 & 29 & 0,855 & 24 \\
\hline 28 & Transporte & 0,969 & 16 & 0,938 & 23 & 0,825 & 25 & 1,192 & 4 & 0,843 & 26 & 0,995 & 16 \\
\hline 29 & Comunicações & 0,946 & 21 & 0,709 & 31 & 0,740 & 30 & 0,681 & 31 & 0,786 & 31 & 0,820 & 27 \\
\hline 30 & Serv. privados & 0,910 & 25 & 0,757 & 28 & 0,793 & 26 & 0,793 & 30 & 0,812 & 28 & 0,809 & 29 \\
\hline 31 & Administração pública & 0,893 & 27 & 0,776 & 27 & 0,772 & 28 & 0,848 & 27 & 0,853 & 24 & 0,855 & 23 \\
\hline
\end{tabular}


Tabela 19. Índice de ligação intersetoriais (independentes) de Hirschman-Rasmussen para frente para as regiões Norte $(\mathrm{N})$, Nordeste (NE), Centro Oeste (CO), São Paulo (SP), resto do Sudeste (RSE) e Sul (S) - 1999

\begin{tabular}{|c|c|c|c|c|c|c|c|c|c|c|c|c|c|}
\hline & Atividades econômicas & $\mathbf{N}$ & ord & $\mathrm{NE}$ & ord & $\mathrm{CO}$ & ord & SP & ord & RSE & ord & $\mathrm{S}$ & ord \\
\hline 1 & Agropecuária & 1,210 & 6 & 1,388 & 5 & 1,511 & 6 & 0,843 & 18 & 1,197 & 8 & 1,361 & 5 \\
\hline 2 & Ext. mineral & 0,898 & 18 & 0,692 & 24 & 0,757 & 19 & 0,651 & 30 & 0,896 & 14 & 0,658 & 28 \\
\hline 3 & Ext. petr., gás, carvão & 0,824 & 23 & 0,855 & 16 & 0,630 & 31 & 0,642 & 31 & 0,867 & 18 & 0,652 & 30 \\
\hline 4 & Min. não metálicos & 0,903 & 15 & 0,826 & 18 & 0,901 & 15 & 0,884 & 15 & 0,969 & 11 & 0,948 & 15 \\
\hline 5 & Siderurgia & 1,229 & 5 & 1,376 & 6 & 1,688 & 4 & 1,098 & 9 & 1,783 & 2 & 1,110 & 8 \\
\hline 6 & Metalurgia & 1,052 & 9 & 1,356 & 7 & 1,255 & 8 & 1,278 & 6 & 1,330 & 6 & 1,104 & 9 \\
\hline 7 & Fab. máq. e tratores & 0,897 & 19 & 0,750 & 20 & 0,761 & 18 & 1,009 & 12 & 0,741 & 24 & 1,011 & 11 \\
\hline 8 & Mat.elétr. e equip. eletron. & 0,873 & 21 & 0,691 & 25 & 0,707 & 21 & 0,793 & 20 & 0,753 & 23 & 0,735 & 23 \\
\hline 9 & Automóveis & 0,740 & 31 & 0,614 & 31 & 0,635 & 30 & 0,655 & 28 & 0,695 & 30 & 0,652 & 31 \\
\hline 10 & Caminhões e ônibus & 0,741 & 30 & 0,615 & 30 & 0,638 & 29 & 0,654 & 29 & 0,689 & 31 & 0,655 & 29 \\
\hline 11 & Peças e outros veículos & 1,049 & 10 & 0,841 & 17 & 0,678 & 24 & 1,060 & 11 & 0,889 & 15 & 0,766 & 20 \\
\hline 12 & Madeira e mobiliário & 0,900 & 16 & 0,706 & 23 & 0,788 & 17 & 0,706 & 23 & 0,721 & 26 & 0,811 & 18 \\
\hline 13 & Celulose papel e gráfica & 0,922 & 12 & 0,862 & 14 & 0,681 & 22 & 1,101 & 8 & 0,876 & 17 & 1,084 & 10 \\
\hline 14 & Ind borracha & 0,909 & 13 & 0,817 & 19 & 0,865 & 16 & 0,954 & 13 & 0,866 & 19 & 0,903 & 16 \\
\hline 15 & Elem. químicos & 0,796 & 25 & 0,857 & 15 & 0,942 & 13 & 0,844 & 17 & 0,923 & 13 & 0,803 & 19 \\
\hline 16 & Refino de petróleo & 0,808 & 24 & 2,397 & 1 & 1,136 & 9 & 2,409 & 1 & 1,148 & 9 & 2,140 & 1 \\
\hline 17 & Químicos diversos & 1,154 & 8 & 1,104 & 10 & 1,030 & 11 & 1,072 & 10 & 1,014 & 10 & 1,002 & 12 \\
\hline 18 & Farmácia e veterinária & 0,772 & 27 & 0,629 & 28 & 0,642 & 28 & 0,697 & 24 & 0,727 & 25 & 0,659 & 27 \\
\hline 19 & Artigos de plásticos & 0,884 & 20 & 0,722 & 22 & 0,675 & 25 & 0,867 & 16 & 0,772 & 22 & 0,814 & 17 \\
\hline 20 & Ind têxtil & 1,199 & 7 & 1,187 & 9 & 1,063 & 10 & 1,347 & 5 & 1,352 & 5 & 1,142 & 7 \\
\hline 21 & Vestuário e calçados & 0,751 & 29 & 0,667 & 26 & 0,668 & 27 & 0,667 & 27 & 0,702 & 28 & 0,710 & 25 \\
\hline 22 & Produtos alimentares & 0,900 & 17 & 0,865 & 13 & 0,932 & 14 & 0,830 & 19 & 0,881 & 16 & 0,957 & 14 \\
\hline 23 & Ind. diversas & 0,786 & 26 & 0,621 & 29 & 0,668 & 26 & 0,690 & 25 & 0,699 & 29 & 0,723 & 24 \\
\hline 24 & SIUP & 1,658 & 2 & 1,568 & 4 & 1,560 & 5 & 1,411 & 4 & 1,514 & 4 & 1,563 & 4 \\
\hline 25 & Construção civil & 0,856 & 22 & 0,727 & 21 & 0,757 & 20 & 0,732 & 21 & 0,809 & 21 & 0,759 & 21 \\
\hline 26 & Comércio & 1,538 & 3 & 1,716 & 3 & 1,755 & 3 & 1,618 & 3 & 1,640 & 3 & 1,719 & 3 \\
\hline 27 & Com. Veículos e peças & 0,770 & 28 & 0,657 & 27 & 0,681 & 23 & 0,682 & 26 & 0,719 & 27 & 0,686 & 26 \\
\hline 28 & Transporte & 1,236 & 4 & 1,240 & 8 & 1,303 & 7 & 1,206 & 7 & 1,250 & 7 & 1,260 & 6 \\
\hline 29 & Comunicações & 0,995 & 11 & 0,911 & 12 & 1,000 & 12 & 0,934 & 14 & 0,966 & 12 & 0,964 & 13 \\
\hline 30 & Serv. privados & 1,845 & 1 & 1,826 & 2 & 1,897 & 1 & 1,953 & 2 & 1,795 & 1 & 1,894 & 2 \\
\hline 31 & Administração pública & 0,904 & 14 & 0,917 & 11 & 1,795 & 2 & 0,712 & 22 & 0,818 & 20 & 0,754 & 22 \\
\hline
\end{tabular}


b) Índices dependentes

Ao considerar a dependência entre as regiões, como mostram a Tabela 20 e a Tabela 21, a análise dos índices puros de ligação intersetorial desfavorece a região Norte. Assim, no setor automotivo, as atividades classificadas como setores-chave no que se refere ao seu poder de encadeamento para trás são Automóveis; Caminhões e Ônibus e Peças e outros veículos nas regiões Nordeste, Centro-Oeste, São Paulo, resto do Sudeste e Sul. No que se refere ao poder de encadeamento para frente, apenas destaca-se Peças e outros veículos de São Paulo.

Por conseguinte, segundo o critério McGilvray, no tocante ao setor automotivo, apenas a atividade Peças e outros veículos localizada em São Paulo se revela como setor chave para a economia brasileira. Em comparação com a análise dos índices independentes, nota-se a perda de importância relativa da mesma atividade econômica da Região Norte. 
Tabela 20. Índices de ligação HR dependentes, para frente e para trás -Regiões Norte, Nordeste e Centro-Oeste -1999

\begin{tabular}{|c|c|c|c|c|c|c|c|c|c|c|c|c|}
\hline \multirow[b]{2}{*}{ Atividades econômicas } & \multicolumn{4}{|c|}{ Norte } & \multicolumn{4}{|c|}{ Nordeste } & \multicolumn{4}{|c|}{ Centro-Oeste } \\
\hline & $\begin{array}{l}\text { para } \\
\text { trás }\end{array}$ & ord & $\begin{array}{l}\text { para } \\
\text { frente }\end{array}$ & ord & $\begin{array}{l}\text { para } \\
\text { trás }\end{array}$ & ord & $\begin{array}{c}\text { para } \\
\text { frente }\end{array}$ & ord & $\begin{array}{l}\text { para } \\
\text { trás }\end{array}$ & ord & $\begin{array}{l}\text { para } \\
\text { frente }\end{array}$ & ord \\
\hline 1 Agropecuária & 0,891 & 138 & 1,133 & 54 & 0,923 & 126 & 1,525 & 27 & 1,052 & 83 & 1,866 & 9 \\
\hline 2 Ext. mineral & 0,980 & 109 & 0,751 & 98 & 0,997 & 102 & 0,626 & 137 & 0,829 & 149 & 0,679 & 112 \\
\hline 3 Ext. petr., gás, carvão & 0,734 & 174 & 0,662 & 125 & 0,841 & 146 & 1,103 & 57 & 0,575 & 185 & 0,533 & 186 \\
\hline 4 Min. Não metálicos & 0,859 & 143 & 0,668 & 120 & 1,017 & 93 & 0,745 & 100 & 1,082 & 64 & 0,797 & 94 \\
\hline 5 Siderurgia & 1,131 & 41 & 0,928 & 73 & 1,365 & 5 & 1,401 & 34 & 1,464 & 1 & 1,493 & 28 \\
\hline 6 Metalurgia & 1,065 & 73 & 0,810 & 92 & 1,232 & 16 & 1,350 & 38 & 1,326 & 7 & 1,097 & 58 \\
\hline 7 Fab. Máq. E tratores & 0,786 & 155 & 0,671 & 117 & 0,843 & 145 & 0,667 & 122 & 0,946 & 119 & 0,654 & 128 \\
\hline 8 Mat.elétr. e equip. eletron. & 0,760 & 165 & 0,659 & 126 & 1,165 & 29 & 0,608 & 142 & 1,294 & 10 & 0,601 & 143 \\
\hline 9 Automóveis & 0,804 & 153 & 0,535 & 185 & 1,101 & 53 & 0,537 & 183 & 1,169 & 28 & 0,538 & 182 \\
\hline 10 Caminhões e ônibus & 0,807 & 151 & 0,535 & 184 & 1,088 & 60 & 0,538 & 181 & 1,156 & 31 & 0,540 & 180 \\
\hline 11 Peças e outros veículos & 0,915 & 129 & 0,811 & 91 & 1,146 & 35 & 0,737 & 102 & 1,228 & 19 & 0,574 & 157 \\
\hline 12 Madeira e mobiliário & 0,948 & 118 & 0,704 & 107 & 1,007 & 97 & 0,621 & 139 & 1,062 & 77 & 0,698 & 108 \\
\hline 13 Celulose papel e gráfica & 0,994 & 103 & 0,693 & 109 & 1,100 & 54 & 0,785 & 96 & 1,101 & 52 & 0,584 & 149 \\
\hline 14 Ind borracha & 0,952 & 117 & $0 ; 664$ & 124 & 1,114 & 46 & 0,721 & 104 & 1,232 & 15 & 0,738 & 101 \\
\hline 15 Elem. químicos & 0,784 & 156 & 0,585 & 148 & 0,979 & 110 & 0,825 & 89 & 1,068 & 71 & 0,869 & 82 \\
\hline 16 Refino de petróleo & 0,805 & 152 & 0,587 & 146 & 1,015 & 94 & 3,063 & 3 & 1,095 & 55 & 0,987 & 66 \\
\hline 17 Químicos diversos & 0,912 & 132 & 0,955 & 71 & 1,170 & 27 & 1,054 & 63 & 1,211 & 23 & 0,912 & 75 \\
\hline 18 Farmácia e veterinária & 0,858 & 144 & 0,562 & 164 & 0,961 & 113 & 0,551 & 170 & 1,050 & 84 & 0,545 & 175 \\
\hline 19 Artigos de plásticos & 0,902 & 134 & 0,665 & 123 & 1,071 & 69 & 0,637 & 135 & 1,177 & 26 & 0,572 & 158 \\
\hline 20 Ind têxtil & 1,032 & 87 & 0,875 & 80 & 1,281 & 11 & 1,080 & 60 & 1,395 & 3 & 0,908 & 77 \\
\hline 21 Vestuário e calçados & 0,925 & 125 & 0,543 & 177 & 1,108 & 49 & 0,587 & 147 & 1,185 & 25 & 0,567 & 161 \\
\hline 22 Produtos alimentares & 1,121 & 44 & 0,684 & 111 & 1,221 & 21 & 0,806 & 93 & 1,339 & 6 & 0,924 & 74 \\
\hline 23 Ind. diversas & 0,869 & 140 & 0,577 & 154 & 1,034 & 86 & 0,544 & 176 & 1,060 & 78 & 0,571 & 159 \\
\hline 24 SIUP & 1,079 & 65 & 1,286 & 39 & 0,917 & 128 & 1,486 & 29 & 0,919 & 127 & 1,381 & 36 \\
\hline 25 Construção civil & 0,869 & 141 & 0,624 & 138 & 0,929 & 124 & 0,650 & 130 & 1,107 & 50 & 0,650 & 129 \\
\hline 26 Comércio & 0,932 & 122 & 1,170 & 51 & 0,942 & 121 & 1,629 & 21 & 1,063 & 76 & 1,612 & 24 \\
\hline 27 Com. Veículos e peças & 0,708 & 180 & 0,559 & 165 & 0,653 & 183 & 0,577 & 155 & 0,872 & 139 & 0,581 & 152 \\
\hline 28 Transporte & 0,953 & 116 & 0,938 & 72 & 0,984 & 108 & 1,177 & 47 & 1,053 & 82 & 1,171 & 50 \\
\hline 29 Comunicações & 0,735 & 173 & 0,732 & 103 & 0,703 & 182 & 0,834 & 86 & 0,729 & 176 & 0,882 & 78 \\
\hline 30 Serv. privados & 0,750 & 167 & 1,395 & 35 & 0,771 & 160 & 1,734 & 15 & 0,769 & 162 & 1,746 & 14 \\
\hline 31 Administração pública & 0,719 & 177 & 0,668 & 121 & 0,764 & 164 & 0,832 & 87 & 0,766 & 163 & 1,627 & 22 \\
\hline
\end{tabular}


Tabela 21. Índices de ligação HR dependentes, para frente e para trás - São Paulo, Resto do Sudeste e Região Sul -1999

\begin{tabular}{|c|c|c|c|c|c|c|c|c|c|c|c|c|}
\hline \multirow[b]{2}{*}{ Atividades econômicas } & \multicolumn{4}{|c|}{ São Paulo } & \multicolumn{4}{|c|}{ Resto do Sudeste } & \multicolumn{4}{|c|}{ Sul } \\
\hline & $\begin{array}{l}\text { para } \\
\text { trás }\end{array}$ & ord & $\begin{array}{c}\text { para } \\
\text { frente }\end{array}$ & ord & $\begin{array}{l}\text { para } \\
\text { trás }\end{array}$ & ord & $\begin{array}{l}\text { para } \\
\text { frente }\end{array}$ & ord & $\begin{array}{l}\text { para } \\
\text { trás }\end{array}$ & ord & $\begin{array}{l}\text { para } \\
\text { frente }\end{array}$ & ord \\
\hline 1 Agropecuária & 0,771 & 159 & 1,172 & 49 & 1,020 & 92 & 1,466 & 32 & 0,896 & 135 & 1,847 & 10 \\
\hline 2 Ext. mineral & 0,953 & 115 & 0,577 & 153 & 0,986 & 107 & 1,206 & 43 & 1,090 & 58 & 0,557 & 167 \\
\hline 3 Ext. petr., gás, carvão & 0,748 & 169 & 0,542 & 178 & 0,752 & 166 & 2,389 & 6 & 0,794 & 154 & 0,596 & 144 \\
\hline 4 Min. não metálicos & 1,064 & 75 & 0,970 & 70 & 0,969 & 111 & 0,912 & 76 & 1,067 & 72 & 0,873 & 81 \\
\hline 5 Siderurgia & 1,369 & 4 & 1,462 & 33 & 1,300 & 9 & 3,235 & 2 & 1,400 & 2 & 0,994 & 65 \\
\hline 6 Metalurgia & 1,231 & 17 & 2,235 & 7 & 1,152 & 33 & 1,467 & 31 & 1,246 & 14 & 1,174 & 48 \\
\hline 7 Fab. máq. E tratores & 0,929 & 123 & 1,707 & 16 & 0,775 & 158 & 0,632 & 136 & 0,894 & 136 & 1,085 & 59 \\
\hline 8 Mat.elétr. e & 1,086 & 61 & 0,978 & 68 & 1,065 & 74 & 0,611 & 141 & 1,110 & 48 & 0,639 & 134 \\
\hline 9 Automóveis & 1,082 & 63 & 0,558 & 166 & 1,056 & 80 & 0,549 & 171 & 1,142 & 37 & 0,545 & 174 \\
\hline 10 Caminhões e ônibus & 1,071 & 70 & 0,556 & 168 & 1,027 & 89 & 0,541 & 179 & 1,124 & 43 & 0,549 & 173 \\
\hline 11 Peças e outros veículos & 1,151 & 34 & 1,478 & 30 & 1,083 & 62 & 0,751 & 99 & 1,190 & 24 & 0,674 & 116 \\
\hline 12 Madeira e mobiliário & 1,093 & 56 & 0,674 & 115 & 1,007 & 98 & 0,581 & 151 & 1,059 & 79 & 0,827 & 88 \\
\hline 13 Celulose $p$ & 1,138 & 39 & 1,703 & 17 & 1,072 & 68 & 0,841 & 85 & 1,164 & 30 & 1,123 & 55 \\
\hline 14 Ind borracha & 1,127 & 42 & 1,183 & 46 & 1,056 & 81 & 0,709 & 105 & 1,156 & 32 & 0,814 & 90 \\
\hline 15 Elem. químicos & 1,026 & 90 & 1,229 & 41 & 0,908 & 133 & 1,105 & 56 & 1,003 & 100 & 0,785 & 95 \\
\hline 16 Refino de petróleo & 1,013 & 96 & 5,939 & 1 & 0,943 & 120 & 1,247 & 40 & 1,029 & 88 & 2,694 & 4 \\
\hline 17 Químicos diversos & 1,111 & 47 & 1,830 & 12 & 1,077 & 66 & 0,985 & 67 & 1,145 & 36 & 1,011 & 64 \\
\hline 18 Farmácia e veterinária & 1,022 & 91 & 0,669 & 119 & 0,915 & 131 & 0,592 & 145 & 1,014 & 95 & 0,549 & 172 \\
\hline 19 Artig & 1,090 & 59 & 1,153 & 52 & 1,005 & 99 & 0,642 & 133 & 1,102 & 51 & 0,767 & 97 \\
\hline 20 Ind têxtil & 1,272 & 12 & 1,626 & 23 & 1,221 & 20 & 1,201 & 44 & 1,317 & 8 & 1,078 & 61 \\
\hline 21 Vestuário e calçados & 1,132 & 40 & 0,569 & 160 & 1,120 & 45 & 0,554 & 169 & 1,139 & 38 & 0,614 & 140 \\
\hline 22 Produtos alimentares & 1,231 & 18 & 1,147 & 53 & 1,212 & 22 & 0,849 & 84 & 1,246 & 13 & 1,070 & 62 \\
\hline 23 Ind. diversas & 0,988 & 106 & 0,671 & 118 & 1,000 & 101 & 0,562 & 163 & 1,039 & 85 & 0,684 & 110 \\
\hline 24 SIUP & 0,834 & 148 & 1,693 & 18 & 0,835 & 147 & 1,561 & 25 & 0,892 & 137 & 1,540 & 26 \\
\hline 25 Construção civil & 0,823 & 150 & 0,650 & 131 & 0,866 & 142 & 0,675 & 114 & 0,915 & 130 & 0,649 & 132 \\
\hline 26 Comércio & 0,988 & 105 & 2,046 & 8 & 0,964 & 112 & 1,632 & 20 & 0,988 & 104 & 1,683 & 19 \\
\hline 27 Com. Veículos e peças & 0,713 & 179 & 0,582 & 150 & 0,643 & 184 & 0,566 & 162 & 0,775 & 157 & 0,577 & 156 \\
\hline 28 Transporte & 1,092 & 57 & 1,380 & 37 & 0,958 & 114 & 1,220 & 42 & 1,073 & 67 & 1,196 & 45 \\
\hline 29 Comunicações & 0,573 & 186 & 0,971 & 69 & 0,732 & 175 & 0,879 & 79 & 0,740 & 170 & 0,866 & 83 \\
\hline 30 Serv. privados & 0,703 & 181 & 2,606 & 5 & 0,748 & 168 & 1,845 & 11 & 0,714 & 178 & 1,782 & 13 \\
\hline 31 Administração pública & 0,738 & 172 & 0,675 & 113 & 0,740 & 171 & 0,705 & 106 & 0,769 & 161 & 0,655 & 127 \\
\hline
\end{tabular}

Na Figura 14, a seguir, é possível visualizar os índices de RasmussenHirschman para os setores-chaves do sistema inter-regional, segundo o critério McGilvray. Como esperado, esses índices indicam especialmente o maior peso das atividades econômicas pertencentes à Indústria de Transformação de São Paulo, como 
Metalurgia, Peças e outros veículos, Celulose, papel e gráfica, Indústria da borracha, Elementos químicos, Refino de petróleo, Químicos diversos, Artigos de plásticos, Indústria têxtil e Produtos alimentares. Acrescenta-se também a importância das atividades do resto do Sudeste como Agropecuária, Siderurgia, Metalurgia, Indústria Têxtil e no Sul, Metalurgia, Celulose, papel e gráfica, Refino de petróleo, Químicos diversos, Indústria têxtil, Produtos alimentares e Transporte. Destaque ainda para Metalurgia e Siderurgia das Regiões Nordeste, Centro-Oeste e Agropecuária no CentroOeste e Refino de petróleo no Nordeste.

A Figura 15, por sua vez, apresenta apenas as atividades com índices de ligação mais elevados. Na Figura 15.1 observa-se que a atividade Siderurgia - CO apresenta um índice de ligação para trás de 1,5, seguida pela atividade Siderurgia - SP e SiderurgiaNE. Já na Figura 15.2, observa-se que os maiores índices de ligação para frente são das atividades Refino de petróleo SP, próximo de 6, seguida pelas atividades Siderugia SER e Refino de petróleo NE. Salienta-se que no conjunto de setores apontados, destacam-se sobretudo a presença de setores com elevados índices de ligação para frente. 


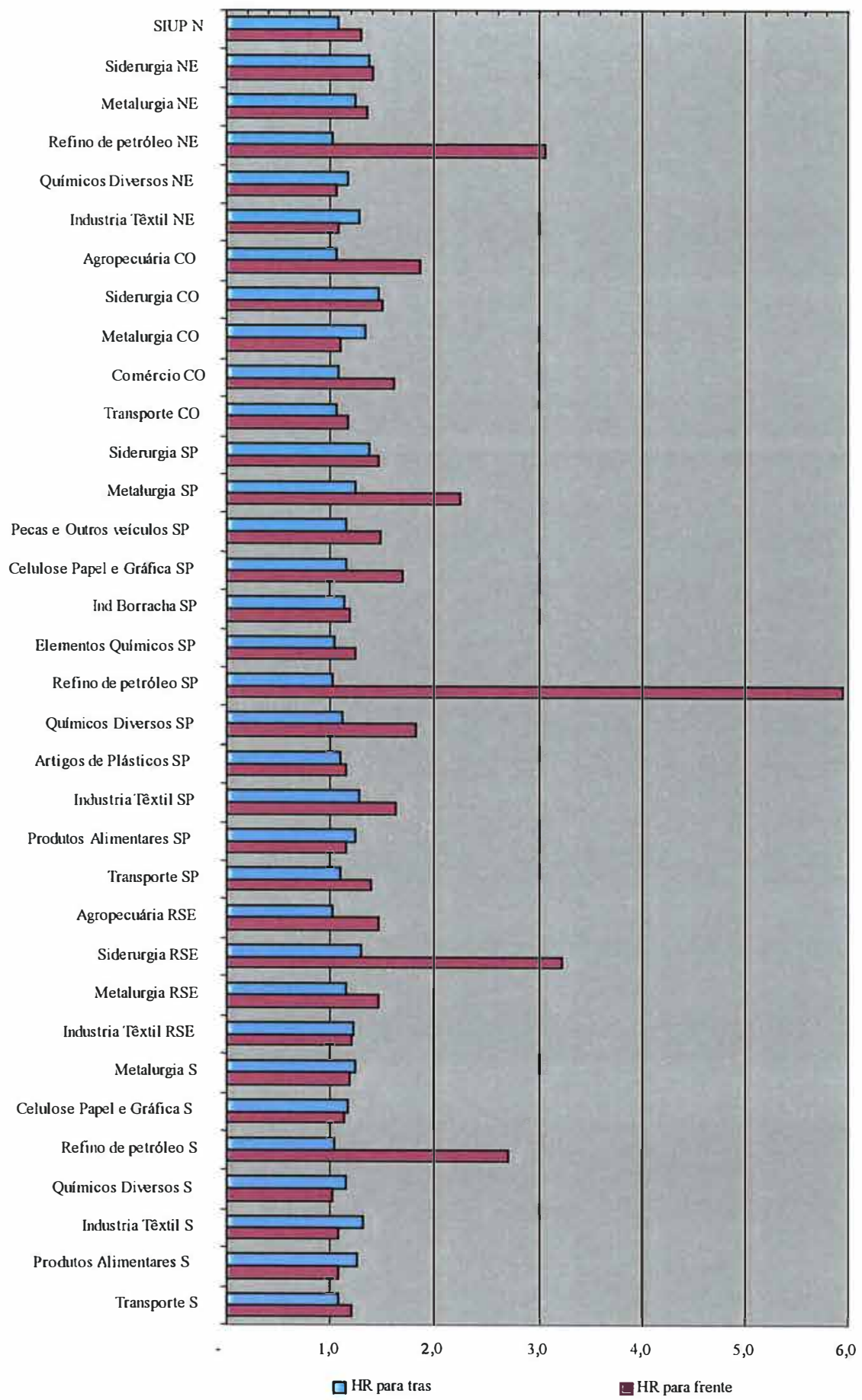

Figura 14 - Índices de ligações intersetoriais de Rasmussen-Hirschman para os setoreschaves do sistema inter-regional (índices dependentes) segundo o critério McGilvray - 1999 


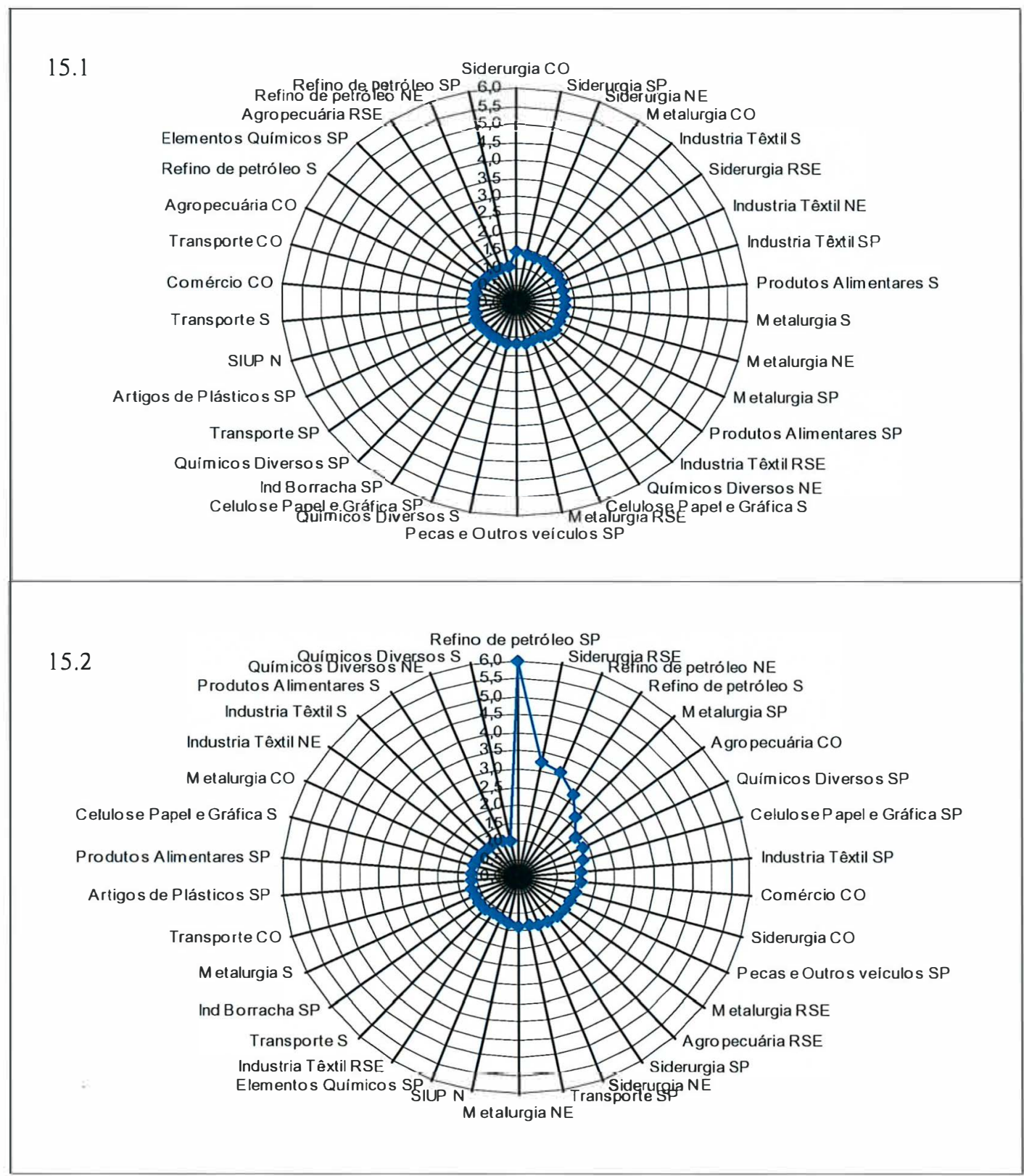

Figura 15 - Índices de ligações intersetoriais Rasmussen-Hirschman para trás (15.1) e para frente (15.2) dos setores chaves do sistema inter-regional (índices dependentes) 


\subsection{2 Índice puro de ligação}

O índice puro de ligação se diferencia do índice de Rasmussem-Hirschman, apresentado anteriormente, pelo fato de considerar, em seu cômputo, a intensidade dos fluxos monetários intersetoriais, em termos de valor. Neste sentido, sua análise permite identificar os setores chave segundo sua capacidade tanto de estabelecer relações com os demais setores, quanto de gerar valor de produção na economia. Serão apresentados nesta seção, os índices puros de ligação normalizados.
a) Índices independentes

As tabelas a seguir apresentam os índices de puros de ligação para trás, para frente e totais para as 6 regiões analisadas.

Analogamente aos índices de Hirschman-Rasmussen, os índices puros de ligação para trás avaliam a importância do setor para os compradores de bens e serviços. Desse modo, acrescentando na análise das interligações setoriais o volume de produção, a única atividade do setor automotivo que mantém a classificação de setor-chave, é a atividade de Automóveis de São Paulo (Tabela 22). 
Tabela 22. Índice puros de ligação para trás (independentes) para as regiões Norte $(\mathrm{N})$, Nordeste (NE), Centro Oeste (CO), São Paulo (SP), resto do Sudeste (RSE) e Sul (S) - 1999)

\begin{tabular}{|c|c|c|c|c|c|c|c|c|c|c|c|c|c|}
\hline & Atividades econômicas & $\mathrm{N}$ & ord & $\mathrm{NE}$ & Ord & $\mathrm{CO}$ & ord & SP & ord & RSE & ord & $\mathrm{S}$ & ord \\
\hline 1 & Agropecuária & 1,847 & 5 & 1,613 & 6 & 1,301 & 6 & 0,695 & 13 & 1,111 & 5 &, 897 & 8 \\
\hline 2 & Ext. mineral & 0,459 & 12 & 0,008 & 30 & 0,000 & 27 & 0,019 & 26 & 0,471 & 14 & 0,012 & 28 \\
\hline 3 & Ext. petr., gás, carvão & 0,037 & 26 & $-0,223$ & 31 & 0,000 & 28 & 0,002 & 28 & 0,099 & 30 & $-0,020$ & 31 \\
\hline 4 & Min. Não metálicos & 0,080 & 22 & 0,158 & 19 & $-0,051$ & 31 & 0,212 & 23 & 0,040 & 31 & 0,009 & 29 \\
\hline 5 & Siderurgia & $-0,051$ & 30 & 0,238 & 15 & $-0,049$ & 30 & 0,364 & 15 & 0,308 & 20 & 0,163 & 22 \\
\hline 6 & Metalurgia & 0,166 & 19 & 0,749 & 10 & 0,119 & 13 & 0,319 & 19 & 0,572 & 12 & 0,094 & 24 \\
\hline 7 & Fab. Máq. e tratores & 0,299 & 16 & 0,105 & 21 & 0,055 & 18 & 0,848 & 12 & 0,346 & 18 & 0,475 & 11 \\
\hline 8 & Mat.elétr. e equip. eletron. & 0,909 & 8 & 0,312 & 13 & 0,131 & 11 & 1,329 & 7 & 0,661 & 10 & 0,591 & 10 \\
\hline 9 & Automóveis & 0,028 & 28 & 0,011 & 29 & 0,008 & 25 & 1,003 & 9 & 0,424 & 17 & 0,401 & 13 \\
\hline 10 & Caminhões e ônibus & 0,049 & 25 & 0,022 & 28 & 0,040 & 20 & 0,915 & 10 & 0,431 & 16 & 0,310 & 18 \\
\hline 11 & Peças e outros veículos & 0,527 & 11 & 0,066 & 25 & 0,011 & 23 & 0,598 & 14 & 0,728 & 9 & 0,414 & 12 \\
\hline 12 & Madeira e mobiliário & 0,716 & 9 & 0,059 & 26 & 0,064 & 16 & 0,324 & 18 & 0,241 & 21 & 0,644 & 9 \\
\hline 13 & Celulose papel e gráfica & 0,300 & 15 & 0,235 & 16 & 0,126 & 12 & 0,300 & 20 & 0,312 & 19 & 0,354 & 16 \\
\hline 14 & Ind borracha & 0,058 & 23 & 0,081 & 24 & 0,017 & 22 & 0,018 & 27 & 0,139 & 26 & 0,082 & 26 \\
\hline 15 & Elem. químicos & 0,028 & 27 & 0,093 & 22 & $-0,048$ & 29 & 0,189 & 24 & 0,112 & 28 & 0,156 & 23 \\
\hline 16 & Refino de petróleo & $-0,068$ & 31 & 1,544 & 8 & 0,051 & 19 & $-0,209$ & 31 & 0,783 & 8 & $-0,011$ & 30 \\
\hline 17 & Químicos diversos & 0,224 & 17 & 0,227 & 17 & 0,028 & 21 & $-0,020$ & 30 & 0,116 & 27 & 0,285 & 19 \\
\hline 18 & Farmácia e veterinária & 0,442 & 13 & 0,107 & 20 & 0,087 & 14 & 0,901 & 11 & 0,459 & 15 & 0,060 & 27 \\
\hline 19 & Artigos de plásticos & 0,026 & 29 & 0,085 & 23 & 0,011 & 24 & $-0,014$ & 29 & 0,164 & 25 & 0,086 & 25 \\
\hline 20 & Ind têxtil & 0,134 & 21 & 0,386 & 11 & 0,058 & 17 & 0,247 & 22 & 0,195 & 24 & 0,373 & 14 \\
\hline 21 & Vestuário e calçados & 0,052 & 24 & 0,757 & 9 & 0,176 & 10 & 1,190 & 8 & 0,915 & 7 & 0,993 & 7 \\
\hline 22 & Produtos alimentares & 4,309 & 4 & 5,410 & 2 & 6,318 & 2 & 3,200 & 5 & 4,963 & 2 & 8,265 & 1 \\
\hline 23 & Ind. diversas & 0,167 & 18 & 0,041 & 27 & 0,080 & 15 & 0,280 & 21 & 0,217 & 22 & 0,330 & 17 \\
\hline 24 & SIUP & 0,690 & 10 & 0,250 & 14 & 0,006 & 26 & 0,336 & 16 & 0,209 & 23 & 0,190 & 21 \\
\hline 25 & Construção civil & 4,828 & 2 & 3,698 & 4 & 3,867 & 4 & 3,643 & 4 & 4,651 & 4 & 4,376 & 2 \\
\hline 26 & Comércio & 1,822 & 6 & 3,018 & 5 & 2,419 & 5 & 3,759 & 3 & 1,102 & 6 & 2,612 & 5 \\
\hline 27 & Com. veículos e & 0,383 & 14 & 0,218 & 18 & 0,962 & 7 & 0,332 & 17 & 0,102 & 29 & 0,371 & 15 \\
\hline 28 & Transporte & 1,119 & 7 & 1,558 & 7 & 0,455 & 8 & 1,487 & 6 & 0,599 & 11 & 1,130 & 6 \\
\hline 29 & Comunicações & 0,150 & 20 & 0,333 & 12 & 0,282 & 9 & 0,087 & 25 & 0,506 & 13 & 0,226 & 20 \\
\hline 30 & Serv. privados & 4,498 & 3 & 3,964 & 3 & 4,262 & 3 & 4,643 & 1 & 4,821 & 3 & 3,521 & 4 \\
\hline 31 & Administração pública & 6,772 & 1 & 5,878 & 1 & 10,212 & 1 & 4,000 & 2 & 5,202 & 1 & 3,612 & 3 \\
\hline
\end{tabular}

No tocante aos encadeamentos para frente, os índices de ligação indicam o impacto puro da produção total dos setores da economia sobre um setor específico. Trata-se, portanto, de uma medida do quanto da produção dos diversos setores da economia são capazes dinamizar a produção de um determinado setor. 
Tabela 23. Índice puros de ligação para frente (independentes) para as regiões Norte $(\mathrm{N})$, Nordeste (NE), Centro Oeste (CO), São Paulo (SP), resto do Sudeste (RSE) e Sul (S) - 1999

\begin{tabular}{|c|c|c|c|c|c|c|c|c|c|c|c|c|c|}
\hline & Atividades econômicas & $\mathbf{N}$ & ord & $\mathrm{NE}$ & ord & $\mathrm{CO}$ & ord & SP & ord & RSE & Ord & $\mathbf{S}$ & ord \\
\hline 1 & Agropecuária & 3,345 & 3 & 3,939 & 31 & 4,871 & 2 & 0,732 & 15 & 3,222 & 3 & 5,821 & 1 \\
\hline 2 & Ext. mineral & 0,243 & 20 & 0,142 & 30 & 0,145 & 14 & 0,021 & 29 & 0,374 & 18 & 0,021 & 28 \\
\hline 3 & Ext. petr., gás, carvão & 0,001 & 31 & 1,106 & 29 & 0,000 & 31 & 0,000 & 31 & 0,390 & 17 & 0,009 & 30 \\
\hline 4 & Min. não metálicos & 0,958 & 10 & 0,707 & 28 & 1,130 & 8 & 0,970 & 11 & 2,179 & 6 & 1,280 & 7 \\
\hline 5 & Siderurgia & 0,196 & 22 & 0,407 & 27 & 0,107 & 16 & 0,103 & 26 & 1,521 & 8 & 0,036 & 26 \\
\hline 6 & Metalurgia & 0,756 & 13 & 0,464 & 26 & 0,067 & 18 & 1,728 & 5 & 1,537 & 7 & 1,148 & 8 \\
\hline 7 & Fab. máq. e tratores & 0,367 & 18 & 0,112 & 25 & 0,088 & 17 & 0,879 & 13 & 0,105 & 23 & 0,624 & 12 \\
\hline 8 & Mat.elétr. e equip. eletron. & 0,617 & 16 & 0,027 & 24 & 0,005 & 24 & 0,389 & 20 & 0,026 & 28 & 0,172 & 23 \\
\hline 9 & Automóveis & 0,003 & 30 & 0,001 & 23 & 0,001 & 30 & 0,029 & 27 & 0,036 & 27 & 0,020 & 29 \\
\hline 10 & Caminhões e ônibus & 0,005 & 28 & 0,001 & 22 & 0,004 & 25 & 0,023 & 28 & 0,007 & 31 & 0,024 & 27 \\
\hline 11 & Peças e outros veículos & 0,977 & 9 & 0,017 & 21 & 0,002 & 28 & 1,052 & 9 & 0,149 & 21 & 0,197 & 21 \\
\hline 12 & Madeira e mobiliário & 0,592 & 17 & 0,047 & 20 & 0,470 & 12 & 0,195 & 23 & 0,018 & 30 & 0,396 & 17 \\
\hline 13 & Celulose papel e gráfica & 0,756 & 12 & 0,285 & 19 & 0,129 & 15 & 1,784 & 4 & 0,991 & 11 & 0,928 & 11 \\
\hline 14 & Ind borracha & 0,092 & 26 & 0,033 & 18 & 0,009 & 23 & 0,539 & 18 & 0,055 & 26 & 0,358 & 18 \\
\hline 15 & Elem. químicos & 0,056 & 27 & 0,702 & 17 & 0,742 & 10 & 0,730 & 16 & 0,442 & 16 & 0,184 & 22 \\
\hline 16 & Refino de petróleo & 0,197 & 21 & 4,363 & 16 & 0,023 & 22 & 4,422 & 2 & 0,233 & 19 & 3,297 & 4 \\
\hline 17 & Químicos diversos & 1,454 & 6 & 0,947 & 15 & 0,165 & 13 & 0,891 & 12 & 0,619 & 14 & 0,620 & 13 \\
\hline 18 & Farmácia e veterinária & 0,127 & 23 & 0,004 & 14 & 0,002 & 27 & 0,164 & 24 & 0,207 & 20 & 0,001 & 31 \\
\hline 19 & Artigos de plásticos & 0,754 & 14 & 0,057 & 13 & 0,001 & 29 & 0,699 & 17 & 0,084 & 24 & 0,501 & 15 \\
\hline 20 & Ind têxtil & 0,098 & 25 & 0,697 & 12 & 0,053 & 20 & 0,972 & 10 & 0,808 & 12 & 0,577 & 14 \\
\hline 21 & Vestuário e calçados & 0,004 & 29 & 0,027 & 11 & 0,003 & 26 & 0,016 & 30 & 0,018 & 29 & 0,058 & 25 \\
\hline 22 & Produtos alimentares & 1,124 & 8 & 1,150 & 10 & 0,994 & 9 & 0,872 & 14 & 0,751 & 13 & 0,967 & 10 \\
\hline 23 & Ind. diversas & 0,258 & 19 & 0,028 & 9 & 0,051 & 21 & 0,231 & 22 & 0,070 & 25 & 0,313 & 20 \\
\hline 24 & SIUP & 2,295 & 4 & 2,110 & 8 & 2,600 & 4 & 1,714 & 6 & 2,289 & 4 & 1,745 & 6 \\
\hline 25 & Construção civil & 0,798 & 11 & 0,601 & 7 & 0,716 & 11 & 0,498 & 19 & 1,327 & 10 & 0,477 & 16 \\
\hline 26 & Comércio & 3,989 & 2 & 3,774 & 6 & 4,139 & 3 & 3,322 & 3 & 3,978 & 2 & 3,721 & 3 \\
\hline 27 & Com. Veículos e peças & 0,116 & 24 & 0,063 & 5 & 0,062 & 19 & 0,117 & 25 & 0,120 & 22 & 0,097 & 24 \\
\hline 28 & Transporte & 2,141 & 5 & 2,058 & 4 & 2,520 & 5 & 1,624 & 7 & 2,187 & 5 & 1,784 & 5 \\
\hline 29 & Comunicações & 1,338 & 7 & 1,131 & 3 & 1,713 & 7 & 1,250 & 8 & 1,371 & 9 & 1,114 & 9 \\
\hline 30 & Serv. privados & 6,694 & 1 & 5,396 & 2 & 7,827 & 1 & 4,756 & 1 & 5,332 & 1 & 4,187 & 2 \\
\hline 31 & Administração pública & 0,649 & 15 & 0,602 & 1 & 2,360 & 6 & 0,278 & 21 & 0,551 & 15 & 0,325 & 19 \\
\hline
\end{tabular}

Observando os índices de ligação para frente, apresentados na Tabela 23, notase que, em quase todas as regiões, $\mathrm{o}$ impacto das demais atividades econômicas sobre aquelas pertencentes ao setor automotivo (Automóveis; Caminhões e Ônibus, e Peças e outros veículos) é relativamente inferior a média da região. Assim como ocorre nas 
regiões Sul, resto do sudeste e São Paulo, nas regiões Norte, Nordeste e Centro-Oeste as atividades Serviços, Transporte e Comunicações, Comércio e S.I.U.P. e Agropecuária, apresentam índices de ligação para frente acima da média. As regiões Sul e resto do Sudeste, em virtude da maior complexidade produtiva, indicam a importância de atividades da indústria de Transformação, a exemplo da Metalurgia, minerais não metálicos e, especificamente para última, a Siderurgia.

Em São Paulo, além das atividades de Metalurgia, Celulose papel e gráfica, Refino de petróleo, a atividade Peças e outros veículos se sobressai em relação a média, sugerindo a importância do segmento de reposição de peças na região paulista.

Os índices de ligação puros totais não apontam como setores-chaves nenhuma das atividades pertencentes ao setor automotivo nas regiões analisadas isoladamente. As atividades que se destacam exercerem impactos sobre a região, e ao mesmo tempo serem impactadas pelas demais atividades econômicas de sua estrutura produtiva são Produtos alimentares, Construção civil, Comércio, Transporte, Serviços Privados e Administração Pública em todas as 6 regiões analisadas. Destacam-se ainda nas 6 regiões, a atividade da Agricultura (exceto em São Paulo), os S.I.U.P. (exceto no Sul). Metalurgia em São Paulo e no resto do Sudeste; Minerais não metálicos, no resto do Sudeste; e Refino de Petróleo, em São Paulo, no Sul e no Nordeste, bem como a atividade de Celulose, papel e gráfica em São Paulo (Tabela 24). 
Tabela 24. Índice puros de ligação totais (independentes) para as regiões Norte $(\mathrm{N})$, Nordeste (NE), Centro Oeste (CO), São Paulo (SP), resto do Sudeste (RSE) e Sul (S) - 1999

\begin{tabular}{|c|c|c|c|c|c|c|c|c|c|c|c|c|c|}
\hline & Atividades econômicas & $\mathbf{N}$ & ord & $\mathrm{NE}$ & ord & $\mathrm{CO}$ & ord & SP & ord & RSE & ord & $\mathrm{S}$ & ord \\
\hline 1 & Agropecuária & 2,595 & 6 & 2,775 & 6 & 3,086 & 5 & 0,714 & 14 & 2,167 & 6 & 3,357 & 3 \\
\hline 2 & Ext. mineral & 0,351 & 18 & 0,075 & 23 & 0,072 & 18 & 0,020 & 30 & 0,422 & 18 & 0,016 & 30 \\
\hline 3 & Ext. petr., gás, carvão & 0,019 & 30 & 0,441 & 14 & 0,000 & 31 & 0,001 & 31 & 0,244 & 23 & $-0,005$ & 31 \\
\hline 4 & Min. não metálicos & 0,519 & 15 & 0,432 & 15 & 0,539 & 10 & 0,591 & 18 & 1,110 & 9 & 0,644 & 11 \\
\hline 5 & Siderurgia & 0,072 & 25 & 0,322 & 18 & 0,029 & 25 & 0,234 & 28 & 0,915 & 12 & 0,100 & 28 \\
\hline 6 & Metalurgia & 0,461 & 16 & 0,607 & 11 & 0,093 & 16 & 1,022 & 10 & 1,055 & 10 & 0,621 & 13 \\
\hline 7 & Fab. máq. e tratores & 0,333 & 19 & 0,109 & 22 & 0,072 & 19 & 0,863 & 11 & 0,225 & 25 & 0,549 & 14 \\
\hline 8 & Mat.elétr. e equip. eletron. & 0,763 & 10 & 0,170 & 20 & 0,068 & 20 & 0,859 & 12 & 0,344 & 20 & 0,382 & 19 \\
\hline 9 & Automóveis & 0,016 & 31 & 0,006 & 31 & 0,004 & 30 & 0,517 & 20 & 0,230 & 24 & 0,210 & 25 \\
\hline 10 & Caminhões e ônibus & 0,027 & 29 & 0,012 & 30 & 0,022 & 26 & 0,470 & 21 & 0,219 & 26 & 0,167 & 27 \\
\hline 11 & Peças e outros veículos & 0,752 & 11 & 0,042 & 28 & 0,007 & 28 & 0,825 & 13 & 0,439 & 17 & 0,306 & 21 \\
\hline 12 & Madeira e mobiliário & 0,654 & 13 & 0,053 & 27 & 0,267 & 13 & 0,260 & 26 & 0,129 & 28 & 0,520 & 16 \\
\hline 13 & Celulose papel e gráfica & 0,528 & 14 & 0,260 & 19 & 0,127 & 14 & 1,042 & 8 & 0,652 & 13 & 0,640 & 12 \\
\hline 14 & Ind borracha & 0,075 & 24 & 0,057 & 25 & 0,013 & 27 & 0,278 & 25 & 0,097 & 31 & 0,220 & 24 \\
\hline 15 & Elem. químicos & 0,042 & 27 & 0,397 & 16 & 0,347 & 12 & 0,459 & 22 & 0,277 & 22 & 0,170 & 26 \\
\hline 16 & Refino de petróleo & 0,064 & 26 & 2,952 & 5 & 0,037 & 24 & 2,103 & 4 & 0,508 & 14 & 1,642 & 7 \\
\hline 17 & Químicos diversos & 0,839 & 9 & 0,587 & 12 & 0,097 & 15 & 0,435 & 23 & 0,367 & 19 & 0,452 & 18 \\
\hline 18 & Farmácia e veterinária & 0,285 & 20 & 0,055 & 26 & 0,045 & 23 & 0,533 & 19 & 0,333 & 21 & 0,031 & 29 \\
\hline 19 & Artigos de plásticos & 0,390 & 17 & 0,071 & 24 & 0,006 & 29 & 0,342 & 24 & 0,124 & 29 & 0,293 & 22 \\
\hline 20 & Ind têxtil & 0,116 & 23 & 0,541 & 13 & 0,056 & 22 & 0,609 & 16 & 0,502 & 15 & 0,475 & 17 \\
\hline 21 & Vestuário e calçados & 0,028 & 28 & 0,393 & 17 & 0,090 & 17 & 0,604 & 17 & 0,466 & 16 & 0,526 & 15 \\
\hline 22 & Produtos alimentares & 2,717 & 5 & 3,282 & 3 & 3,656 & 3 & 2,037 & 6 & 2,857 & 4 & 4,619 & 1 \\
\hline 23 & Ind. diversas & 0,212 & 22 & 0,034 & 29 & 0,066 & 21 & 0,256 & 27 & 0,143 & 27 & 0,321 & 20 \\
\hline 24 & SIUP & 1,492 & 8 & 1,179 & 9 & 1,303 & 8 & 1,024 & 9 & 1,249 & 8 & 0,967 & 9 \\
\hline 25 & Construção civil & 2,814 & 4 & 2,151 & 7 & 2,292 & 6 & 2,073 & 5 & 2,989 & 2 & 2,428 & 5 \\
\hline 26 & Comércio & 2,905 & 3. & 3,396 & 2 & 3,279 & 4 & 3,540 & 2 & 2,540 & 5 & 3,166 & 4 \\
\hline 27 & Com. veículos e peças & 0,250 & 21 & 0,141 & 21 & 0,512 & 11 & 0,225 & 29 & 0,111 & 30 & 0,234 & 23 \\
\hline 28 & Transporte & 1,630 & 7 & 1,808 & 8 & 1,487 & 7 & 1,555 & 7 & 1,393 & 7 & 1,457 & 8 \\
\hline 29 & Comunicações & 0,744 & 12 & 0,732 & 10 & 0,997 & 9 & 0,668 & 15 & 0,938 & 11 & 0,670 & 10 \\
\hline 30 & Serv. privados & 5,595 & 1 & 4,679 & 1 & 6,044 & 2 & 4,700 & 1 & 5,077 & 1 & 3,854 & 2 \\
\hline 31 & Administração pública & 3,712 & 2 & 3,242 & 4 & 6,287 & 1 & 2,141 & 3 & 2,876 & 3 & 1,970 & 6 \\
\hline
\end{tabular}


b) Índices dependentes

Levando em conta a interação entre as regiões econômicas no computo dos índices puros, como verificado na análise dos índices de Hirschman Rasmussen, constase novamente que a relevância do setor automotivo recai sobre a região de São Paulo.

As Tabelas 25, 26 e 27 apresentam os 3 tipos de índices puros de ligação (para frente, para trás e totais) calculados para o sistema inter-regional. Em linhas gerais, estas informações possibilitam reafirmar a relevância do setor automotivo em São Paulo e na região Sul.

As três atividades relacionadas ao setor automotivo: Automóveis; Caminhões e Ônibus e Peças e outros veículos localizadas em São Paulo, apresentam poder de encadeamento para trás superior a média do sistema. Na região Sul, o mesmo destaque pode ser atribuído à atividade Caminhões e Ônibus. Em termos de poder de encadeamento pra frente, somente Peças e outros veículos localizada em São Paulo aparece como setor-chave no setor automotivo. Posto isso, o critério mais restritivo aponta a atividade Peças e outros veículos localizada em São Paulo como setor-chave, convergindo com os resultados obtidos com o índice Hirschman-Rasmussen. 
Tabela 25. Índice puros de ligação para trás, para frente e totais (dependentes) para as regiões Norte $(\mathrm{N})$ e Nordeste $(\mathrm{NE})$ - 1999

\begin{tabular}{|c|c|c|c|c|c|c|c|c|c|c|c|c|}
\hline \multirow[b]{2}{*}{ Atividades econômicas } & \multicolumn{6}{|c|}{ Norte } & \multicolumn{6}{|c|}{ Nordeste } \\
\hline & trás & ord & frente & ord & total & Ord & trás & ord & frente & ord & total & ord \\
\hline 1 Agropecuária & 0,780 & 55 & 1,469 & 42 & 1,124 & 52 & 1,445 & 39 & 2,949 & 20 & 2,196 & 30 \\
\hline 2 Ext. mineral & 0,120 & 117 & 0,187 & 110 & 0,154 & 128 & 0,005 & 166 & 0,113 & 125 & 0,059 & 149 \\
\hline 3 Ext. petr., gás, carvão & 0,005 & 164 & 0,113 & 124 & 0,059 & 148 & $-0,171$ & 185 & 1,073 & 51 & 0,450 & 94 \\
\hline 4 Min. Não metálicos & 0,015 & 154 & 0,161 & 116 & 0,088 & 138 & 0,089 & 122 & 0,357 & 94 & 0,223 & 117 \\
\hline 5 Siderurgia & $-0,008$ & 176 & 0,125 & 122 & 0,058 & 150 & 0,190 & 101 & 0,629 & 72 & 0,409 & 98 \\
\hline 6 Metalurgia & 0,041 & 137 & 0,225 & 104 & 0,133 & 131 & 0,689 & 60 & 0,625 & 73 & 0,657 & 74 \\
\hline 7 Fab. Máq. e tratores & 0,050 & 131 & 0,083 & 134 & 0,066 & 143 & 0,057 & 126 & 0,071 & 137 & 0,064 & 146 \\
\hline 8 Mat.elétr. e equip. eletron. & 0,312 & 89 & 0,145 & 120 & 0,228 & 116 & 0,179 & 102 & 0,026 & 160 & 0,103 & 135 \\
\hline 9 Automóveis & 0,004 & 168 & 0,001 & 183 & 0,002 & 184 & 0,005 & 165 & 0,000 & 184 & 0,003 & 182 \\
\hline 10 Caminhões e & 0,007 & 162 & 0,001 & 180 & 0,004 & 180 & 0,011 & 159 & 0,001 & 181 & 0,006 & 178 \\
\hline 11 Peças e & 0,290 & 92 & 0,253 & 100 & 0,271 & 111 & 0,035 & 140 & 0,012 & 170 & 0,024 & 169 \\
\hline 12 Madeira e mobiliário & 0,161 & 105 & 0,242 & 102 & 0,202 & 120 & 0,032 & 144 & 0,030 & 153 & 0,031 & 160 \\
\hline 13 Celulose papel e gráfica & 0,065 & 125 & 0,168 & 115 & 6 & 133 & 0,127 & 112 & 0,199 & 108 & 163 & 126 \\
\hline 14 Ind borracha & 0,014 & 155 & 0,028 & 156 & 0,021 & 170 & 0,044 & 136 & 0,031 & 152 & 0,037 & 157 \\
\hline 15 Eler & 0,005 & 167 & 0,020 & 164 & 0,012 & 173 & 0,055 & 128 & 0,475 & 86 & 0,265 & 112 \\
\hline 16 Refino de & $-0,009$ & 177 & 0,028 & 157 & 0,009 & 175 & 1,312 & 43 & 3,550 & 12 & 2,430 & 25 \\
\hline 17 Químicos di & 0,115 & 119 & 0,508 & 82 & 0,311 & 106 & 0,156 & 106 & 0,696 & 69 & 0,426 & 97 \\
\hline 18 Farmácia e v & 0,101 & 121 & 0,032 & 151 & 0,067 & 142 & 0,055 & 129 & 0,004 & 173 & 0,029 & 162 \\
\hline $19 \mathrm{Art}$ & 0,013 & 156 & 0,159 & 117 & 0,086 & 139 & 0,044 & 134 & 0,042 & 146 & 0,043 & 155 \\
\hline 20 Ind têxtil & 0,032 & 143 & 0,026 & 159 & 0,029 & 163 & 0,259 & 95 & 0,379 & 90 & 0,319 & 105 \\
\hline 21 Vestuário e calçados & 0,007 & 161 & 0,001 & 182 & 0,004 & 179 & 0,464 & 76 & 0,020 & 165 & 0,242 & 115 \\
\hline 22 Produtos alimentares & 1,019 & 48 & 0,326 & 97 & 0,673 & 73 & 3,778 & 15 & 0,757 & 65 & 2,269 & 29 \\
\hline 23 Ind. diversas & 0,033 & 141 & 0,062 & 140 & 0,048 & 153 & 0,021 & 152 & 0,018 & 167 & 0,019 & 171 \\
\hline 24 SIUP & 0,213 & 98 & 0,463 & 87 & 0,338 & 104 & 0,198 & 100 & 1,150 & 49 & 0,674 & 72 \\
\hline 25 Construção & 1,179 & 44 & 0,108 & 126 & 0,644 & 75 & 5,466 & 6 & 0,301 & 99 & 2,887 & 17 \\
\hline 26 Comércio & 0,534 & 68 & 0,606 & 74 & 0,570 & 85 & 1,726 & 32 & 1,930 & 34 & 1,828 & 38 \\
\hline 27 Com. Veíc & 0,053 & 130 & 0,018 & 166 & 0,035 & 158 & 0,121 & 116 & 0,034 & 150 & 0,078 & 140 \\
\hline 28 Transporte & 0,370 & 82 & 0,359 & 93 & 0,364 & 100 & 1,103 & 47 & 1,101 & 50 & 1,102 & 53 \\
\hline 29 Comunicações & 0,021 & 151 & 0,182 & 112 & 0,101 & 136 & 0,279 & 94 & 0,578 & 79 & 0,429 & 96 \\
\hline 30 Serv. $p$ & 0,892 & 54 & 0,902 & 57 & 0,897 & 64 & 3,501 & 16 & 2,610 & 23 & 3,056 & 13 \\
\hline 31 Administração pública & 1,153 & 46 & 0,115 & 123 & 0,635 & 77 & 3,930 & 14 & 0,334 & 96 & 2,134 & 32 \\
\hline
\end{tabular}


Tabela 26. Índice puros de ligação para trás, para frente e totais (independentes) para as regiões Centro-Oeste (CO) e São Paulo (SP) - 1999

\begin{tabular}{|c|c|c|c|c|c|c|c|c|c|c|c|c|}
\hline \multirow[b]{2}{*}{ Atividades econômicas } & \multicolumn{6}{|c|}{ Centro-Oeste } & \multicolumn{6}{|c|}{ São Paulo } \\
\hline & trás & ord & Frente & ord & total & ord & trás & ord & frente & ord & total & ord \\
\hline 1 Agropecuária & 1,670 & 34 & 3,442 & 14 & 2,555 & 22 & 1,348 & 42 & 2,555 & 24 & 1,951 & 35 \\
\hline 2 Ext. mineral & 0,000 & 174 & 0,108 & 127 & 0,054 & 152 & 0,031 & 145 & 0,091 & 132 & 0,061 & 147 \\
\hline 3 Ext. petr., gás, carvão & 0,000 & 175 & 0,000 & 185 & 0,000 & 186 & 0,003 & 172 & 0,012 & 169 & 0,007 & 176 \\
\hline 4 Min. Não metálicos & $-0,026$ & 182 & 0,354 & 95 & 0,164 & 125 & 0,366 & 83 & 1,949 & 33 & 1,157 & 51 \\
\hline 5 Siderurgia & $-0,019$ & 178 & 0,147 & 118 & 0,064 & 145 & 0,619 & 63 & 0,877 & 59 & 0,748 & 71 \\
\hline 6 Metalurgia & 0,039 & 139 & 0,094 & 130 & 0,066 & 144 & 1,169 & 45 & 4,578 & 7 & 2,872 & 18 \\
\hline 7 Fab. Máq. e tratores & 0,023 & 150 & 0,037 & 148 & 0,030 & 161 & 2,169 & 25 & 2,459 & 25 & 2,314 & 28 \\
\hline 8 Mat.elétr. & 0,044 & 135 & 0,012 & 171 & 0,028 & 164 & 3,500 & 17 & 1,447 & 43 & 2,475 & 23 \\
\hline 9 Automóveis & 0,002 & 173 & 0,000 & 186 & 0,001 & 185 & 1,796 & 30 & 0,069 & 139 & 0,934 & 62 \\
\hline 10 Caminhões e ônibus & 0,012 & 157 & 0,001 & 179 & 0,006 & 177 & 1,669 & 35 & 0,055 & 142 & 0,863 & 67 \\
\hline 11 Peças e outros veículos & 0,003 & 170 & 0,002 & 178 & 0,002 & 183 & 1,640 & 36 & 2,721 & 22 & 2,180 & 31 \\
\hline 12 Madeira e mobiliário & 0,030 & 146 & 0,203 & 107 & 0,117 & 132 & 0,708 & 59 & 0,502 & 84 & 0,605 & 80 \\
\hline 13 Celulose papel & 0,040 & 138 & 0,048 & 145 & 0,044 & 154 & 0,682 & 61 & 4,013 & 9 & 2,346 & 27 \\
\hline 14 Ind borracha & 0,007 & 163 & 0,016 & 168 & 0,011 & 174 & 0,045 & 133 & 1,619 & 40 & 0,831 & 68 \\
\hline 15 Elem. químicos & $-0,024$ & 181 & 0,376 & 91 & 0,176 & 122 & 0,400 & 81 & 2,088 & 30 & 1,243 & 49 \\
\hline 16 Refino de pe & 0,027 & 148 & 0,051 & 143 & 0,039 & 156 & $-0,732$ & 186 & 12,584 & 1 & 5,918 & 4 \\
\hline 17 Químicos diversos & 0,017 & 153 & 0,168 & 114 & 0,092 & 137 & $-0,042$ & 184 & 3,747 & 11 & 1,850 & 37 \\
\hline 18 Farmácia e veterinária & 0,027 & 147 & 0,004 & 174 & 0,016 & 172 & 2,791 & 22 & 0,597 & 76 & 1,696 & 42 \\
\hline 19 Artigos de plásticos & 0,003 & 169 & 0,004 & 176 & 0,003 & 181 & $-0,029$ & 183 & 2,003 & 32 & 0,986 & 58 \\
\hline 20 Ind têxtil & 0,024 & 149 & 0,030 & 154 & 0,027 & 165 & 0,480 & 73 & 2,187 & 26 & 1,333 & 47 \\
\hline 21 Vestuário e calçados & 0,113 & 120 & 0,003 & 177 & 0,058 & 151 & 1,675 & 33 & 0,051 & 144 & 0,864 & 66 \\
\hline 22 Produtos alimentares & 2,669 & 23 & 0,862 & 61 & 1,766 & 41 & 10,861 & 1 & 2,982 & 18 & 6,926 & 2 \\
\hline 23 Ind. Diversas & 0,032 & 142 & 0,030 & 155 & 0,031 & 159 & 0,441 & 77 & 0,591 & 78 & 0,516 & 89 \\
\hline 24 SIUP & 0,003 & 171 & 0,720 & 66 & 0,361 & 101 & 0,572 & 66 & 3,138 & 17 & 1,853 & 36 \\
\hline 25 Construção civil & 3,157 & 20 & 0,190 & 109 & 1,675 & 43 & 5,210 & 10 & 0,684 & 70 & 2,950 & 16 \\
\hline 26 Comércio & 1,377 & 40 & 1,309 & 44 & 1,343 & 46 & 5,281 & 9 & 5,752 & 4 & 5,516 & 6 \\
\hline 27 Com. Veículos & 0,293 & 91 & 0,025 & 161 & 0,159 & 127 & 0,429 & 79 & 0,172 & 113 & 0,301 & 110 \\
\hline 28 Transporte & 0,435 & 78 & 0,762 & 64 & 0,598 & 83 & 2,130 & 26 & 2,790 & 21 & 2,459 & 24 \\
\hline 29 Comunicações & 0,133 & 111 & 0,476 & 85 & 0,304 & 108 & 0,122 & 115 & 1,913 & 35 & 1,016 & 56 \\
\hline 30 Serv. privados & 1,989 & 29 & 2,097 & 29 & 2,043 & 33 & 8,125 & 3 & 8,173 & 2 & 8,149 & 1 \\
\hline 31 Administração pública & 4,680 & 11 & 0,825 & 62 & 2,755 & 19 & 5,424 & 7 & 0,561 & 80 & 2,995 & 15 \\
\hline
\end{tabular}


Tabela 27. Índice puros de ligação para trás, para frente e totais (independentes) para as regiões resto do Sudeste (RSE) e Sul (S) - 1999

\begin{tabular}{|c|c|c|c|c|c|c|c|c|c|c|c|c|}
\hline \multirow[b]{2}{*}{ Atividades econômicas } & \multicolumn{6}{|c|}{ Resto do Sudeste } & \multicolumn{6}{|c|}{ Sul } \\
\hline & trás & ord & frente & ord & total & Ord & trás & ord & frente & ord & total & ord \\
\hline 1 Agropecuária & 1,609 & 37 & 4,615 & 6 & 3,110 & 11 & 2,105 & 27 & 7,170 & 3 & 4,634 & 7 \\
\hline 2 Ext. mineral & 0,903 & 53 & 0,824 & 63 & 0,864 & 65 & 0,011 & 158 & 0,038 & 147 & 0,024 & 168 \\
\hline 3 Ext. petr., gás, carvão & 0,145 & 108 & 2,960 & 19 & 1,551 & 45 & $-0,020$ & 179 & 0,070 & 138 & 0,025 & 167 \\
\hline 4 Min. Não metálicos & 0,055 & 127 & 1,905 & 37 & 0,979 & 59 & 0,010 & 160 & 1,193 & 47 & 0,601 & 81 \\
\hline 5 Siderurgia & 0,519 & 70 & 4,879 & 5 & 2,696 & 20 & 0,156 & 107 & 0,183 & 111 & 0,170 & 123 \\
\hline 6 Metalurgia & 0,506 & 71 & 2,026 & 31 & 1,265 & 48 & 0,304 & 90 & 1,498 & 41 & 0,901 & 63 \\
\hline 7 Fab. $\mathrm{N}$ & 0,246 & 96 & 0,141 & 121 & 0,194 & 121 & 1,013 & 49 & 0,865 & 60 & 0,939 & 61 \\
\hline 8 Mat.elétr. $€$ & 0,526 & 69 & 0,080 & 135 & 0,303 & 109 & 0,709 & 58 & 0,208 & 106 & 0,459 & 93 \\
\hline 9 Automóveis & 0,966 & 51 & 0,035 & 149 & 0,501 & 91 & 0,596 & 65 & 0,021 & 163 & 0,309 & 107 \\
\hline 10 Caminhões e & 0,322 & 88 & 0,008 & 172 & 0,165 & 124 & 1,001 & 50 & 0,027 & 158 & 0,515 & 90 \\
\hline 11 Peças e ou & 0,603 & 64 & 0,208 & 105 & 0,406 & 99 & 0,477 & 74 & 0,244 & 101 & 0,361 & 102 \\
\hline 12 Madeira e mobiliário & 0,352 & 84 & 0,058 & 141 & 0,205 & 119 & 1,365 & 41 & 0,713 & 67 & 1,040 & 55 \\
\hline 13 Celulose & 0,498 & 72 & 1,046 & 52 & 0,772 & 70 & 0,413 & 80 & 1,209 & 46 & 0,810 & 69 \\
\hline 14 Ind & 0,126 & 113 & 0,094 & 129 & 0,110 & 134 & 0,087 & 123 & 0,405 & 88 & 0,246 & 114 \\
\hline 15 Elem. químicos & 0,174 & 103 & 1,038 & 53 & 0,606 & 79 & 0,137 & 110 & 0,371 & 92 & 0,254 & 113 \\
\hline 16 Refino de petróleo & 0,563 & 67 & 0,656 & 71 & 0,609 & 78 & $-0,022$ & 180 & 3,960 & 10 & 1,967 & 34 \\
\hline 17 Quími & 0,124 & 114 & 0,992 & 54 & 0,558 & 86 & 0,281 & 93 & 0,916 & 56 & 0,598 & 82 \\
\hline 18 Farmácia e veterinária & 0,662 & 62 & 0,230 & 103 & 0,446 & 95 & 0,049 & 132 & 0,004 & 175 & 0,027 & 166 \\
\hline 19 Artigos & 0,144 & 109 & 0,145 & 119 & 0,145 & 129 & 0,115 & 118 & 0,594 & 77 & 0,354 & 103 \\
\hline 20 Ind têxtil & 0,339 & 85 & 0,702 & 68 & 0,520 & 88 & 0,470 & 75 & 0,604 & 75 & 0,537 & 87 \\
\hline 21 Vestuário e ca & 0,912 & 52 & 0,022 & 162 & 0,467 & 92 & 2,082 & 28 & 0,092 & 131 & 1,088 & 54 \\
\hline 22 Produtos alime & 5,376 & 8 & 1,256 & 45 & 3,319 & 10 & 10,365 & 2 & 2,163 & 27 & 6,269 & 3 \\
\hline 23 Ind. Diversas & 0,164 & 104 & 0,102 & 128 & 0,133 & 130 & 0,743 & 56 & 0,540 & 81 & 0,642 & 76 \\
\hline 24 SIUP & 0,325 & 87 & 2,159 & 28 & 1,241 & 50 & 0,211 & 99 & 1,774 & 38 & 0,991 & 57 \\
\hline 25 Constr & 5,924 & 5 & 0,896 & 58 & 3,413 & 8 & 4,335 & 13 & 0,394 & 89 & 2,367 & 26 \\
\hline 26 Comércio & 2,822 & 21 & 3,327 & 16 & 3,074 & 12 & 2,666 & 24 & 3,330 & 15 & 2,998 & 14 \\
\hline 27 Com. Veícul & 0,069 & 124 & 0,079 & 136 & 0,074 & 141 & 0,339 & 86 & 0,084 & 133 & 0,212 & 118 \\
\hline 28 Transporte & 1,728 & 31 & 1,912 & 36 & 1,820 & 39 & 1,559 & 38 & 1,664 & 39 & 1,611 & 44 \\
\hline 29 Comunicações & 0,739 & 57 & 1,162 & 48 & 0,950 & 60 & 0,214 & 97 & 0,958 & 55 & 0,586 & 84 \\
\hline 30 Serv. privados & 7,179 & 4 & 4,261 & 8 & 5,721 & 5 & 3,298 & 18 & 3,512 & 13 & 3,405 & 9 \\
\hline 31 Administração pública & 4,619 & 12 & 0,503 & 83 & 2,563 & 21 & 3,235 & 19 & 0,305 & 98 & 1,772 & 40 \\
\hline
\end{tabular}

Os índices puros totais sintetizam a importância das atividades econômicas de uma economia em termos dos seus impactos para frente e para trás. Nesta perspectiva, foram identificados 55 setores-chave no sistema inter-regional. 
Considerando a estrutura produtiva nacional, os setores-chave que apresentam índices puros totais superiores, no mínimo, duas vezes à média da economia, podem ser identificados na Figura 16. Os setores com maiores índices de ligação são apresentados em sentido horário, partindo do eixo central com a escala de valores. Merecem destaque $^{18}$, sobretudo, as seguintes atividades: (i) Serviços privados e Produtos Alimentares, em São Paulo, no resto do Sudeste e na região Sul; (ii) Agropecuária no resto do Sudeste e no Sul; (iii) Comércio em São Paulo e no resto do Sudeste; (iv) Refino de petróleo em São Paulo; (v) Construção Civil no Sudeste; e (vi) Serviços privados no Nordeste.

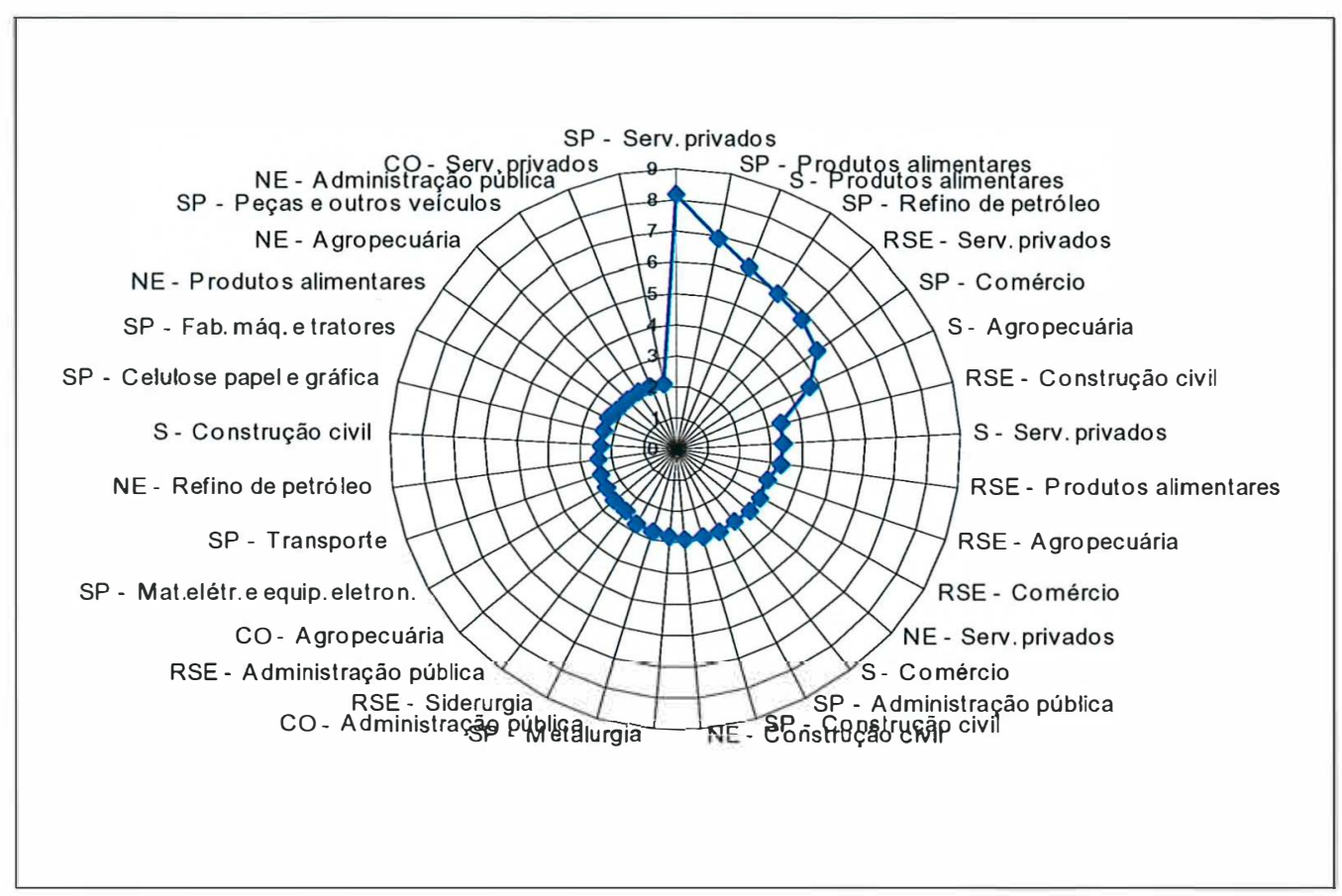

Figura 16 - Índices de ligação totais mais elevados do sistema inter-regional

${ }^{18}$ Considerou-se os índices superiores a três. 


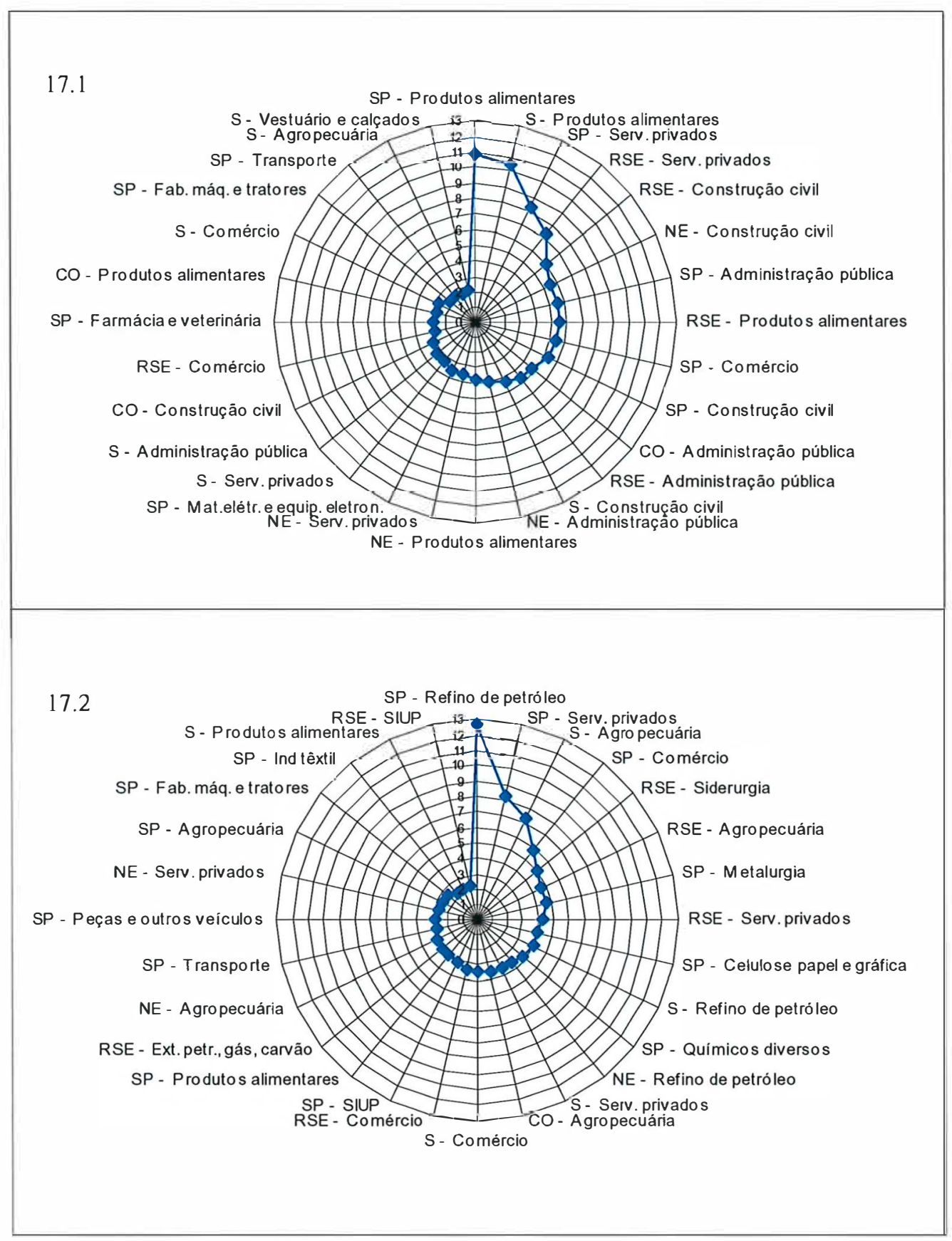

Figura 17 - Índices puros de ligação pra trás (17.1) e para frente (17.2) mais elevados do sistema inter-regional 


\subsection{Multiplicadores}

Os multiplicadores do modelo insumo-produto, ao considerarem a interdependência setorial, visam subsidiar uma avaliação detalhada acerca dos impactos da demanda final. No presente trabalho foram calculados os multiplicadores de produção, emprego e renda, sendo que os dois últimos são avaliados de forma associada ao número de emprego gerados na economia.

$\mathrm{Na}$ análise desses multiplicadores foram considerados os multiplicadores do tipo I e do tipo II. Os primeiros se restringem aos impactos decorrentes das relações intersetoriais diretas (no próprio setor) e indiretas (nos demais setores da economia). Os multiplicadores do tipo II, consideram os efeitos induzidos pelo fluxo de consumo e de renda das famílias na atividade econômica.

\subsubsection{Produção}

O multiplicador de produção é utilizado a fim de quantificar a produção gerada por um setor específico da economia, decorrente do aumento de uma unidade monetária da demanda final.

Os multiplicadores de produção do tipo I e do tipo II foram calculados para todas as atividades do sistema inter-regional, sendo no entanto enfatizados na análise a seguir os multiplicadores referentes ao setor automotivo e a atividade de comércio de peças e outros veículos.

A Tabela 28 apresenta os multiplicadores de produção do tipo I para as atividades pertencentes ao setor automotivo e para atividades Comércio de peças e veículos. Assim, considerando inicialmente o consumo das famílias exógeno, o aumento de uma unidade monetária da demanda por produtos do setor Automóveis do Norte implica um aumento total da produção na economia de $\mathrm{R} \$ 1,51$ reais, sendo que deste valor um real será destinado a demanda final. Do total gerado na economia, $R \$ 1,36$ será gerado na própria região e o valor restante é atribuído ao estímulo da produção gerado nas demais regiões do sistema. 
Tabela 28. Multiplicadores de produção do tipo I para atividades selecionadas - 1999

\begin{tabular}{|c|c|c|c|c|c|c|c|c|}
\hline & & $\mathrm{N}$ & $\mathrm{NE}$ & $\mathrm{CO}$ & SP & RSE & $\mathrm{S}$ & total \\
\hline $\mathrm{N}$ & Automóveis & 1,36 & 0,02 & 0,01 & 0,07 & 0,03 & 0,02 & 1,51 \\
\hline $\mathrm{N}$ & Caminhões e ônibus & 1,37 & 0,02 & 0,01 & 0,07 & 0,03 & 0,02 & 1,52 \\
\hline $\mathrm{N}$ & Peças e outros veículos & 1,20 & 0,05 & 0,02 & 0,25 & 0,14 & 0,05 & 1,72 \\
\hline $\mathrm{N}$ & Com. Veículos e peças & 1,24 & 0,01 & 0,01 & 0,04 & 0,01 & 0,01 & 1,33 \\
\hline $\mathrm{NE}$ & Automóveis & 0,01 & 1,88 & 0,01 & 0,09 & 0,05 & 0,02 & 2,07 \\
\hline NE & Caminhões e ônibus & 0,01 & 1,86 & 0,00 & 0,09 & 0,05 & 0,02 & 2,04 \\
\hline NE & Peças e outros veículos & 0,01 & 1,92 & 0,01 & 0,11 & 0,08 & 0,03 & 2,15 \\
\hline NE & Com. Veículos e peças & 0,00 & 1,17 & 0,00 & 0,03 & 0,01 & 0,01 & 1,23 \\
\hline $\mathrm{CO}$ & Automóveis & 0,01 & 0,02 & 1,91 & 0,15 & 0,07 & 0,04 & 2,19 \\
\hline $\mathrm{CO}$ & Caminhões e ônibus & 0,01 & 0,02 & 1,88 & 0,15 & 0,07 & 0,04 & 2,17 \\
\hline $\mathrm{CO}$ & Peças e outros veículos & 0,01 & 0,02 & 2,00 & 0,15 & 0,09 & 0,04 & 2,30 \\
\hline $\mathrm{CO}$ & Com. Veículos e peças & 0,01 & 0,01 & 1,45 & 0,10 & 0,04 & 0,03 & 1,64 \\
\hline SP & Automóveis & 0,02 & 0,05 & 0,02 & 1,70 & 0,18 & 0,07 & 2,03 \\
\hline SP & Caminhões e ônibus & 0,02 & 0,05 & 0,02 & 1,67 & 0,18 & 0,07 & 2,01 \\
\hline SP & Peças e outros veículos & 0,03 & 0,07 & 0,02 & 1,62 & 0,29 & 0,12 & 2,16 \\
\hline SP & Com. Veículos e peças & 0,00 & 0,01 & 0,00 & 1,30 & 0,02 & 0,01 & 1,34 \\
\hline RSE & Automóveis & 0,03 & 0,04 & 0,02 & 0,47 & 1,33 & 0,09 & 1,98 \\
\hline RSE & Caminhões e ônibus & 0,01 & 0,02 & 0,01 & 0,13 & 1,73 & 0,03 & 1,93 \\
\hline RSE & Peças e outros veículos & 0,01 & 0,02 & 0,01 & 0,18 & 1,77 & 0,04 & 2,03 \\
\hline RSE & Com. Veículos e peças & 0,00 & 0,00 & 0,00 & 0,02 & 1,18 & 0,01 & 1,21 \\
\hline $\mathrm{S}$ & Automóveis & 0,02 & 0,03 & 0,02 & 0,39 & 0,15 & 1,55 & 2,14 \\
\hline$S$ & Caminhões e ônibus & 0,03 & 0,04 & 0,02 & 0,55 & 0,19 & 1,27 & 2,11 \\
\hline $\mathrm{S}$ & Peças e outros veículos & 0,01 & 0,04 & 0,01 & 0,23 & 0,16 & 1,78 & 2,23 \\
\hline $\mathrm{S}$ & Com. Veículos e peças & 0,00 & 0,01 & 0,01 & 0,08 & 0,02 & 1,34 & 1,46 \\
\hline
\end{tabular}

Observando os multiplicadores do tipo I totais, somente para o setor automotivo, como mostra a Tabela 28 , nas diversas regiões tem-se que as cinco atividades com maior capacidade de estimular a produção da economia no setor automotivo são as atividades de Peças e outros veículos do Centro-Oeste e do Sul e São Paulo, bem como nas atividades de Automóveis e Caminhões e Ônibus do Centro-Oeste. Considerando aquelas com multiplicadores acima de dois, acrescentam-se na seqüência as atividades Peças e outros veículos no Nordeste, Automóveis e Caminhões e Ônibus no Sul, Automóveis, Caminhões e Ônibus no Nordeste, Peças e outros veículos no Resto do Sudeste e automóveis Caminhões e Ônibus em São Paulo. 
Dessas regiões a região que mais se beneficia do efeito multiplicador de produção do setor automotivo provenientes das demais regiões do sistema é a região de São Paulo, seguida do Resto do Sudeste e Centro-Oeste.

Cabe salientar ainda que das atividades mencionadas na Tabela 28, somente Peças e outros veículos do Centro-Oeste encontram-se entre as vinte com maiores multiplicadores de produção. As demais atividades destacadas neste ranking (ver tabelas 54 a 59 do Anexo), são: Siderurgia e Indústria têxtil, em todas as regiões, exceto no Norte; Produtos alimentares, no Centro-Oeste; São Paulo e Sul, Metalurgia no CentroOeste, Sul , Nordeste e São Paulo; e Indústria da borracha no Centro-Oeste.

O efeito do multiplicador de produção do tipo I pode ser visualizado em termos percentuais na Tabela 29. Segundo as informações apresentadas nesta tabela, cerca de $90,26 \%$ do efeito multiplicador gerado pelo aumento de uma unidade monetária da demanda final por produtos do setor Automóveis do Norte, afeta a própria região. $\mathrm{O}$ restante do impacto gerado por essa atividade se distribui entre as demais regiões, da seguinte forma: $1,16 \%$ impacta o Nordeste, $0,43 \%$ o Centro-Oeste, 4,80\% São Paulo, $2,28 \%$ o resto do Sudeste, $1,06 \%$ afeta o Sul.

Do ponto de vista dos multiplicadores do tipo II, os quais levam em conta o estímulo da produção induzido pelo consumo das famílias, as atividades localizadas no Nordeste se sobressaem, apresentando os maiores efeitos multiplicadores, quando consideradas somente as atividades do setor automotivo e o Comércio de peças (Tabela $30)$. 
Tabela 29. Multiplicadores de produção do tipo I em percentual para atividades selecionadas - 1999

\begin{tabular}{llrrrrrrr}
\hline & & $\mathrm{N}$ & \multicolumn{1}{c}{$\mathrm{NE}$} & \multicolumn{1}{c}{$\mathrm{CO}$} & \multicolumn{1}{c}{$\mathrm{SP}$} & \multicolumn{1}{c}{$\mathrm{RSE}$} & \multicolumn{1}{c}{$\mathrm{S}$} & \multicolumn{1}{c}{ total } \\
\hline $\mathrm{N}$ & Automóveis & 90,26 & 1,16 & 0,43 & 4,80 & 2,28 & 1,06 & 100,00 \\
$\mathrm{~N}$ & Caminhões e ônibus & 90,09 & 1,19 & 0,44 & 4,89 & 2,31 & 1,08 & 100,00 \\
$\mathrm{~N}$ & Peças e outros veículos & 69,56 & 2,97 & 1,45 & 14,60 & 8,34 & 3,09 & 100,00 \\
$\mathrm{~N}$ & Com. Veículos e peças & 93,30 & 0,65 & 0,85 & 3,35 & 1,07 & 0,78 & 100,00 \\
$\mathrm{NE}$ & Automóveis & 0,44 & 91,19 & 0,24 & 4,36 & 2,60 & 1,17 & 100,00 \\
$\mathrm{NE}$ & Caminhões e ônibus & 0,43 & 91,29 & 0,24 & 4,31 & 2,57 & 1,16 & 100,00 \\
$\mathrm{NE}$ & Peças e outros veículos & 0,58 & 89,11 & 0,29 & 5,13 & 3,49 & 1,40 & 100,00 \\
$\mathrm{NE}$ & Com. Veículos e peças & 0,20 & 95,32 & 0,24 & 2,51 & 1,01 & 0,72 & 100,00 \\
$\mathrm{CO}$ & Automóveis & 0,42 & 0,70 & 86,90 & 6,86 & 3,21 & 1,91 & 100,00 \\
$\mathrm{CO}$ & Caminhões e ônibus & 0,43 & 0,71 & 86,64 & 7,04 & 3,21 & 1,97 & 100,00 \\
$\mathrm{CO}$ & Peças e outros veículos & 0,44 & 0,71 & 86,63 & 6,65 & 3,72 & 1,85 & 100,00 \\
$\mathrm{CO}$ & Com. Veículos e peças & 0,42 & 0,46 & 88,58 & 6,25 & 2,41 & 1,89 & 100,00 \\
$\mathrm{SP}$ & Automóveis & 1,06 & 2,31 & 0,85 & 83,47 & 8,92 & 3,40 & 100,00 \\
$\mathrm{SP}$ & Caminhões e ônibus & 1,10 & 2,36 & 0,86 & 83,12 & 8,99 & 3,56 & 100,00 \\
$\mathrm{SP}$ & Peças e outros veículos & 1,61 & 3,47 & 1,01 & 74,93 & 13,47 & 5,51 & 100,00 \\
$\mathrm{SP}$ & Com. Veículos e peças & 0,25 & 0,38 & 0,23 & 97,13 & 1,17 & 0,84 & 100,00 \\
$\mathrm{RSE}$ & Automóveis & 1,56 & 1,99 & 0,93 & 23,72 & 67,06 & 4,74 & 100,00 \\
$\mathrm{RSE}$ & Caminhões e ônibus & 0,33 & 0,97 & 0,43 & 6,97 & 89,58 & 1,71 & 100,00 \\
$\mathrm{RSE}$ & Peças e outros veículos & 0,41 & 1,14 & 0,47 & 8,82 & 87,02 & 2,13 & 100,00 \\
$\mathrm{RSE}$ & Com. Veículos e peças & 0,11 & 0,21 & 0,14 & 1,64 & 97,43 & 0,46 & 100,00 \\
$\mathrm{~S}$ & Automóveis & 0,80 & 1,36 & 0,72 & 18,01 & 7,01 & 72,09 & 100,00 \\
$\mathrm{~S}$ & Caminhões e ônibus & 1,37 & 1,91 & 1,09 & 26,13 & 9,14 & 60,37 & 100,00 \\
$\mathrm{~S}$ & Peças e outros veículos & 0,40 & 1,57 & 0,67 & 10,47 & 7,13 & 79,76 & 100,00 \\
$\mathrm{~S}$ & Com. Veículos e peças & 0,18 & 0,37 & 0,70 & 5,55 & 1,36 & 91,86 & 100,00 \\
\hline & & & & & & & &
\end{tabular}

Além das quatro atividades apontadas no Nordeste, estão entre as cinco com maiores efeitos multiplicadores a atividade de Peças e outros veículos do Centro -Oeste. Na seqüência aparecem Peças e Outros veículos e Comércio de veículos e peças no Sul, Comércio de veículos e peças no Norte e Peças e Outros veículos em São Paulo. 
Tabela 30. Multiplicadores de Produção do tipo II para atividades selecionadas - 1999

\begin{tabular}{llccccccc}
\hline & $\mathrm{N}$ & $\mathrm{NE}$ & $\mathrm{CO}$ & $\mathrm{SP}$ & $\mathrm{RSE}$ & $\mathrm{S}$ & $\mathrm{TOTAL}$ \\
\hline \multirow{4}{*}{$\mathrm{N}$} & 1,77 & 0,10 & 0,06 & 0,32 & 0,14 & 0,12 & 2,51 \\
& Automóveis & 1,73 & 0,09 & 0,05 & 0,29 & 0,13 & 0,11 & 2,41 \\
& Caminhões e ônibus & 1,55 & 0,16 & 0,08 & 0,56 & 0,28 & 0,19 & 2,82 \\
& Peças e outros veículos & 2,15 & 0,16 & 0,12 & 0,54 & 0,22 & 0,23 & 3,41 \\
& Com. Veículos e peças & 0,06 & 3,21 & 0,06 & 0,63 & 0,31 & 0,26 & 4,54 \\
& Automóveis & 0,06 & 3,21 & 0,06 & 0,63 & 0,31 & 0,26 & 4,54 \\
$\mathrm{NE}$ & Caminhões e ônibus & 0,07 & 3,28 & 0,07 & 0,67 & 0,35 & 0,28 & 4,72 \\
& Peças e outros veículos & 0,07 & 2,91 & 0,08 & 0,69 & 0,33 & 0,30 & 4,37 \\
& Com. Veículos e peças & 0,04 & 0,10 & 2,32 & 0,48 & 0,22 & 0,19 & 3,35 \\
& Automóveis & 0,04 & 0,10 & 2,29 & 0,49 & 0,22 & 0,19 & 3,32 \\
CO & Caminhões e ônibus & 0,05 & 0,12 & 2,55 & 0,58 & 0,28 & 0,23 & 3,80 \\
& Peças e outros veículos & 0,04 & 0,10 & 2,01 & 0,53 & 0,23 & 0,22 & 3,13 \\
& Com. Veículos e peças & 0,06 & 0,14 & 0,05 & 2,22 & 0,33 & 0,21 & 3,01 \\
& Automóveis & 0,06 & 0,14 & 0,05 & 2,19 & 0,33 & 0,21 & 2,98 \\
SP & Caminhões e ônibus & 0,08 & 0,20 & 0,07 & 2,26 & 0,49 & 0,30 & 3,41 \\
& Peças e outros veículos & 0,06 & 0,12 & 0,06 & 2,41 & 0,21 & 0,22 & 3,08 \\
& Com. Veículos e peças & 0,07 & 0,13 & 0,06 & 0,84 & 1,72 & 0,25 & 3,07 \\
& Automóveis & 0,03 & 0,10 & 0,05 & 0,45 & 2,27 & 0,17 & 3,07 \\
RSE & Caminhões e ônibus & 0,04 & 0,12 & 0,06 & 0,56 & 2,41 & 0,21 & 3,40 \\
& Peças e outros veículos & 0,04 & 0,12 & 0,07 & 0,53 & 2,22 & 0,22 & 3,21 \\
& Com. Veículos e peças & 0,05 & 0,11 & 0,06 & 0,76 & 0,30 & 2,12 & 3,40 \\
& Automóveis & 0,06 & 0,13 & 0,07 & 0,96 & 0,35 & 1,76 & 3,34 \\
S Caminhões e ônibus & 0,04 & 0,13 & 0,06 & 0,63 & 0,32 & 2,55 & 3,72 \\
& Peças e outros veículos & 0,04 & 0,10 & 0,07 & 0,59 & 0,20 & 2,50 & 3,50 \\
\hline & Com. Veículos e peças & & & & & & &
\end{tabular}

Da mesma forma que no caso dos multiplicadores do tipo I, os dados da Tabela 30 podem ser observados em percentual na Tabela 31. Considerando endógeno o consumo das famílias, $70,68 \%$ do efeito multiplicador sobre gerado pelo aumento de uma unidade monetária da demanda final por produtos do setor Automóveis do Norte, afeta a própria região. $\mathrm{O}$ restante do impacto gerado por essa atividade se distribui entre as demais regiões. Nota-se que os efeitos de transbordamento para a região de São Paulo se apresentam bem superiores àqueles absorvidos pelas demais regiões. 
Tabela 31. Multiplicadores de Produção do tipo II em percentual para atividades selecionadas - 1999

\begin{tabular}{lrrrrrrr}
\hline & $\mathrm{N}$ & \multicolumn{1}{c}{ NE } & \multicolumn{1}{c}{ CO } & \multicolumn{1}{l}{ SP } & \multicolumn{1}{c}{ RSE } & \multicolumn{1}{l}{ S } & TOTAL \\
\hline Automóveis & 70,68 & 4,03 & 2,24 & 12,61 & 5,52 & 4,92 & 100,00 \\
Caminhões e ônibus & 71,69 & 3,92 & 2,11 & 12,21 & 5,37 & 4,71 & 100,00 \\
Peças e outros veículos & 55,10 & 5,66 & 2,81 & 19,79 & 10,02 & 6,62 & 100,00 \\
Com. Veículos e peças & 62,97 & 4,83 & 3,46 & 15,72 & 6,39 & 6,63 & 100,00 \\
Automóveis & 1,38 & 70,79 & 1,41 & 13,78 & 6,92 & 5,71 & 100,00 \\
Caminhões e ônibus & 1,38 & 70,69 & 1,42 & 13,83 & 6,94 & 5,74 & 100,00 \\
Peças e outros veículos & 1,47 & 69,55 & 1,45 & 14,24 & 7,43 & 5,87 & 100,00 \\
Com. Veículos e peças & 1,54 & 66,50 & 1,75 & 15,86 & 7,53 & 6,82 & 100,00 \\
Automóveis & 1,16 & 2,85 & 69,22 & 14,47 & 6,64 & 5,66 & 100,00 \\
Caminhões e ônibus & 1,17 & 2,87 & 68,94 & 14,65 & 6,66 & 5,72 & 100,00 \\
Peças e outros veículos & 1,25 & 3,07 & 67,02 & 15,24 & 7,38 & 6,05 & 100,00 \\
Com. Veículos e peças & 1,39 & 3,23 & 64,36 & 16,86 & 7,24 & 6,91 & 100,00 \\
Automóveis & 1,96 & 4,70 & 1,81 & 73,78 & 10,88 & 6,87 & 100,00 \\
Caminhões e ônibus & 2,00 & 4,77 & 1,82 & 73,44 & 10,95 & 7,02 & 100,00 \\
Peças e outros veículos & 2,44 & 5,92 & 2,01 & 66,37 & 14,36 & 8,91 & 100,00 \\
Com. Veículos e peças & 2,04 & 3,95 & 2,08 & 78,02 & 6,89 & 7,02 & 100,00 \\
Automóveis & 2,15 & 4,35 & 1,94 & 27,35 & 56,17 & 8,05 & 100,00 \\
Caminhões e ônibus & 1,06 & 3,31 & 1,57 & 14,65 & 73,91 & 5,50 & 100,00 \\
Peças e outros veículos & 1,18 & 3,61 & 1,68 & 16,49 & 70,94 & 6,10 & 100,00 \\
Com. Veículos e peças & 1,31 & 3,80 & 2,16 & 16,45 & 69,35 & 6,93 & 100,00 \\
Automóveis & 1,38 & 3,24 & 1,69 & 22,47 & 8,74 & 62,48 & 100,00 \\
Caminhões e ônibus & 1,91 & 3,94 & 2,01 & 28,73 & 10,57 & 52,84 & 100,00 \\
Peças e outros veículos & 1,02 & 3,39 & 1,67 & 16,84 & 8,62 & 68,45 & 100,00 \\
Com. Veículos e peças & 1,07 & 2,88 & 2,12 & 16,94 & 5,71 & 71,28 & 100,00 \\
\hline & & & & & & &
\end{tabular}

\subsubsection{Emprego}

O multiplicador de emprego expressa o número de empregos gerados por um setor no total da economia, para cada pessoa adicional empregada nesse setor

Os multiplicadores de emprego do tipo I e do tipo II segundo as regiões do sistema inter-regional podem ser visualizados na Tabelas 32 e 33. Em linhas gerais, verifica-se que algumas das atividades econômicas pertencentes ao setor automotivo apresentam elevados efeitos multiplicadores do tipo I. São elas: Caminhões e ônibus no Sul (em quarto lugar no sistema) e no Centro-Oeste, Peças e outros veículos no Norte e Automóveis em São Paulo. 
Tabela 32. Multiplicador de Emprego do tipo I e do tipo II segundo as regiões Norte, Nordeste e Centro-Oeste

\begin{tabular}{lcccccc}
\hline \multirow{2}{*}{ Atividades econômicas } & \multicolumn{2}{c}{ Norte } & \multicolumn{2}{c}{ Nordeste } & \multicolumn{2}{c}{ Centro- Oeste } \\
\cline { 2 - 7 } & tipo I & tipo II & tipo I & tipo II & tipo I & tipo II \\
\hline Agropecuária & 1,41 & 2,30 & 1,19 & 1,74 & 1,52 & 1,99 \\
Ext. mineral & 3,31 & 10,39 & 1,20 & 2,32 & 1,38 & 2,45 \\
Ext. petr., gás, carvão & 6,01 & 31,63 & 9,40 & 80,65 & 2,12 & 7,35 \\
Min. Não metálicos & 1,64 & 4,33 & 1,55 & 3,74 & 2,26 & 4,36 \\
Siderurgia & 4,36 & 13,42 & 23,80 & 95,78 & 7,36 & 14,40 \\
Metalurgia & 2,41 & 6,82 & 3,48 & 13,89 & 1,73 & 2,69 \\
Fab. Máq. E tratores & 1,54 & 4,79 & 1,42 & 5,60 & 1,30 & 1,93 \\
Mat.elétr. e equip. eletron. & 2,54 & 8,78 & 3,05 & 10,79 & 2,23 & 3,55 \\
Automóveis & 1,68 & 4,24 & 1,87 & 4,97 & 2,33 & 3,95 \\
Caminhões e ônibus & 1,90 & 4,95 & 2,94 & 10,15 & 8,42 & 17,78 \\
Peças e outros veículos & 12,93 & 52,28 & 2,26 & 7,36 & 1,52 & 2,27 \\
Madeira e mobiliário & 1,56 & 2,75 & 1,23 & 1,54 & 1,54 & 2,18 \\
Celulose papel e gráfica & 2,37 & 6,02 & 2,85 & 8,46 & 1,70 & 3,14 \\
Ind borracha & 2,38 & 6,01 & 3,72 & 13,02 & 2,53 & 4,15 \\
Elem. químicos & 3,44 & 14,91 & 16,62 & 55,85 & 12,29 & 20,46 \\
Refino de petróleo & 1,27 & 2,43 & 27,06 & 293,62 & 5,11 & 15,78 \\
Químicos diversos & 7,47 & 31,25 & 5,19 & 24,88 & 3,83 & 9,08 \\
Farmácia e veterinária & 3,34 & 10,92 & 1,99 & 6,96 & 1,66 & 2,58 \\
Artigos de plásticos & 2,14 & 7,66 & 1,33 & 3,59 & 1,20 & 1,57 \\
Ind têxtil & 2,90 & 6,35 & 3,50 & 8,73 & 3,98 & 7,03 \\
Vestuário e calçados & 1,04 & 1,14 & 1,23 & 1,86 & 1,14 & 1,32 \\
Produtos alimentares & 5,53 & 10,64 & 7,44 & 14,11 & 7,04 & 10,50 \\
Ind. Diversas & 2,20 & 6,10 & 1,11 & 1,46 & 1,59 & 2,72 \\
SIUP & 3,03 & 11,30 & 3,40 & 31,66 & 2,44 & 7,06 \\
Construção civil & 1,80 & 5,04 & 1,64 & 6,53 & 2,00 & 3,42 \\
Comércio & 1,24 & 2,35 & 1,29 & 3,41 & 1,30 & 2,17 \\
Com. Veículos e peças & 1,20 & 2,62 & 1,16 & 3,82 & 1,37 & 2,42 \\
Transporte & 1,41 & 3,05 & 1,37 & 3,81 & 1,45 & 2,72 \\
Comunicações & 3,63 & 17,98 & 2,86 & 30,52 & 2,60 & 8,34 \\
Serv. privados & 1,20 & 2,43 & 1,24 & 3,18 & 1,28 & 2,28 \\
Administração pública & 1,35 & 4,02 & 1,67 & 6,90 & 1,71 & 5,83 \\
\hline & & & & & & \\
\hline
\end{tabular}


Tabela 33. Multiplicador de Emprego do tipo I e do tipo II segundo as regiões São Paulo, resto do Sudeste e Sul

\begin{tabular}{|c|c|c|c|c|c|c|}
\hline \multirow{2}{*}{ Atividades econômicas } & \multicolumn{2}{|c|}{ São Paulo } & \multicolumn{2}{|c|}{ Resto do Sudeste } & \multicolumn{2}{|c|}{ Sul } \\
\hline & Tipo I & tipo II & tipo I & tipo II & tipo I & tipo II \\
\hline Agropecuária & 1,26 & 1,88 & 1,42 & 2,01 & 1,29 & 1,98 \\
\hline Ext. mineral & 1,31 & 2,21 & 2,88 & 8,24 & 1,22 & 1,73 \\
\hline Ext. petr., gás, carvão & 1,61 & 4,44 & 6,54 & 31,95 & 1,21 & 2,14 \\
\hline Min. Não metálicos & 2,65 & 6,38 & 2,08 & 5,59 & 2,26 & 5,47 \\
\hline Siderurgia & 8,63 & 18,96 & 28,20 & 77,92 & 4,84 & 11,74 \\
\hline Metalurgia & 2,61 & 6,25 & 1,97 & 4,60 & 2,04 & 4,68 \\
\hline Fab. Máq. E tratores & 2,52 & 7,70 & 1,33 & 3,22 & 2,24 & 7,71 \\
\hline Mat.elétr. e equip. eletron. & 4,41 & 11,60 & 3,43 & 8,99 & 3,27 & 8,51 \\
\hline Automóveis & 7,40 & 19,11 & 7,01 & 20,01 & 8,40 & 22,85 \\
\hline Caminhões e ônibus & 5,72 & 14,49 & 5,44 & 15,71 & 23,90 & 70,40 \\
\hline Peças e outros veículos & 3,21 & 8,05 & 2,96 & 8,16 & 4,23 & 11,39 \\
\hline Madeira e mobiliário & 2,20 & 3,92 & 1,43 & 2,24 & 2,20 & 4,32 \\
\hline Celulose papel e gráfica & 3,06 & 7,25 & 3,29 & 8,11 & 2,97 & 6,84 \\
\hline Ind borracha & 6,75 & 16,24 & 4,27 & 11,63 & 7,70 & 21,52 \\
\hline Elem. químicos & 13,10 & 25,90 & 11,84 & 41,65 & 8,06 & 21,75 \\
\hline Refino de petróleo & 33,57 & 149,92 & 7,40 & 35,76 & 22,85 & 110,97 \\
\hline Químicos diversos & 4,83 & 13,21 & 3,19 & 9,64 & 4,01 & 11,45 \\
\hline Farmácia e veterinária & 5,42 & 14,63 & 4,50 & 14,43 & 1,44 & 2,40 \\
\hline Artigos de plásticos & 2,00 & 5,76 & 1,64 & 4,41 & 1,58 & 3,74 \\
\hline Ind têxtil & 4,73 & 9,02 & 4,34 & 9,45 & 4,87 & 10,33 \\
\hline Vestuário e calçados & 1,32 & 1,96 & 1,21 & 1,70 & 1,46 & 2,40 \\
\hline Produtos alimentares & 8,87 & 15,05 & 5,29 & 8,90 & 10,79 & 18,93 \\
\hline Ind. Diversas & 1,77 & 3,53 & 1,40 & 2,28 & 3,44 & 9,05 \\
\hline SIUP & 3,55 & 21,88 & 3,10 & 19,14 & 3,72 & 23,32 \\
\hline Construção civil & 1,41 & 2,95 & 1,56 & 3,63 & 1,65 & 3,84 \\
\hline Comércio & 1,22 & 2,09 & 1,23 & 2,28 & 1,21 & 2,05 \\
\hline Com. Veículos e peças & 1,15 & 2,31 & 1,11 & 2,34 & 1,25 & 2,52 \\
\hline Transporte & 1,69 & 3,46 & 1,46 & 3,34 & 1,75 & 4,16 \\
\hline Comunicações & 1,34 & 10,36 & 3,13 & 14,49 & 2,79 & 12,89 \\
\hline Serv. privados & 1,29 & 3,01 & 1,23 & 2,37 & 1,21 & 2,62 \\
\hline Administração pública & 1,47 & 4,65 & 1,51 & 4,83 & 1,58 & 4,89 \\
\hline
\end{tabular}

Essas atividades se encontram entre as 20 atividades com maiores multiplicadores de emprego do tipo I. Além delas, destacam-se as atividades de Refino de petróleo de São Paulo, do Nordeste e do Sul, Siderurgia de São Paulo, resto do 
Sudeste e Nordeste, Elementos químicos de todas as regiões, Produtos alimentares no Sul e em São Paulo, Automóveis em São Paulo, Indústria da borracha no Sul.

Considerando o efeito induzido pelo consumo das famílias, mediante a análise do multiplicador do tipo II, entretanto, esse efeito se transfere para boa parte das atividades localizadas na região Norte, com destaque para Extração de petróleo, gás e carvão, Agropecuária, Metalurgia, Siderurgia, Celulose papel e gráfica, Extrativa mineral, Minerais não metálicos, Fabricação de máquinas e tratores, Automóveis, Peças e outros veículos, Produtos alimentares e Transporte, Comunicações e Indústria Têxtil, Material elétrico e equipamento eletrônico; e para a região Nordeste no caso de Transporte, Minerais não metálicos e artigos plásticos e no Centro-Oeste para a Indústria da Borracha.

A análise de emprego mais precisa requer informações sobre o número de empregos gerados, haja vista as especificidades setoriais em termos de intensidade de capital e mão de obra relativamente aos demais fatores de produção. Dentro desta perspectiva, são apresentados na Tabela 34, o número de empregos gerados na economia pelos setores pertencentes ao setor automotivo e o Comércio varejista de veículos e peças.

De acordo com os dados da Tabela 34, constata-se as atividades pertencentes ao setor automotivo geram cerca de 1967,19 empregos. O número de emprego gerados diretamente no setor, 297 , representa cerca de $15 \%$ do total. Os empregos gerados indiretamente nos demais setores da economia representam $24, \%$, enquanto verifica-se que $60 \%$ dos empregos totais se referem aos empregos induzidos pelo consumo das famílias. Esta decomposição se altera um pouco se acrescentarmos a atividade Comércio de veículos e peças, favorecendo o peso dos empregos diretos. Este setor contribui para a geração de cerca de 758 empregos no total da economia.

Em se tratando da geração de empregos diretos no próprio setor, salienta-se a maior capacidade de geração de emprego das atividade Peças e outros veículos, (com exceção do Norte) e Comércio de veículos e pecas em quase todas as regiões analisadas. 
Nas regiões Nordeste e Centro-Oeste pode se destacar os efeitos indiretos que as atividades do setor automotivo geram nos demais atividades econômicas.

Tabela 34. Número total de empregados gerados na economia, pela variação de um milhão de reais na demanda final

\begin{tabular}{|c|c|c|c|c|c|}
\hline Região & Atividade econômica & direto & indireto & Induzido & total \\
\hline \multirow{4}{*}{$\mathrm{N}$} & Automóveis & 16,75 & 11,35 & 42,95 & 71,05 \\
\hline & Caminhões e Ônibus & 12,63 & 11,34 & 38,50 & 62,48 \\
\hline & Pecas e Outros veículos & 1,20 & 14,37 & 47,37 & 62,95 \\
\hline & Com. Veículos e peças & 62,61 & 12,42 & 88,71 & 163,74 \\
\hline \multirow{4}{*}{ NE } & Automóveis & 49,96 & 43,28 & 155,09 & 248,33 \\
\hline & Caminhões e Ônibus & 21,71 & 42,16 & 156,55 & 220,42 \\
\hline & Pecas e Outros veículos & 31,50 & 39,69 & 160,60 & 231,79 \\
\hline & Com. Veículos e peças & 75,06 & 12,32 & 199,64 & 287,02 \\
\hline \multirow{4}{*}{$\mathrm{CO}$} & Automóveis & 28,83 & 38,34 & 46,59 & 113,76 \\
\hline & Caminhões e Ônibus & 4,96 & 36,79 & 46,44 & 88,19 \\
\hline & Pecas e Outros veículos & 80,06 & 41,78 & 60,26 & 182,10 \\
\hline & Com. Veículos e peças & 56,39 & 20,62 & 59,60 & 136,60 \\
\hline \multirow{4}{*}{ SP } & Automóveis & 3,23 & 20,68 & 37,86 & 61,77 \\
\hline & Caminhões e Ônibus & 4,31 & 20,35 & 37,86 & 62,53 \\
\hline & Pecas e Outros veículos & 10,13 & 22,44 & 49,05 & 81,62 \\
\hline & Com. Veículos e peças & 54,48 & 8,35 & 63,14 & 125,97 \\
\hline \multirow{4}{*}{ RSE } & Automóveis & 3,46 & 20,83 & 44,98 & 69,27 \\
\hline & Caminhões e Ônibus & 4,66 & 20,68 & 47,84 & 73,18 \\
\hline & Pecas e Outros veículos & 10,98 & 21,53 & 57,05 & 89,55 \\
\hline & Com. Veículos e peças & 67,66 & 7,60 & 83,18 & 158,45 \\
\hline \multirow{4}{*}{$S$} & Automóveis & 3,46 & 25,61 & 50,03 & 79,10 \\
\hline & Caminhões e Ônibus & 1,06 & 24,18 & 49,09 & 74,33 \\
\hline & Pecas e Outros veículos & 8,32 & 26,88 & 59,58 & 94,79 \\
\hline & Com. Veículos e peças & 63,47 & 15,63 & 80,69 & 159,79 \\
\hline $\begin{array}{l}\text { Total do } \\
\text { pecas) }\end{array}$ & Setor Automotivo (excluindo Com veic & 297,22 & 482,28 & $1.187,69$ & $1.967,19$ \\
\hline Total & & 676,88 & 559,22 & $1.762,66$ & $2.998,76$ \\
\hline
\end{tabular}

A avaliação dos efeitos induzidos elevados no multiplicador e no gerador de emprego das regiões do Norte e Nordeste requerem certa cautela. Isso porque a estrutura de consumo das famílias destas regiões é composta, em grande parte, por bens produzidos em setores intensivos em mão de obra. Os efeitos do multiplicador e do 
gerador de emprego, e conseqüentemente de renda discutido adiante, podem se apresentar sobreestimados.

Observando os dados da Tabela 35, é possível verificar os transbordamentos regionais de geração de emprego. Assim, dos 71, 05 empregos gerados pela variação da demanda final de um milhão de reais da atividade de Automóveis no Norte, apenas 45, 68 são gerados na própria região.

Tabela 35. Número total de empregos gerados pela variação da demanda final de um milhão de reais, considerando o consumo das famílias endógeno, segundo regiões -1999

\begin{tabular}{|c|c|c|c|c|c|c|c|c|}
\hline Região & Atividade econômica & $\mathrm{N}$ & $\mathrm{NE}$ & $\mathrm{CO}$ & SP & RSE & $\mathrm{S}$ & Total \\
\hline \multirow{4}{*}{$\mathrm{N}$} & Automóveis & 45,68 & 7,66 & 2,61 & 5,95 & 4,53 & 4,62 & 71,05 \\
\hline & Caminhões e Ônibus & 39,16 & 7,08 & 2,36 & 5,49 & 4,16 & 4,22 & 62,48 \\
\hline & Pecas e Outros veículos & 24,13 & 11,09 & 3,49 & 10,07 & 7,51 & 6,65 & 62,95 \\
\hline & Com. Veículos e peças & 116,41 & 13,67 & 5,55 & 11,02 & 8,26 & 8,83 & 163,74 \\
\hline \multirow{4}{*}{ NE } & Automóveis & 2,29 & 210,43 & 2,91 & 12,16 & 10,80 & 9,75 & 248,33 \\
\hline & Caminhões e Ônibus & 2,30 & 182,35 & 2,92 & 12,21 & 10,84 & 9,80 & 220,42 \\
\hline & Pecas e Outros veículos & 2,50 & 191,06 & 3,09 & 13,03 & 11,74 & 10,37 & 231,79 \\
\hline & Com. Veículos e peças & 2,59 & 243,18 & 3,49 & 14,00 & 12,33 & 11,44 & 287,02 \\
\hline \multirow{4}{*}{$\mathrm{CO}$} & Automóveis & 1,45 & 7,81 & 81,76 & 8,78 & 7,14 & 6,82 & 113,76 \\
\hline & Caminhões e Ônibus & 1,45 & 7,79 & 56,20 & 8,81 & 7,11 & 6,83 & 88,19 \\
\hline & Pecas e Outros veículos & 1,78 & 9,62 & 142,78 & 10,64 & 8,89 & 8,39 & 182,10 \\
\hline & Com. Veículos e peças & 1,74 & 8,80 & 98,80 & 10,66 & 8,42 & 8,18 & 136,60 \\
\hline \multirow{4}{*}{ SP } & Automóveis & 2,43 & 11,18 & 2,42 & 28,96 & 8,78 & 8,00 & 61,77 \\
\hline & Caminhões e Ônibus & 2,44 & 11,18 & 2,42 & 29,60 & 8,82 & 8,06 & 62,53 \\
\hline & Pecas e Outros veículos & 3,10 & 14,61 & 2,99 & 37,42 & 12,52 & 10,97 & 81,62 \\
\hline & Com. Veículos e peças & 2,88 & 12,18 & 2,91 & 90,24 & 8,47 & 9,29 & 125,97 \\
\hline \multirow{4}{*}{ SER } & Automóveis & 2,10 & 10,43 & 2,65 & 14,86 & 30,72 & 8,52 & 69,27 \\
\hline & Caminhões e Ônibus & 1,34 & 8,46 & 2,18 & 8,26 & 46,61 & 6,33 & 73,18 \\
\hline & Pecas e Outros veículos & 1,63 & 10,16 & 2,57 & 10,14 & 57,37 & 7,69 & 89,55 \\
\hline & Com. Veículos e peças & 1,75 & 11,04 & 3,13 & 10,39 & 123,37 & 8,78 & 158,45 \\
\hline \multirow{4}{*}{$S$} & Automóveis & 1,63 & 8,58 & 2,49 & 13,49 & 7,68 & 45,24 & 79,10 \\
\hline & Caminhões e Ônibus & 2,05 & 10,15 & 2,90 & 16,80 & 9,17 & 33,26 & 74,33 \\
\hline & Pecas e Outros veículos & 1,48 & 9,54 & 2,67 & 11,30 & 7,91 & 61,89 & 94,79 \\
\hline & Com. Veículos e peças & 1,58 & 8,86 & 3,38 & 12,77 & 7,22 & 125,98 & 159,79 \\
\hline Total & & 265,87 & $1.026,91$ & 438,67 & 407,06 & 430,36 & 429,90 & $2.998,76$ \\
\hline
\end{tabular}


Tabela 36. Percentual de empregos gerados pela variação da demanda final de um milhão de reais, considerando o consumo das famílias endógeno, segundo regiões -1999 .

\begin{tabular}{|c|c|c|c|c|c|c|c|c|}
\hline Região & Atividade econômica & $\mathrm{N}$ & $\mathrm{NE}$ & $\mathrm{CO}$ & SP & RSE & $S$ & Total \\
\hline \multirow{4}{*}{$\mathbf{N}$} & Automóveis & 64,29 & 10,78 & 3,67 & 8,38 & 6,37 & 6,51 & 100,00 \\
\hline & Caminhões e Ônibus & 62,67 & 11,33 & 3,78 & 8,79 & 6,67 & 6,76 & 100,00 \\
\hline & Pecas e Outros veículos & 38,34 & 17,62 & 5,54 & 16,00 & 11,93 & 10,57 & 100,00 \\
\hline & Com. Veículos e peças & 71,09 & 8,35 & 3,39 & 6,73 & 5,05 & 5,40 & 100,00 \\
\hline \multirow{4}{*}{$\mathrm{NE}$} & Automóveis & 0,92 & 84,74 & 1,17 & 4,90 & 4,35 & 3,92 & 100,00 \\
\hline & Caminhões e Ônibus & 1,04 & 82,73 & 1,33 & 5,54 & 4,92 & 4,44 & 100,00 \\
\hline & Pecas e Outros veículos & 1,08 & 82,43 & 1,33 & 5,62 & 5,06 & 4,47 & 100,00 \\
\hline & Com. Veículos e peças & 0,90 & 84,72 & 1,22 & 4,88 & 4,29 & 3,98 & 100,00 \\
\hline \multirow{4}{*}{$\mathrm{CO}$} & Automóveis & 1,27 & 6,87 & 71,87 & 7,72 & 6,28 & 5,99 & 100,00 \\
\hline & Caminhões e Ônibus & 1,64 & 8,84 & 63,73 & 9,99 & 8,06 & 7,74 & 100,00 \\
\hline & Pecas e Outros veículos & 0,98 & 5,29 & 78,41 & 5,84 & 4,88 & 4,61 & 100,00 \\
\hline & Com. Veículos e peças & 1,27 & 6,44 & 72,33 & 7,81 & 6,17 & 5,99 & 100,00 \\
\hline \multirow{4}{*}{ SP } & Automóveis & 3,93 & 18,09 & 3,92 & 46,89 & 14,22 & 12,95 & 100,00 \\
\hline & Caminhões e Ônibus & 3,90 & 17,89 & 3,88 & 47,35 & 14,10 & 12,89 & $\cdot 100,00$ \\
\hline & Pecas e Outros veículos & 3,80 & 17,89 & 3,66 & 45,85 & 15,34 & 13,45 & 100,00 \\
\hline & Com. Veículos e peças & 2,29 & 9,67 & 2,31 & 71,64 & 6,72 & 7,37 & 100,00 \\
\hline \multirow{4}{*}{ SER } & Automóveis & 3,04 & 15,05 & 3,82 & 21,45 & 44,34 & 12,30 & 100,00 \\
\hline & Caminhões e Ônibus & 1,84 & 11,56 & 2,98 & 11,29 & 63,69 & 8,64 & 100,00 \\
\hline & Pecas e Outros veículos & 1,82 & 11,34 & 2,87 & 11,32 & 64,06 & 8,58 & 100,00 \\
\hline & Com. Veículos e peças & 1,10 & 6,97 & 1,97 & 6,56 & 77,86 & 5,54 & 100,00 \\
\hline \multirow{4}{*}{ S } & Automóveis & 2,06 & 10,84 & 3,15 & 17,05 & 9,71 & 57,19 & 100,00 \\
\hline & Caminhões e Ônibus & 2,76 & 13,65 & 3,90 & 22,60 & 12,34 & 44,75 & 100,00 \\
\hline & Pecas e Outros veículos & 1,57 & 10,06 & 2,82 & 11,92 & 8,34 & 65,29 & 100,00 \\
\hline & Com. Veículos e peças & 0,99 & 5,55 & 2,12 & 7,99 & 4,52 & 78,84 & 100,00 \\
\hline
\end{tabular}

Verificando aos dados da Tabela 36, é possível observar qual a proporção do emprego é gerado na própria região. Do total de empregos gerados pela variação da demanda final de um milhão de reais da atividade de Automóveis no Norte, 64,29\% é gerado na própria região, ao passo que aproximadamente $35 \%$ é gerado nas demais regiões, com destaque para o Nordeste e São Paulo.

Analisando as regiões em conjunto, novamente sobressaem os efeitos induzidos do Norte e Nordeste, as quais o nível de emprego gerados na própria região é elevado 
em comparação com as demais regiões. Todavia, descontando os efeitos da própria região, as regiões Nordeste, São Paulo demonstram maior capacidade de geração de emprego em função do transbordamento de outras regiões. Na seqüência aparecem o Resto do Sudeste e Sul. Como esperado, os menores efeitos de transbordamento do emprego são registrados no Centro-Oeste e Norte.

As Tabelas 60 a 65 do Anexo apresentam os dados de geração de emprego para todos os setores do sistema inter-regional. Considerando apenas os efeitos diretos e indiretos no conjunto de atividades dos sistema a atividade de Peças e outros veículos no Centro-Oeste se posiciona entre as vinte com maior poder de geração de emprego na economia, gerando 80,1 empregos diretos e 41,8 empregos indiretos. Destacam-se sobretudo as atividades da região Nordeste como o Comércio, Serviços Privados, Extrativa mineral, Madeira e Mobiliário, Indústrias diversas, Agropecuária, Produtos Alimentares e Minerais não metálicos; além de Madeira e mobiliário, Artigos de Plástico e Vestuário e Calçados. No mesmo grupo, merecem ser mencionadas Artigos de vestuário, Madeira e mobiliário e Agropecuária no resto do Sudeste; e Agropecuária e extrativa mineral no Sul.

Tomando por base o número de empregos totais, incluindo portanto, os empregos gerados em razão da demanda proporcionada pelo consumo das famílias na economia, a situação é distinta. Do setor automotivo somente Automóveis no Nordeste se posiciona entre as vinte com maiores número de empregos gerados na economia. Esta atividade gera cerca de 248 empregos totais, dos quais 50 são diretos. A atividade de Comércio de veículos e peças no Nordeste também se destaca gerando 75 empregos diretos e 287 no total da economia. Neste conjunto, com exceção de Vestuário e calçados do Norte e do Centro-Oeste, todas as demais atividades, são da região Nordeste: Madeira e Mobiliário, Indústrias diversas, Agropecuária, Vestuário e calçados, Extrativa mineral, Produtos Alimentares, Serviços Privados, Minerais não metálicos, Comércio, Comércio de veículos e peças, Farmácia e Veterinária, Transporte, Artigos de Plásticos, Elementos Químicos, Administração Pública, Celulose Papel e Gráfica, Máquinas e tratores. 


\subsection{Renda}

Como nas análises dos efeitos sobre a produção e o emprego, recorreu-se ao cálculo dos multiplicadores de renda do tipo I, do tipo II e da geração de renda, a fim de avaliar o impacto do setor automotivo sobre essa variável.

Os multiplicadores de renda expressam a renda gerada em todos os setores da economia em virtude da variação de um unidade monetária da demanda final de um setor específico.

As Tabelas 37 e 38 apresentam os multiplicadores do tipo I e do tipo II para os setores do sistema inter-regional. No que se refere ao setor automotivo, as atividades Automóveis no Centro-Oeste, Sul, Nordeste, e Caminhões e Ônibus no Centro-Oeste, se posicionam entre os vinte setores com maiores multiplicadores de renda do tipo I do sistema. Todas essas atividades geram uma renda superior a $\mathrm{R} \$ 3,4$ para variação de cada real na sua demanda final.

Nas demais atividades da economia destacam-se Siderurgia no resto do Sudeste, Nordeste, São Paulo, Norte e Centro-oeste; Refino de Petróleo no Nordeste, São Paulo, Sul e Norte; Metalurgia no Nordeste; Produtos alimentares no Centro-Oeste, São Paulo e Sul; e Indústria Têxtil, Elementos Químicos e Indústria da borracha no Sul entre as vinte que apresentam os maiores multiplicadores de renda, além das atividades anteriormente mencionadas Automóveis do Nordeste, Centro-oeste e Sul; e Caminhões e Ônibus no Centro-Oeste.

Ao incluir os efeitos induzidos, destaque para a Automóveis, Caminhões ônibus do Nordeste e Automóveis no Sul, as quais apresentam capacidade de geração de renda superior a R \$ 7 reais para variação de cada real da sua demanda final.

Neste recorte, as atividades do setor automotivo do Centro-Oeste e do Sul; a Siderurgia do Centro-Oeste e produtos alimentares Centro-Oeste, São Paulo e Sul destacadas no multiplicador do tipo I cedem lugar para as atividade de Refino de petróleo e Elementos químicos no resto do Sudeste, Extração de petróleo, Produtos 
alimentares, Elementos Químicos e Automóveis no Nordeste e Extração Mineral no Norte.

Tabela 37. Multiplicador de Renda do tipo I e do tipo II segundo as regiões Norte, Nordeste e Centro-Oeste

\begin{tabular}{|c|c|c|c|c|c|c|}
\hline \multirow{2}{*}{ Atividades econômicas } & \multicolumn{2}{|c|}{ Norte } & \multicolumn{2}{|c|}{ Nordeste } & \multicolumn{2}{|c|}{ Centro- Oeste } \\
\hline & tipo I & Tipo II & tipo I & tipo II & tipo I & tipo II \\
\hline Agropecuária & 1,86 & 4,78 & 1,64 & 4,84 & 2,65 & 4,71 \\
\hline Ext. mineral & 3,35 & 8,15 & 2,42 & 7,59 & 1,54 & 2,52 \\
\hline Ext. petr., gás, carvão & 2,26 & 6,65 & 2,75 & 11,97 & 1,32 & 2,36 \\
\hline Min. Não metálicos & 1,87 & 4,57 & 1,81 & 4,71 & 2,30 & 3,81 \\
\hline Siderurgia & 5,40 & 15,01 & 8,88 & 31,43 & 4,72 & 7,93 \\
\hline Metalurgia & 1,76 & 3,31 & 5,50 & 17,50 & 2,27 & 3,68 \\
\hline Fab. Máq. E tratores & 1,40 & 2,98 & 1,49 & 4,89 & 1,56 & 2,50 \\
\hline Mat.elétr. e equip. eletron. & 1,80 & 4,02 & 2,13 & 5,16 & 3,27 & 5,35 \\
\hline Automóveis & 1,40 & 2,34 & 3,46 & 9,47 & 4,20 & 6,94 \\
\hline Caminhões e ônibus & 1,75 & 3,33 & 3,29 & 9,06 & 3,98 & 6,58 \\
\hline Peças e outros veículos & 1,63 & 2,90 & 1,87 & 4,37 & 2,00 & 3,18 \\
\hline Madeira e mobiliário & 1,66 & 3,34 & 1,72 & 4,27 & 1,79 & 2,97 \\
\hline Celulose papel e gráfica & 1,99 & 3,70 & 2,14 & 4,64 & 2,70 & 4,44 \\
\hline Ind borracha & 2,24 & 5,12 & 1,80 & 4,17 & 3,33 & 5,73 \\
\hline Elem. químicos & 1,90 & 5,00 & 2,38 & 8,62 & 2,83 & 4,98 \\
\hline Refino de petróleo & 5,33 & 17,76 & 11,52 & 70,84 & 2,32 & 4,46 \\
\hline Químicos diversos & 1,83 & 4,09 & 2,24 & 5,97 & 2,47 & 4,24 \\
\hline Farmácia e veterinária & 1,84 & 3,99 & 2,22 & 7,24 & 2,57 & 4,21 \\
\hline Artigos de plásticos & 2,03 & 5,04 & 1,54 & 3,91 & 1,86 & 3,06 \\
\hline Ind têxtil & 2,27 & 4,42 & 2,30 & 4,80 & 3,22 & 5,34 \\
\hline Vestuário e calçados & 1,55 & 3,32 & 1,95 & 4,47 & 1,94 & 3,48 \\
\hline Produtos alimentares & 3,07 & 7,02 & 3,04 & 7,95 & 4,33 & 7,50 \\
\hline Ind. Diversas & 1,80 & 3,67 & 2,45 & 6,87 & 1,98 & 3,21 \\
\hline SIUP & 1,93 & 3,49 & 1,65 & 4,09 & 1,73 & 2,72 \\
\hline Construção civil & 2,34 & 6,46 & 2,12 & 7,90 & 3,21 & 5,60 \\
\hline Comércio & 1,37 & 2,62 & 1,30 & 2,87 & 1,65 & 2,90 \\
\hline Com. Veículos e peças & 1,43 & 3,46 & 1,21 & 3,45 & 2,10 & 3,82 \\
\hline Transporte & 1,52 & 3,05 & 1,57 & 4,15 & 1,65 & 2,97 \\
\hline Comunicações & 1,30 & 2,54 & 1,23 & 3,57 & 1,29 & 1,99 \\
\hline Serv. privados & 1,23 & 2,39 & 1,27 & 3,21 & 1,27 & 1,99 \\
\hline Administração pública & 1,12 & 1,82 & 1,17 & 2,21 & 1,21 & 2,07 \\
\hline
\end{tabular}


Tabela 38. Multiplicador de Renda do tipo I e do tipo II segundo as regiões São Paulo, resto do Sudeste e Sul

\begin{tabular}{|c|c|c|c|c|c|c|}
\hline \multirow{2}{*}{ Atividades econômicas } & \multicolumn{2}{|c|}{ São Paulo } & \multicolumn{2}{|c|}{ Resto do Sudeste } & \multicolumn{2}{|r|}{ Sul } \\
\hline & tipo I & tipo II & tipo I & tipo II & tipo I & tipo II \\
\hline Agropecuária & 1,73 & 4,56 & 2,17 & 4,57 & 2,04 & 5,47 \\
\hline Ext. mineral & 2,07 & 3,93 & 2,15 & 4,18 & 2,52 & 4,95 \\
\hline Ext. petr., gás, carvão & 2,23 & 5,58 & 2,37 & 6,35 & 2,27 & 6,09 \\
\hline Min. Não metálicos & 2,07 & 3,71 & 1,88 & 3,63 & 2,18 & 4,37 \\
\hline Siderurgia & 6,77 & 13,49 & 10,17 & 23,51 & 3,35 & 6,30 \\
\hline Metalurgia & 2,11 & 3,76 & 1,82 & 3,20 & 1,87 & 3,44 \\
\hline Fab. Máq. E tratores & 1,56 & 2,81 & 1,37 & 2,72 & 1,52 & 3,09 \\
\hline Mat.elétr. e equip. eletron. & 2,55 & 4,69 & 2,50 & 4,69 & 2,07 & 3,82 \\
\hline Automóveis & 3,36 & 6,12 & 3,25 & 6,28 & 3,65 & 7,17 \\
\hline Caminhões e ônibus & 3,35 & 6,16 & 2,65 & 4,95 & 3,45 & 6,72 \\
\hline Peças e outros veículos & 2,03 & 3,47 & 1,81 & 3,09 & 2,23 & 4,09 \\
\hline Madeira e mobiliário & 1,68 & 2,85 & 1,55 & 2,69 & 2,00 & 4,00 \\
\hline Celulose papel e gráfica & 2,33 & 3,99 & 2,31 & 4,19 & 2,16 & 3,81 \\
\hline Ind borracha & 2,78 & 5,76 & 2,30 & 4,74 & 3,52 & 8,40 \\
\hline Elem. químicos & 3,26 & 7,38 & 3,17 & 7,93 & 3,54 & 9,13 \\
\hline Refino de petróleo & 8,52 & 23,80 & 3,13 & 8,33 & 7,76 & 24,41 \\
\hline Químicos diversos & 2,43 & 4,81 & 1,99 & 3,79 & 2,27 & 4,70 \\
\hline Farmácia e veterinária & 2,18 & 4,16 & 2,22 & 4,87 & 2,29 & 4,88 \\
\hline Artigos de plásticos & 1,56 & 2,79 & 1,47 & 2,64 & 1,49 & 2,70 \\
\hline Ind têxtil & 3,41 & 6,30 & 3,20 & 6,34 & 3,55 & 7,12 \\
\hline Vestuário e calçados & 1,68 & 3,00 & 1,71 & 3,21 & 1,86 & 3,52 \\
\hline Produtos alimentares & 3,58 & 7,19 & 3,17 & 6,29 & 3,83 & 8,38 \\
\hline Ind. diversas & 2,05 & 3,71 & 2,15 & 3,97 & 2,27 & 4,40 \\
\hline SIUP & 1,63 & 3,12 & 1,54 & 2,83 & 1,65 & 3,13 \\
\hline Construção civil & 2,04 & 4,83 & 2,25 & 5,40 & 2,33 & 5,90 \\
\hline Comércio & 1,46 & 2,62 & 1,39 & 2,62 & 1,50 & 2,85 \\
\hline Com. Veículos e peças & 1,36 & 2,78 & 1,17 & 2,38 & 1,52 & 3,22 \\
\hline Transporte & 1,63 & 2,70 & 1,48 & 2,78 & 1,61 & 2,96 \\
\hline Comunicações & 1,05 & 1,98 & 1,28 & 2,30 & 1,28 & 2,41 \\
\hline Serv. privados & 1,21 & 2,19 & 1,25 & 2,32 & 1,22 & 2,44 \\
\hline Administração pública & 1,12 & 1,73 & 1,13 & 1,77 & 1,14 & 1,80 \\
\hline
\end{tabular}


Tabela 39. Geração de renda direta, indireta e induzido na economia, considerando o consumo das famílias endógeno - 1999

\begin{tabular}{|c|c|c|c|c|c|}
\hline & Atividade econômica & direto & indireto & induzido & total \\
\hline $\mathrm{N}$ & Automóveis & 139,44 & 55,74 & 131,64 & 326,82 \\
\hline $\mathrm{N}$ & Caminhões e ônibus & 74,57 & 56,20 & 117,93 & 248,70 \\
\hline $\mathrm{N}$ & Peças e outros veículos & 114,51 & 72,52 & 144,95 & 331,99 \\
\hline $\mathrm{N}$ & Com. Veículos e peças & 134,50 & 57,71 & 273,30 & 465,51 \\
\hline $\mathrm{NE}$ & Automóveis & 59,51 & 146,38 & 357,87 & 563,77 \\
\hline $\mathrm{NE}$ & Caminhões e Ônibus & 62,58 & 143,19 & 361,09 & 566,86 \\
\hline $\mathrm{NE}$ & Pecas e Outros veículos & 148,78 & 129,55 & 371,66 & 649,99 \\
\hline $\mathrm{NE}$ & Com. Veículos e peças & 204,44 & 43,78 & 456,96 & 705,18 \\
\hline $\mathrm{CO}$ & Automóveis & 59,51 & 190,55 & 163,11 & 413,17 \\
\hline $\mathrm{CO}$ & Caminhões e Ônibus & 62,58 & 186,66 & 162,56 & 411,79 \\
\hline $\mathrm{CO}$ & Pecas e Outros veículos . & 178,98 & 178,95 & 211,84 & 569,77 \\
\hline $\mathrm{CO}$ & Com. Veículos e peças & 122,86 & 135,17 & 211,02 & 469,05 \\
\hline SP & Automóveis & 45,29 & 106,86 & 125,21 & 277,37 \\
\hline SP & Caminhões e Ônibus & 44,61 & 104,90 & 125,14 & 274,65 \\
\hline SP & Pecas e Outros veículos & 111,70 & 114,90 & 160,43 & 387,04 \\
\hline SP & Com. Veículos e peças & 155,90 & 56,28 & 221,87 & 434,05 \\
\hline RSE & Automóveis & 45,78 & 103,05 & 138,68 & 287,51 \\
\hline RSE & Caminhões e Ônibus & 63,10 & 104,31 & 144,68 & 312,09 \\
\hline RSE & Pecas e Outros veículos & 135,02 & 109,38 & 172,73 & 417,14 \\
\hline RSE & Com. Veículos e peças & 206,41 & 34,50 & 251,17 & 492,07 \\
\hline $\mathrm{S}$ & Automóveis & 45,78 & 121,15 & 161,09 & 328,02 \\
\hline $\mathrm{S}$ & Caminhões e Ônibus & 48,13 & 117,82 & 157,70 & 323,65 \\
\hline $\mathrm{S}$ & Pecas e Outros veículos & 102,40 & 126,10 & 190,82 & 419,32 \\
\hline $\mathrm{S}$ & Com. Veículos e peças & 153,67 & 79,18 & 261,70 & 494,54 \\
\hline \multicolumn{2}{|c|}{$\begin{array}{l}\text { Total Setor Automotivo } \\
\text { (excluindo Comercio de Veículos e Pecas) }\end{array}$} & $1.788,00$ & $2.438,56$ & $3.821,19$ & $8.047,76$ \\
\hline \multicolumn{2}{|c|}{$\underline{\text { Total }}$} & $2.520,05$ & $2.574,84$ & $5.075,17$ & $10.170,06$ \\
\hline
\end{tabular}

A capacidade de um setor relativa a geração de renda apresenta relação com a intensidade da mão de obra empregada no setor e com seus níveis de remuneração. As Tabelas 66 a 71 do Anexo detalham a renda gerada pela demanda final de todas as atividades econômicas nas seis regiões. Na Tabela 39 é possível avaliar esse indicador para as atividades do setor automotivo. Dentre essas, a atividade Peças e outros veículos e Comércio peças e veículos, relacionado ao setor automotivo, se destacam perante a geração de renda das atividades de Automóveis, Caminhões e Ônibus. Não obstante os salários mais elevados observados nas atividades Automóveis, Caminhões e Ônibus, o 
número de pessoas empregadas nas atividades de Peças e outros veículos é bem superior, justificando a geração de renda superior nesta atividade. $\mathrm{O}$ mesmo ocorre com a atividade de comércio veículos e peças.

Com relação a geração de renda direta e indireta verifica-se que cerca de $22 \%$ do total da renda gerada se concentra no próprio setor. $\mathrm{O}$ restante se divide em $30 \%$ que é gerado nos demais setores da economia (renda indireta) e $47 \%$ em renda induzida pelo consumo das famílias.

O transbordamento da renda gerada por uma atividade de um região para as demais atividades localizadas em outra regiões é uma das formas de avaliar os efeitos de interação entres as regiões. A Tabela 40, quantifica esse transbordamento ao apresentar a renda diretamente gerada no setor e a renda indireta para as demais regiões. Dessa forma, a atividade de automóveis do Norte gera uma renda total de $\mathrm{R} \$ 326,82$, porém deste total apenas $\mathrm{R} \$ 248,87$ fica na própria região. A Tabela 41 pode ser utilizada para complementar a análise. Seus dados mostram que $76,15 \%$ da renda total gerada pela atividade de automóveis do Norte, permanece na região. $\mathrm{O}$ restante beneficia as demais regiões do sistema, em especial São Paulo (9,50\%).

Tendo por base as informações das Tabelas 40 e 41, constata-se que o transbordamento de renda gerado pelo setor automotivo prevalece em favor das regiões São Paulo e Resto do Sudeste. Destaca-se sobretudo a renda gerada em São Paulo por intermédio da atividade Caminhões e Ônibus no Sul e da atividade de Automóveis no resto do Sudeste. 
Tabela 40. Geração de renda direta e indireta considerando o consumo das famílias endógeno, segundo regiões - 1999

\begin{tabular}{|c|c|c|c|c|c|c|c|c|}
\hline \multicolumn{2}{|c|}{ Atividade econômica } & \multirow{2}{*}{$\begin{array}{c}\mathrm{N} \\
248,87\end{array}$} & \multirow{2}{*}{$\begin{array}{l}\mathrm{NE} \\
13,12\end{array}$} & \multirow{2}{*}{$\begin{array}{r}\mathrm{CO} \\
7,45\end{array}$} & \multirow{2}{*}{$\begin{array}{l}\text { SP } \\
31,06\end{array}$} & \multirow{2}{*}{$\frac{\mathrm{RSE}}{13,85}$} & \multirow{2}{*}{$\begin{array}{l}S \\
12,48\end{array}$} & \multirow{2}{*}{$\begin{array}{l}\text { Total } \\
326,82\end{array}$} \\
\hline $\mathrm{N}$ & Automóveis & & & & & & & \\
\hline $\mathrm{N}$ & Caminhões e ônibus & 176,61 & 12,19 & 6,78 & 28,81 & 12,85 & 11,46 & 248,70 \\
\hline $\mathrm{N}$ & Peças e outros veículos & 198,94 & 19,89 & 10,73 & 56,68 & 25,90 & 19,85 & 331,99 \\
\hline $\mathrm{N}$ & Com. Veículos e peças & 323,15 & 22,90 & 16,81 & 55,61 & 23,86 & 23,18 & 465,51 \\
\hline $\mathrm{NE}$ & Automóveis & 7,26 & 420,85 & 8,27 & 66,26 & 33,47 & 27,66 & 563,77 \\
\hline NE & Caminhões e Ônibus & 7,28 & 423,44 & 8,31 & 66,49 & 33,55 & 27,78 & 566,86 \\
\hline $\mathrm{NE}$ & Pecas e Outros veículos & 7,95 & 495,39 & 8,85 & 71,08 & 37,06 & 29,66 & 649,99 \\
\hline $\mathrm{NE}$ & Com. Veículos e peças & 7,92 & 543,71 & 10,02 & 75,00 & 36,58 & 31,95 & 705,18 \\
\hline $\mathrm{CO}$ & Automóveis & 4,56 & 13,00 & 305,71 & 47,29 & 23,13 & 19,48 & 413,17 \\
\hline $\mathrm{CO}$ & Caminhões e & 4, & 8 & 303,99 & 47,63 &, 06 & 19,59 & 11,79 \\
\hline $\mathrm{CO}$ & Pecas e Outros veículos & 5,50 & 15,92 & 438,92 & 56,84 & 28,75 & 23,85 & 569,77 \\
\hline $\mathrm{CO}$ & Com. Veículos e peças & 5,32 & 14,49 & 341,61 & 57,28 & 26,72 & 23,63 & 469,05 \\
\hline SP & Automóveis & 7,03 & 18,94 & 7,17 & 192,01 & 29,49 & 22,73 & 277,37 \\
\hline SP & Caminhões e Ônibus & 7,13 & 19,02 & 7,20 & 188,52 & 29,71 & 23,08 & 274,65 \\
\hline SP & Pecas e Outros veículos & 9,77 & 25,54 & 8,82 & 264,28 & 44,85 & 33,78 & 387,04 \\
\hline SP & Com. Veículos e peças & 7,33 & 17,93 & 7,37 & 355,14 & 23,67 & 22,60 & 434,05 \\
\hline RSE & Automóveis & 7,88 & 17,78 & 8,02 & 89,60 & 137,90 & 26,33 & 287,51 \\
\hline RSE & Caminhões e Ôn & 3,72 & 13,41 & 5,81 & 43,31 & 228,92 & 16,92 & 312,09 \\
\hline RSE & Pecas e Outros veículos & 4,59 & 16,15 & 6,92 & 54,72 & 313,74 & 21,01 & 417,14 \\
\hline RSE & Com. Veículos e peças & 4,69 & 16,51 & 7,83 & 50,31 & 391,04 & 21,69 & 492,07 \\
\hline $\mathrm{S}$ & Automóveis & 5,60 & 14,78 & 8,21 & 82,89 & 27,85 & 188,68 & 328,02 \\
\hline $\mathrm{S}$ & Caminhões e Ônibus . & 7,64 & 17,62 & 9,65 & 103,03 & 34,12 & 151,60 & 323,65 \\
\hline S & Pecas e Outros veículos & $4 ; 39$ & 16,48 & 8,45 & 62,52 & 27,66 & 299,83 & 419,32 \\
\hline $\mathrm{S}$ & Com. Veículos e peças & 4,61 & 15,09 & 11,62 & 70,83 & 23,21 & 369,18 & 494,54 \\
\hline
\end{tabular}


Tabela 41. Percentual de geração de renda direta e indireta considerando o consumo das famílias endógeno, segundo regiões - 1999

\begin{tabular}{|c|c|c|c|c|c|c|c|c|}
\hline \multicolumn{2}{|c|}{ Atividade econômica } & \multirow{2}{*}{$\frac{\mathrm{N}}{76,15}$} & \multirow{2}{*}{$\frac{\mathrm{NE}}{4,02}$} & \multirow{2}{*}{$\frac{\mathrm{CO}}{2,28}$} & \multirow{2}{*}{$\begin{array}{l}\text { SP } \\
9,50\end{array}$} & \multirow{2}{*}{$\begin{array}{l}\text { RSE } \\
4,24\end{array}$} & \multirow{2}{*}{$\frac{\mathrm{S}}{3,82}$} & \multirow{2}{*}{$\begin{array}{l}\text { Total } \\
100,00\end{array}$} \\
\hline $\mathrm{N}$ & Automóveis & & & & & & & \\
\hline $\mathrm{N}$ & Caminhões e ônibus & 71,01 & 4,90 & 2,72 & 11,58 & 5,17 & 4,61 & 100,00 \\
\hline $\mathrm{N}$ & Peças e outros veículos & 59,92 & 5,99 & 3,23 & 17,07 & 7,80 & 5,98 & 100,00 \\
\hline $\mathrm{N}$ & Com. Veículos e peças & 69,42 & 4,92 & 3,61 & 11,95 & 5,13 & 4,98 & 100,00 \\
\hline $\mathrm{NE}$ & Automóveis & 1,29 & 74,65 & 1,47 & 11,75 & 5,94 & 4,91 & 100,00 \\
\hline $\mathrm{NE}$ & Caminhões e Ônibus & 1,28 & 74,70 & 1,47 & 11,73 & 5,92 & 4,90 & 100,00 \\
\hline $\mathrm{NE}$ & Pecas e Outros veículos & 1,22 & 76,22 & 1,36 & 10,94 & 5,70 & 4,56 & 100,00 \\
\hline $\mathrm{NE}$ & Com. Veículos e peças & 1,12 & 77,10 & 1,42 & 10,64 & 5,19 & 4,53 & 100,00 \\
\hline $\mathrm{CO}$ & Automóveis & 1,10 & 3,15 & 73,99 & 11,45 & 5,60 & 4,71 & 100,00 \\
\hline $\mathrm{CO}$ & Caminhões e Ônibus & 1,11 & 3,15 & 73,82 & 11,57 & 5,60 & 4,76 & 100,00 \\
\hline $\mathrm{CO}$ & Pecas e Outros veículos & 0,97 & 2,79 & 77,03 & 9,98 & 5,04 & 4,19 & 100,00 \\
\hline $\mathrm{CO}$ & Com. Veículos e peças & 1,13 & 3,09 & 72,83 & 12,21 & 5,70 & 5,04 & 100,00 \\
\hline SP & Automóveis & 2,53 & 6,83 & 2,58 & 69,23 & 10,63 & 8,19 & 100,00 \\
\hline SP & Caminhões e Ônibus & 2,60 & 6,92 & 2,62 & 68,64 & 10,82 & 8,40 & 100,00 \\
\hline SP & Pecas e Outros veículos & 2,52 & 6,60 & 2,28 & 68,28 & 11,59 & 8,73 & 100,00 \\
\hline SP & Com. Veículos e peças & 1,69 & 4,13 & 1,70 & 81,82 & 5,45 & 5,21 & 100,00 \\
\hline RSE & Automóveis & 2,74 & 6,19 & 2,79 & 31,16 & 47,96 & 9,16 & 100,00 \\
\hline RSE & Caminhões e Ônibus & 1,19 & 4,30 & 1,86 & 13,88 & 73,35 & 5,42 & 100,00 \\
\hline RSE & Pecas e Outros veículos & 1,10 & 3,87 & 1,66 & 13,12 & 75,21 & 5,04 & 100,00 \\
\hline RSE & Com. Veículos e peças & 0,95 & 3,36 & 1,59 & 10,22 & 79,47 & 4,41 & 100,00 \\
\hline $\mathrm{S}$ & Automóveis & 1,71 & 4,51 & 2,50 & 25,27 & 8,49 & 57,52 & 100,00 \\
\hline $\mathrm{S}$ & Caminhões e Ônibus & 2,36 & 5,44 & 2,98 & 31,83 & 10,54 & 46,84 & 100,00 \\
\hline $\mathrm{S}$ & Pecas e Outros veículos & 1,05 & 3,93 & 2,02 & 14,91 & 6,60 & 71,50 & 100,00 \\
\hline$\underline{S}$ & Com. Veículos e peças & 0,93 & 3,05 & 2,35 & 14,32 & 4,69 & 74,65 & 100,00 \\
\hline
\end{tabular}




\section{CONCLUSÕES}

Este trabalho teve como objetivo realizar uma análise sobre a evolução e a importância regional do setor automotivo na economia brasileira nos anos 90. A fim de testar se esse setor pode ser caracterizado como um setor chave para a economia brasileira, recorreu-se aos fundamentos da teoria insumo-produto. Além da análise da importância dos encadeamentos setoriais e dos impactos gerados pelo setor sobre a renda, emprego e produção em seis regiões brasileiras (Norte, Nordeste, Centro-Oeste, São Paulo, Resto do Sudeste e Sul) buscou-se mais especificamente, caracterizar a importância desse setor sob a ótica de clusters do tipo fuzzy, bem como avaliar a importância na geração de valor adicionado, pessoal ocupado e produtividade do trabalho no período de 1990 a 2002.

Estudos dessa natureza, em especial os que tratam da economia brasileira, se deparam com as dificuldades e as limitações decorrentes da utilização de matrizes insumo-produto e de sistemas inter-regionais estimados. No caso das matrizes nacionais, os últimos dados oficiais divulgados pelo IBGE, por ocasião da realização deste trabalho, se referem ao ano de 1996. Dessa forma, foram obtidas as matrizes estimadas para os anos de 1997 a 2002, tendo por base as informações do Sistema de Contas Nacionais para os mesmos anos. Já as informações do sistema inter-regional foram obtidas a partir de um conjunto de dados que reúne diversas pesquisas, entre as quais o Sistema de Contas Regionais, as Pesquisas Industriais, Censo Agropecuário, Pesquisas do Comércio e dos Serviços, divulgadas pelo IBGE; assim como informações provenientes da Gazeta Mercantil e de outras fontes. 
Mesmo com todos os critérios utilizados na obtenção de informações de fluxos das matrizes insumo-produto brasileiras, como métodos de consistência entre sistemas nacionais e regionais, os dados ainda são passíveis de refinamento. Ressalta-se, entretanto que os aprimoramentos possíveis, dependem sobretudo, da disponibilidade e da precisão das informações em níveis regionais e setoriais, provenientes de bases de dados complementares. Atualmente, mesmo com os avanços nas pesquisas dos IBGE e de algumas instituições setoriais, persiste a dificuldade de se obter informações mais detalhadas acerca das regiões Norte, Nordeste e Centro-Oeste brasileiras, bem como, de alguns setores, em particular daqueles em que predomina a informalidade na atividade econômica.

Além disso, merece destaque a escolha da metodologia de análise de clusters do tipo fuzzy. Essa metodologia apresenta vantagens em relação aos métodos de análise clusters tradicionais que identificam clusters do tipo crisp, os quais em geral requerem arbitrariedade do pesquisador e não consideram o fato de um setor estar presente em mais de um cluster na economia. Ao contrário, na abordagem do tipo fuzzy, os agrupamentos não excluem a possibilidade de todas as atividades econômicas pertencerem aos agrupamentos. Este trabalho contribuiu no sentido de aplicar uma metodologia de análise ainda pouco explorada nos estudos que recorrem à teoria insumo-produto. Neste sentido, as dificuldades e limitações encontradas na aplicação do método podem ser vistas como estímulos ao desenvolvimento de trabalhos futuros.

A necessidade de sofisticação metodológica é mais evidente na análise de clusters do sistema inter-regional. Isso porque os dados não apontam claramente para a relevância das atividades da região São Paulo e resto do Sudeste nos clusters das demais regiões. Uma alternativa interessante visando aprimorar a análise, poderia ser estudar a possibilidade de considerar o valor da produção na ponderação dos dados submetidos à análise de cluster.

O método, por sua vez mostrou interessantes resultados na análise da estrutura produtiva nacional. Com a abertura da economia e a conseqüente entrada de produtos importados na economia brasileira na década de 90 , os clusters nacionais apresentam 
menor dependência entre si, refletindo menor dinamismo nas relações produtivas realizadas na economia nacional. Em outras palavras, os resultados sugerem que, com a abertura da economia ao comércio internacional, as relações produtivas entre os clusters domésticos ficaram mais frágeis.

No que se refere à caracterização da evolução recente do setor automotivo, observou-se que mesmo com os maciços investimentos realizados na indústria automobilística a partir de meados dos anos 90, a produtividade do trabalho não apresenta um crescimento expressivo e contínuo no final da década, em especial no agregado da produção. Esses resultados, associados aos dados de faturamento das empresas, à crescente participação relativa de carros populares nas vendas da companhias e à elevada capacidade ociosa do setor, revelam um cenário econômico pouco favorável às empresas instaladas no mercado nacional. Neste sentido, a fim de elaborar estratégias futuras de desenvolvimento setorial, caberia avaliar a possibilidade de criar ou reforçar os mecanismos de política de comércio exterior existentes, que permitam aproveitar melhor a capacidade e a tecnologia de produção nacional, permitindo que o setor se beneficie dos ganhos de escala.

Considerando como atividade principal a produção de Automóveis, caminhões e ônibus, o setor automotivo foi responsável pela geração de R $\$ 17.080$ milhões de valor adicionado e 604,2 mil empregos na economia em 2002. Os resultados acerca da evolução do emprego ressaltam a importância da atividade de autopeças na geração de emprego no setor automotivo, em contraposição ao observado no agregado da produção. Este último, melhor representado pelas montadoras de veículos, vem registrando um persistente e significativo declínio do emprego. Dessa forma, cabe ao governo investir de forma efetiva em políticas de estímulo a geração de emprego, bem como em programas que visem a melhor qualificação e modernização da mão de obra dos setores de autopeças e componentes de veículos, em especial nas regiões onde esse setor se instalou mais recentemente.

Segundo as informações obtidas neste trabalho, as atividades do setor automotivo, em geral apresentam elevado poder de interligação para trás, ou seja, 
exercem um papel chave como setores demandantes de insumos da economia. Essa constatação reforça a importância de se fortalecer a capacidade produtiva e tecnológica das atividades econômicas fornecedoras de insumos a esse setor, como a metalurgia, siderurgia, indústria de plásticos, componentes, eletrônicos e peças. Há, portanto, espaço para o desenho de políticas de desenvolvimento industrial e tecnológico que tenham por objetivo melhor capacitar empresas nacionais fornecedoras de insumos ao setor automotivo, de segunda e terceira camadas, a fim de que essas possam atingir níveis de qualidade e padrões de eficiência internacionais. Essas políticas, além de beneficiarem a geração de emprego e renda regional, haja vista seu efeito multiplicador, contribuem para o desenvolvimento da dinâmica industrial nacional.

Destaque especial pode ser atribuído à atividade de Peças e outros veículos de São Paulo, classificada como um setor-chave na economia, revelando sua importância na dinâmica produtiva nacional. Conclui-se que, além dos encadeamentos para trás gerados no fornecimento de peças e componentes às montadoras, a importância do setor é também verificada em virtude da oferta de peças de reposição para manutenção da frota nacional de veículos. Essa atividade, portanto, ao mesmo tempo em que apresenta potencial de geração de emprego, intensifica as relações produtivas econômicas.

O presente trabalho, ao confirmar e, sobretudo, quantificar a importância do setor automotivo localizado nas regiões de São Paulo, Resto do Sudeste e Sul na estrutura produtiva nacional, pode fornecer mais subsídios na elaboração de políticas futuras de desenvolvimento regional. A partir dos seus resultados torna-se possível considerar os transbordamentos regionais de renda, produção e emprego gerados pelo setor que, em geral, favorecem mais a região de São Paulo, na elaboração de políticas regionais especialmente daquelas que recorram à utilização de incentivos, a fim de atrair novas unidades produtivas do setor automotivo. 
ANEXOS 


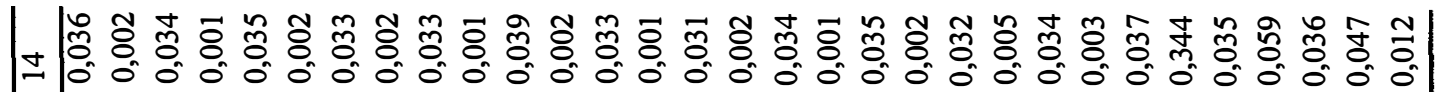

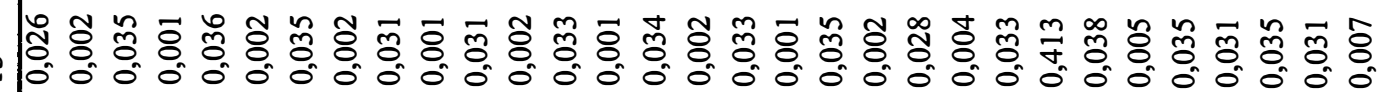

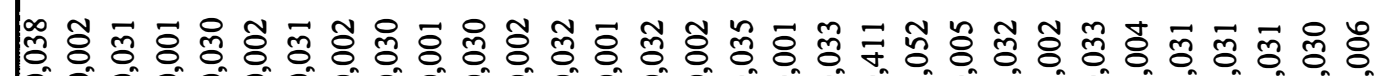

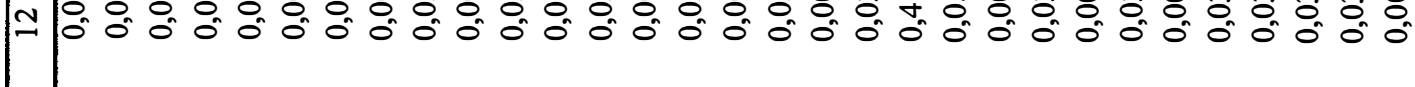

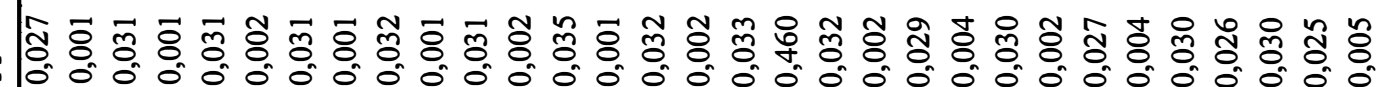

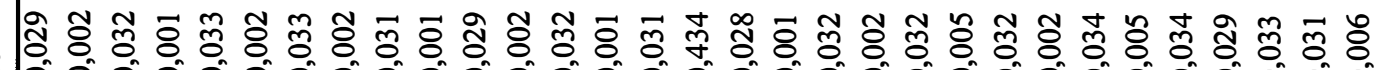

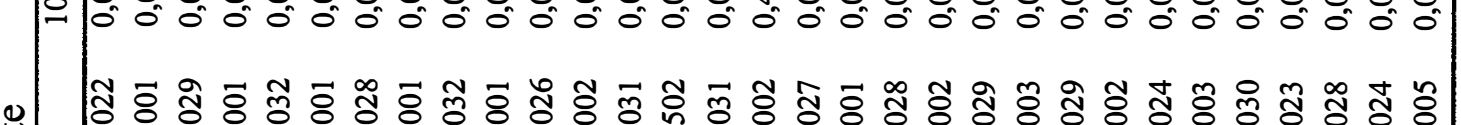
วั้

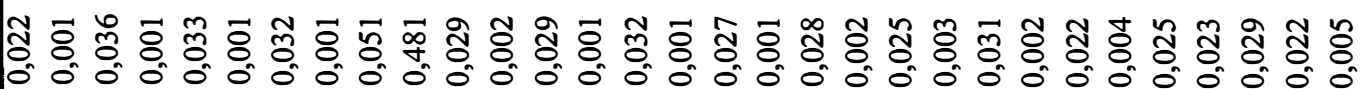

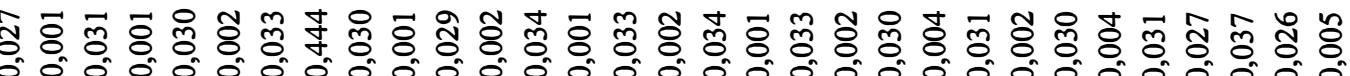

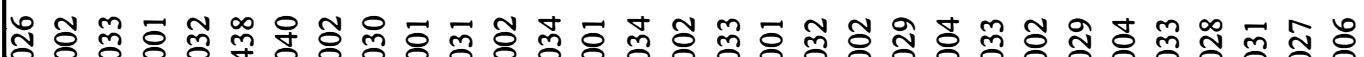

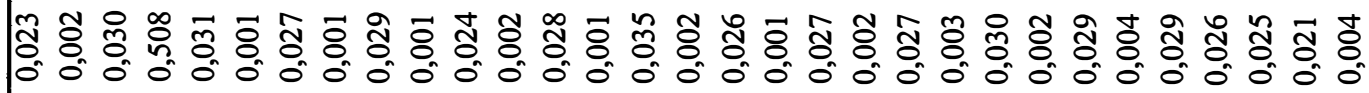

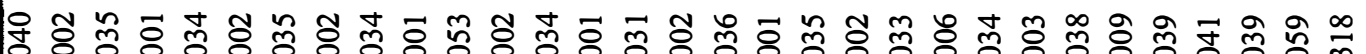

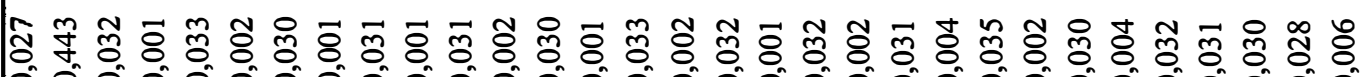

ช สี

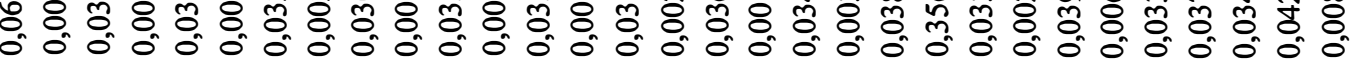

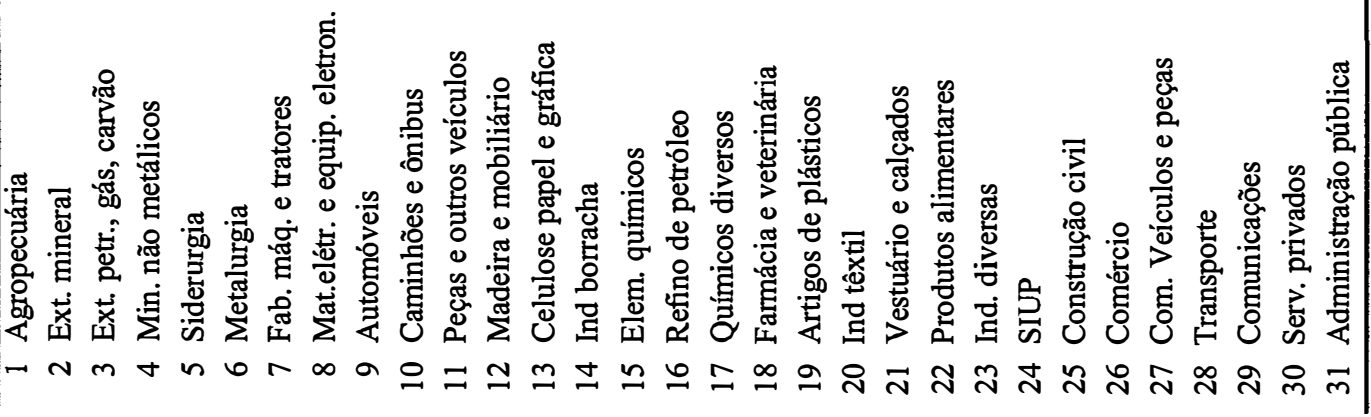




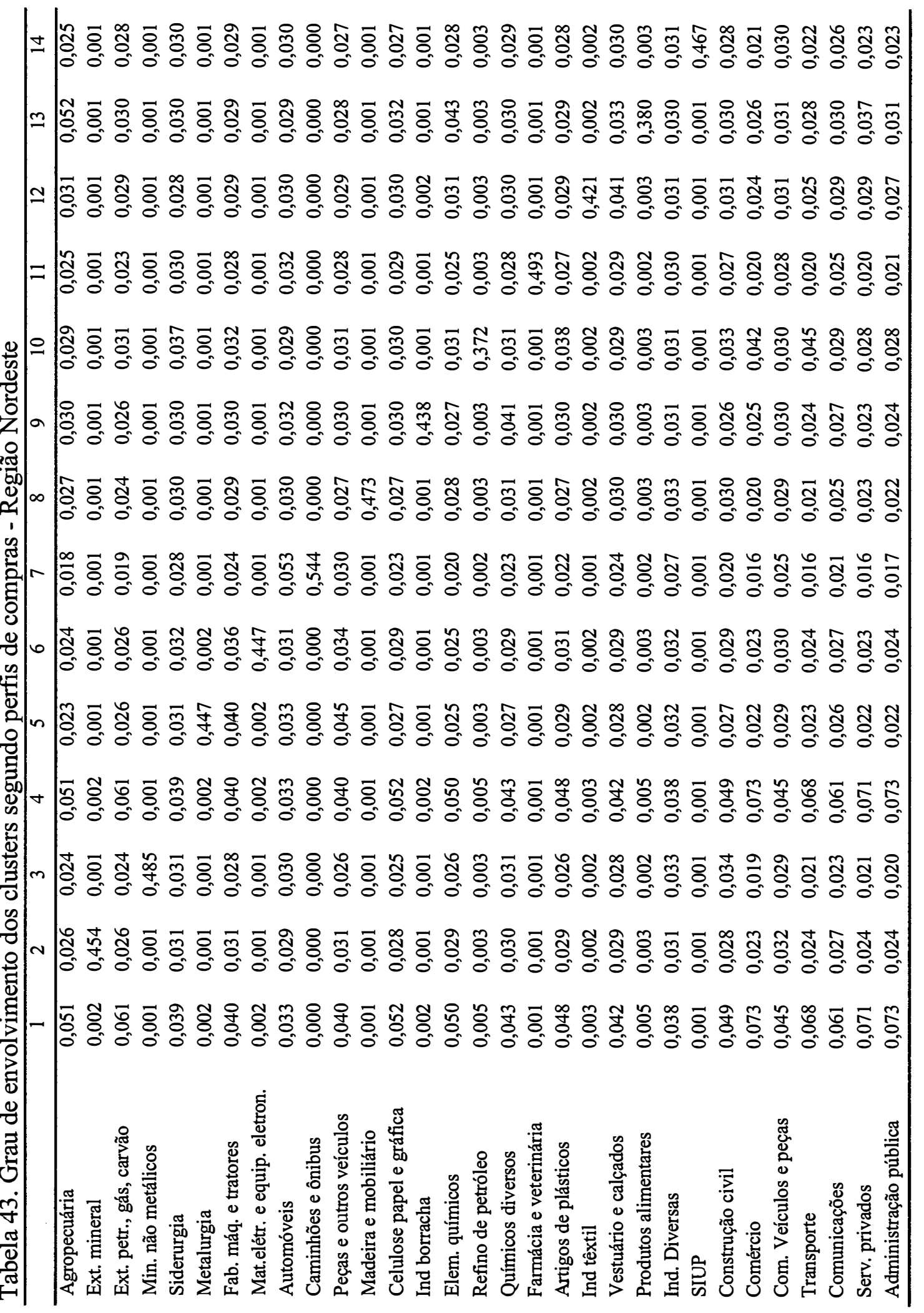




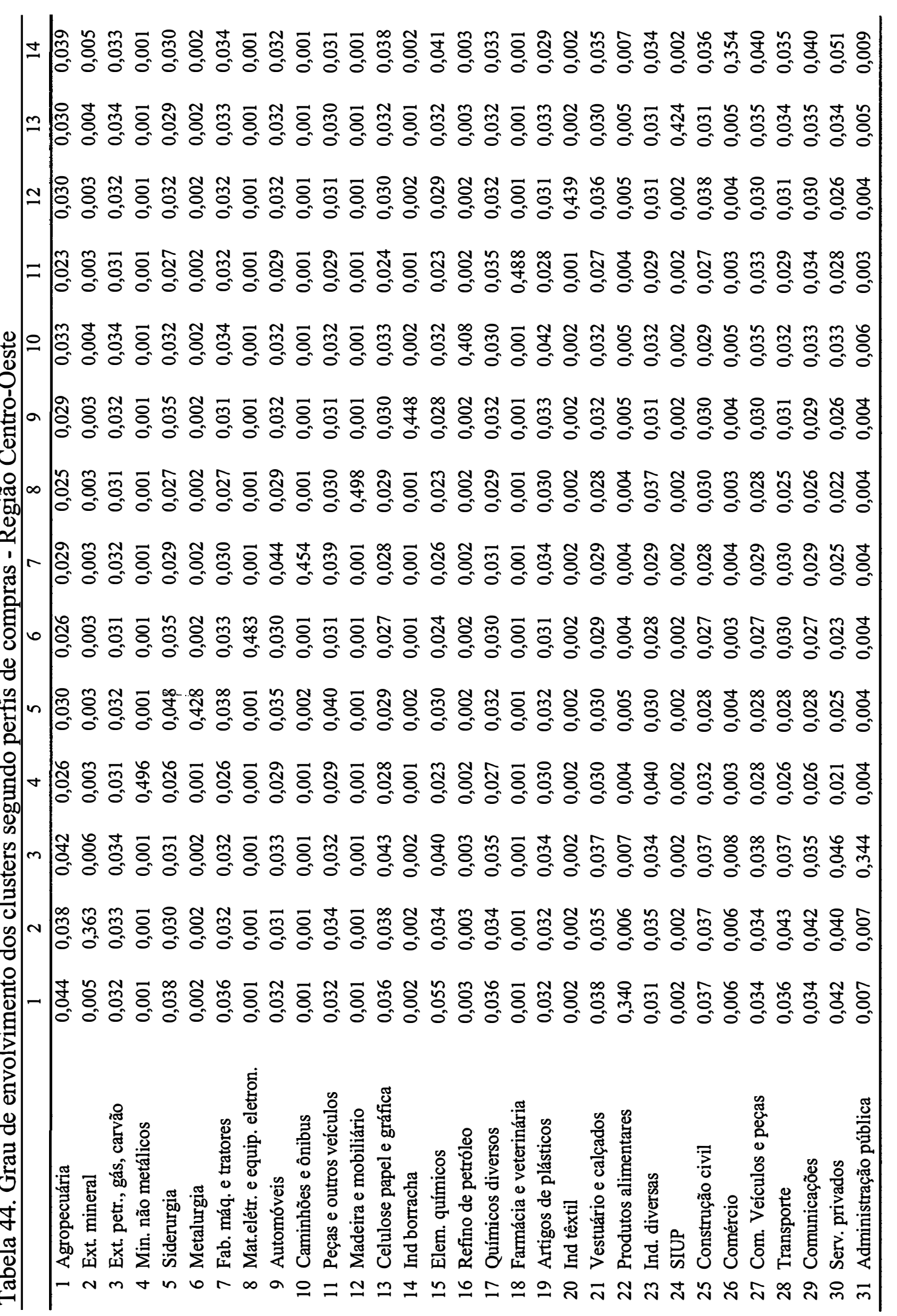




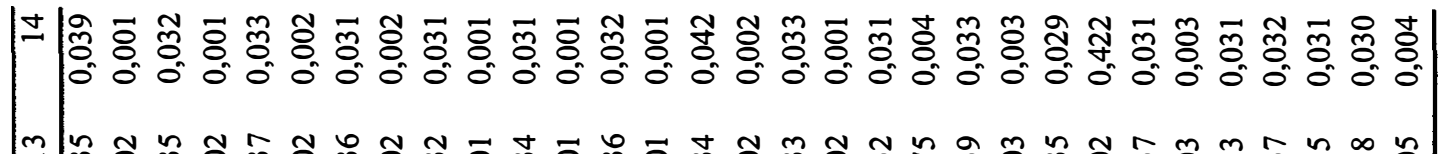

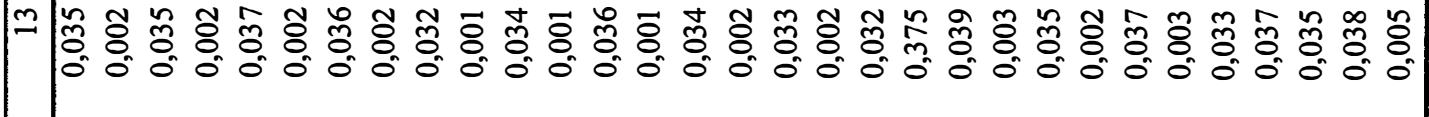

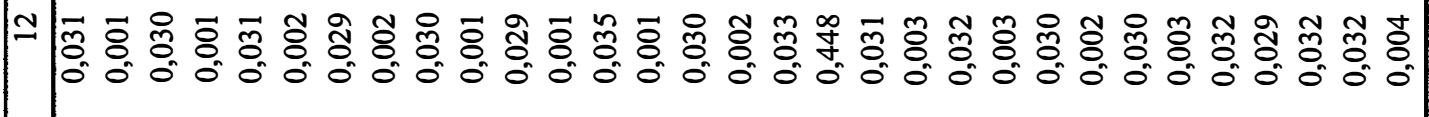

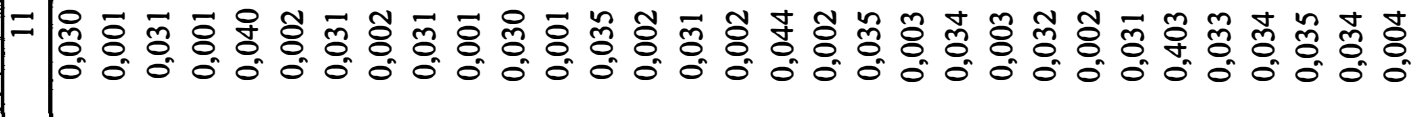

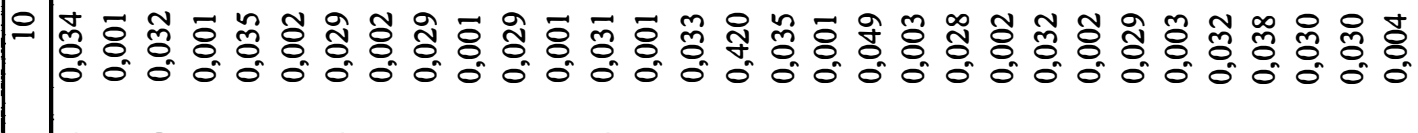

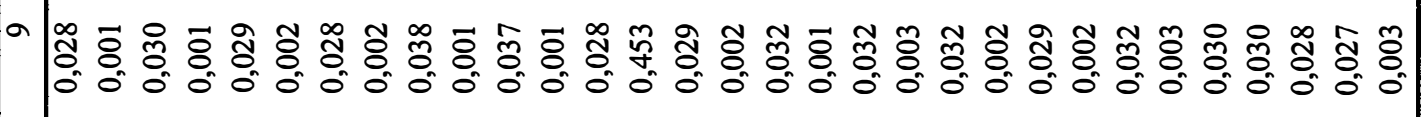

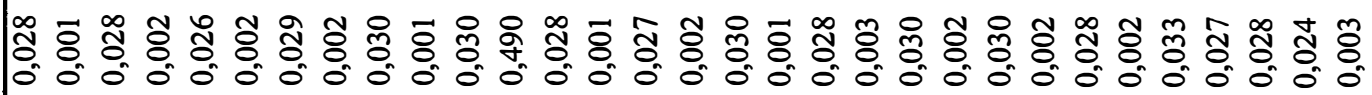

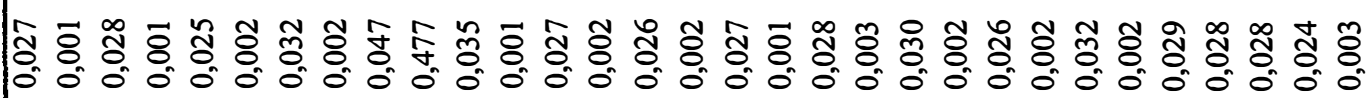

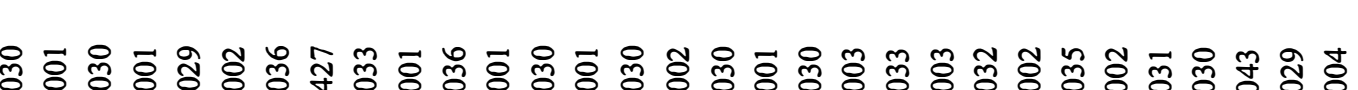

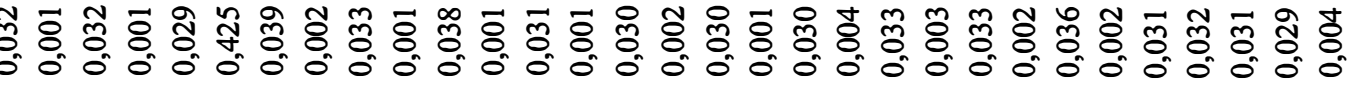

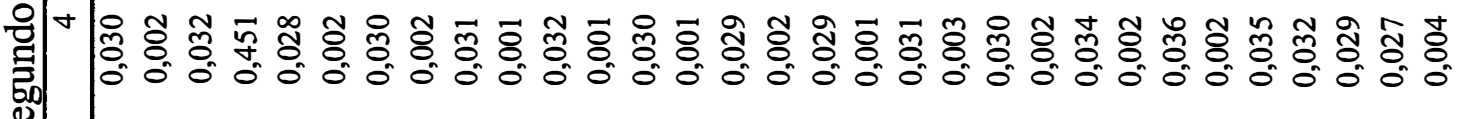

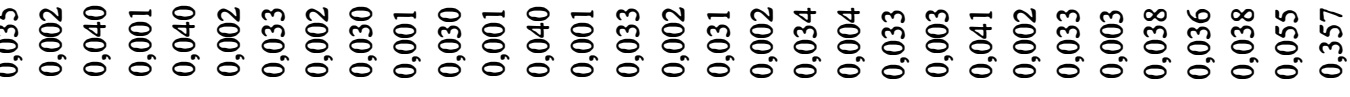

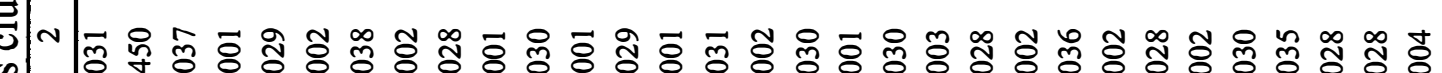

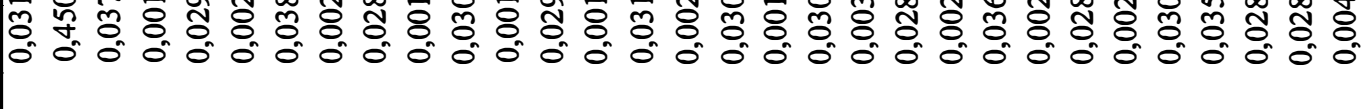

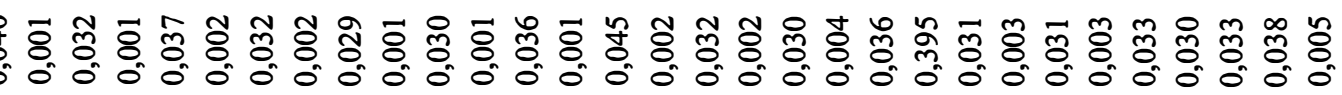

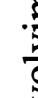




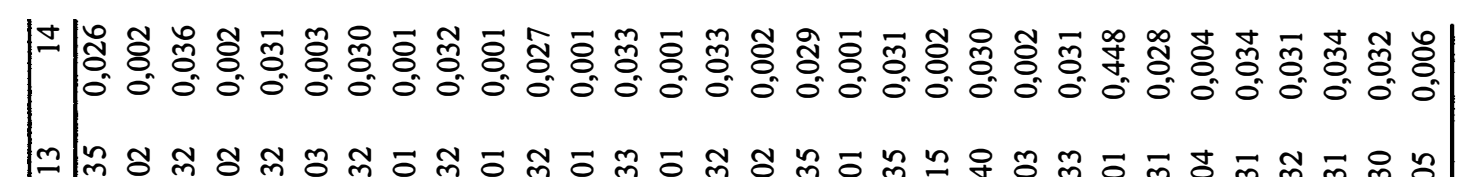

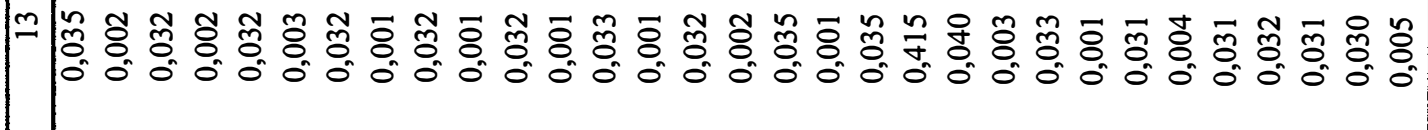

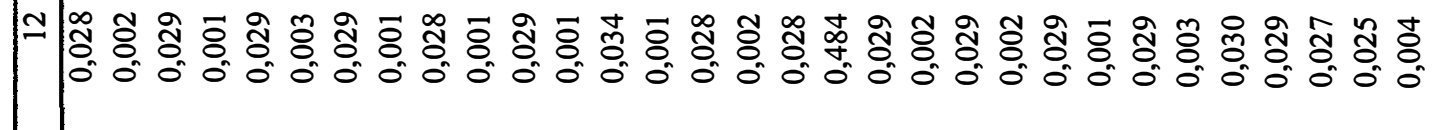

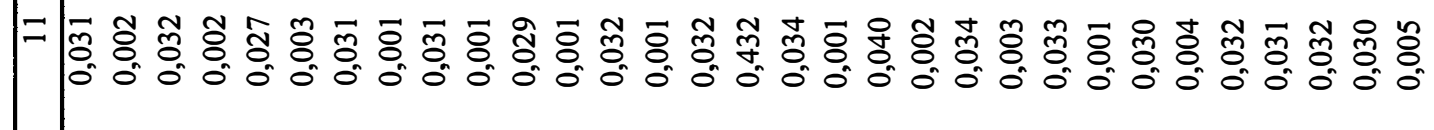

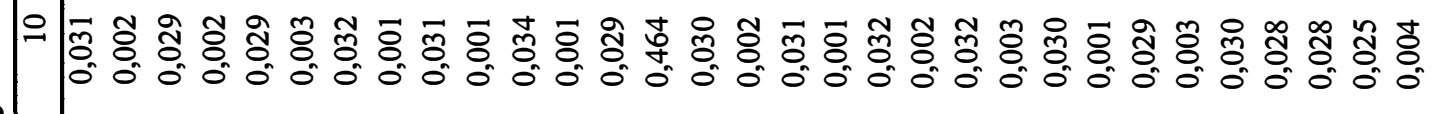

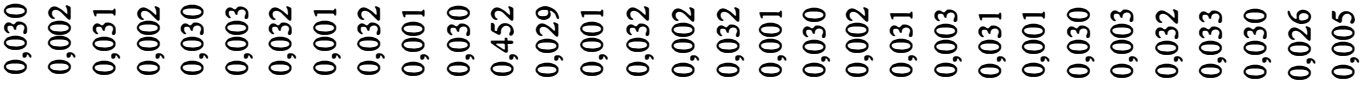

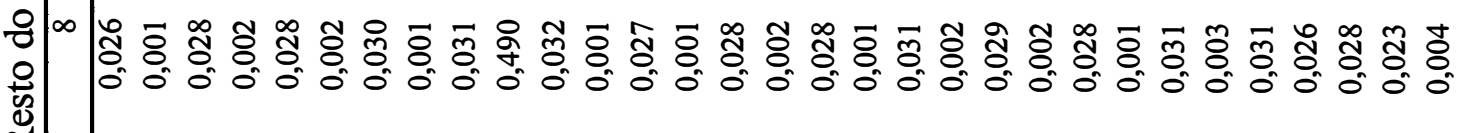

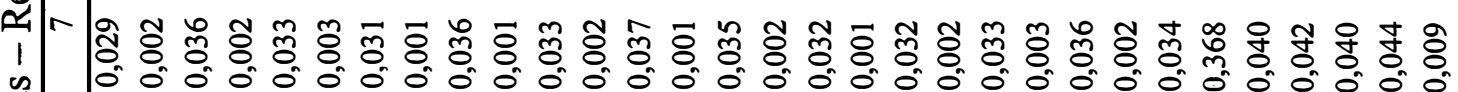

西

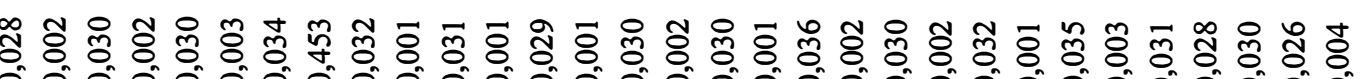

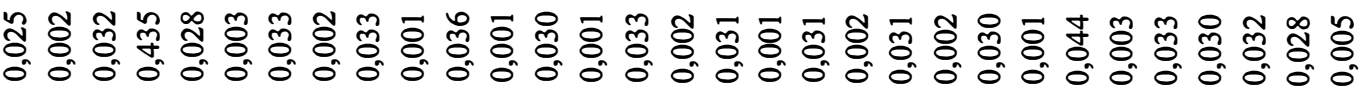

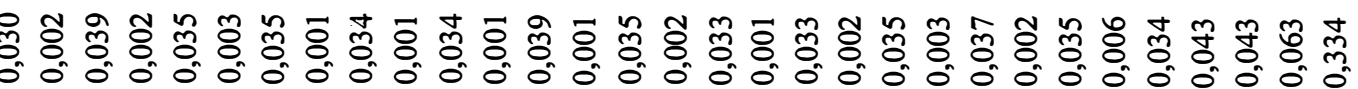

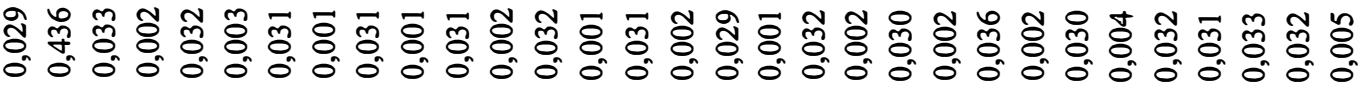

卷 


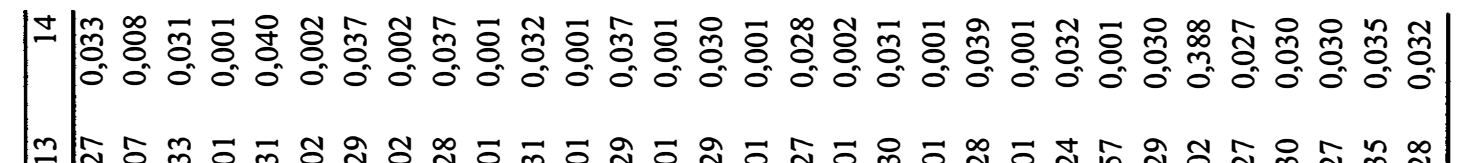

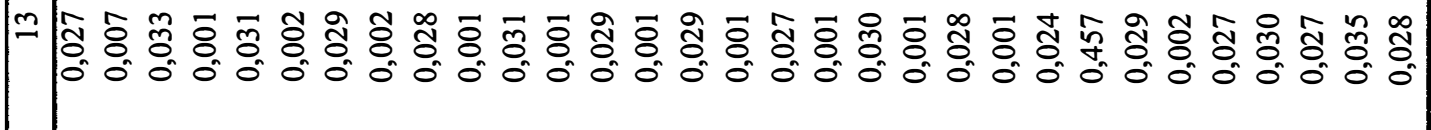

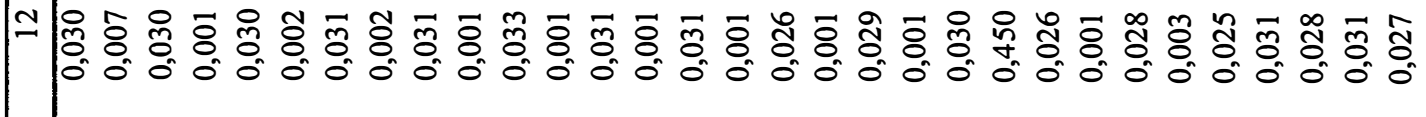

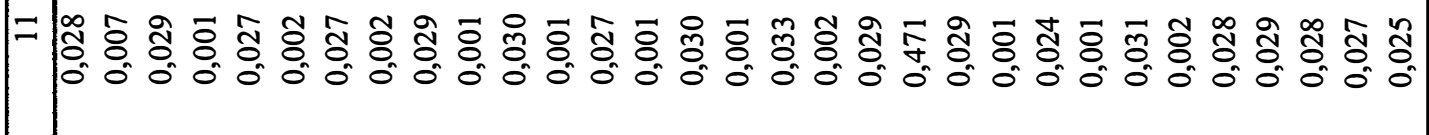

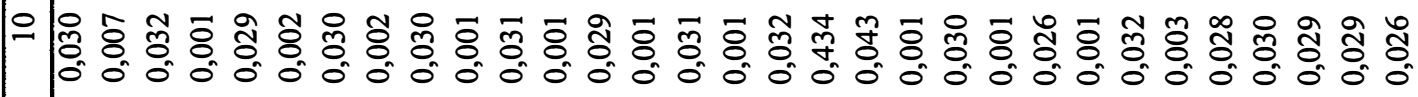

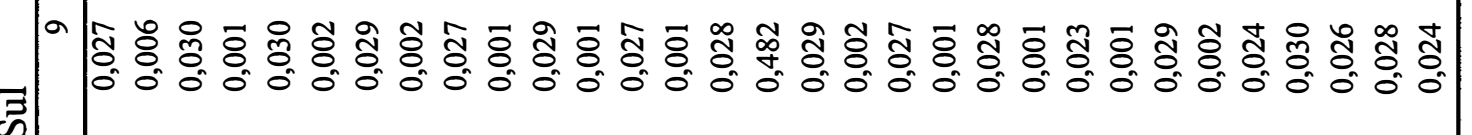

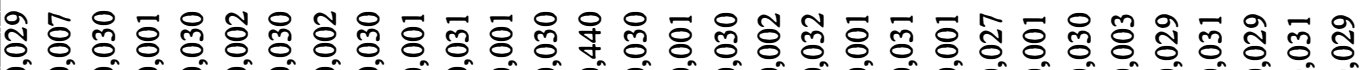

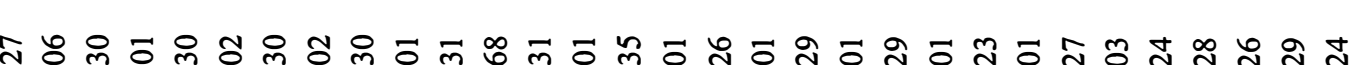

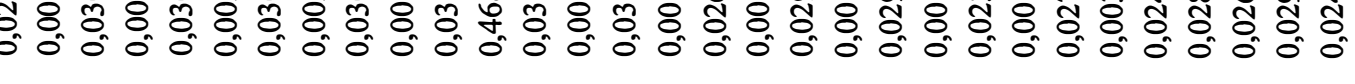

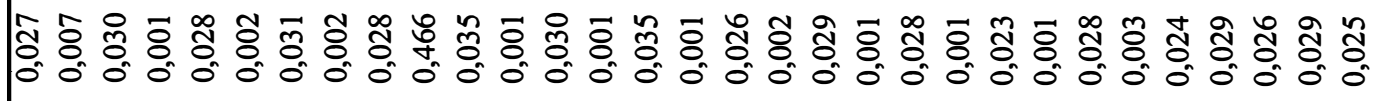

б

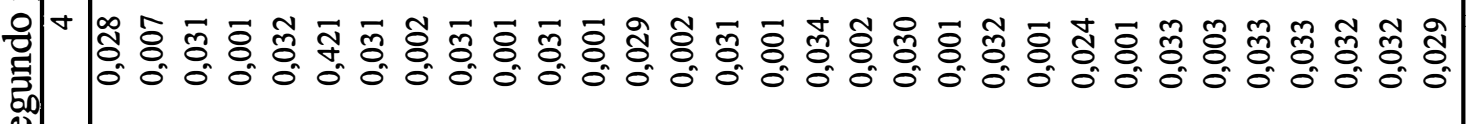

๙

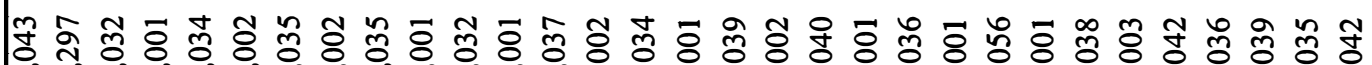

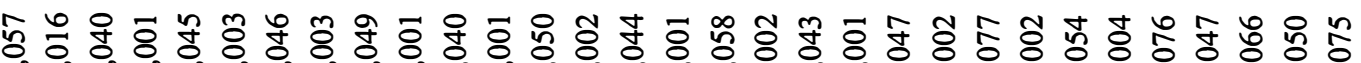

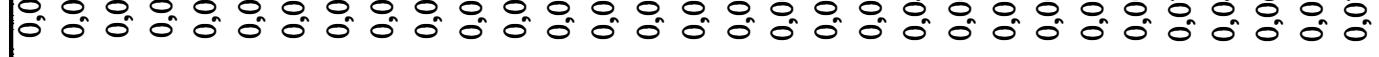

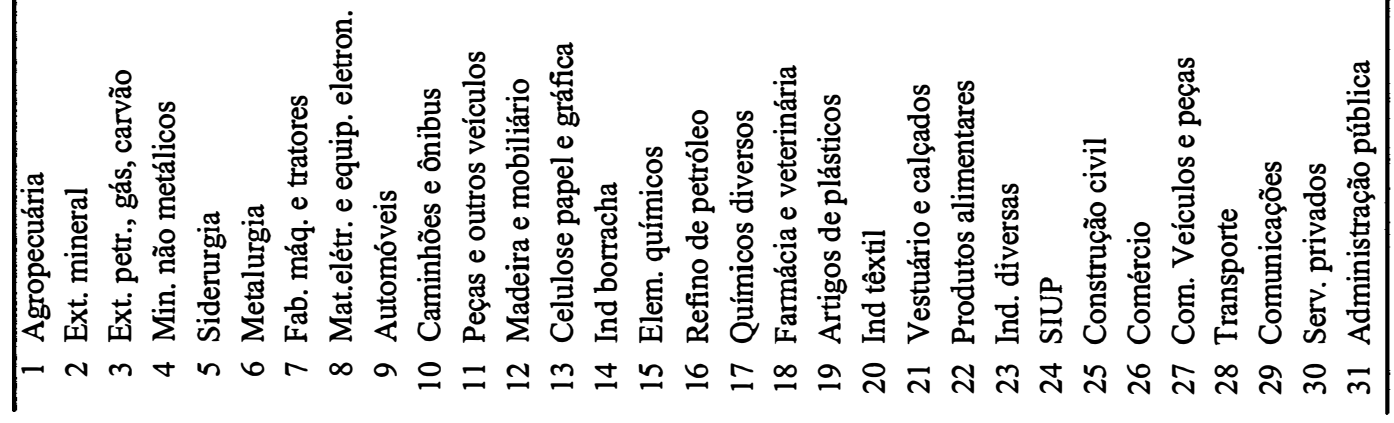




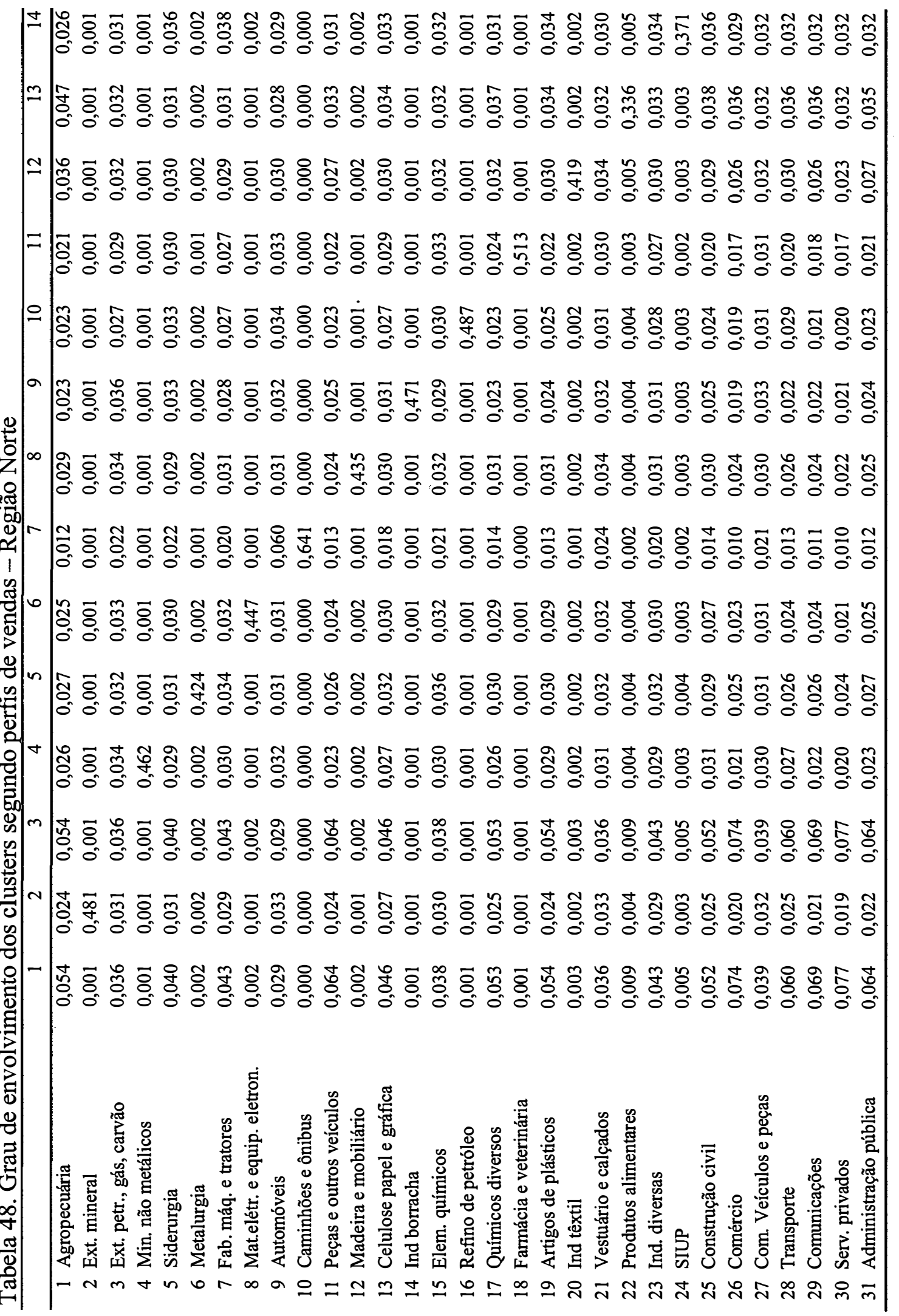




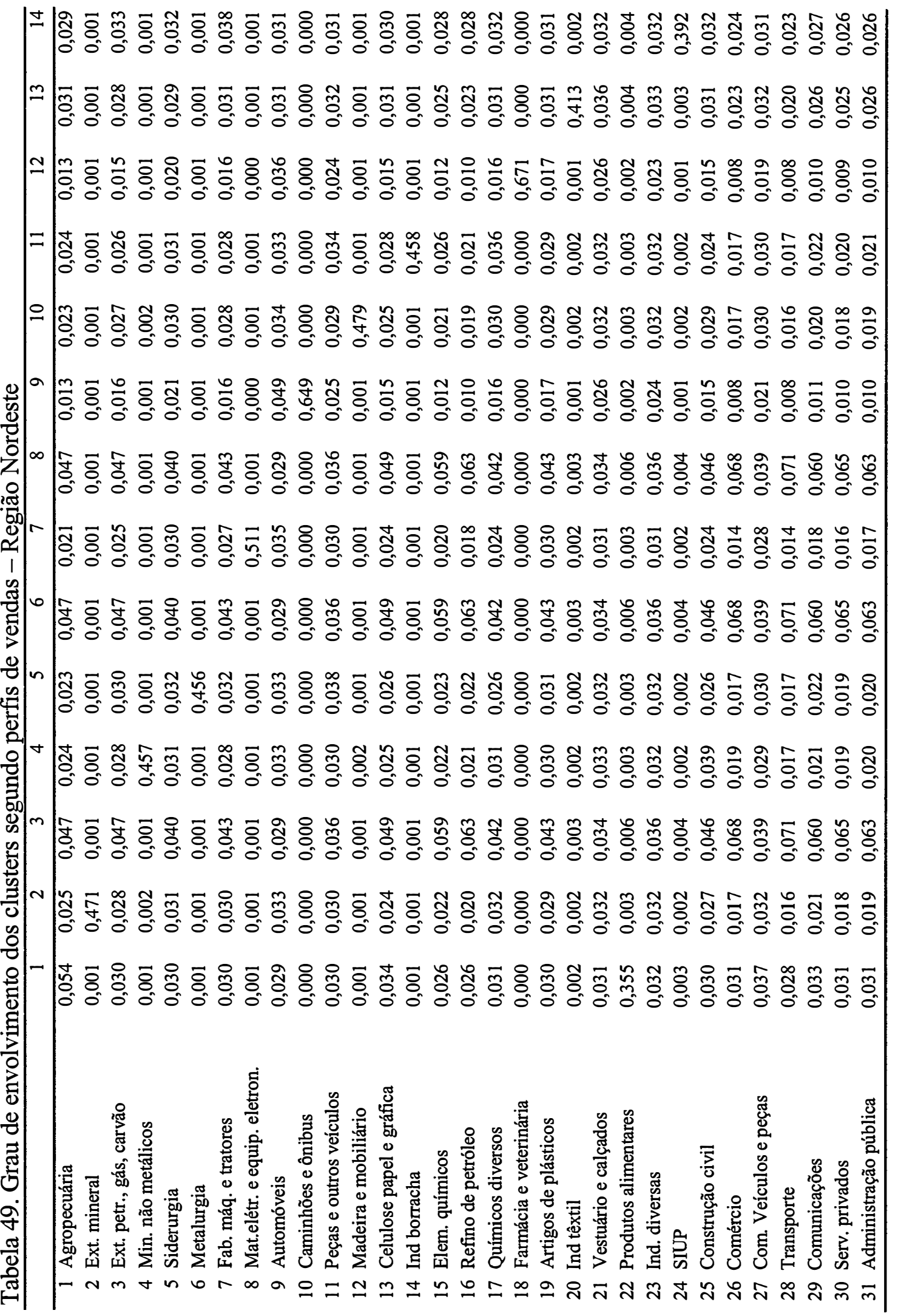




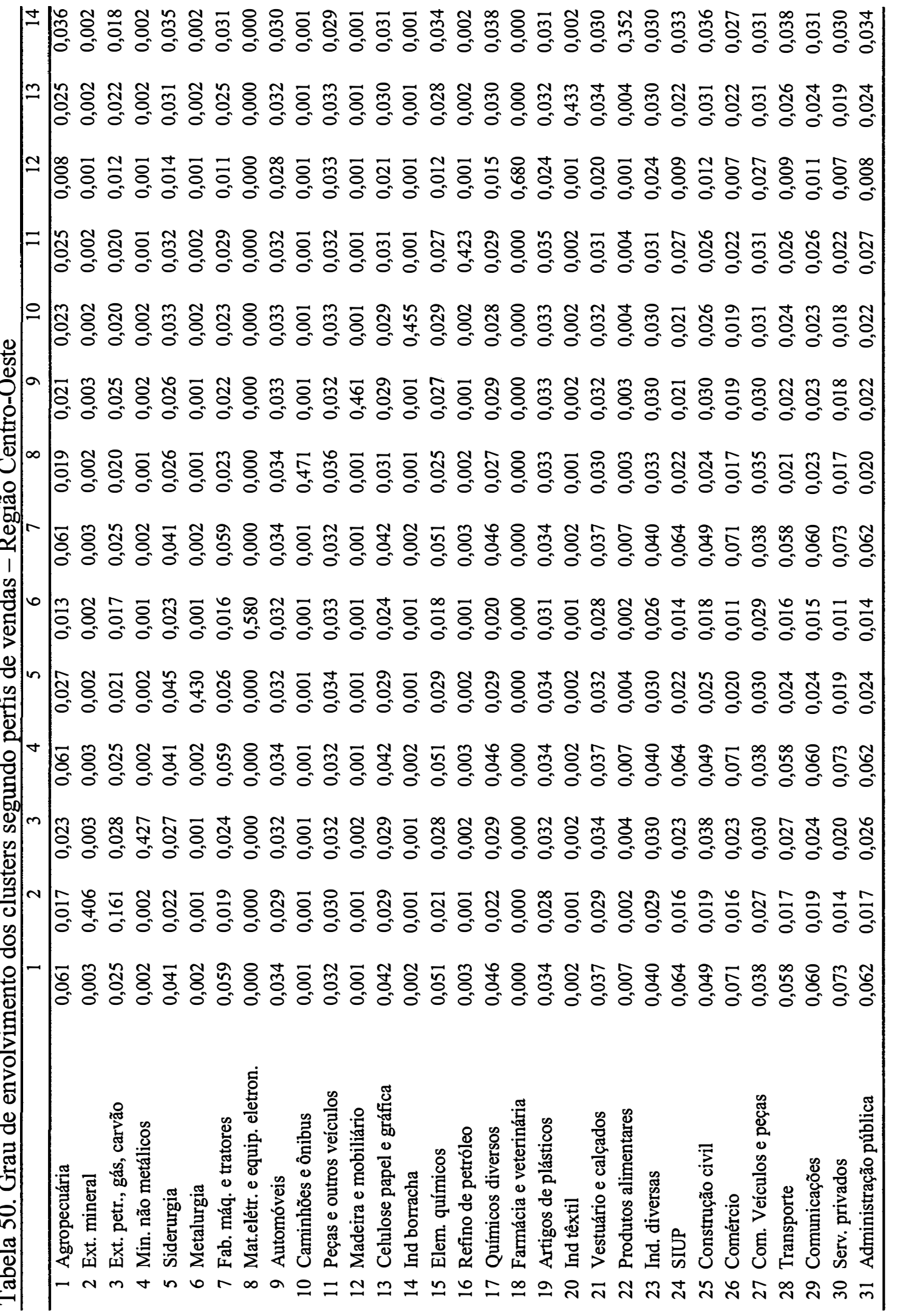




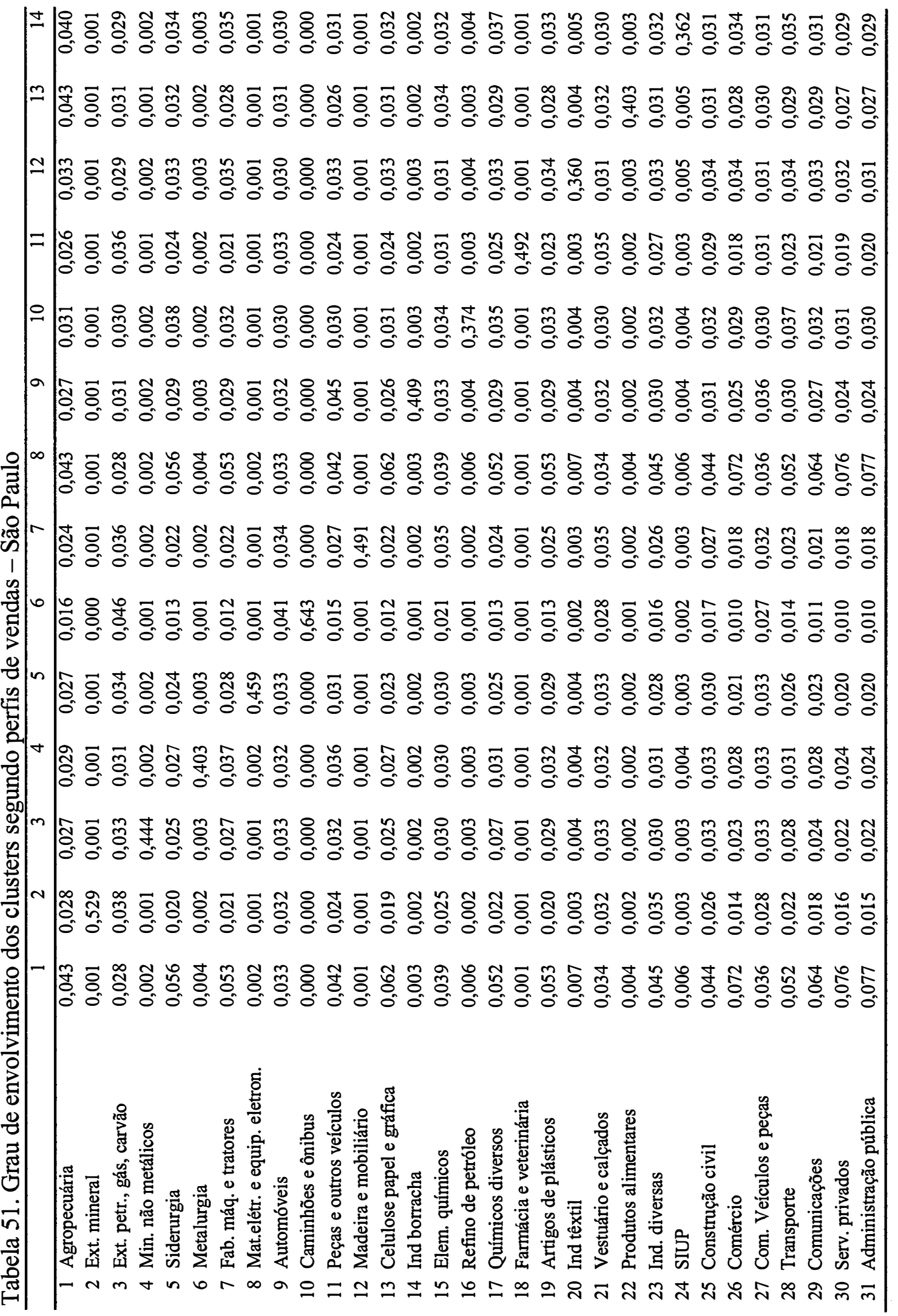




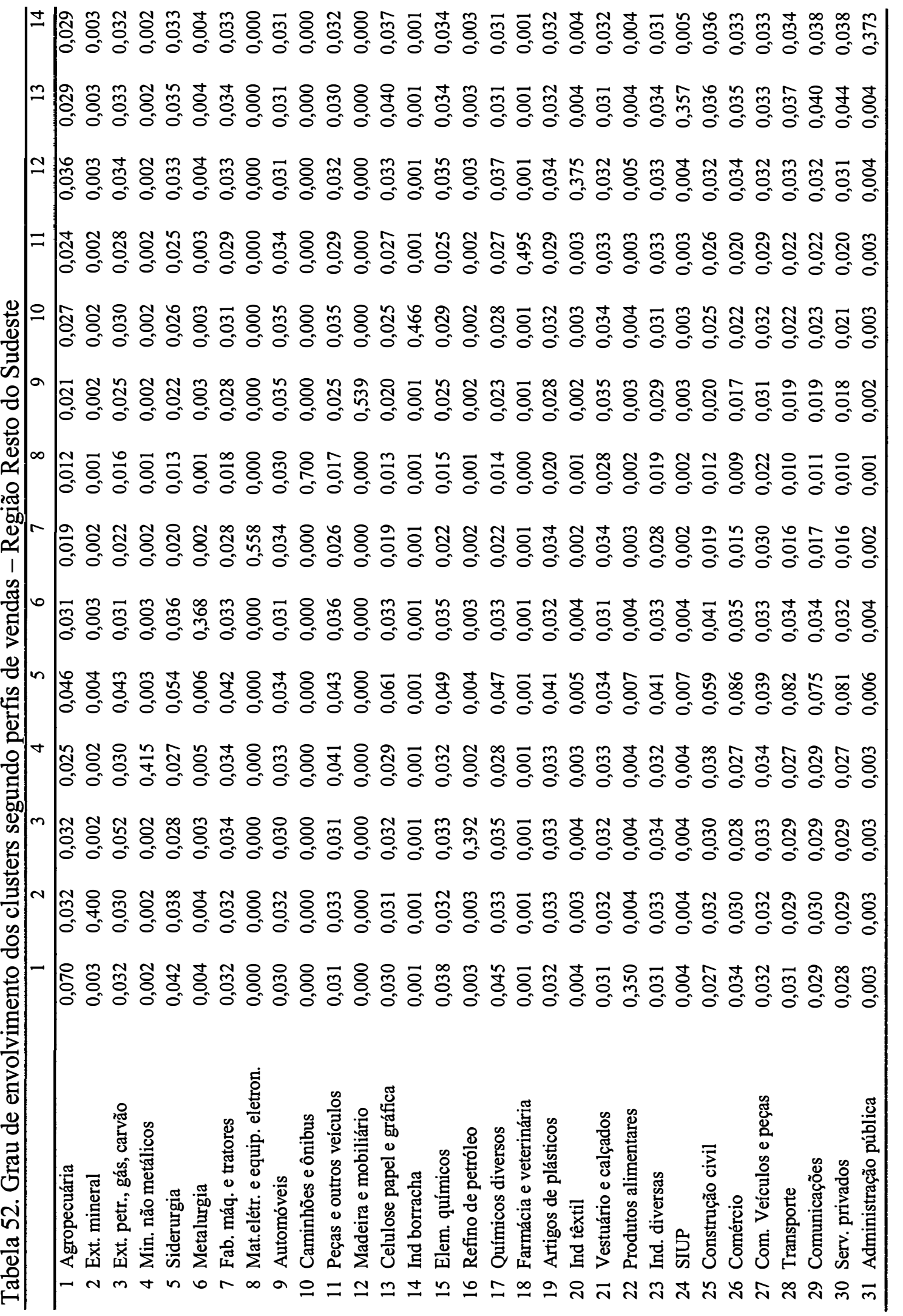




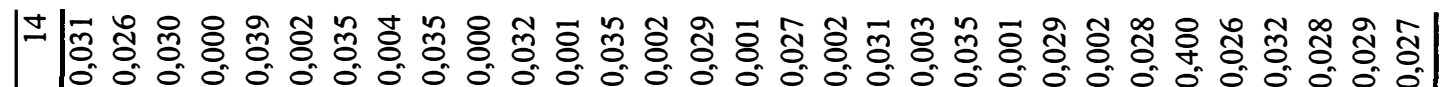

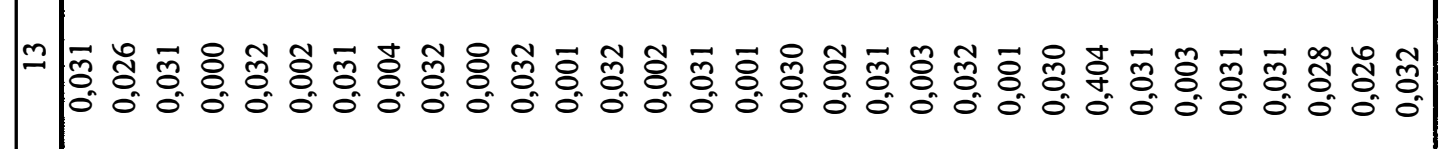

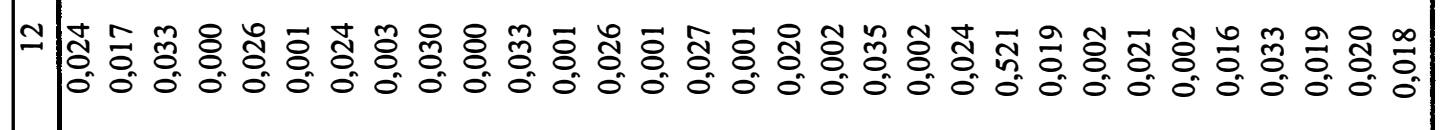

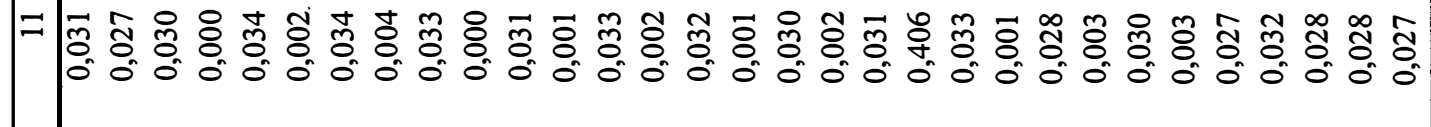

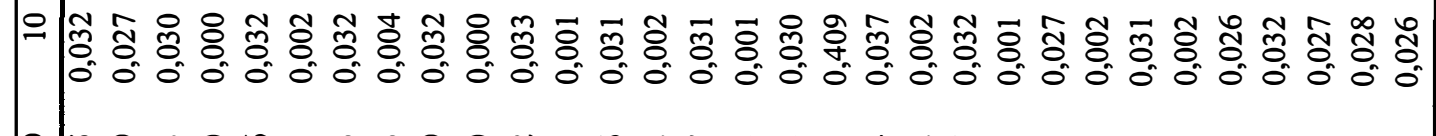

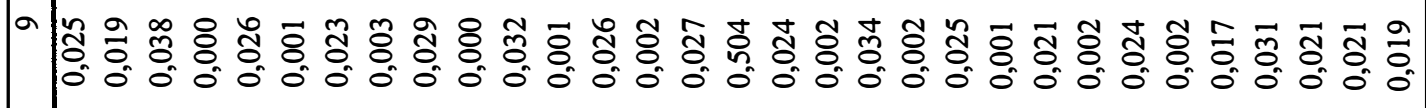

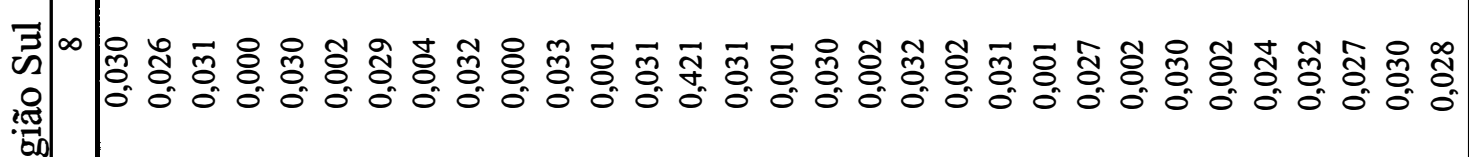

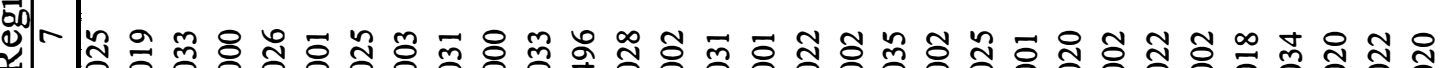

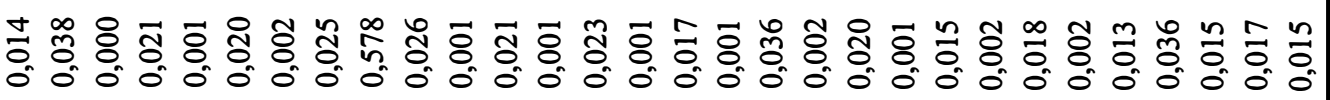

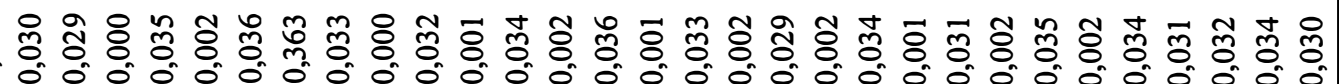

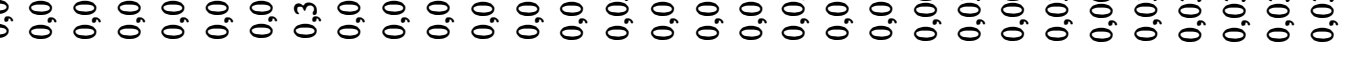

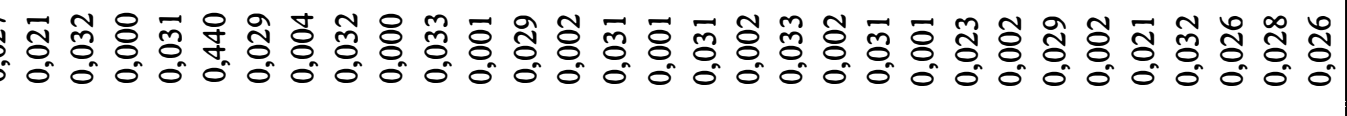

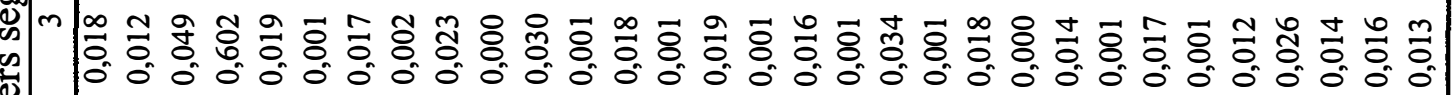

(1)

苞

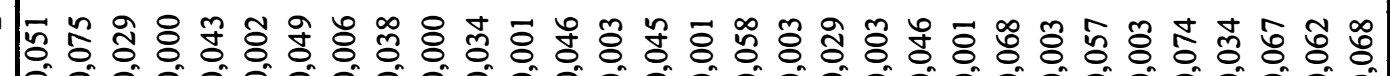
-0,000000000000000000000

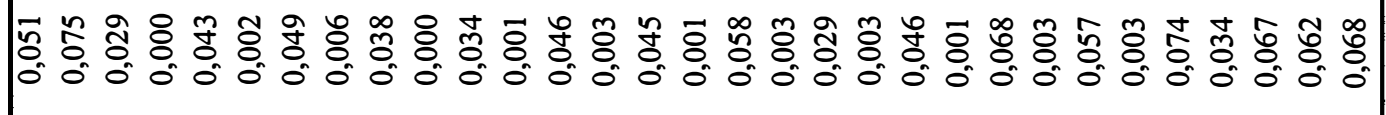

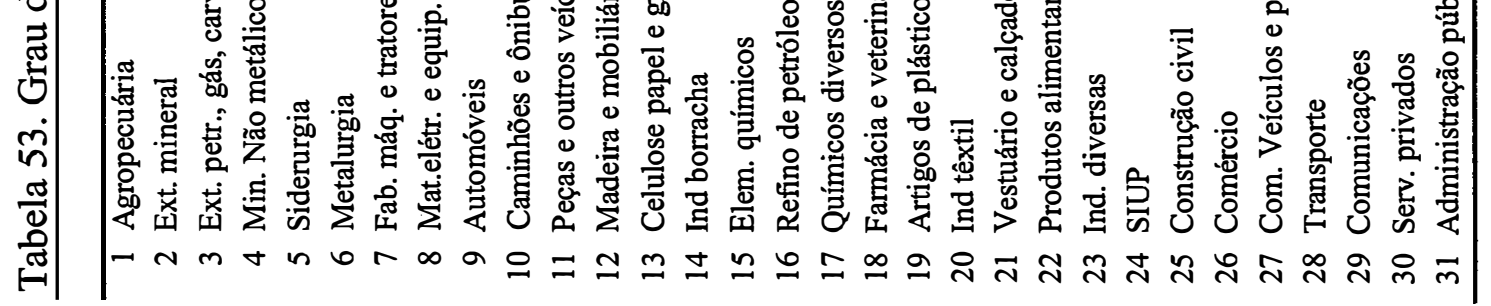




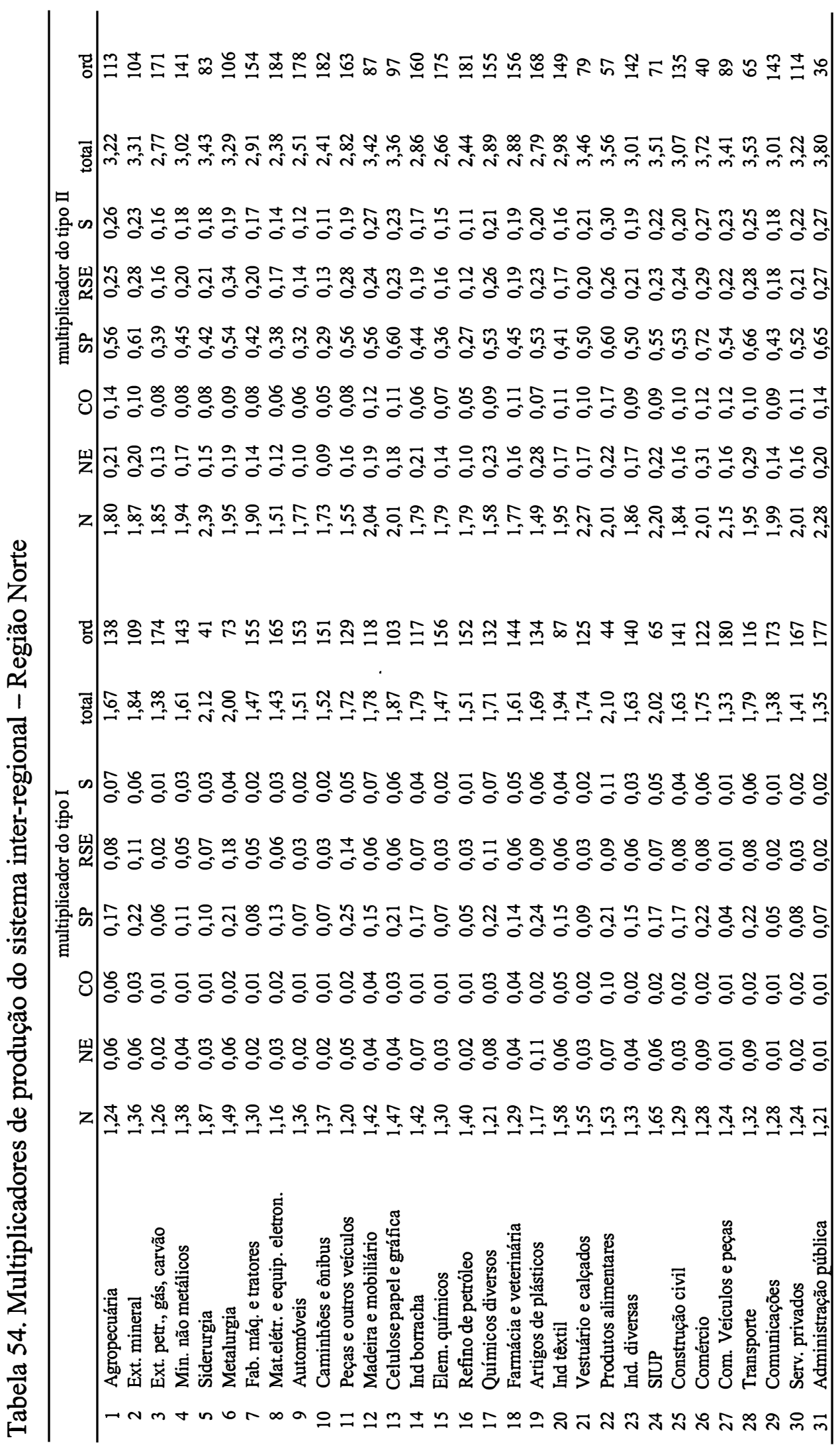




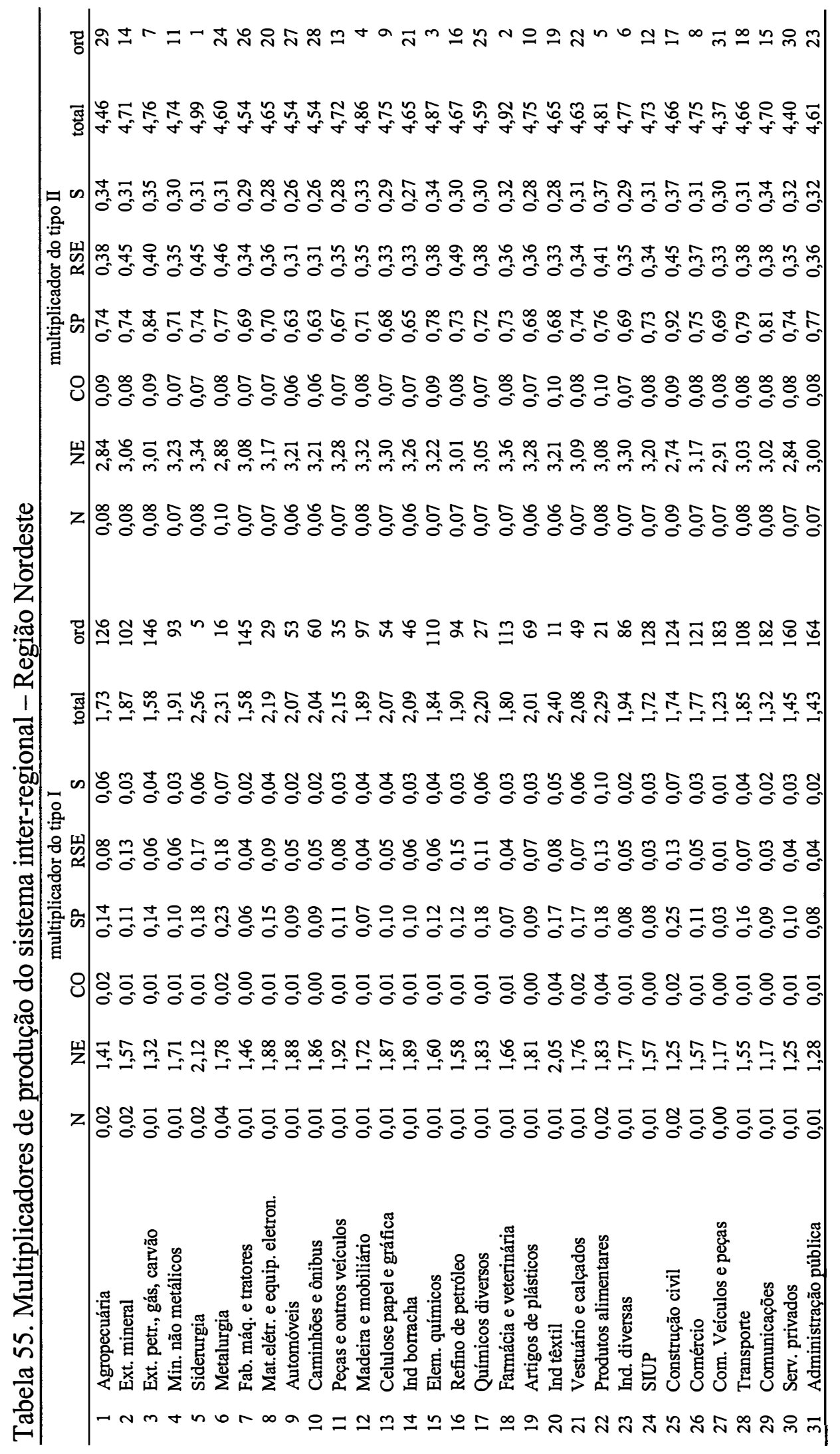




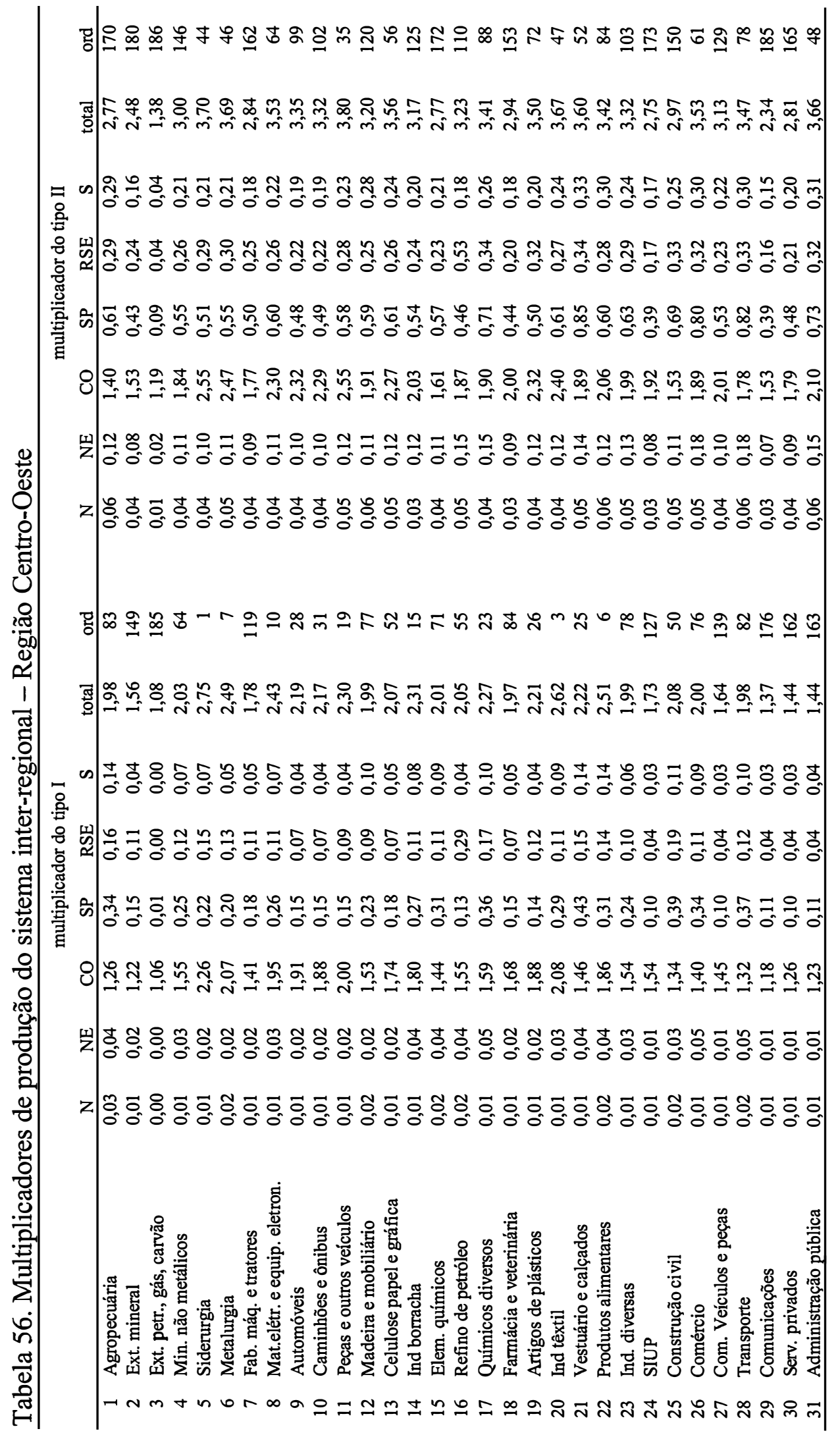




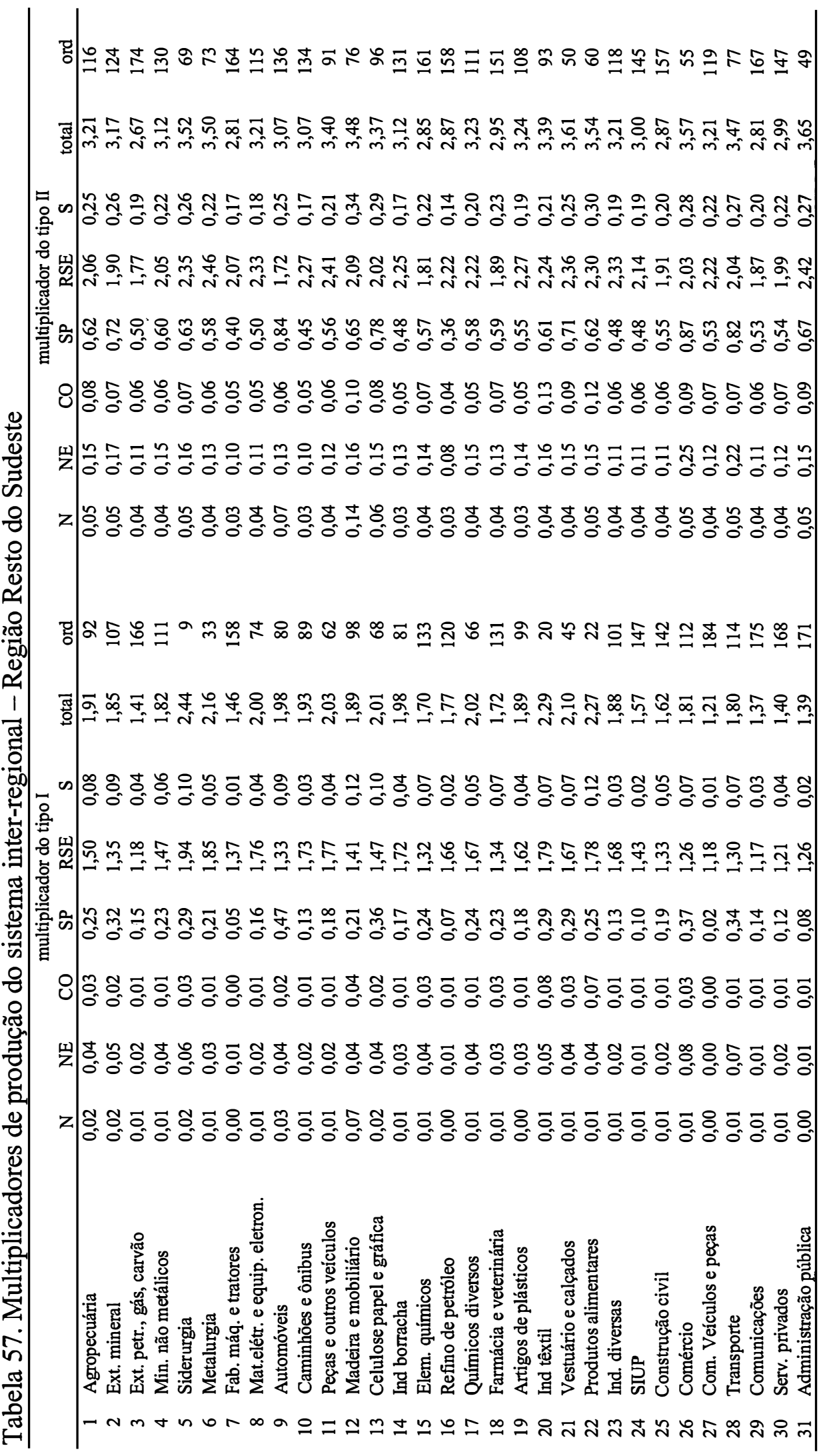




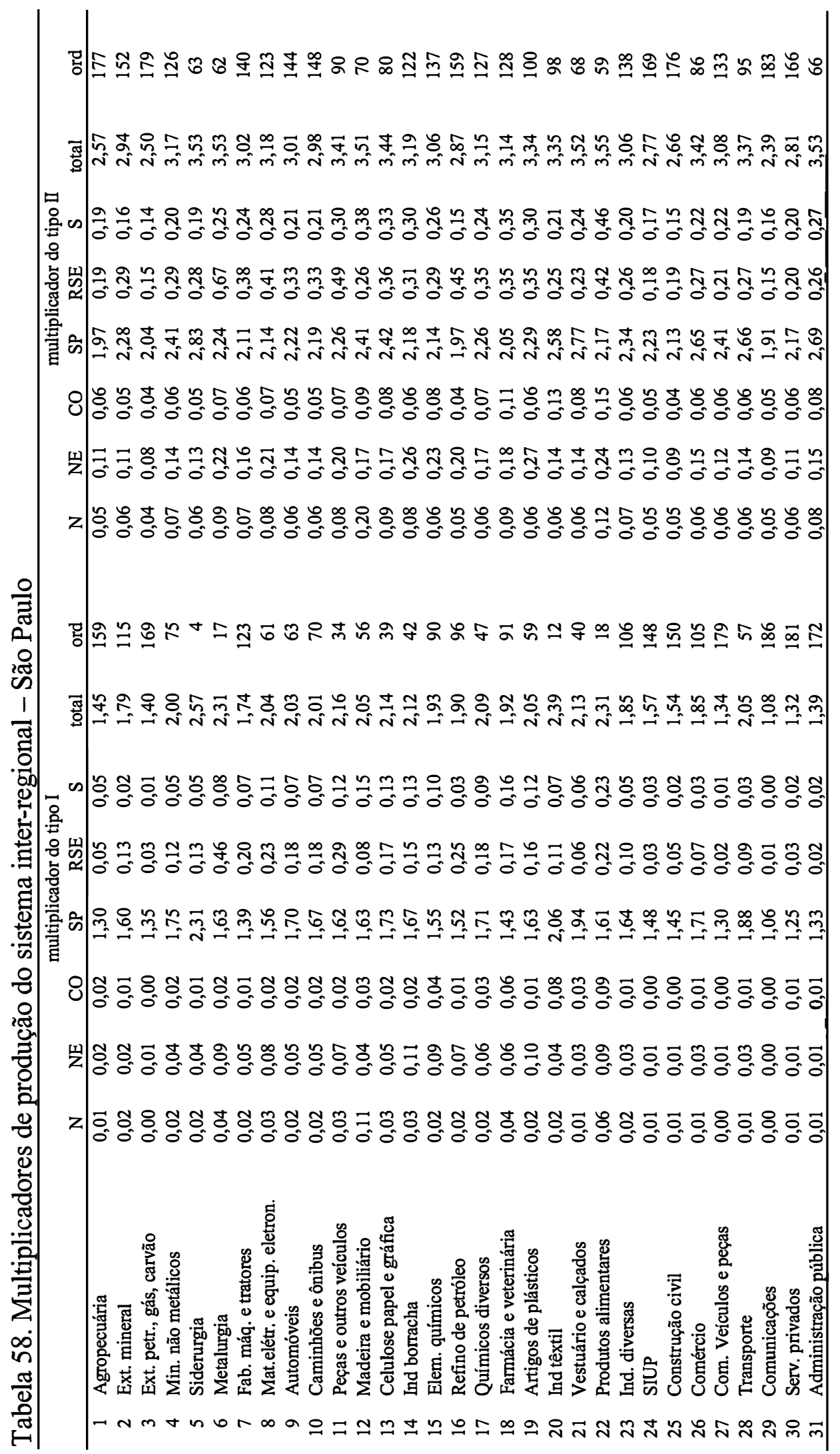




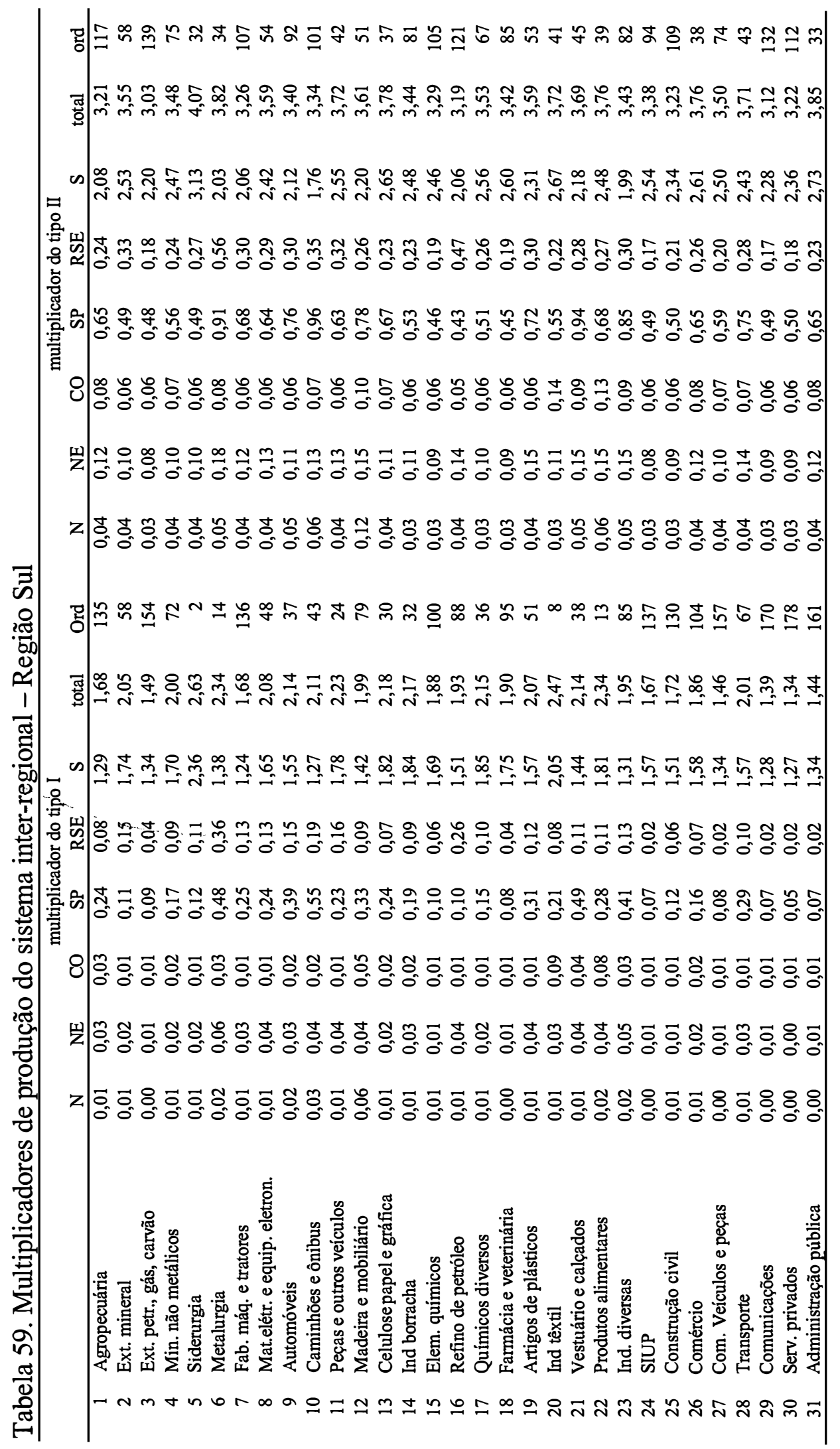




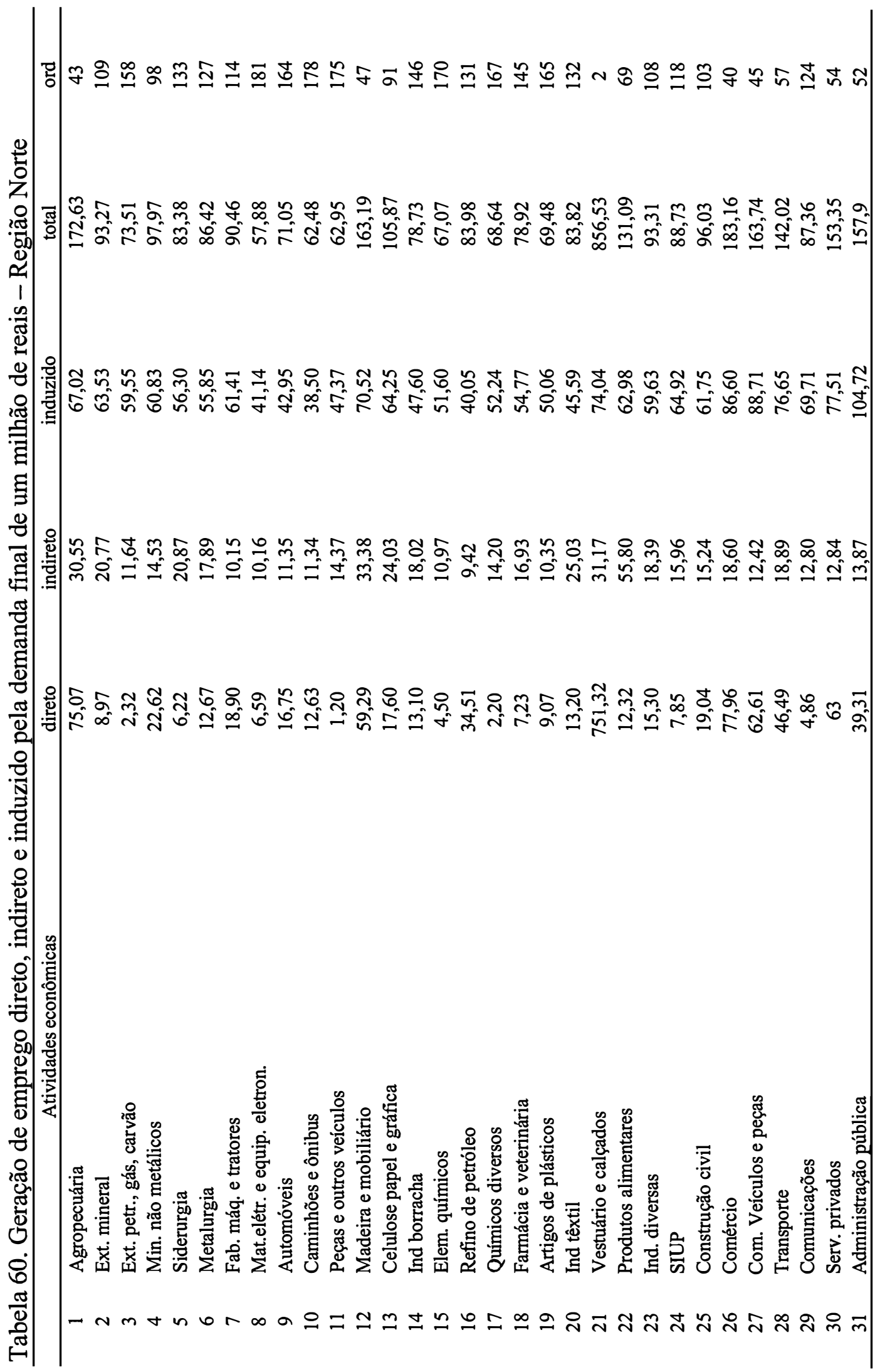




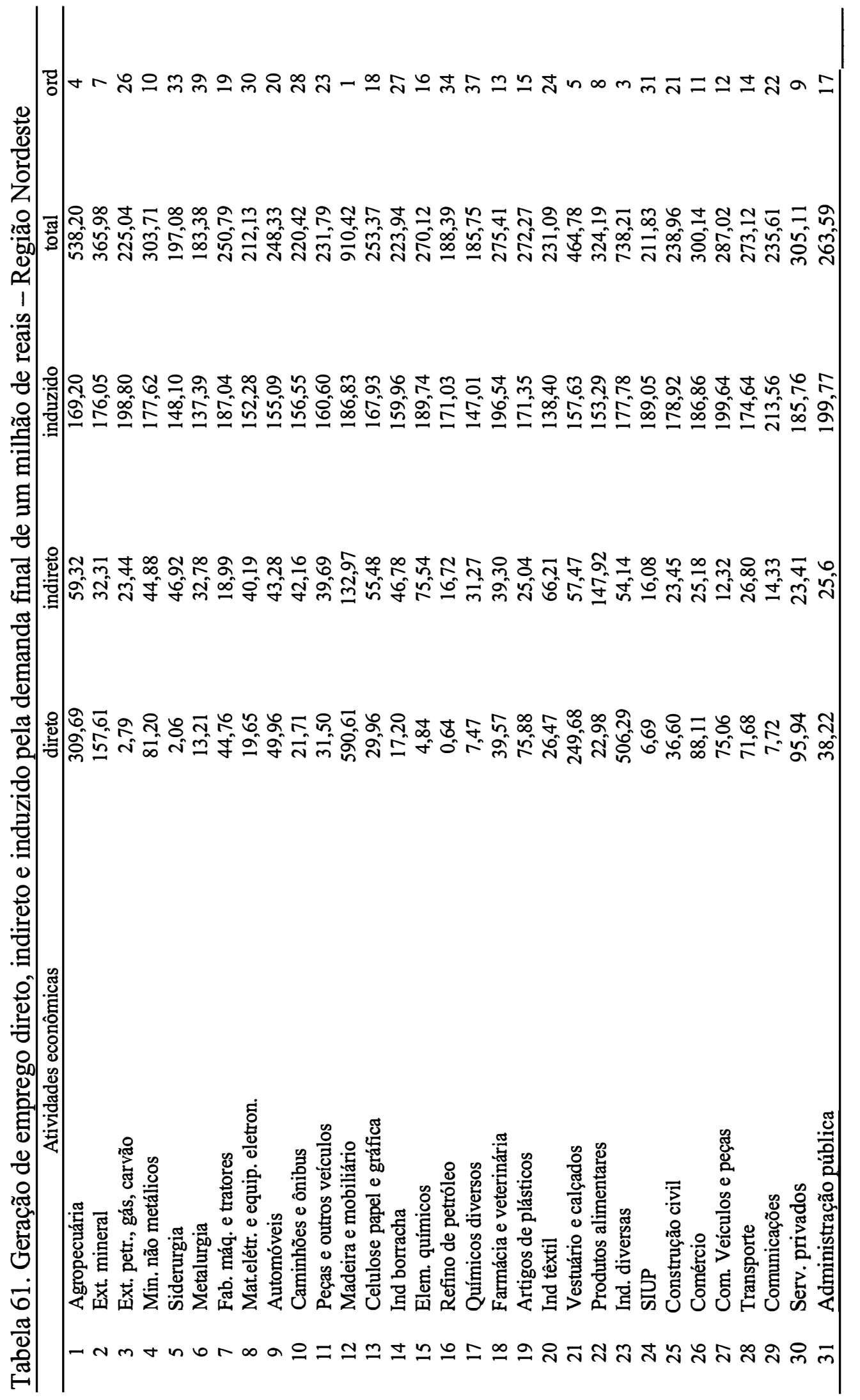




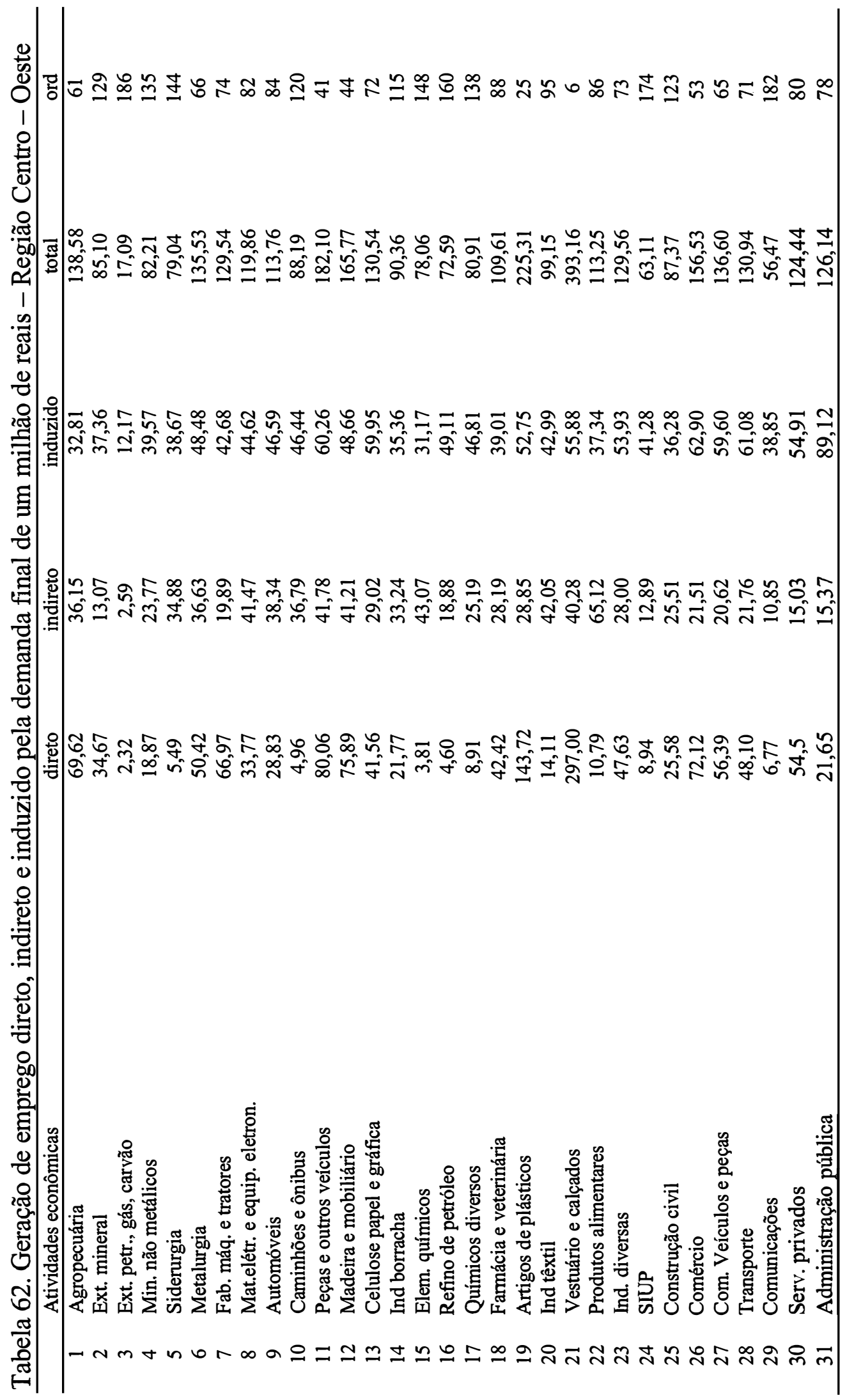




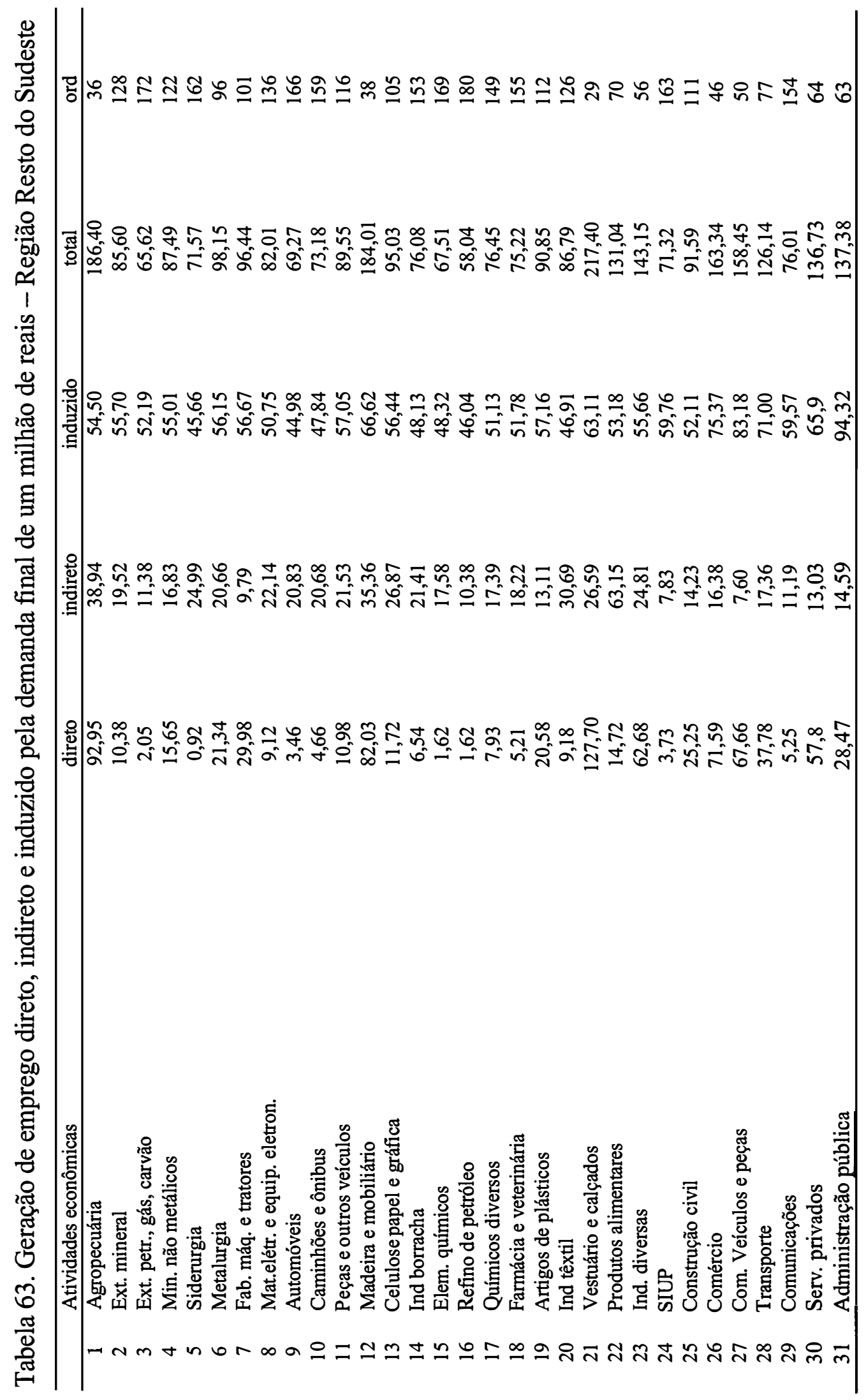




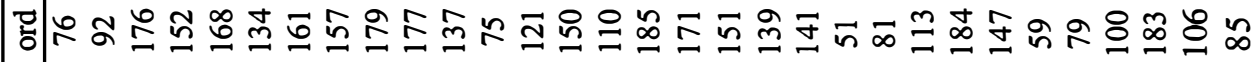

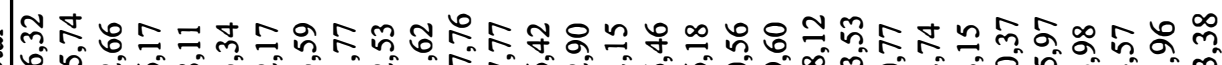

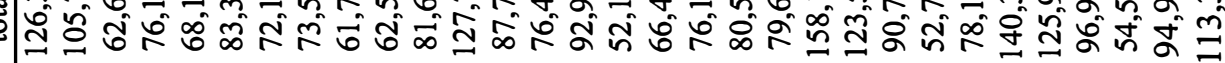

여예

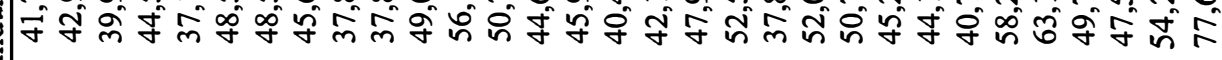

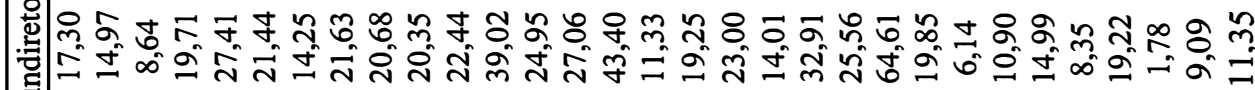

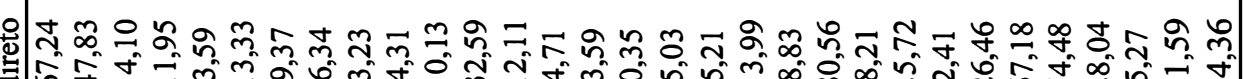




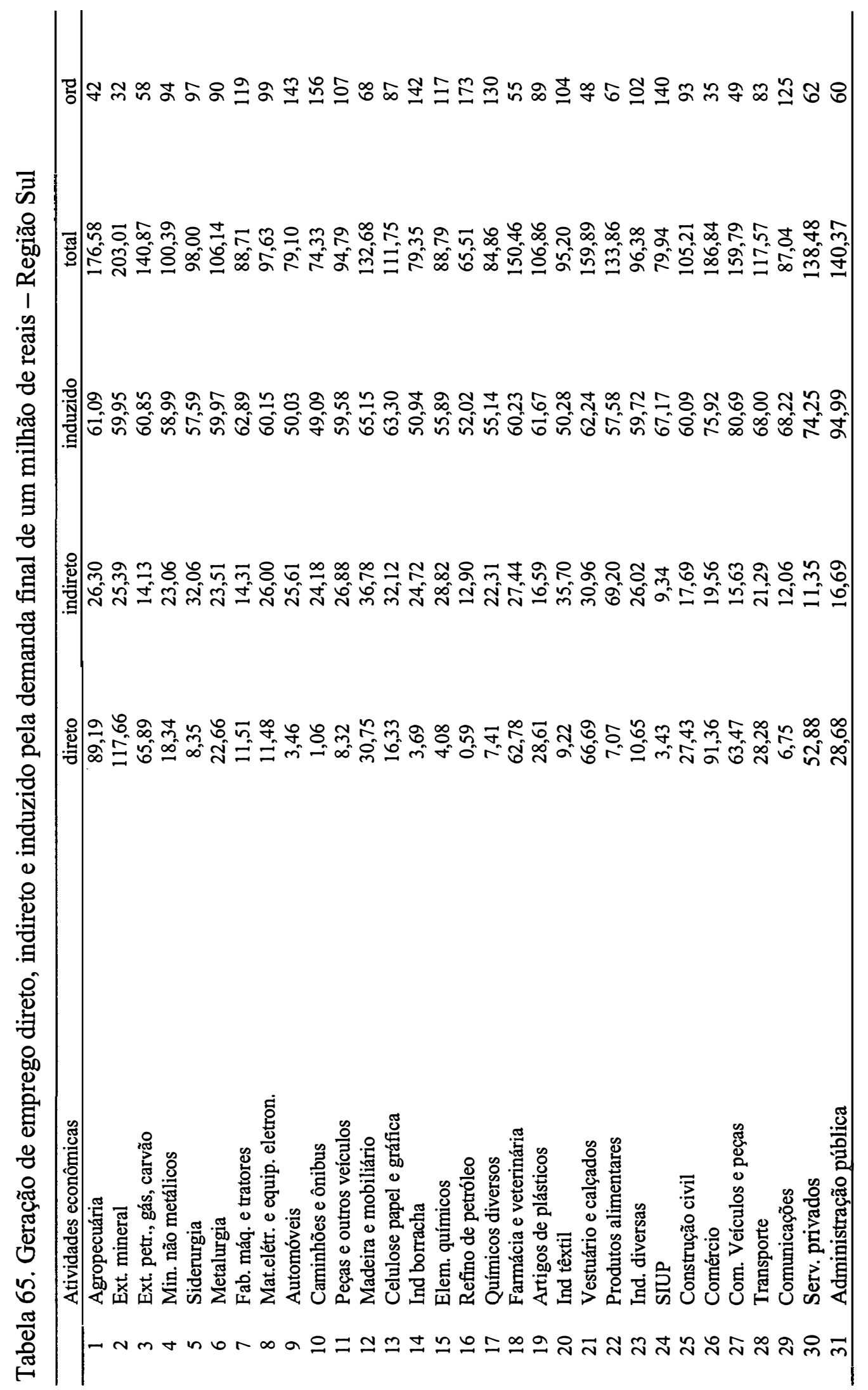




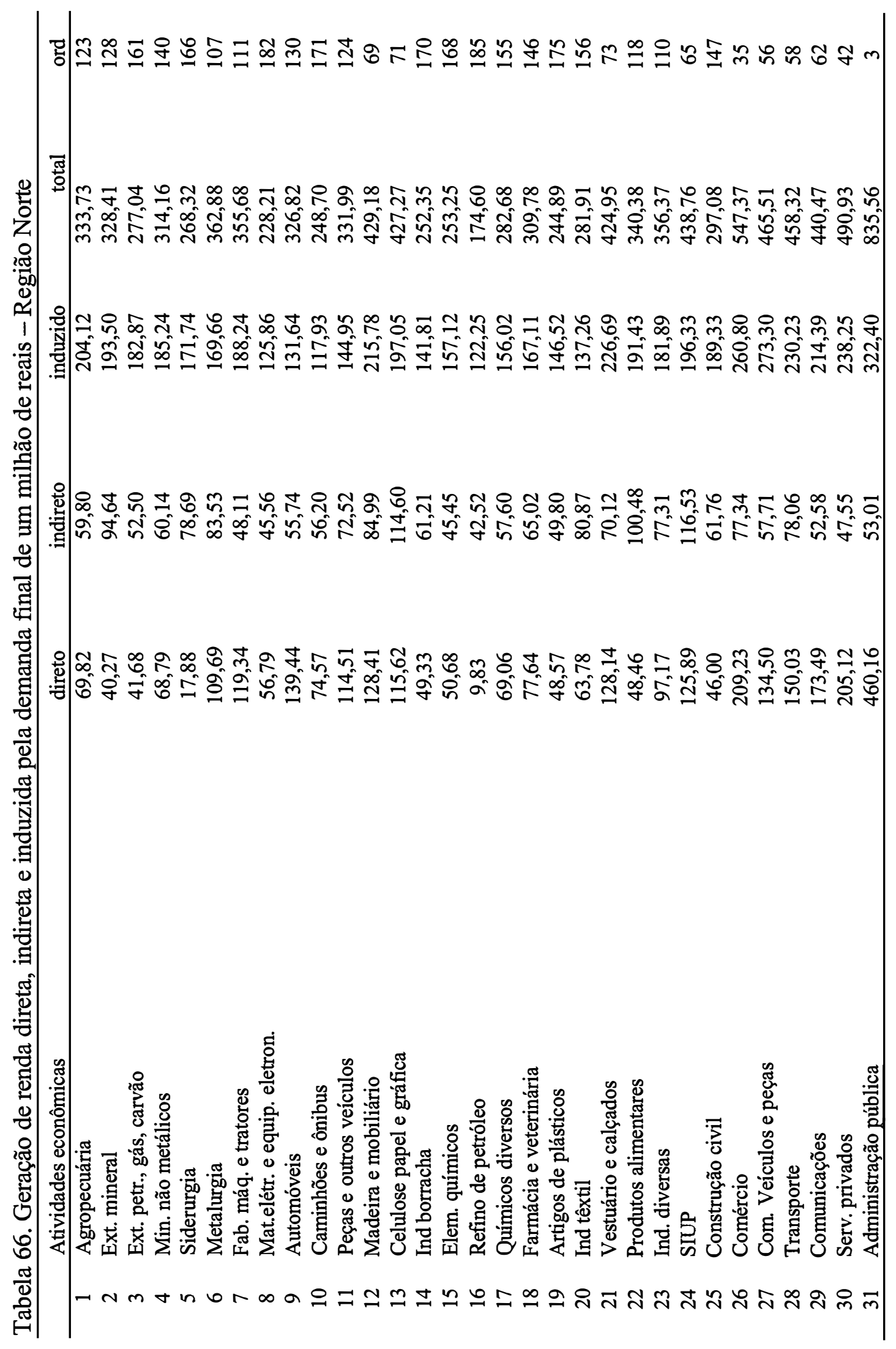


क t

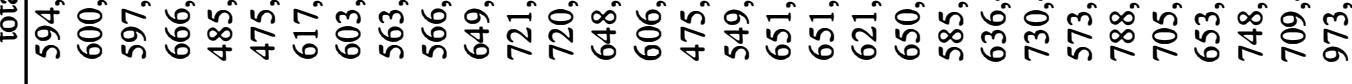

⿹勹巳

ก

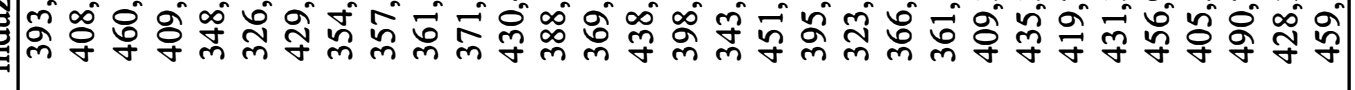

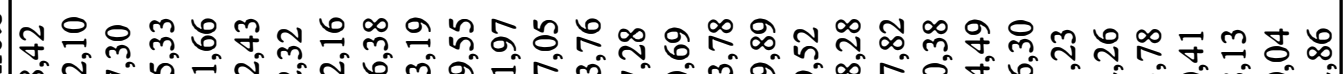

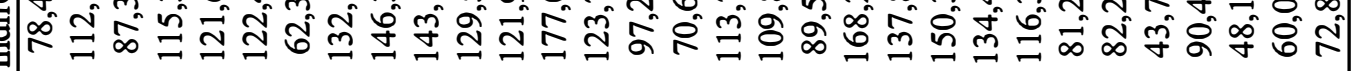

원 ร

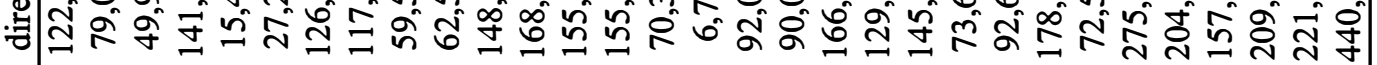

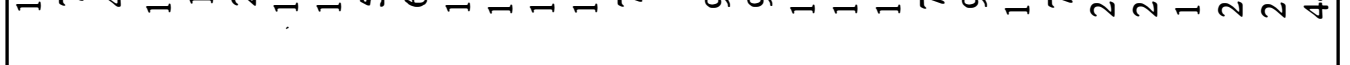

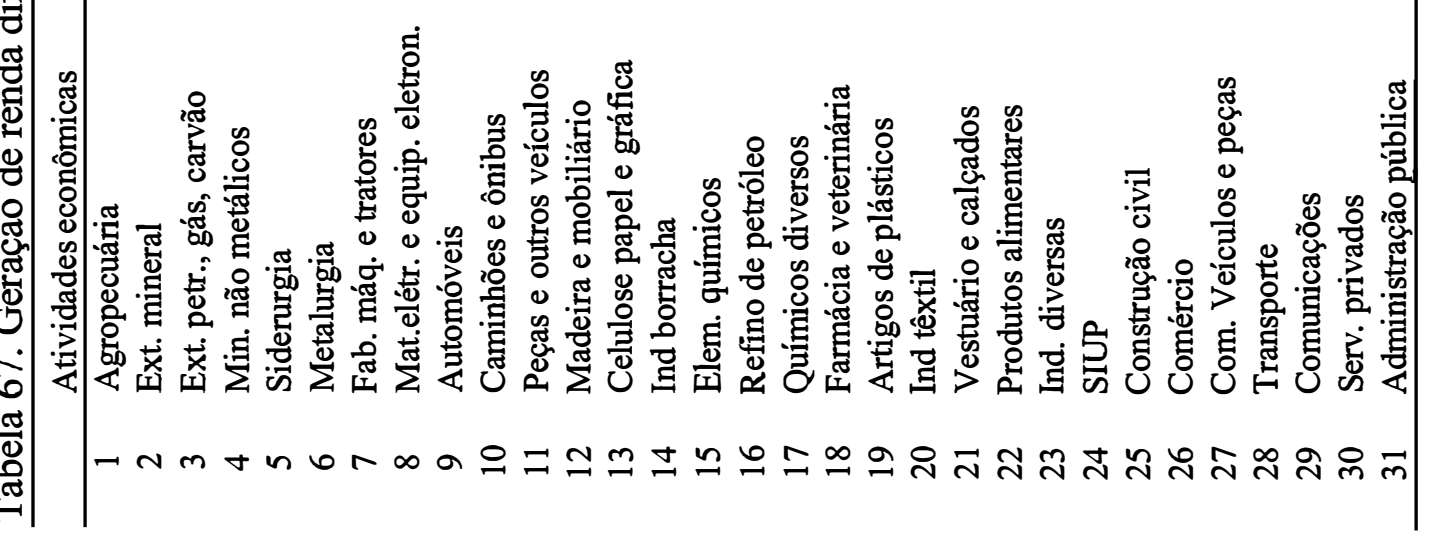




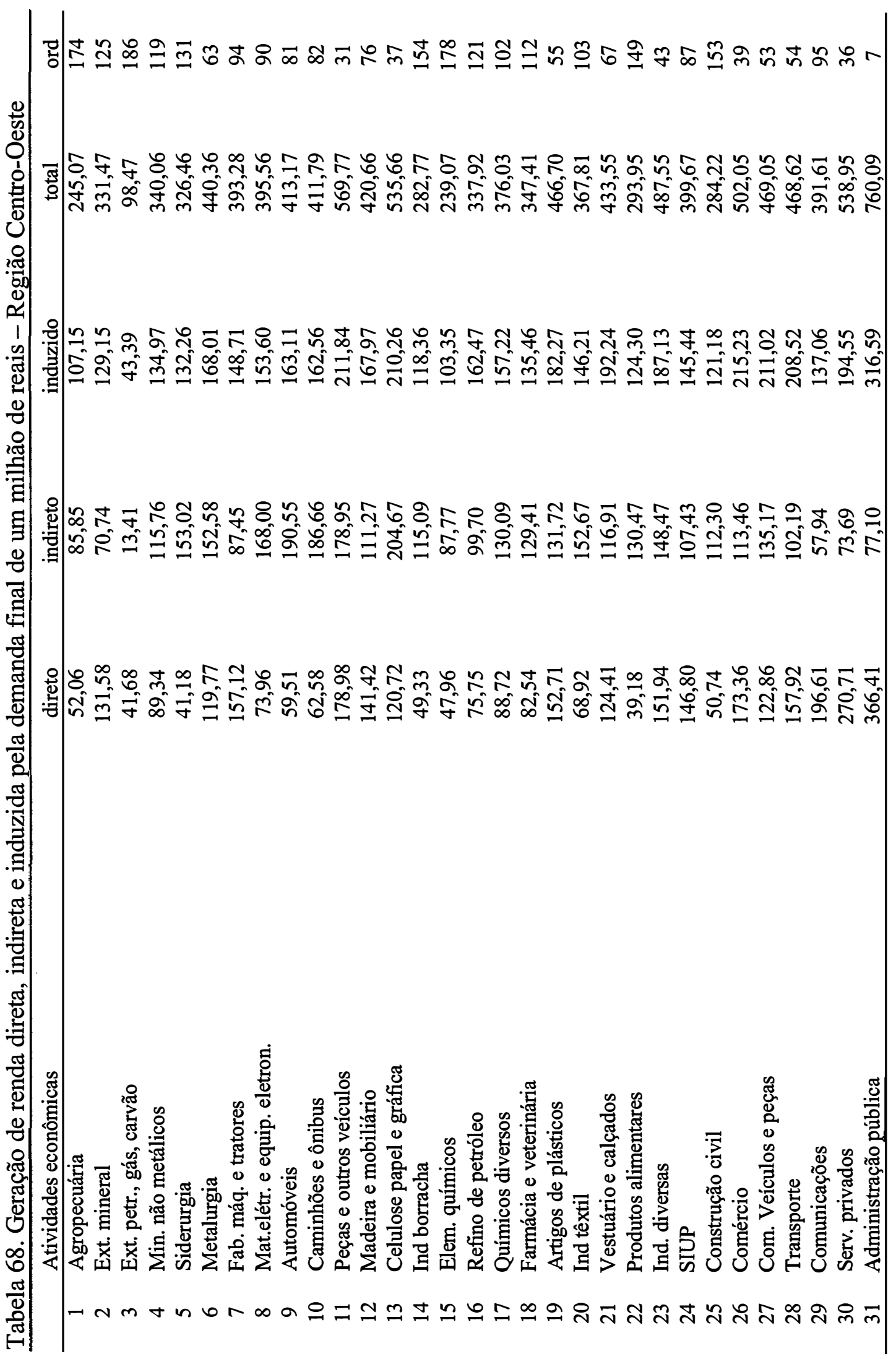




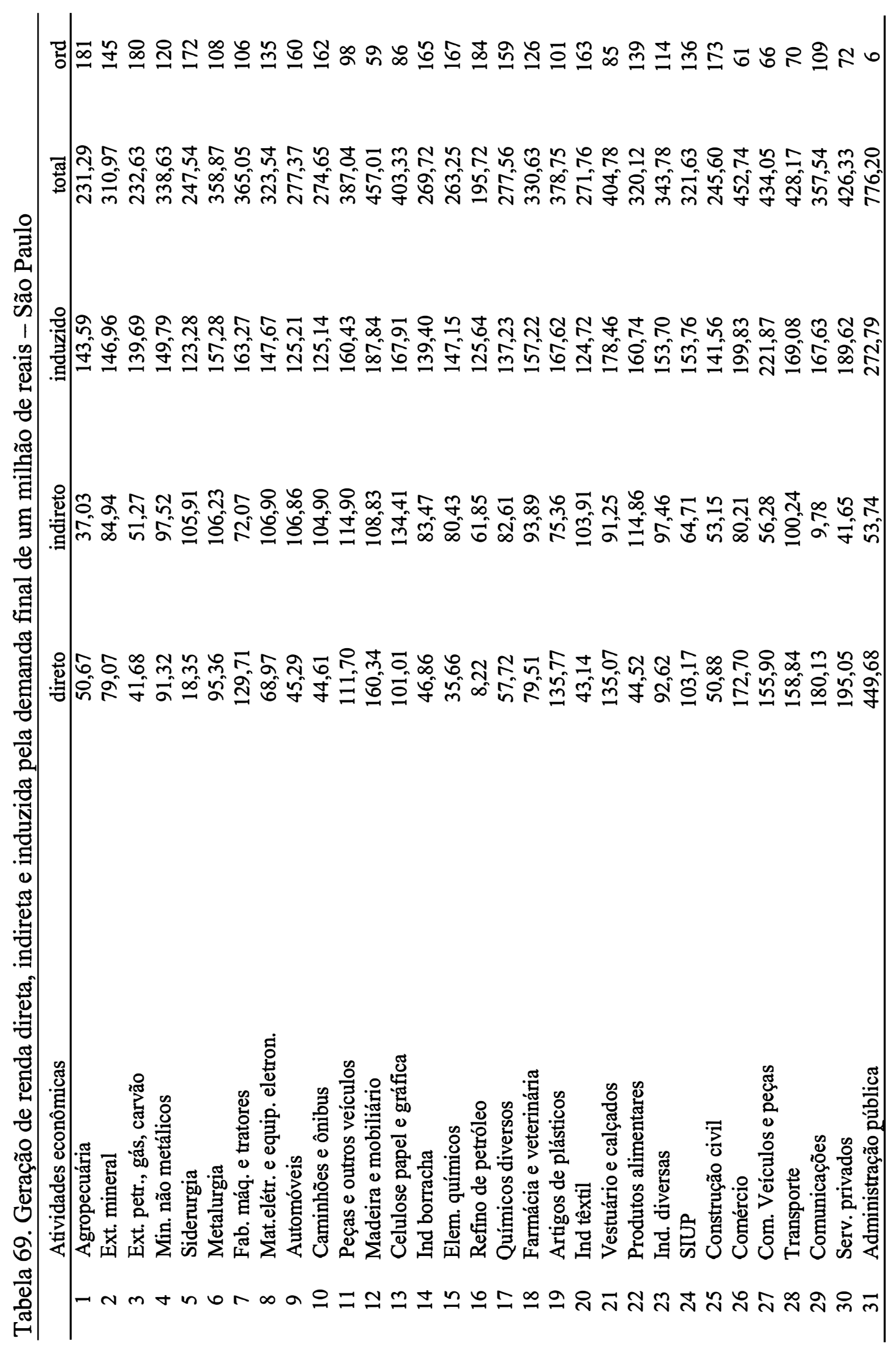




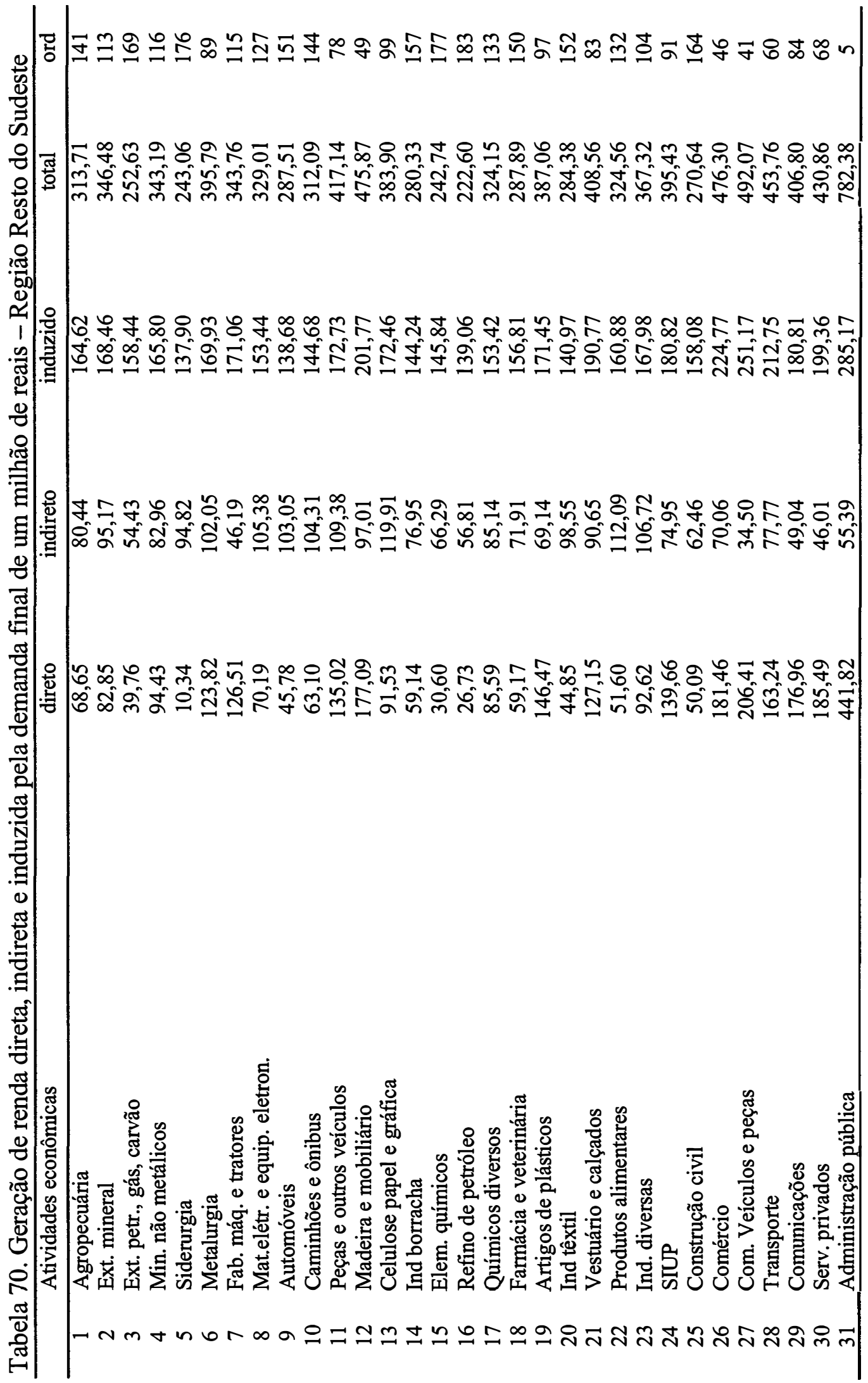




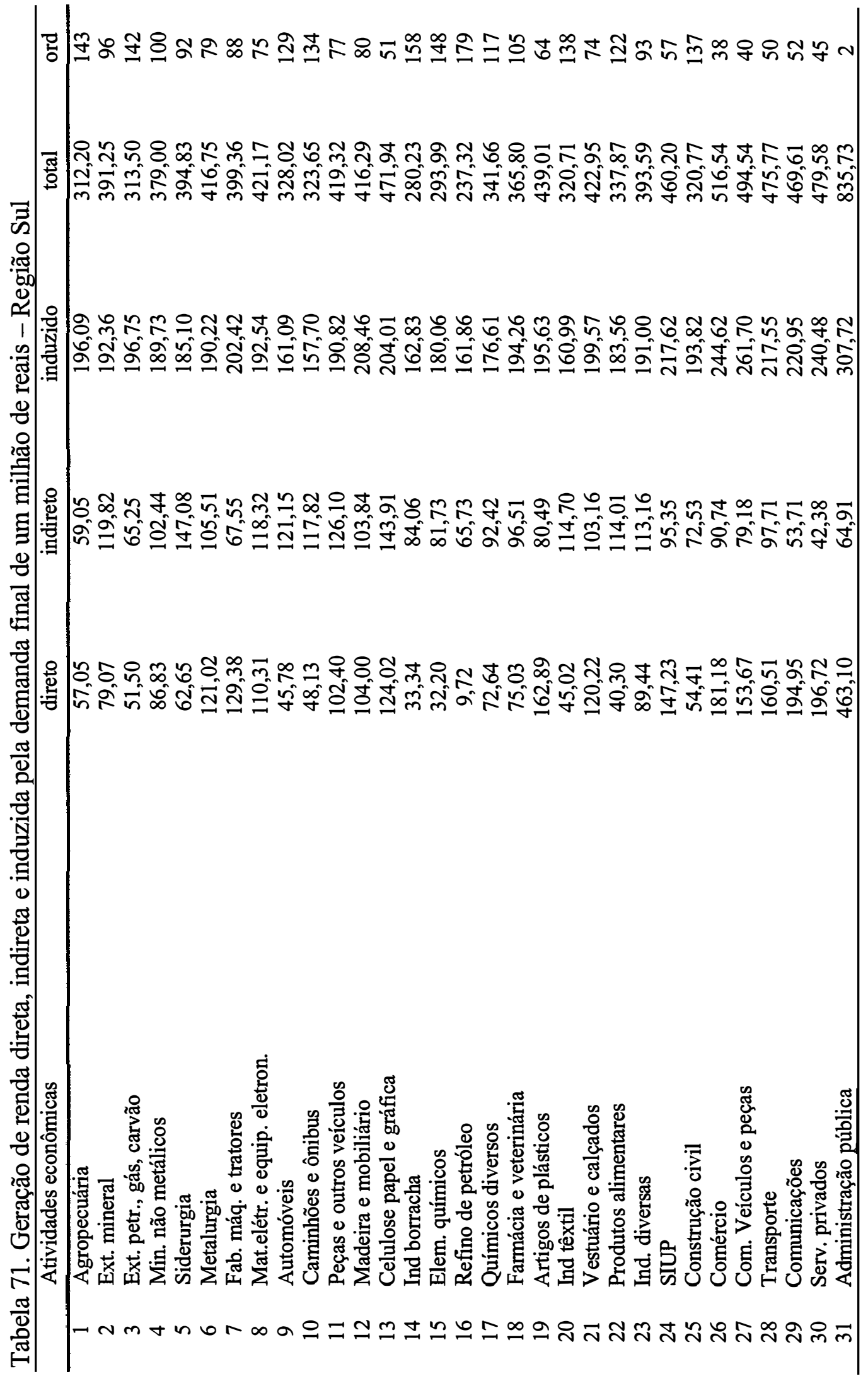




\section{REFERÊNCIAS BIBLIOGRÁFICAS}

ASSOCIAÇÃO NACIONAL DE VEÍCULOS AUTOMOTORES. Anuário da indústria automobilística brasileira 2003. http://www.anfavea.com.br (10 abr. 2004)

ASSOCIAÇÃO NACIONAL DE VEÍCULOS AUTOMOTORES. Anuário da indústria automobilística brasileira 2004. http://www.anfavea.com.br (07 ago. 2004)

AUTOMOTIVEBUSINESS. O mapa da produção. $h$ ttp://www.automotivebusiness.com (12 jul. 2004)

ARBIX, G.; RODRIGUEZ-POSE, A. Strategies of waste: bidding wars in the brazilian automomotive sector. International Journal of Urban and Regional Research, v.25, n.1, p.134-154, Mar. 2001.

BAER, W. Economia brasileira. São Paulo: Nobel, 1995. 416p.

BALDWIN, C.Y.; CLARK, C.B. Managing in age of modularity. Harvard Business Review, v.75, n.5, p.84-93, Sept./Oct. 1997. 
BEDÊ, M.A. A política automotiva nos anos 90. In: ARBIX, G.; ZILBOVICIUS, M. (Org.). De JK a FHC: a reinvenção dos carros. São Paulo: Scritta, 1997. p.357-387.

BERGSMAN, J.; GREENSTON, P.; HEALY, R. The agglomeration process in urban growth. Urban Studies, v.9, n.3, p.263-288, 1972.

BERGSMAN, J.; GREENSTON, P.; HEALY, R. A classification of economic activities based on location patterns. Journal of Urban Economics, v.2, n.1, p.1-28, 1975.

BLIN, J.M.; COHEN, C. Technological similarity and aggregation in input-output systems: a cluster-analytic approach. Review of Economic Statistics, v.59, n.1, p.82-91, 1977.

BONELLI, R. Políticas de competitividade industrial no Brasil: 1995/2000. Brasília: IPEA, 2001. 44p. (Texto para discussão, 810)

BONELLI, R.; VEIGA, P.M. Dinâmica das políticas setoriais no Brasil na década de 1990: continuidade e mudança. Revista Brasileira de Comércio Exterior, n.75, p.1-24, abr./jun. 2003.

BRASIL. Ministério do Desenvolvimento, Indústria e Comércio Exterior. Secretaria do Desenvolvimento da Produção. Indústria automotiva. http://www.desenvolvimento.gov.br/sitio/sdp/proacao/forcompetitividade/docreferen cia.php (07 ago. 2003) 
CAVALCANTE, L.C.; UDERMAN, S. The cost of a structural change: a large automobile plant in a brazilian less developed region. Urbana: University of Illinois, Regional Economics Applications Laboratory, 2002. 34p. (Discussion paper, 04-T5)

CELLA, G. The input-output measurement of interindustry linkages. Oxford Bulletin of Economics and Statistics, v.46, n.1, p.73-84, 1984.

CLEMENTES, B.J. On the decomposition and normalization of industry linkages. Economic Letters, v.33, n.4, p.337-340, 1990.

COX, E. Fuzzy logic for business and industry. Rockland: InterCity Press, 1995. 601p.

CZAMANSKI, S.; ABLAS, L.A.Q. Identification of industrial clusters and complexes: a comparison of methods and findings. Urban Studies, v.16, p.61-80, 1979.

CZAMANSKI, S. Study of clustering of industries. Halifax: Dalhouse University, Institute of Public Affairs, 1974. 154p.

DORFMAN, R. The nature and significance of Input-output. The Review of Economics and Statistics, v.36, n.2, p.121-133, May 1954.

DIETZENBACHER, E. An algorithm for finding block-triangular forms. Applied Mathematics and Computation, v.76, n.2, p.161-171, 1996. 
DRIDI, C.; HEWINGS, G.J.D. Toward a quantitative analysis of industrial clusters I: fuzzy clusters vs crisp cluster. Urbana: University of Illinois, Regional Economics Applications Laboratory, 2002a. 33p. (Discussion paper, 02-T-1)

DRIDI, C.; HEWINGS, G.J.D. Toward a quantitative analysis of industrial clusters II: shapley value, entropy, and other fuzzy measures. Urbana: University of Illinois, Regional Economics Applications Laboratory, 2002b. 26p. (Discussion paper, 02T-6)

FEIJÓ, C.A.; RAMOS, R.L.O.; YOUNG, C.E.F.; LIMA, F.C.G.C.; GALVÃO, O.J.A. Contabilidade social: o novo sistema de contas nacionais do Brasil. Rio de Janeiro: Editora Campus, 2001. 356p.

FERRO, J.R. A produção enxuta no Brasil. In: WOMACK, J.P.; JONES, D.T.; ROSS, D. et al. A máquina que mudou o mundo. Rio de Janeiro: Campus, 1992. p.311-337.

GUILHOTO, J.J.M.; SONIS, M.; HEWINGS, G.J.D.; MARTINS, E.B. Índices de ligações chave na economia brasileira: 1959/90. Pesquisa e Planejamento Econômico, v.2, n.24, p.287-314, ago. 1994.

GUILHOTO, J.J.M.; SONIS, M.; HEWINGS, G.J.D.; MARTINS, E.B. Linkages and multipliers in a multiregional framework: integration of alternative approaches. Urbana: University of Illinois, Regional Economics Applications Laboratory, 1996. 20p. (Discussion paper, 96-T-8) 
GUILHOTO, J.J.M.; FURTUOSO, M.C.O.; BARROS, G.S.C. O agronegócio na economia brasileira (1994-1999). Piracicaba: Centro de Estudos Avançados em Economia Aplicada (CEPEA), 2000. 112p.

GUILHOTO, J.J.M. Leontief e insumo-produto: antecedentes, princípios e evolução. Piracicaba: ESALQ, Depto. Economia, Administração e Sociologia, 2000. 22p. (Série Seminários da Pós-Graduação, 15)

GUILHOTO, J.J.M.; SESSO FILHO, U.A.; LOPES, R.L.; HILGEMBERG, C.M.A.T.; HLGEMBERG, E.M. Nota metodológica: construção da matriz insumo-produto utilizando dados preliminares das contas nacionais (compact disc). In: ENCONTRO BRASILEIRO DE ESTUDOS REGIONAIS E URBANOS, 2., São Paulo, 2002. Anais. Belo Horizonte: Associação Brasileira de Estudos Regionais, 2002.

HEWINGS, G.J.; SCHINDLER, G.R; ISRAILEVICH, P.R; SONIS, M. Agglomeration, clustering, and structural change: interpreting changes in the Chicago regional economy. In: STEINER, M. (Ed.). Clusters and regional specialization. Heidelberg: Springer Verlag, 1998.

HOEN, A.R. Identyfing linkages with cluster based methodology. Economic Systems Research, v.14, n.2, p131-146, 2002.

HUMPHREY, J.; LECLER, Y.; SALERNO, M. (Ed). Global strategies and local realities: the auto industry in emerging markets. New York: St. Martins Press, 2000. $265 \mathrm{p}$. 
INSTITUTO BRASILEIRO DE GEOGRAFIA E ESTATÍSTICA. Sistema de contas nacionais 1990-1995. Rio de Janeiro, 1997. 2v.

INSTITUTO BRASILEIRO DE GEOGRAFIA E ESTATÍSTICA. Sistema de contas nacionais 1995-1999. Rio de Janeiro, 1997. 2v.

INSTITUTO BRASILEIRO DE GEOGRAFIA E ESTATÍSTICA. Tradutor de atividades econômicas. Rio de Janeiro, 1999. 34p

INSTITUTO BRASILEIRO DE GEOGRAFIA E ESTATÍSTICA. Sistema de contas nacionais 1998-2001. http://www.ibge.gov.br (13 fev. 2004)

INSTITUTO BRASILEIRO DE GEOGRAFIA E ESTATÍSTICA. Sistema de contas nacionais 2000-2002. http://www.ibge.gov.br (13 fev. 2004)

ISARD, W.; KUENNE, R.E. The impact of steel upon the greater New York: Philadelphia industrial regional. Review of Economic and Statistics, v.35, n.4, p.289-301, Nov. 1953.

KAUFMAN, L.; ROSSEEUW, P.J. Finding groups in data: an introduction to cluster analysis. New York: Wiley, 1990. 342p.

LAPLANE, M.F.; SARTI, F. The restructuring of brazilian automobile industry in the nineties. Actes du GERPISA, n.20, p.31-48, 1997. 
LEONTIEF, W. Input-output economics. 2.ed. New York: Oxford University Press, 1986. 436p.

MILLER, R.E. The impact of the aluminum industry on the Pacific Northwest: a regional input-output analysis. Review of Economics and Statistics, v.39, n.2, p.200-209, May 1957.

McGILVRAY, J. Linkages, key sector and development strategy. In: LEONTIEF, W. (Ed.). Structure, system and economic policy. Cambridge: Cambridge University Press, 1977. p.49-56.

MIERNYK, W.H. Elementos de análise do insumo-produto. São Paulo: Atlas, 1975. $164 \mathrm{p}$.

MILLER, R.E.; BLAIR, P.D. Input-output analysis: foundations and extensions. New Jersey: Englewood Cliffs, 1985. 464p.

NISHISATO, S. Elements of dual scaling: an introduction to practical data analysis. New Jersey: Lawrence Erlbaum Associates, 1994. 400p.

OOSTERHAVEN, J.; EDING, G.J.; STELDER, D. Clusters, forward and backward linkages, and bi-regional spillovers: policy implications for the two dutch mainport regions and the rural north (compact disc). In: EUROPEAN CONGRESS OF THE REGIONAL SCIENCE ASSOCIATION, 39., Dublin, 1999. Proceedings. Dublin: Carfax, 1999. 
ORENSTEIN, L.; SOCHACZEWSKI, A.C. Democracia com desenvolvimento. In: ABREU, M. (Org.). A ordem do progresso: cem anos de política econômica 18891989. 10.ed. Rio de Janeiro: Campus, 1999. 445p.

PIANCASTELLI, M.; PEROBELLI, F. ICMS: evolução recente e guerra fiscal. Brasília: IPEA, 1996. 59p. (Texto para Discussão, 402)

RICHARDSON, H.W. Input-output and regional economics. London: Weidenfeld and Nicolson, 1972. 294p.

ROELANDT, T.J.A.; HERTOG, P. Boosting innovation: the cluster approach. Paris: OECD, 1999. p.413-427: Cluster analysis and cluster-based policy making in OECD: the state of the art. (OECD Proceedings)

ROEPKE, H.; ADAMS, D.; WISEMAN, R. A new approach to the identification of industrial complexes using input-output data. Journal of Regional Science, v.14, p.1529, 1974.

SALERNO, M.S.; MARX, S.; ZILBOVICIUS, M. et al. A nova configuração da cadeia automotiva brasileira. São Paulo: EP/USP, Depto. Engenharia de Produção, Grupo de Estudo em Trabalho, Tecnologia e Organização (TTO). http://www.prd.usp/br/cadeiaautomotiva. (03 mar. 2003)

SANTOS, A.M.M.M.; BURITY, P. Complexo automotivo. In: BANCO NACIONAL DE DESENVOLVIMENTO ECONÔMICO E SOCIAL. BNDES 50 anos: histórias setoriais. Rio de Janeiro, 2002. 387p. 
SANTOS, A.M.M.M.; PINHÃO, C.M.A. Pólos automotivos brasileiros. BNDES Setorial, n.10, p.173-200, set. 1999.

SHAPIRO, H. Engines of growth: the state and transational auto companies in Brasil. New York: Cambridge University Press, 1994. 281 p.

SIMÕES, R.F. Complexos industriais no espaço: uma análise de fuzzy cluster. Belo Horizonte: Universidade Federal de Minas Gerais (UFMG)/Cedeplar, 2003. 26p. (Texto para discussão, 209)

STREIT, M.E. Spatial association and economics linkages between industries. Journal of Regional Science, v.9, p.177-188, 1969.

WOMACK, J.P.; JONES, D.T.; ROSS, D. et al. A máquina que mudou o mundo. Rio de Janeiro: Campus, 1992. 347p. 